\title{
Assessment of MIT and UCB Wall Condensation Tests and of the Pre-Release RELAP5/Mod3.2 Code Condensation Models
}

\author{
Rex W. Shumway \\ January 1995 \\ Idaho National Engineering Laboratory \\ Lockheed Idaho Technologies Company \\ Idaho Falls, Idaho 83415 \\ Prepared for the \\ Office of Nuclear Regulatory Research \\ U.S. Nuclear Regulatory Commission \\ Washington, DC 20555 \\ Under DOE Idaho Field Office \\ Contract DE-AC07-94ID13223
}

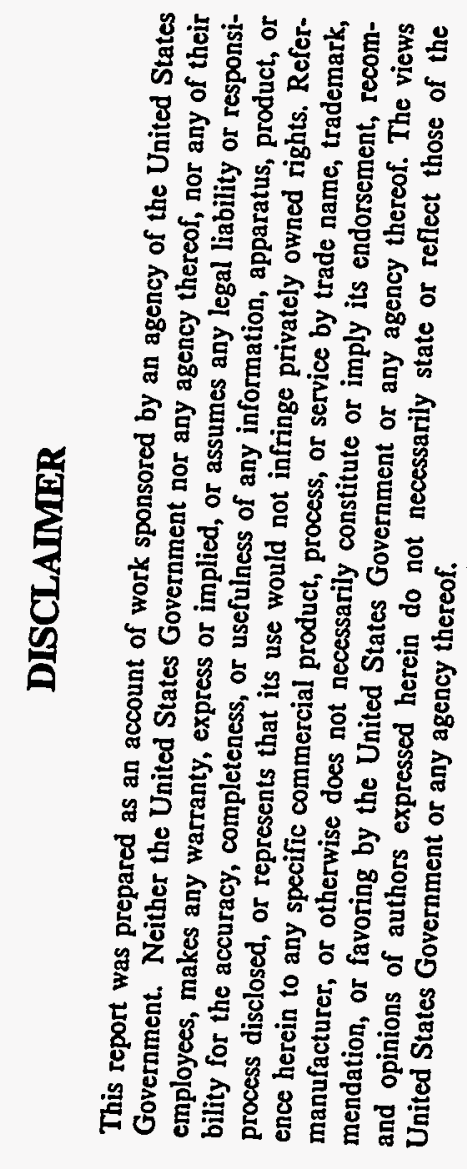

DISTRIBUTION OF THIS DOCUMENT IS UNLIMITED DLe 


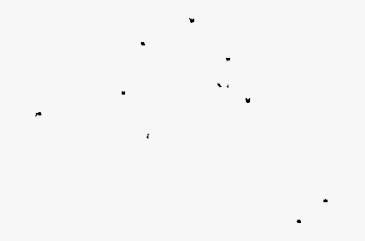




\section{DISCLAIMER}

Portions of this document may be illegible in electronic image products. Images are produced from the best available original document. 


\begin{abstract}
In recent years, a new class of reactor designs has been proposed that utilize passive safety systems. General Electric has developed a Simplified Boiling Water Reactor (SBWR) design that relies on such passive systems. The SBWR has two passive cooling systems that involve energy transfer by condensation. These are the isolation condenser system (ICS) and the passive containment cooling systems (PCCS). It is important that such heat transfer phenomena be correctly understood and quantified. The General Electric Company has sponsored tests at the Massachusetts Institute of Technology (MIT) and at the University of California at Berkeley (UCB) to obtain data simulating PCCS conditions. Data was obtained with pure steam, steam-air mixtures and steam-helium mixtures. INEL has been contracted by the NRC to evaluate these tests and assess existing condensation heat transfer correlations against the test data. This report assesses the relevance of the tests to SBWR conditions and shows RELAP5/MOD3.2 predictions of the tests.
\end{abstract}




\section{ACKNOWLEDGEMENT}

Thanks to Craig Kullberg and Richard Schultz for their assistance and ideas. 


\section{SUMMARY}

Simplified Boiling Water Reactor designs have heat exchangers in the containment building to remove reactor decay heat in the event of an accident. The heat exchangers are bundles of tubes submerged in large pools of water. Steam or a mixture of steam and noncondensable gases flows downward through the heat exchanger tubes where steam is conclensed to help maintain a low containment and primary system pressure. When air and other noncondensable gases are entrained in the mixture, the condensation efficiency of the heat exchanger is reduced. The question of the amount of reduction was experimentally investigated by two university prograns sponsored by the General Electric Company. Both the Massachusetts Institute of Technology (MIT) and the University of California at Berkeley (UCB) obtained data simulating reactor plant conditions.

This report discusses those tests and points out strengths and weaknesses of these programs relative to the reactor containment heat exchangers. The test scaling and parameter ranges were adequate except for the lack of high pressure data. No limitations or qualifications to the application of these data within their data range are needed. The test section dimensions closely matched the prototypic plant system, and the test pressure, fluids and flow rates are representative of anticipated operating conditions. However, the reported error bands appear optimistic.

This report also addresses RELAP5/MOD3.2 (a pre-release version of 3.2) predictions of the university tests. Ninety RELAP5 calculations were performed using two different condensation models. Based on these calculations, the RELAP5 'default' condensation model accuracy is considered marginal. The other model ('diffusion') agreed reasonably well with the data, and would make an improved RELAP5 'default' model. 


\section{CONTENTS}

1.0 Introduction ........................................................................................... 1

2.0 Wall Condensation in SBWRs ................................................................ 2

$2.1 \quad$ PCCS ........................................................................................................................4

$2.2 \quad$ ICS .........................................................................................................................

2.3 Key SBWR PCCS/ICS Phenomena .......................................................................6

3.0 Report Objectives and Scope .....................................................................6 6

4.0 UCB Tests............................................................................................... 7

4.1 UCB-Kuhn Test Apparatus.............................................................................9

4.2 UCB-Kuhn Test Scaling............................................................................ 10

4.2.1 Entrance Length.....................................................................................................10

4.2.2 Entrance Geometry and Entrance Fluid Conditions................................................10

4.2.3 Flow Range........................................................................................................12

4.2.4 Secondary Side Conditions.............................................................................12

4.3 UCB-Kuhn Test Instrumentation ...............................................................13

4.4 UCB-Kuhn Data Uncertainty .......................................................................14

4.5 UCB-Kuhn Data Repeatability ................................................................... 15

4.6 UCB-Kuhn Data Reduction Method ..........................................................16

4.7 UCB-Kuhn Test Deficiencies .........................................................................21

5.0 MIT Tests ............................................................................................. 21

5.1 MIT-Siddique Test Apparatus ....................................................................22

5.2 MIT-Siddique Test Scaling............................................................................24

5.3 MIT-Siddique Test Instrumentation ...........................................................24

5.4 MIT-Siddique Data Uncertainty................................................................25

5.5 MIT-Siddique Data Repeatability .............................................................26

5.6 MIT-Siddique Data Reduction Method .......................................................26

5.7 MIT-Siddique Test Deficiencies .................................................................27

6.0 RELAP5 Wall Condensation Models....................................................... 27

7.0 RELAP5 Model of UCB-Kuhn Test Apparatus ....................................... 27

7.1 UCB-Kuhn Tests Chosen for Assessment .....................................................28

7.2 UCB-Kuhn Heat Flux Comparisons with RELAP5 .......................................30

7.3 UCB-Kuhn NC Quality Comparisons with RELAP5 ..................................34

8.0 RELAP5 Model of MIT-Siddique Test Apparatus ................................... 34

8.1 MIT-Siddique Tests Chosen for Assessment................................................34

8.2 MIT-Siddique Heat Flux Comparisons with RELAP5 ......................................35

8.3 MIT-Siddique NC Quality Comparisons with REI_AP5 ...................................36

9.0 Summary and Conclusions.......................................................................... 38

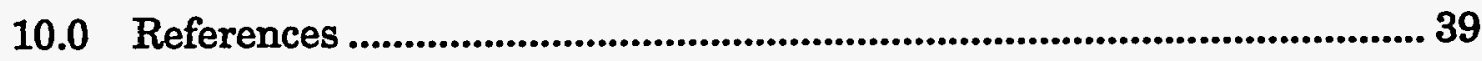

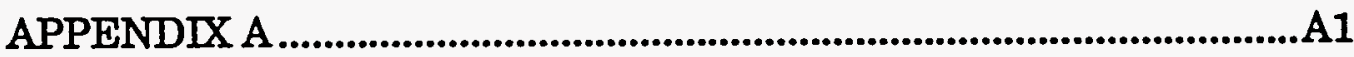

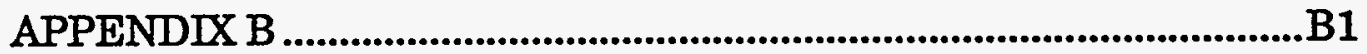




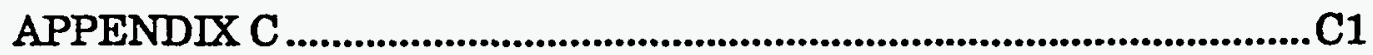

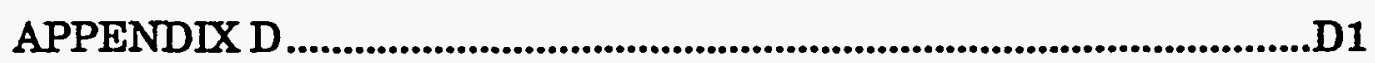




\section{FIGURES}

FIGURE 1. Film condensation schematic......................................................................2

FIGURE 2. SBWR passive containment cooling systems....................................................3

FIGURE 3. UCB-Kuhn test section. ...........................................................................11

FIGURE 4. Schematic of PCCS upper header..............................................................12

FIGURE 5. UCB-Kuhn thermocouple attachment............................................................14

FIGURE 6. Axial heat flux for UCB-Kuhn steam Test 1.1-1 and repeats...................17

FIGURE 7. Axial heat flux for UCB-Kuhn steam Test 1.1-2 and repeats.....................17

FIGURE 8. Axial heat flux for UCB-Kuhn steam Test $1.1-4$ and repeats.....................18

FIGURE 9. Axial heat flux for UCB-Kuhn steam Test 1.1-5 and repeats.....................18

FIGURE 10. Axial heat flux for UCB-Kuhn steam-air Test 3.4-2 and repeats................19

FIGURE 11. Axial heat fiux for UCB-Kuhn steam-air Test 3.5-2 and repeats................19

FIGURE 12. Axial heat flux for UCB-Kuhn steam-helium Test 5.2-6 and repeats.........20

FIGURE 13. MIT-Siddique Test Apparatus.........................................................................23

FIGURE 14. RELAP5 Model of UCB and MIT experiment...........................................28

FIGURE 15. RELAP5 Default errors vs. pressure using Kuhn steam data....................31

FIGURE 16. RELAP5 Diffusion errors vs. pressure using Kuhn steam data...................32

FIGURE 17. RELAP5 Default method errors versus UCB NC quality.............................32

FIGURE 18. RELAP5 Diffusion method errors versus UCB NC quality. ........................33

FIGURE 19. UCB measured vs. RELAP5 Default method predicted heat flux..............33

FIGURE 20. UCB measured vs. RELAP5 Diffusion method predicted heat flux...........34

FIGURE 21. MIT measured vs. RELAP5 Default method predicted heat flux................37

FIGURE 22. MIT measured vs. RELAP5 Diffusion method predicted heat flux.............37

FIGURE A1. RELAP5 heat flux comparison with UCB-Kuhn Test 1.1-1 ......................A2

FIGURE A2. RELAP5 heat flux comparison with UCB-Kuhn Test 1.1-2......................A2

FIGURE A3. RELAP5 heat flux comparison with UCB-Kuhn Test 1.1-3......................A3

FIGURE A4. RELAP5 heat flux comparison with UCB-Kuhn Test 1.1-4......................A3

FIGURE A5. RELAP5 heat flux comparison with UCB-Kuhn Test 1.1-5......................A4

FIGURE A6. RELAP5 heat flux comparison with UCB-Kuhn Test 1.4-1.......................A4

FIGURE A7. RELAP5 heat flux comparison with UCB-Kuhn Test 1.4-3......................A5

FIGURE A8. RELAP5 heat flux comparison with UCB-Kuhn Test 1.4-5.......................A5

FIGURE A9. RELAP5 heat flux comparison with UCB-Kuhn Test 6.1-5.......................A6

FIGURE A10. RELAP5 heat flux comparison with UCB-Kuhn Test 2.1-1......................A6

FIGURE A11. RELAP5 heat flux comparison with UCB-Kuhn Test 2.1-7 ......................A7

FIGURE A12. RELAP5 heat flux comparison with UCB-Kuhn Test 3.1-2......................A7

FIGURE A13. RELAP5 heat flux comparison with UCB-Kuhn Test 3.1-5.......................A8

FIGURE A14. RELAP5 heat flux comparison with UCB-Kuhn Test 3.2-2.....................A8

FIGURE A15. RELAP5 heat flux comparison with UCB-Kuhn Test 3.3-2 ......................A9

FIGURE A16. RELAP5 heat flux comparison with UCB-Kuhn Test 3.3-5.....................A9

FIGURE A17. RELAP5 heat flux comparison with UCB-Kuhn Test 3.4-2....................A10 
FIGURE A18. RELAP5 heat flux comparison with UCB-Kuhn Test 3.5-2...................A10 FIGURE A19. RELAP5 heat flux comparison with UCB-Kuhn Test 3.5-5..................A11 FIGURE A20. RELAP5 heat flux comparison with UCB-Kuhn Test 4.1-2 ...................A11 FIGURE A21. RELAP5 heat flux comparison with UCB-Kuhn Test 4.3-2 ...................A12 FIGURE A22. RELAP5 heat flux comparison with UCB-Kuhn Test 4.3-5...................A12 FIGURE A23. RELAP5 heat flux comparison with UCB-Kuhn Test 4.5-2...................A13 FIGURE A24. RELAP5 heat flux comparison with UCB-Kuhn Test 4.5-5 ..................A13 FIGURE A25. RELAP5 heat flux comparison with UCB-Kuhn Test 5.2-1 ...................A14 FIGURE A26. RELAP5 heat flux comparison with UCB-Kuhn Test 5.2-3...................A14 FIGURE A27. RELAP5 heat flux comparison with UCB-Kuhn Test 5.2-6...................A15 FIGURE B1. RELAP5 NC quality comparison with UCB-Kuhn Test $2.1-1$................. B2 FIGURE B2. RELAP5 NC quality comparison with UCB-Kuhn Test $2.1-7 \ldots \ldots . . . . . . . .$. B2 FIGURE B3. RELAP5 NC quality comparison with UCB-Kuhn Test $3.1-2$.................B3 FIGURE B4. RELAP5 NC quality comparison with UCB-Kuhn Test $3.1-5$................B3 FIGURE B5. RELAP5 NC quality comparison with UCB-Kuhn Test 3.2-2 .................B4 FIGURE B6. RELAP5 NC quality comparison with UCB-Kuhn Test 3.3-2 .................B4 FIGURE B7. RELAP5 NC quality comparison with UCB-Kuhn Test $3.3-5 \ldots . . . . . . . . . . .85$ FIGURE B8. RELAP5 NC quality comparison with UCB-Kuhn Test 3.4-2 ................ B5 FIGURE B9. RELAP5 NC quality comparison with UCB-Kuhn Test 3.5-2 ................ B6 FIGURE B10. RELAP5 NC quality comparison with UCB-Kuhn Test 3.5-5 ................ B6 FIGURE B11. RELAP5 NC quality comparison with UCB-Kuhn Test 4.1-2 ................ B7 FIGURE B12. RELAP5 NC quality comparison with UCB-Kuhn Test 4.3-2 ................. B7 FIGURE B13. RELAP5 NC quality comparison with UCB-Kuhn Test 4.3-5 ................B8 FIGURE B14. RELAP5 NC quality comparison with UCB-Kuhn Test 4.5-2 ............... B8 FIGURE B15. RELAP5 NC quality comparison with UCB-Kuhn Test 4.5-5 ................. B9 FIGURE B16. RELAP5 NC quality comparison with UCB-Kuhn Test 5.2-1 ................. 9 FIGURE B17. RELAP5 NC quality comparison with UCB-Kuhn Test 5.2-3 ...............B10 FIGURE B18. RELAP5 NC quality comparison with UCB-Kuhn Test 5.2-6..............B10 FIGURE C1. RELAP5 heat flux comparison with MIT-Siddique Test 7A ...................C2 FIGURE C2. RELAP5 heat flux comparison with MIT-Siddique Test 8A ...................C2 FIGURE C3. RELAP5 heat fiux comparison with MIT-Siddique Test 19A ................... 3 FIGURE C4. RELAP5 heat flux comparison with MIT-Siddique Test 24A ..................C3 FIGURE C5. RELAP5 heat flux comparison with MIT-Siddique Test 25A ..................C4 FIGURE C6. RELAP5 heat flux comparison with MIT-Siddique Test 26A ..................C4 FIGURE C7. RELAP5 heat flux comparison with MIT-Siddique Test 27A ...................C5 FIGURE C8. RELAP5 heat fiux comparison with MIT-Siddique Test 28A ................... C5 FIGURE C9. RELAP5 heat flux comparison with MIT-Siddique Test 29A .................. C6 FIGURE C10. RELAP5 heat flux comparison with MIT-Siddique Test 31A ..................C6 FIGURE C11. RELAP5 heat flux comparison with MIT-Siddique Test 42A ...................C7 FIGURE C12. RELAP5 heat flux comparison with MIT-Siddique Test $6 \mathrm{H}$...................... 7 FIGURE C13. RELAP5 heat flux comparison with MIT-Siddique Test $14 \mathrm{H}$.................. 8 
FIGURE C14. RELAP5 heat flux comparison with MIT-Siddique Test $16 \mathrm{H}$...................C8 FIGURE C15. RELAP5 heat flux comparison with MIT-Siddique Test $17 \mathrm{H}$................... 9

FIGURE C16. RELAP5 heat flux comparison with MIT-Siddique Test 18H ................... FIGURE C17. RELAP5 heat flux comparison with MIT-Siddique Test 19H ..................C10 FIGURE C18. RELAP5 heat flux comparison with MIT-Siddique Test 22H .................C10 FIGURE D1. RELAP5 NC quality comparison with MIT-Siddique Test 7A. ...............D2 FIGURE D2. RELAP5 NC quality comparison with MIT-Siddique Test 8A...............D2 FIGURE D3. RELAP5 NC quality comparison with MIT-Siddique Test 19A. .............D3 FIGURE D4. RELAP5 NC quality comparison with MIT-Siddique Test 24A. ............D3 FIGURE D5. RELAP5 NC quality comparison with MIT-Siddique Test 25A. ............D4 FIGURE D6. RELAP5 NC quality comparison with MIT-Siddique Test 26A. .............D4 FIGURE D7. RELAP5 NC quality comparison with MIT-Siddique Test 27A. ............D5 FIGURE D8. RELAP5 NC quality comparison with MIT-Siddique Test 28A. .............D5 FIGURE D9. RELAP5 NC quality comparison withMIT-Siddique Test 29A. ..............D6 FIGURE D10. RELAP5 NC quality comparison with MIT-Siddique Test 31A. ..............D6 FIGURE D11. RELAP5 NC quality comparison with MIT-Siddique Test 42A............D7 FIGURE D12. RELAP5 NC quality comparison with MIT-Siddique Test $6 \mathrm{H}$.................D7 FIGURE D13. RELAP5 NC quality comparison with MIT-Siddique Test 14H. .............D8 FIGURE D14. RELAP5 NC quality comparison with MIT-Siddique Test 16H. .............D8 FIGURE D15. RELAP5 NC quality comparison with MIT-Siddique Test 17H. ............D9 FIGURE D16. RELAP5 NC quality comparison with MIT-Siddique Test $18 \mathrm{H}$..............D9 FIGURE D17. RELAP5 NC quality comparison with MIT-Siddique Test $19 H$. ..........D10 FIGURE D18. RELAP5 NC quality comparison with MIT-Siddique Test 22H. ...........D10 


\section{TABLES}

Table 1. SBWR PCCS/ICS Nominal Bundle Capacity Specifications........................4

Table 2. Comparison of Experimental Parameters ......................................................7

Table 3. Uncertainty of UCB-Kuhn Data ................................................................14

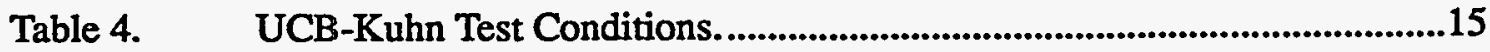

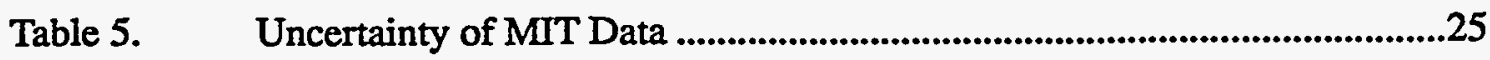

Table 6. UCB-Kuhn Tests Selected for Assessment.........................................29

Table 7. Summary of RMS Values for UCB Data versus RELAP5 Prediction........31

Table 8. MIT-Siddique Test Chosen for Assessment.................................................35

Table 9. Summary of RMS Values for MIT Data versus RELAP5 Prediction.........36 


\section{ACRONYMS}

\begin{tabular}{ll} 
BWR & Boiling Water Reactor \\
DOE & Department of Energy \\
DW & Dry Well \\
GDCS & Gravity-Driven Cooling System \\
GE & General Electric \\
GIRAFFE & Gravity Driven Integral Eull Height Test for Passive Heat \\
& Removal,SBWR test facility in Toshiba Japan \\
ICS & Isolation Condenser System \\
ID & Inside Diameter \\
INEL & Idaho National Engineering Laboratory \\
LOCA & Loss of Coolant Accident \\
LITCO & Lockheed Idaho Technologies Company \\
MIT & Massachusetts Institute of Technology \\
MSL & Main Steam Line \\
NC & NonCondensable \\
NRC & Nuclear Regulatory Commission \\
OD & Outside Diameter \\
NA & Not Applicable \\
PANDA & Passive Nachwaermeabfuhr und Druckabbau Testanlage, SBWR test \\
PANTHERS & Pacitity at Paul Sherrer Institute, Switzeriand \\
PCCS & scale IC and PCCS test facility at Siet, Italy \\
PSI & Passive Containment Cooling System \\
P & The Paul Scherrer Institute \\
RPV & Pressure Transducer \\
SBWR & Reactor Pressure Vessel \\
SP & Simplified Boiling Water Reactor \\
SS & Suppression Pool \\
TC & Stainless Steel \\
TRACG & Thermocouple \\
UCB & GE Version TRAC \\
WW & University of California, Berkeley \\
& Wet Well \\
\hline
\end{tabular}




\section{Assessment of UCB and MIT Wall Condensation Tests and of the Pre-Release RELAP5/Mod3.2 Code Condensation Models}

\subsection{Introduction}

Condensation of steam on cold walls is an integral part of the passive safety features in the Simplified Boiling Water Reactor (SBWR) design. Wall condensation is the process of changing a vapor near a cold wall to a liquid on the wall by removing heat. In many postulated light viater reactor accident conditions, there may be noncondensable (NC) gases mixed with steam. The noncondensable gases have an insulating effect on the heat transfer between the steam and the wall. The rate of the condensation process and heat transfer to the wall depends on the degree of wall subcooling relative to the saturation temperature of the steam based on the partial pressure of the steam and other factors, such as the water film thickness, turbulence, vapor shear, etc. The heat released at the vapor-liquid interface is transferred through the liquid film and into the wall. Heat exchanger tubes in the SBWR have water on the outside of the walls (the shell side) to absorb the heat.

Two general classifications of condensation are "film" and "dropwise." Film condensation has been studied experimentally more than dropwise condensation because metal tubes are easily wetted. Special coating materials are sometimes applied to metals to increase the surface areas over which beads of water drops exist because dropwise condensation rates can be an order of magnitude larger than film condensation rates. Coatings are not used in the SBWR heat exchangers. A schematic of film condensation on a vertical surface is shown in Figure 1. Radial flow of steam toward the cold wall pushes the NC towards the wall. The NC concentration gradient results in NC diffusion toward the mainstream counter to the steam flow direction. The steam partial pressure and temperature are lower in the NC buffer layer than in the mainstream as shown in the figure. The effect of the NC is to cause a reduced temperature difference $\left(\mathrm{T}_{\mathrm{gi}}-\mathrm{T}_{\mathrm{w}}\right)$ and a reduced heat flux through the water film.

Figure 1 also shows that as the condensate layer thickness increases it can undergo a transition from laminar to turbulent flow. McAdams ${ }^{1}$ suggests that transition occurs at a condensate Reynolds number of 1800 where the Reynolds number ( $R e)$ is defined as:

$$
R e=\frac{4 \Gamma}{\mu_{f}}
$$

where

$$
\begin{array}{ll}
\mu_{f} & =\text { liquid viscosity } \\
\Gamma & =\text { liquid mass flow rate per unit periphery: }
\end{array}
$$




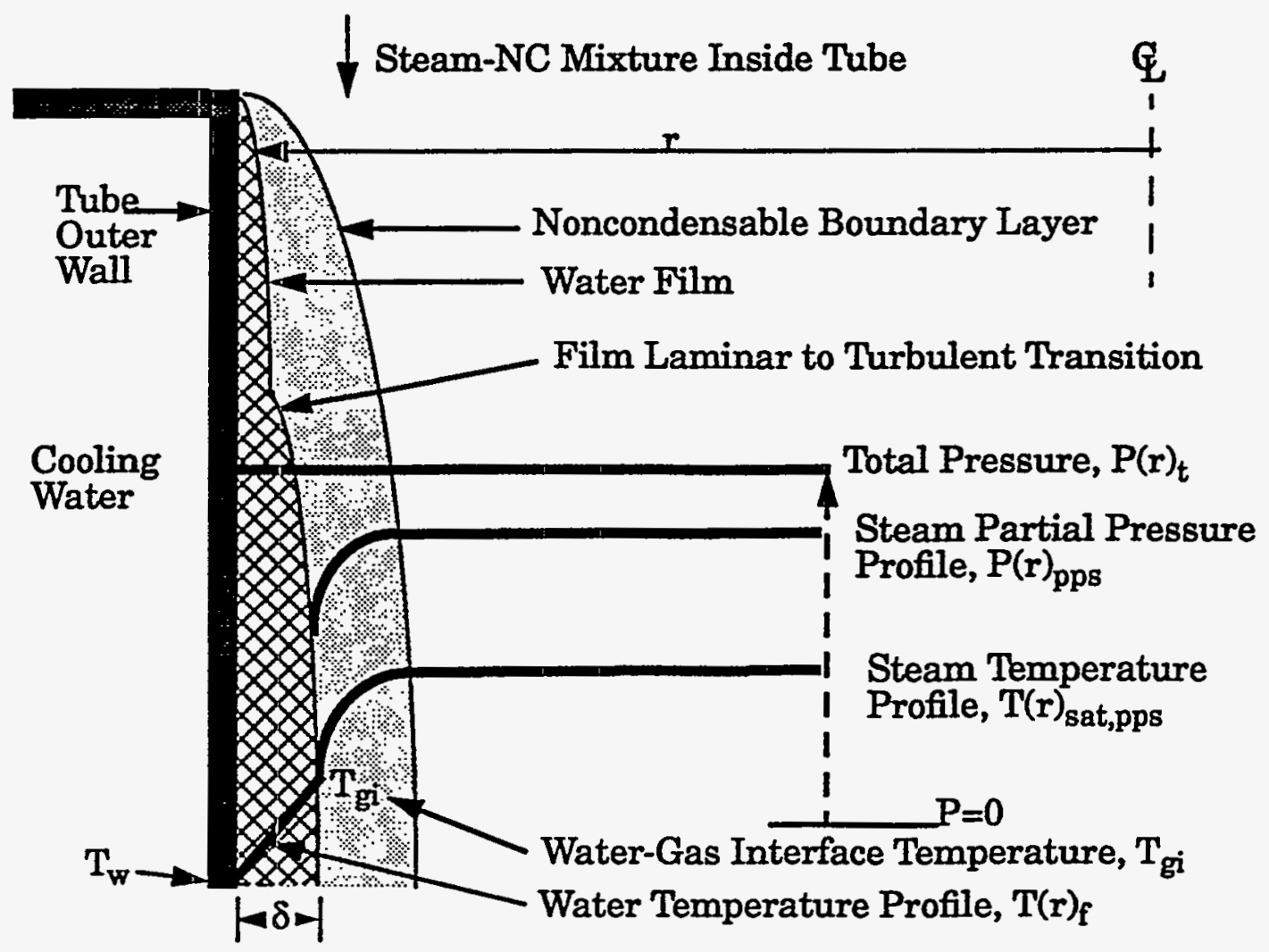

FIGURE 1. Film condensation schematic.

$$
\Gamma=\frac{\dot{m}_{f}}{\pi D}
$$

$\dot{m}_{\mathrm{f}} \quad=$ liquid mass flow rate

D = inner diameter of the tube.

At high values of the vapor shear stress, however, Carpenter and Colburn ${ }^{2}$ found transition values as low as 200 to $300 .^{3}$

This report concentrates on low pressure, low flow, condensation data (taken at two universities) pertinent to the SBWR design.

\subsection{Wall Condensation in SBWRs}

The SBWR is an advanced design which relies on a passive containment cooling system (PCCS) and isolation condenser system (ICS) for decay heat removal. Nominal values for key PCCS/ICS parameters are presented in Table 1. ${ }^{4}$ These systems include large arrays of vertical tubes in compartmentalized pools of water located at the top of the containment dry well (DW) in the reactor building (see Figure 2). These pools are vented to atmosphere and are designed with enough initial water inventory to provide decay heat cooling for three days. The design operating pressure of the PCCS is low and 


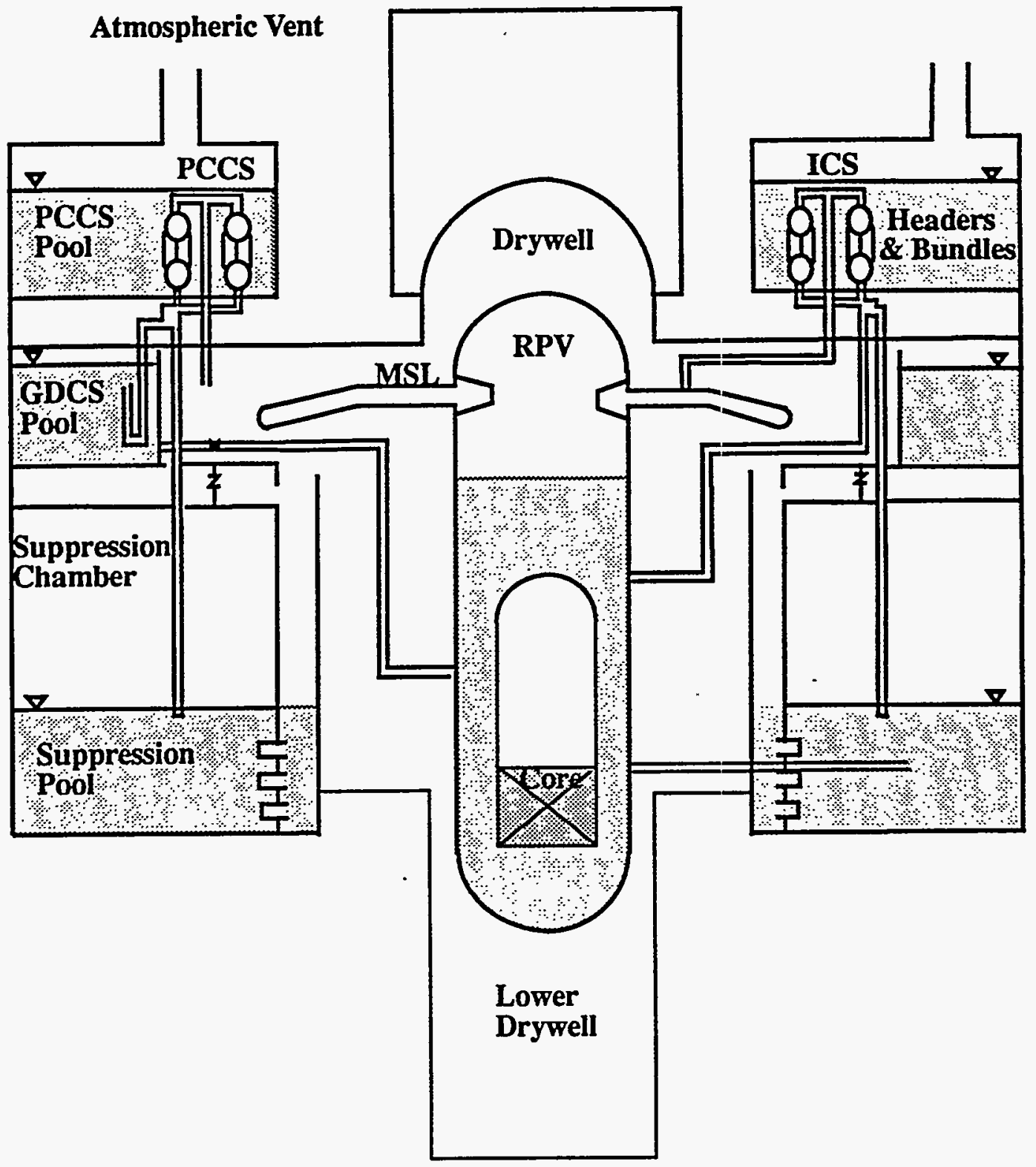

FIGUURE 2. SBWR passive containment cooling systems. 
the ICS can operate at low or high pressure levels.

Table 1. SBWR PCCS/ICS Nominal Bundle Capacity Specifications.a

\begin{tabular}{|l|l|l|}
\hline Nominal Design Specifications & PCCS & ICS \\
\hline \hline Thermal power (MW/unit) & $10(3$ units) & $30(3$ units) \\
\hline Operating pressure [MPa (psia)] & $0.31(45)$ & $7.18(1041)$ \\
\hline Operating temperature [K $\left.\left({ }^{\circ} \mathrm{F}\right)\right]$ & $407(273)$ & $561(550)$ \\
\hline Number of tubes per unit & 496 & 240 \\
\hline Tube material & $\begin{array}{l}\text { Stainless } \\
\text { Steel }\end{array}$ & Inconel-600 \\
\hline Tube Effective length (m) & 1.8 & 1.8 \\
\hline Tube OD (mm) & 50.8 & 50.8 \\
\hline Tube wall thickness (mm) & 1.65 & 2.1 \\
\hline
\end{tabular}

a. Various sources give different values for some of the specifications.

A summary of the data available to study the behavior of condensation in the presence of noncondensables for the PCCS and the ICS follow.

\subsection{PCCS}

The PCCS is designed to remove the decay heat rejected to the containment building following a loss-of-coolant-accident (LOCA) and operates at the containment pressure ( 0.1-0.4 MPa). The system includes three condenser units each with two tube bundles in a water pool high in the drywell area of the containment building. Each tube in the vertical bundle is connected to an upper and lower header. Condensation in the tubes lowers the local pressure and causes steam to be drawn into the exchanger. Gas flow rates are also influenced by the wetwell-drywell pressure difference. The surface area of the tube bundles is sized to limit the containment pressure to less than the design value of $0.48 \mathrm{MPa}$ (70 psia). The tubes have an outside diameter of 0.0508 meters ( 2 inches), a $1.65 \mathrm{~mm}$ wall thickness, and are 1.8 meters long.

Condensate from the bundle is routed from the bottom header to the gravity driven cooling system (GDCS) tank. The GDCS tank is an elevated tank of water located inside the drywell. Drain lines at the bottom of the pool are connected to the vessel downcomer. A second line from the bottom header of the PCCS vents noncondensables to the wetwell suppression pool. The PCCS has no valves at its inlets or outlets and is thus a totally self-starting passive system. During a LOCA, the drywell becomes pressurized relative to the suppression chamber. This differential pressure is one of the key forces that produces circulation into the PCCS.

The General Electric Company (GE) sponsored tests at the Massachusetts 
Institute of Technology (MIT) and at the University of California at Berkeley (UCB) to obtain data simulating PCCS conditions. Data were obtained with pure steam, steam-air mixtures and steam-helium mistures flowing down inside of a tube. Steam-helium data were obtained to simulate steam-hydrogen. Hydrogen gas can be generated in a reactor accident if the core becomes hot enough to undergo a zircaloy-water reaction. Condensation correlations were developed from the test for use in GE's TRACG reactor transient code.

Separate effects and integral effects experiments for the PCCS have been conducted in the GIRAFFE Test Facility by Toshiba in Japan. PANDA ${ }^{5,6}$ and PANTHERS ${ }^{7}$ are additional facilities in which PCCS clata will be obtained. PANDA is a facility at the Paul Scherrer Institute in Switzerland. PANTHERS is a full scale facility at SIET in Italy. GIRAFTE and PANDA will include $\mathrm{NC}$ venting.

\subsection{ICS}

The ICS can operate in either a high pressure mode during plant isolation or in a low pressure mode during and after a LOCA. The principal design objective of the ICS is to provide an alternate heat sink in the event of sudden termination of the steam flow to the turbine/condenser system.

The primary inlet sides of the ICS are connected to the main steam line and condensate is returned to the vessel via return lines. During normal plant operation the condensate return lines are valved off. When ICS operation is needed these valves are opened and steam flows from the vessel to the ICS. The ICS condensate is then gravity drained back to the vessel via the return lines. Vent lines which are normally valved off are connected to the ICS to remove noncondensables to the suppression pool. During normal use of the ICS these noncondensables may include radiolytic hyclrogen and oxygen. During long term post LOCA conditions these noncondensables may also include nitrogen.

The UCB and MIT test programs did not provide high pressure data. Condensation at high pressure is not much different than condensation at low pressure, however, correlations for predicting condensation do not necessarily contain enough of the physics to be applicable over a wide pressure range. For instance, the default condensation model in RELAP5 is based on the earlier UCB tests and is more of a simple curve fit than a model of all the physics. Thus, existing RELAP5 condensation models that are based on low pressure test data may not adequately predict condensation under high pressure ICS operating conditions. There are two known sources of high pressure data currently available with steam-NC in tubes: Borishanskiy ${ }^{8}$ and Babcock-Wilcox ${ }^{9}$. Downflow data were taken by B\&W and will be discussed in a RELAP5 developmental assessment report by Rex Shumway available in the first quarter of 1995.

Test plans for PANDA and PANTHERS include provisions to obtain high pressure data. 


\subsection{Key SBWR PCCS/ICS Phenomena}

The key phenomena associated with PCCS/ICS energy transport are summarized as follows.

1. Tube side condensation heat transfer with laminar and turbulent liquid films.

2. Tube side condensate films in the presence of forced gas flow and associated boundary layer effects in the presence of noncondensables.

3. Tube side parallel channel effects and nonuniform distribution on noncondensable in the header supplying the tubes.

4. Shell side nucleate boiling and multi-dimensional flow effects.

5. Noncondensables venting to suppression pool (SP).

Items one and two will be discussed in this report and are directly applicable to the MIT/UCB test results. Items three and four are not applicable to the MIT/UCB experiments. Because the MIT/UCB experiments are single tube down-flow experiments with annular cooling jackets, multi-dimensional effects characteristic of a full scale PCCS/ICS are not captured in these experiments. The effects of shell side boundary conditions will be discussed in Section 4.2 below.

Likewise, item five is not simulated in the MIT/UCB tests but is an important factor in controlling the condensation heat transfer rate. Noncondensable venting is controlled by the suppression pool/dry well (SP/DW) differential pressure.

Phenomena associated with items 3-5 are expected to be addressed in other SBWR experimental programs including PANTHERS, PANDA, and the GIRAFFE facilities.

\subsection{Report Objectives and Scope}

The objectives of this report are:

1. Evaluate the hardware scaling, range of test conditions, and instrumentation of the UCB/MIT facilities and note geometric distortions and measurement uncertainties.

2. Review the UCB/MIT test results against the needs for assessment of the RELAP5 code and advise if any additional experimentation may be needed.

3. Assess the current RELAP5/MOD3 condensation models using the UCB/ MIT tests. 


\subsection{UCB Tests}

UCB performed four different series of condensation tests (see Table 2).

Table 2. Comparison of Experimental Parameters

\begin{tabular}{|c|c|c|c|c|c|c|}
\hline parameter & $\begin{array}{l}\text { SBWR } \\
\text { PCCS } \\
\text { Design }\end{array}$ & $\begin{array}{l}\text { UCB-1 } \\
\text { Vierow }\end{array}$ & $\begin{array}{l}\text { UCB-2 } \\
\text { Ogg }\end{array}$ & $\begin{array}{l}\text { UCB-3 } \\
\text { Kage- } \\
\text { yama }\end{array}$ & $\begin{array}{l}\text { UCB-4 } \\
\text { Kuhn }\end{array}$ & $\begin{array}{l}\text { MIT } \\
\text { Siddique }\end{array}$ \\
\hline $\begin{array}{l}\text { Inlet Pressure } \\
\text { (MPa) }\end{array}$ & $\begin{array}{l}0.27- \\
0.48\end{array}$ & $\begin{array}{l}0.028- \\
0.448\end{array}$ & $\begin{array}{l}0.089- \\
0.303\end{array}$ & $\begin{array}{l}0.101- \\
0.13\end{array}$ & $\begin{array}{l}0.109- \\
0.518\end{array}$ & $0.11-0.48$ \\
\hline $\begin{array}{l}\text { Inlet Tempera- } \\
\text { ture }(\mathrm{K})\end{array}$ & $393-423$ & $345-419$ & $368-407$ & & $373-427$ & $373-413$ \\
\hline $\begin{array}{l}\text { Inlet Steam Flow } \\
(\mathrm{kg} / \mathrm{s}) \times 100\end{array}$ & $\begin{array}{l}0.1667- \\
1.1\end{array}$ & $\begin{array}{l}0.164- \\
0.69\end{array}$ & $0.42-2.0$ & $\begin{array}{l}0.069- \\
0.86\end{array}$ & $\begin{array}{l}0.83- \\
1.67\end{array}$ & $0.28-0.92$ \\
\hline $\begin{array}{l}\text { Inlet Steam Mass } \\
\text { Flux }\left(\mathrm{kg} / \mathrm{s}-\mathrm{m}^{2}\right)\end{array}$ & $0.94-6.2$ & $4.3-18.1$ & $2.2-10.4$ & $\begin{array}{l}0.49- \\
6.1\end{array}$ & $4.7-9.4$ & $1.7-5.5$ \\
\hline $\begin{array}{l}\text { Inlet Gas: } \\
\text { Air mass fraction } \\
\text { He mass fraction }\end{array}$ & $0-0.4$ & $0-0.14$ & $\begin{array}{l}0.0 .4 \\
0-0.15\end{array}$ & $\begin{array}{l}0-0.7 \\
0-0.05\end{array}$ & $\begin{array}{l}0-0.4 \\
0.003- \\
0.15\end{array}$ & $\begin{array}{l}0.09-0.35 \\
0.02-0.05\end{array}$ \\
\hline $\begin{array}{l}\text { Condensing } \\
\text { Tube: } \\
\text { Mat'l Type } \\
\text { Length (m) } \\
\text { O.D. (m) } \\
\text { Thickness (m) }\end{array}$ & $\begin{array}{l}\text { SS } \\
1.8 \\
0.0508 \\
0.00165\end{array}$ & $\begin{array}{l}\text { Copper } \\
2.1 \\
0.0254 \\
0.0017\end{array}$ & $\begin{array}{l}\text { SS } \\
2.44 \\
.0508 \\
0.00071\end{array}$ & $\begin{array}{l}\text { Glass } \\
1.0 \\
0.0508 \\
0.00426\end{array}$ & $\begin{array}{l}\text { SS } \\
2.42 \\
0.0508 \\
0.00165\end{array}$ & $\begin{array}{l}\text { SS } \\
2.54 \\
0.0508 \\
0.0024\end{array}$ \\
\hline Jacket I. D. (m) & & 0.0483 & 0.0574 & 0.0592 & 0.0737 & 0.0627 \\
\hline $\begin{array}{l}\text { Cooling Water: } \\
\text { Flow rate }(\mathrm{kg} / \mathrm{s}) \\
\text { Inlet Temp }(\mathrm{K}) \\
\text { Temperature rise } \\
\text { (Tout-Tin) }(\mathrm{K})\end{array}$ & $\begin{array}{l}\text { NA } \\
\text { NA } \\
\text { NA }\end{array}$ & $\begin{array}{l}0.11-.39 \\
322-326 \\
18-26\end{array}$ & $\begin{array}{l}0.27-.34 \\
290-305 \\
7-43\end{array}$ & $\begin{array}{l}\text { NA } \\
\text { NA } \\
\text { NA }\end{array}$ & $\begin{array}{l}0.17-.33 \\
299-305 \\
20-40\end{array}$ & $\begin{array}{l}0.057-.06 \\
280-297 \\
20-87\end{array}$ \\
\hline
\end{tabular}

The first, Vierow ${ }^{10}$ tests, used a one inch diameter copper test section which operated in a natural convection mode. The natural convection loop led to flow instabilities in some cases and on some "steady" tests, axial "temperature inversions" were observed which are difficult to explain with the measure- 
ments available. A condensation correlation was developed ${ }^{11}$ which had an enhancement factor $\mathrm{fl}$ and a degradation factor $\mathrm{f2}$. $\mathrm{fl}$ accounts for the effects of shear of the gas on the liquid film and $\mathrm{f2}$ accounts for NC effects on the heat transfer coefficient. The Nusselt number is defined as the ratio of the measured heat transfer coefficient $h_{\text {meas }}$ to the film conductivity over thickness. Vierow relates the f factors to the Nusselt Number by:

$$
N u=\frac{h_{\text {meas }} \delta}{k_{f}}=\frac{h_{\text {meas }}}{h_{t}}=f 1 f 2
$$

where from Nusselt's ${ }^{12}$ derivation of the theoretical coefficient $h_{t}$

$$
h_{t}=\frac{k_{f}}{\delta}=k_{f}\left[\frac{g \rho_{f} \Delta \rho}{3 \mu_{f} \Gamma}\right]^{\frac{1}{3}}
$$

where

$$
\begin{array}{ll}
k_{f} & =\text { liquid conductivity } \\
\delta & =\text { liquid film thickness } \\
\mu_{f} & =\text { liquid viscosity } \\
\Gamma & =\text { liquid mass flow rate per unit periphery: } \\
\rho_{f} & =\text { liquid density } \\
\Delta p & =\text { difference between liquid and gas density } \\
\mathrm{g} & =\text { gravitational constant. }
\end{array}
$$

Thus, the expression for the measured heat transfer coefficient is:

$$
h_{\text {meas }}=f 1 f 2 k_{f}\left[\frac{g \rho_{f} \Delta \rho}{3 \mu_{f} \Gamma}\right]^{\frac{1}{3}}
$$

Expressions for $\mathrm{f} 1$ and $\mathrm{f} 2$ derived from fits to the measured data are:

$$
f 1=1+2.88 \times 10^{-5} R e_{m i x}^{1.18}
$$

where

$$
R e_{m i x}=\text { steam-NC gas mixture Reynolds number= }
$$

$$
\frac{G_{g} D}{\mu_{g}}
$$

$G_{g} \quad=$ steam-NC gas mixture mass flux

$\mu_{g} \quad=$ gas mixture viscosity. 


$$
f 2=\left\{\begin{array}{c}
1-10 M a ; M a<0.063 \\
1-0.938 M a^{0.13} ; 0.063<M a<0.60 \\
1-M a^{0.22} ; M a>0.60
\end{array}\right.
$$

where

$$
\mathrm{Ma}=\text { mass fraction of noncondensable in the vapor-gas mixture. }
$$

f1 is limited to 2.0 based on Toshiba data applicable to the SBWR ${ }^{\mathrm{a}}$.

Vierow's tests used natural convection, but by the time Ogg's experiment was run the importance of the pressure drop between the drywell and the wetwell was realized. The second tests series was performed by $\operatorname{Ogg}^{13}$ using forced convection and a stainless steel test section similar to SBWR PCCS tubes. Using forced convection eliminated the unsteady flow problem, but temperature inversions near the inlet still occurred during some tests. Posttest examination of the condenser tube wall thermocouples suggested that these inversions might have been caused by faulty thermocouple mounting procedures ${ }^{14}$.

The third UCB tests series was by Kageyama ${ }^{15}$. Kageyama used a 1 meter long glass test section with a traversing wet-bulb probe to obtain the local radial and axial gas concentration profiles. The outer cooling water annulus was also made from glass. INEL does not have this thesis. It appears that the profiles were used to help establish analytical models of diffusion theory.

Kuhn ${ }^{16}$ tests were the last in the series to obtain PCCS related data. Kuhn et. al. show a table of important parameters for the four UCB tests, the MIT tests and the SBWR PCCS, which is reproduced as Table 2.They also itemize nine hardware improvements required to overcome problems with previous experiments.

The Kuhn test series avoided problems encountered in the previous UCB series and produced excellent data. Because of known problems with the earlier data, only the Kuhn data is analyzed in this report.

Kuhn performed more than 100 tests; over 40 tests used pure steam as the test gas. Thirty-three 'steam only' tests were 'qualified' and used to improve the f1 factor and 68 'qualified steam-air tests' were used to improve the f2 factor.

\subsection{UCB-Kuhn Test Apparatus}

The test section (condenser tube) was a vertical pipe with downflow of steam and noncondensable (see Figure 3 ). The steam came from the building service steam supply furnished at $0.86 \mathrm{MPa}$. Kuhn calculated that the amount of inlet moisture in the Ogg experiment could have been as high as $3.5 \%$. He therefore installed a centrifugal separator with a bleed valve to help dry out the steam before it reached the test section. No inlet quality measurements

a. Personal communication from V. E. Schrock of UCB to Gary Johnsen, INEL, 1991. 
were reported but the data reduction procedure assumed the quality was 1.0.

Air also came from the building supply lines at $0.79 \mathrm{MPa}$ but was preheated to match the steam temperature. Helium was supplied from high pressure cylinders and no mention of preheating is given.

The condenser tube was $3.37 \mathrm{~m}$ long with the same $O D$ and $\mathrm{ID}$ as the PCCS but was cooled over only $2.418 \mathrm{~m}$ starting at $0.8065 \mathrm{~m}$ from the top of the tube.

Water was pumped upward through an annular jacket around the condenser tube absorbing the energy conducted through the test section wall. The discharged water could be sent through a heat exchanger or mixed with city water to obtain the desired inlet temperature for recirculation.

Twenty nylon spacers held the inner tube a uniform distance from the outer tube. The spacers were oriented to not disrupt the flow next to a thermocouple location.

A two phase, two component mixture or liquid-only (for steam only tests) was discharged at the bottom of the test section. After leaving the test section the effluent went through a separator.

\subsection{UCB-Kuhn Test Scaling}

Four issues regarding scaling are addressed: (1) entrance length, (2) entrance geometry and entrance fluid conditions, (3) flow range, and (4) secondary side conditions.

No attempt was made to study the effects (if any) of tube vibrations on condensation rates in the SBWR.

Other than the entrance differences, the facility hardware was adequately scaled. The experimental tube ID and OD were exactly the same as the SBWR PCCS tubes. Therefore, for the same pressure and flow conditions, nondimensional numbers such as the inlet Reynolds, Prandtl and Jacob numbers in the test will be the same as in the plant.

\subsubsection{Entrance Length}

The test section used by Kuhn had the same inner and outer dimensions as the SBWR PCCS tubes. However, it had an entrance length of 0.8065 meters $(\mathrm{L} / \mathrm{D}=16)$ upstream of the cooling water annulus. An $\mathrm{L} / \mathrm{D}$ of about 10 results in a fully developed turbulent velocity profile. The SBWR PCCS upper header is in the water pool and therefore no tube entrance length exists upstream of the condensing section. However, Lucas and Moser ${ }^{17}$ claim that the entrance velocity profile has a negligible effect on the condensation process. Thus, differences caused by entrance length are probably negligible.

\subsubsection{Entrance Geometry and Entrance Fluid Conditions}

Another difference between the test tube and the PCCS tubes is that the entrance section in the PCCS is not vertical. Most of the PCCS tubes come out of the header at an angle before they become vertical. Different tubes have different angles depending on their azimuthal attachment point to the header. There are ten tubes at each axial connection region. Figure 4 illustrates four 


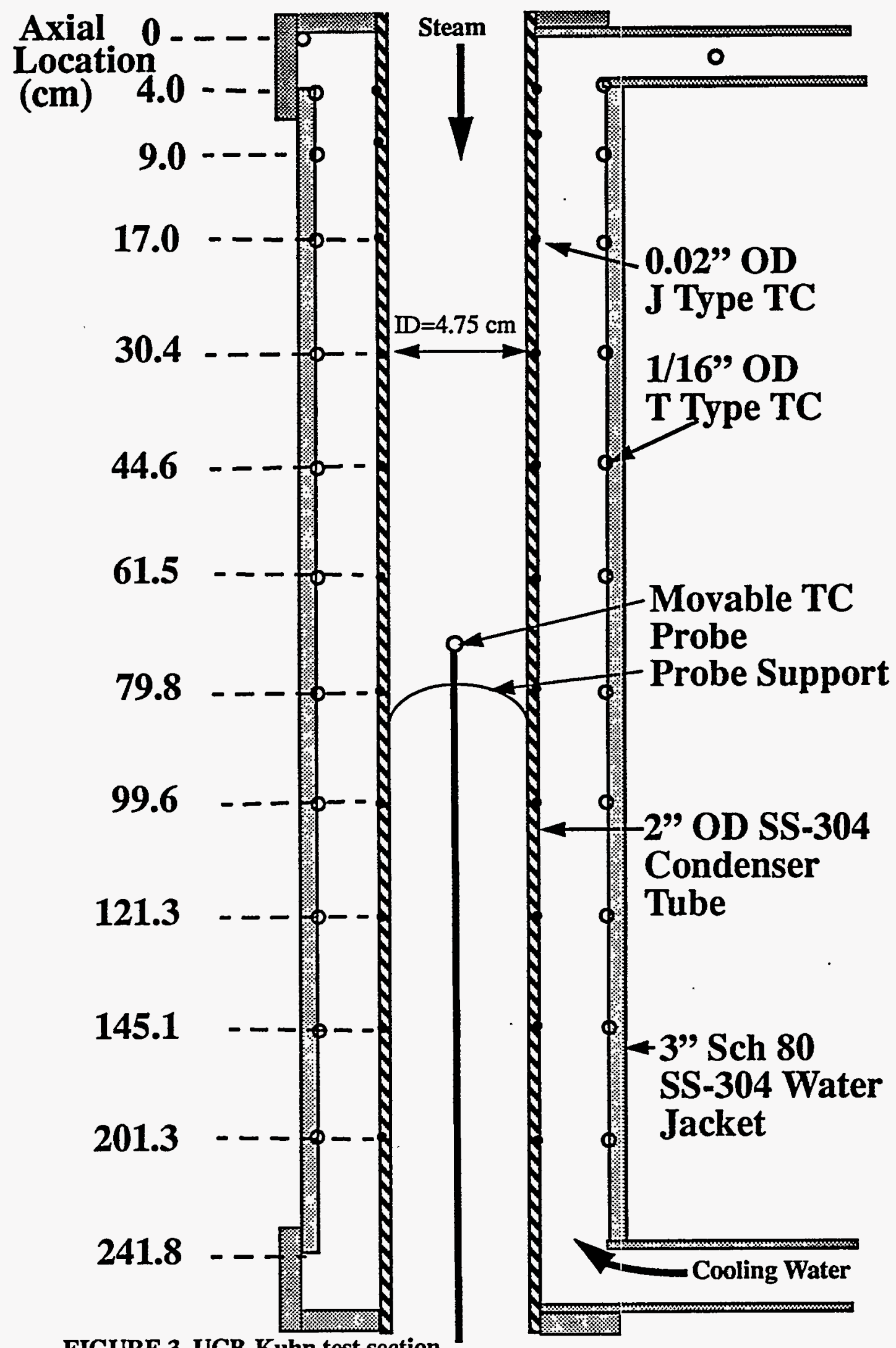

FIGURE 3. UCB-Kuhn test section. 
of the ten tubes. The entrance angle differences between the actual tubes and

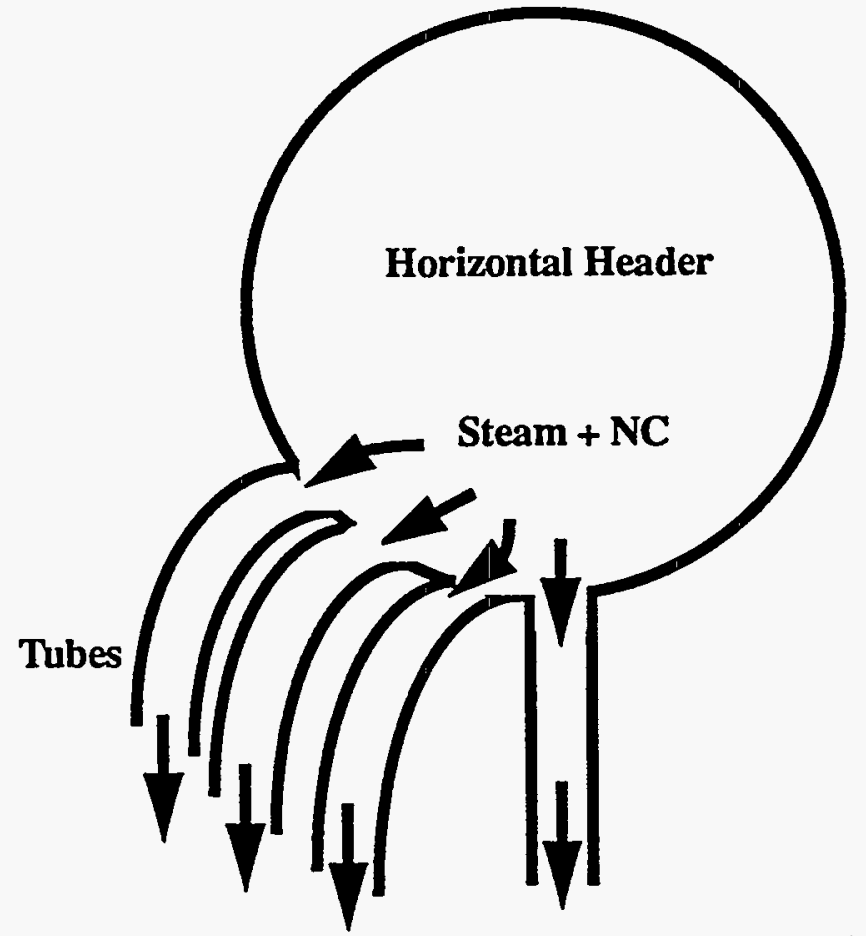

FIGURE 4. Schematic of PCCS upper header.

the experimental tubes means that the axial film thickness profiles and heat flux profiles will not be the same even with all other parameters similar. NCsteam separation or stratification in the header could cause the tube-to tube entrance quality to be different. More will be said about the practical effect of differences between the experiment and PCCS.

The PCCS tubes attached to the lowest position on the header are likely to have condensate running into them. Since the header walls also sit in the water pool (see Figure 2), condensation will occur on these walls and condensate will drain down into the tube bundle.

\subsubsection{Flow Range}

The test section inlet conditions cover the PCCS operating ranges for temperature and pressure but miss the low end flow rate by a factor of 5 as shown in Table 2. The MIT data set covers an inlet low flow value which is within $60 \%$ of the SBWR value. The minimum inlet gas Reynolds numbers are all in the turbulent range. They range from approximately 2900,4600 , and 14000 for the SBWR, MIT tests, and UCB-Kuhn tests, respectively. Having inlet flow rates higher than the SBWR is not believed to be a significant problem because the steam flow approaches zero as it condenses. Therefore, condensation models are assessed at low steam flow rates.

\subsubsection{Secondary Side Conditions}

Another remaining scaling issue is the water jacket water temperature 
axial profile. The axial profile of the inner wall temperature of the condenser tube will not be the same in the PCCS or the ICS as it was in the experiment. The water in the pool surrounding the PCCS tube bundle will be warmer than it was in the experiment and will circulate naturally upwards through the bundle. In the ICS pool, because the pressure and saturation temperature can be high in the tubes, the water on the outside of the ICS tubes may boil. Cooling water flow was forced in the test. The forced flow water Reynolds number in the test varied from about 1000 to about 2000.

Although the axial temperature profile and condensate thickness profile inside the condenser will differ between the SBWR and the experiments for the same gas side inlet conditions, this fact does not invalidate the usefulness or purpose of the data. Because the data are used to assess numerical models which make use of the calculated condensate film thickness or flow rate (see Equation 5) to predict the resistance in the heat flux flow path, they are designed to predict the condensate thickness profile independent of the wall temperature profile. Because the steam inlet flow range is similar between the experiments and the reactor, the film flow regimes will be similar, the resistances to heat transfer through the film will be similar and the heat flux values will be similar. Film Reynolds numbers varied from zero at the inlet of all tests to over 2000 at the outlet on some tests. Therefore, both laminar and turbulent films are represented in the data base and the experiment will have similar condensate film thicknesses-but at different elevations than the SBWR. Even so, such differences are acceptable for assessment purposes.

\subsection{UCB-Kuhn Test Instrumentation}

Twenty two thermocouples (TCs) were embedded at 11 axial elevations in the condenser tube outer wall. Pairs of TCs were placed 180 degrees apart from each other. Thermocouples were attached to the inner wall of the water jacket at the same locations as they were attached to the condenser tube (see Figure 3) plus additional cooling water temperature measurements were made at the inlet and outlet. Condenser tube thermocouple problems were avoided in this series by silver soldering the thermocouples in an axial grove in the test section wall (see Figure 5). The water jacket thermocouples protruded about $1 \mathrm{~mm}$ into the water and the stainless steel sheath ran azimuthally for a short distance before penetrating through the wall in a plastic sheath. Kuhn discovered that an earlier attachment rnethod where they did not wrap azimuthally caused low readings because of axial conduction down the metal sheath.

Variable reluctance (magnetic resistance) delta-pressure transducers were placed across square edged orifices to measure the liquid and gas flow rates. Rotameters were also used to measure the air flow.

Test section pressure was measured at the top of the test section with a variable reluctance transducer.

The movable probe inside the test section was used to measure the steamNC mixture temperature and the water level in steam-only tests. It was not used in the calculation of the heat transfer coefficients. On some steam-only 


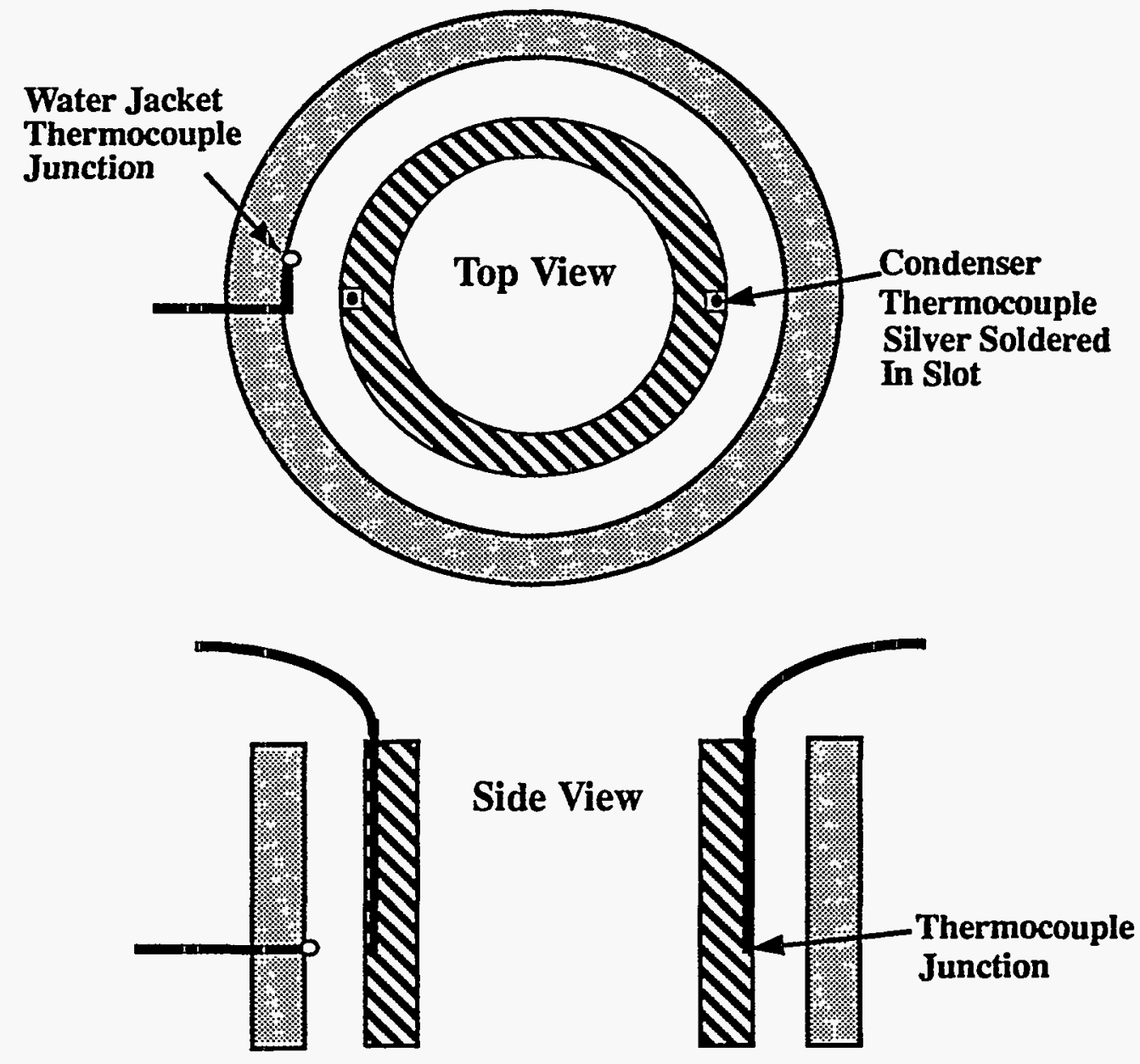

FIGURE 5. UCB-Kuhn thermocouple attachment.

tests the condenser was mainly full of condensate. The data report ${ }^{16}$ does not contain measured temperature readings below the liquid level.

\subsection{UCB-Kuhn Data Uncertainty}

Even though this is the most carefully instrumented test set available, the reported uncertainties in the heat transfer coefficients and degradation factor are high, as shown in Table 3.

Table 3. Uncertainty of UCB-Kuhn Data

\begin{tabular}{|l|l|}
\hline Reduced Quantity & Average Relative uncertainty \\
\hline \hline Heat Flux & $\pm 10.4 \%$ \\
\hline
\end{tabular}


Table 3. Uncertainty of UCB-Kuhn Data (Continued)

\begin{tabular}{|l|l|}
\hline Reduced Quantity & Average Relative uncertainty \\
\hline \hline Tinlet & $\pm 0.99^{\circ} \mathrm{K}$ \\
\hline Experimental Heat Transfer Coefficient & $\pm 18.7 \%$ \\
\hline Theoretical Heat Transfer Coefficient & $\pm 3.36 \%$ \\
\hline Degradation Factor & $\pm 19.0 \%$ \\
\hline
\end{tabular}

Uncertainties in the NC quality at each axial location were not reported but they are probably close to the heat flux uncertainty. Because NC uncertainty are not reported, uncertainty bars are not shown in the comparisons with the RELAP5 predictions.

Based on the repeatability tests discussed in the next section, the estimated heat flux uncertainty is suspect (see especially Test 1.1-4). Uncertainty bars should overlap on repeat tests.

\subsection{UCB-Kuhn Data Repeatability}

Comparisons were made between temperatures recorded on thermocouples circumferentially offset from one another by $180^{\circ}$. Excellent agreement was found. However, it appeared the condenser thermocouples at the $9 \mathrm{~cm}$ elevation were affected by the water jacket connector, and the first axial position where measurements are reported is therefore at $17 \mathrm{~cm}$.

Some tests were repeated long after the initial data were taken to confirm such important aspects as: instrument calibration drift, and chemical fouling of the walls causing heat transfer reductions. The data report ${ }^{16}$ (page 71) says that tests with NC show a larger repeatability problem than the steamonly data. Plots of the inner surface heat flux profiles from repeatability sets do not support this statement. Table 4 gives the conditions for seven sets of repeatability runs. The first four are steam-only at pressures of about 1, 2, 4,

Table 4. UCB-Kuhn Test Conditions.

\begin{tabular}{|l|l|l|l|l|l|}
\hline $\begin{array}{l}\text { Test } \\
\text { Number }\end{array}$ & $\begin{array}{l}\text { Pressure } \\
(\mathrm{kPa})\end{array}$ & $\begin{array}{l}\text { Steam } \\
\text { Inlet Flow } \\
\text { Rate } \\
(\mathrm{kg} / \mathrm{hr})\end{array}$ & $\begin{array}{l}\text { NC Inlet } \\
\text { Flow Rate } \\
(\mathrm{kg} / \mathrm{hr}) / g a s- \\
\text { species }\end{array}$ & $\begin{array}{l}\text { NC Inlet } \\
\text { Mass } \\
\text { Fraction } \\
(\%)\end{array}$ & $\begin{array}{l}\text { Water } \\
\text { Inlet Flow } \\
\text { Rate } \\
(\mathrm{kg} / \mathrm{hr})\end{array}$ \\
\hline \hline $1.1-1$ & 116.1 & 60.2 & 0 & 0 & 999.8 \\
\hline $1.1-1 \mathrm{R}$ & 116.9 & 59.40 & 0 & 0 & 1018.8 \\
\hline $1.1-1 \mathrm{R} 2$ & 120.2 & 59.20 & 0 & 0 & 993.1 \\
\hline $1.1-2$ & 202.0 & 61.5 & 0 & 0 & 1085.8 \\
\hline $1.1-2 \mathrm{R}$ & 206.5 & 61.2 & 0 & 0 & 1078.7 \\
\hline
\end{tabular}


Table 4. UCB-Kuhn test conditions.

\begin{tabular}{|l|l|l|l|l|l|}
\hline $\begin{array}{l}\text { Test } \\
\text { Number }\end{array}$ & $\begin{array}{l}\text { Pressure } \\
(\mathbf{k P a})\end{array}$ & $\begin{array}{l}\text { Steam } \\
\text { Inlet Flow } \\
\text { Rate } \\
(\mathrm{kg} / \mathrm{hr})\end{array}$ & $\begin{array}{l}\text { NC Inlet } \\
\text { Flow Rate } \\
(\mathbf{k g} / \mathbf{h r}) / \text { gas- } \\
\text { species }\end{array}$ & $\begin{array}{l}\text { NC Inlet } \\
\text { Mass } \\
\text { Fraction } \\
(\%)\end{array}$ & $\begin{array}{l}\text { Water } \\
\text { Inlet Flow } \\
\text { Rate } \\
(\mathrm{kg} / \mathrm{hr})\end{array}$ \\
\hline \hline $1.1-4$ & 407.4 & 60.2 & 0 & 0 & 1086.6 \\
\hline $1.1-4 \mathrm{R} 1$ & 410.3 & 60.7 & 0 & 0 & 1084.5 \\
\hline $1.1-4 \mathrm{R} 2$ & 393.3 & 60.5 & 0 & 0 & 1081.1 \\
\hline $1.1-5$ & 504.2 & 61.0 & 0 & 0 & 1085.5 \\
\hline $1.1-5 \mathrm{R} 1$ & 503.4 & 61.3 & 0 & 0 & 1074.0 \\
\hline $1.1-5 \mathrm{R} 2$ & 499.5 & 61.4 & 0 & 0 & 1082.0 \\
\hline $1.1-5 \mathrm{R} 3$ & 517.7 & 61.2 & 0 & 0 & 1020.4 \\
\hline $1.1-5 \mathrm{R} 4$ & 498.0 & 57.1 & 0 & 0 & 1057.6 \\
\hline $3.4-2$ & 212.0 & 59.9 & $14.60 / \mathrm{Air}$ & 19.577 & 838.8 \\
\hline $3.4-2 \mathrm{R} 1$ & 206.3 & 60.3 & $14.25 / \mathrm{Air}$ & 19.115 & 836.0 \\
\hline $3.5-2$ & 205.9 & 59.8 & $39.20 / \mathrm{Air}$ & 39.596 & 819.2 \\
\hline $3.5-2 \mathrm{R}$ & 208.9 & 60.1 & $34.35 / \mathrm{Air}$ & 36.368 & 820.5 \\
\hline $5.2-6$ & 433.0 & 45.1 & $5.54 / \mathrm{He}$ & 10.94 & 641.1 \\
\hline $5.2-6 \mathrm{R}$ & 388.0 & 47.1 & $5.60 / \mathrm{He}$ & 10.63 & 634.3 \\
\hline
\end{tabular}

and 5 bars. Next are two steam-air sets at two different NC fractions followed by a steam-helium set. The heat flux values are shown in Figure 6 through Figure 12 as negative values because, by INEL convention, heat flux into a surface is negative. The uncertainty bars result from the $10.4 \%$ uncertainty reported in Table 3. Some of the tests show repeatability problems; the uncertainty bars on Test 1.1-4 do not overlap near the tube entrance. When uncertainty bars do not overlap using the same test conditions, the size of the uncertainty bars should be increased.

\subsection{UCB-Kuhn Data Reduction Method}

The iterative procedure used by Kuhn to obtain the heat flux uncertainties is explained below.

1. The measured annulus outer wall temperature was initially assumed to be the cooling water bulk temperature. An energy balance relates the axial rate of heat-up of the water jacket wall to the condenser inner wall heat flux: 


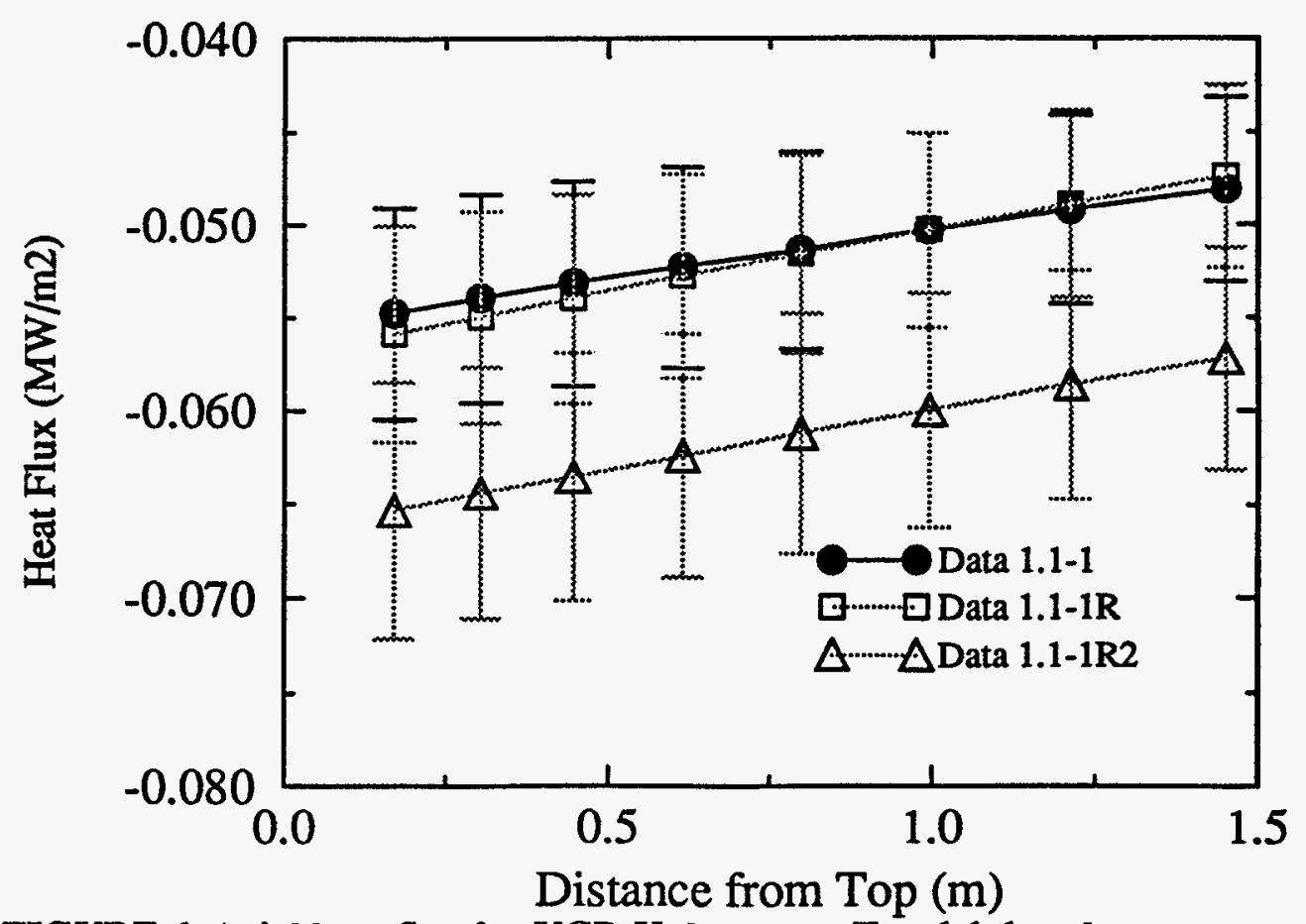

FIGURE 6. Axial heat flux for UCB-Kuhn steam Test 1.1-1 and repeats.

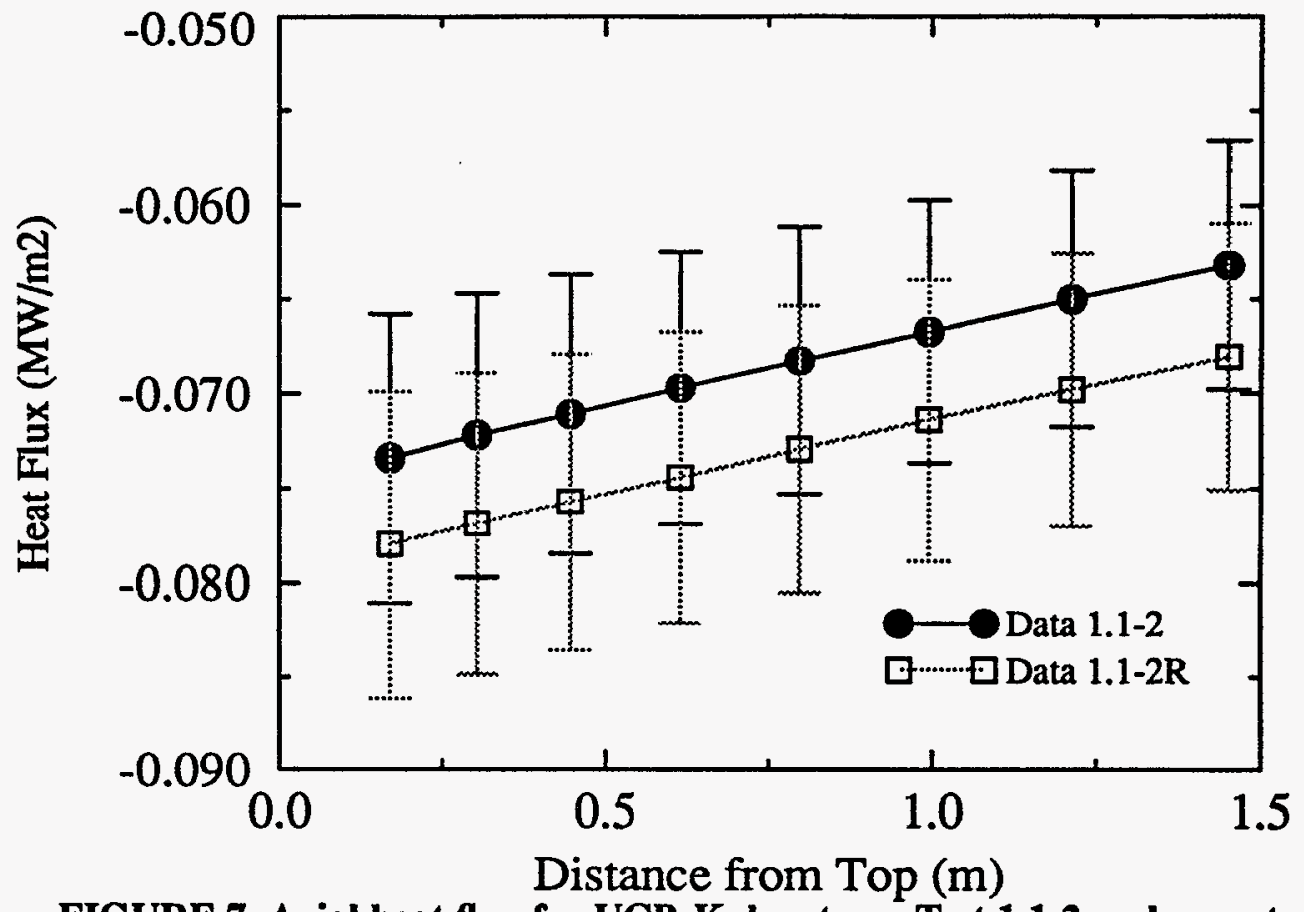

FIGURE 7. Axial heat flux for UCB-Kuhn steam Test 1.1-2 and repeats. 


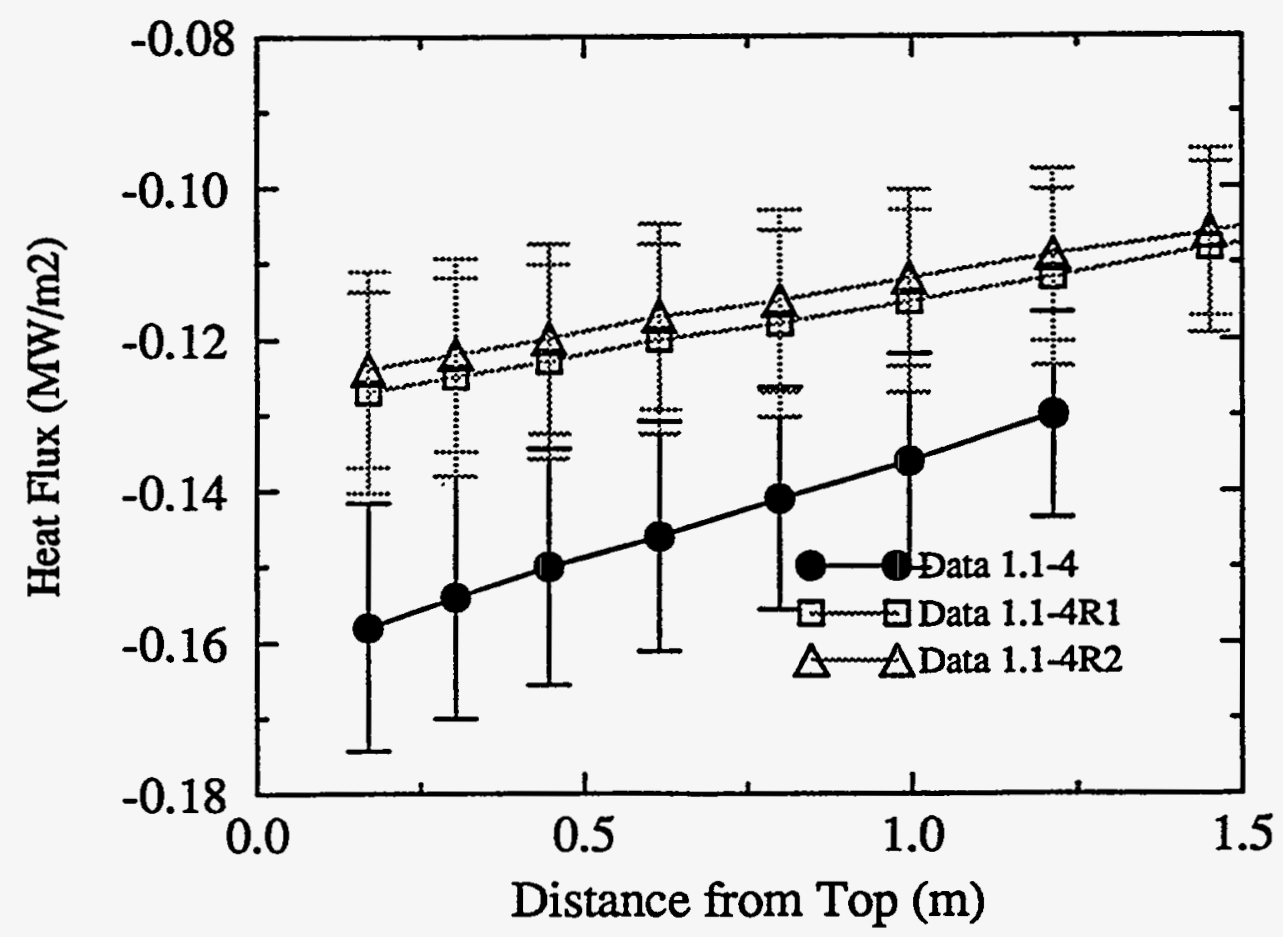

FIGURE 8. Axial heat flux for UCB-Kuhn steam Test 1.1-4 and repeats.

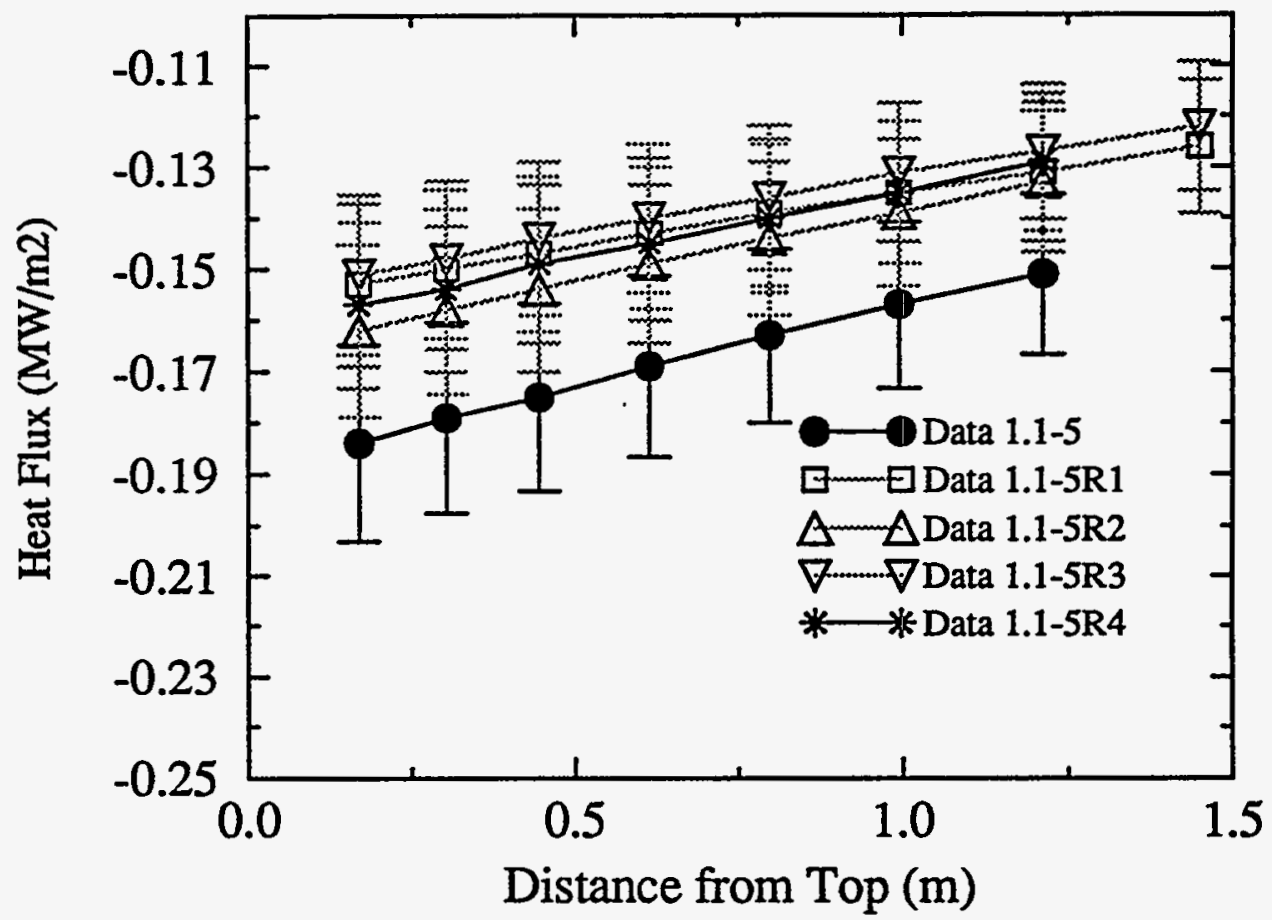

FIGURE 9. Axial heat flux for UCB-Kuhn steam Test 1.1-5 and repeats. 


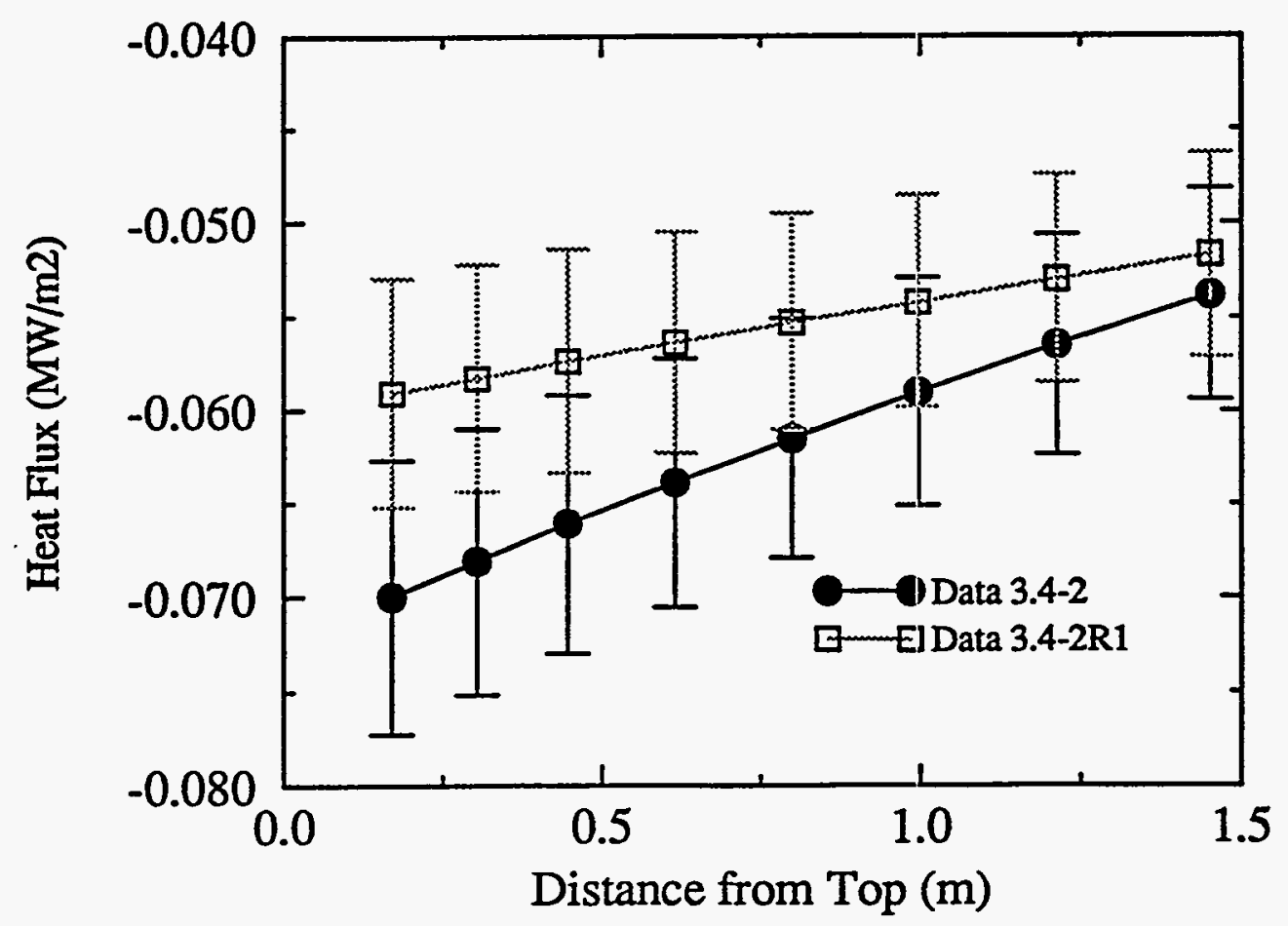

FIGURE 10. Axial heat flux for UCB-Kuhn steam-air Test 3.4-2 and repeats.

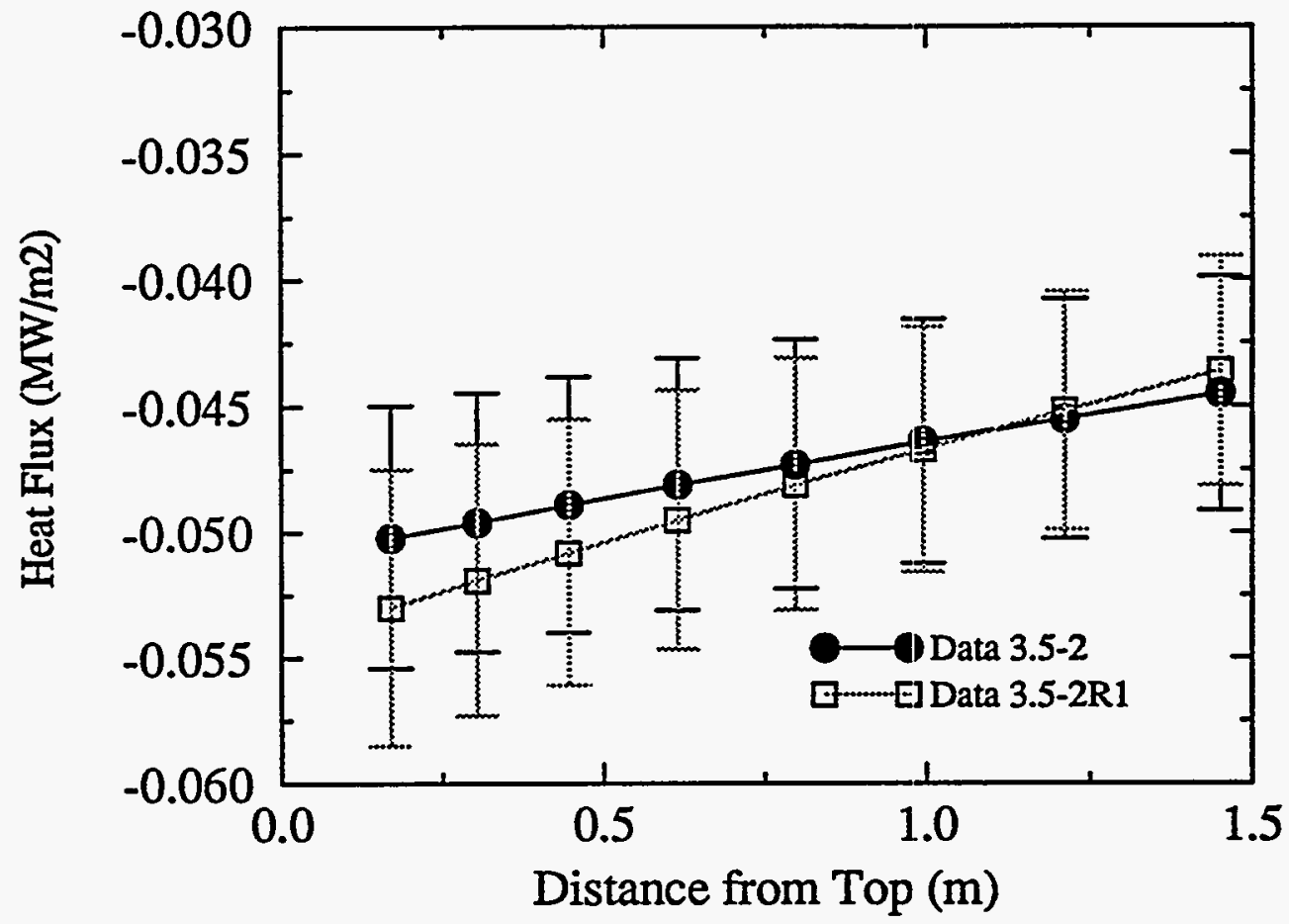

FIGURE 11. Axial heat flux for UCB-Kuhn steam-air Test 3.5-2 and repeats. 


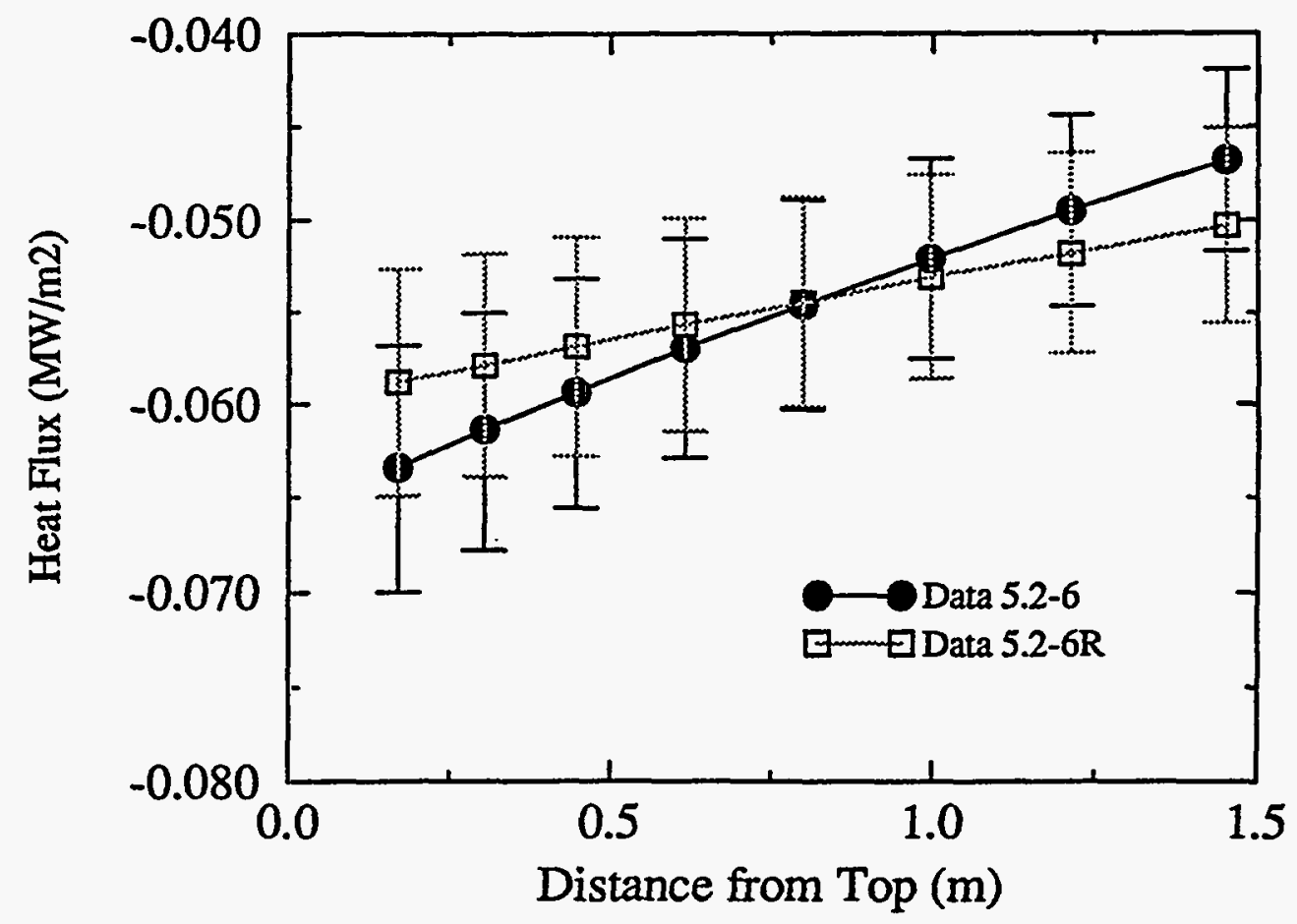

FIGURE 12. Axial heat flux for UCB-Kuhn steam-helium Test 5.2-6 and repeats.

$$
q_{w i}^{\prime \prime}(x)=-\frac{W_{c w} C_{p}}{\pi d_{i}} \cdot \frac{d T_{a}(x)}{d x}
$$

where

$$
\begin{array}{ll}
\mathrm{q}_{\text {wi }}(\mathrm{x}) & =\text { condenser inner wall heat flux at the } \mathrm{x} \text { position. } \\
\mathrm{W}_{\mathrm{cw}} & =\text { cooling water flow rate. } \\
\mathrm{C}_{\mathrm{p}} & =\text { water specific heat. } \\
\mathrm{d}_{\mathrm{i}} & =\text { condenser tube inner diameter. } \\
\mathrm{T}_{\mathrm{a}} & =\text { annulus outer wall temperature. }
\end{array}
$$

Various curve fitting methods were used to obtain the derivative.

2. The radial conduction equation was then solved to obtain the inner wall temperature using the heat flux and outer temperature as boundary conditions.

3. With the inner and outer annulus wall temperature known, a numerical solution of the radial water jacket water temperature profile at each axial position is found by solving the conservation equations. 
4. The average or bulk temperature was found by integrating the radial temperature profile. If the calculated annulus outlet temperature disagreed with the measured outlet temperature by more than 0.2 degrees Kelvin, the new values of the axial bulk temperature profile were used to obtain the gradient in Equation 9 and the steps were repeated.

The heat transfer coefficients in the condenser tube were found from:

$$
h_{\exp }(x)=\frac{q^{\prime \prime}{ }_{w i}(x)}{T_{s, b}(x)-T_{w i}(x)}
$$

where

$$
\begin{array}{ll}
\mathrm{h}_{\text {exp }}(\mathrm{x}) & =\text { experimental heat transfer coefficients. } \\
\mathrm{T}_{\mathrm{s}, \mathrm{b}} & =\text { bulk steam saturation temperature based on the partial pressure } \\
& \text { based on an energy and mass balance. } \\
\mathrm{T}_{\mathrm{wi}}(\mathrm{x}) & =\text { tube inner wall temperature. }
\end{array}
$$

Knowledge of the axial variation of the heat flux allowed the condensate mass flow rate to be found at each axial position by integrating the flux profile. The mass flow rate of steam was also known at each axial position because the energy transfer was the result of condensing steam, and therefore the NC quality was found at each position.

\subsection{UCB-Kuhn Test Deficiencies}

Test deficiencies were:

1. Test pressures were not high enough for examination of high pressure ICS performance (see Section 2.2).

2. Minimum steam flow rates were well above the lowest expected values in the PCCS operating range.

3. The test section had a hydrodynamic entrance prior to the condensing section.

4. The test section did not simulate the non-vertical part of the PCCS tubes.

5. The PCCS cooling water temperatures and velocities were not matched.

6. The liquid mass flow rate at the test section inlet was assumed to be zero. No inlet condensate measurements were made to confirm the assumption.

Deficiencies 2 through 6 were discussed in Section 4.2 and are of minor importance. Deficiency 1 , however, is significant since additional test data is needed to confirm predictions of ICS condensation behavior.

\subsection{MIT Tests}

The MIT NC study addresses many issues that parallel the UCB experimental work relative to condensation heat transfer in the presence of noncondensables. The MIT study dealt with both the effects of air and helium in 
degrading condensation heat transfer in a single tube test apparatus. However, no steam-only experiments were conducted. Both experimental and theoretical analysis were done in the course of this work. These investigations were performed by a student by the name of Siddique ${ }^{18}$.

These data were used to generate wall condensation heat transfer correlations in the presence of air and helium. Helium was used in the experimental apparatus as a surrogate for hydrogen for safety reasons. The thermo-physical properties of helium are closer to hydrogen than are those of air. Hydrogen is expected to be released into the containment during a postulated degraded core accident scenario. Siddique concluded that: (1) air had a more inhibiting effect on condensation heat transfer than helium at the same mole fraction, and (2) for the same mass fraction, helium is more inhibiting. The reason for (1) is unknown but the cause of (2) is that helium has a lower molecular weight than air. Therefore at the same mass fraction, there are more molecules of helium blocking the diffusion of steam toward the wall than if the noncondensable were air. The molecular weight difference between helium and hydrogen is much less than between helium and air, but the same trend should be evident if hydrogen were used as the noncondensable instead of helium.

\subsection{MIT-Siddique Test Apparatus}

The MIT test apparatus was composed of the following key components

- Pressure vessel/boiler system

- Steam inlet lines

- Condenser test section

- Condensate separator drain system

- Instrumentation

The above components comprise an open forced flow test loop to measure condensation heat transfer in the presence of noncondensables. Figure 13 shows a schematic of the test apparatus with distances between thermocouples in the test section.

The boiler system was an electrically heated, 4.5 meter high cylindrical stainless steel vessel with an inside diameter of $0.45 \mathrm{~m}$ (1.48 ft). Power was supplied by four immersion heaters, each rated at approximately 7 kilowatts.

Noncondensables were injected into the base of the boiler. The noncondensable flow was measured and controlled using a calibrated rotameter, a pressure regulating valve, and a flow control valve. Injected noncondensables were subsequently mixed with the steam in the boiler vessel as both flowed toward the test section. Thermal equilibrium between the steam and noncondensable was assumed. It also appears that the flow quality of the steam/ $/ \mathrm{NC}$ entering the test section was assumed to be $100 \%$. In actuality, some condensation could have occurred in the pipe connecting the boiler to the test section. No measurements confirmed the 'complete mixing' and 'no condensation' assumptions. Water at the inlet would have caused a heat flux reduction. 


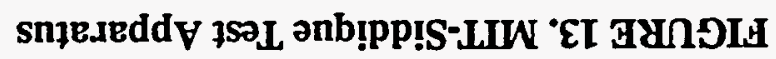

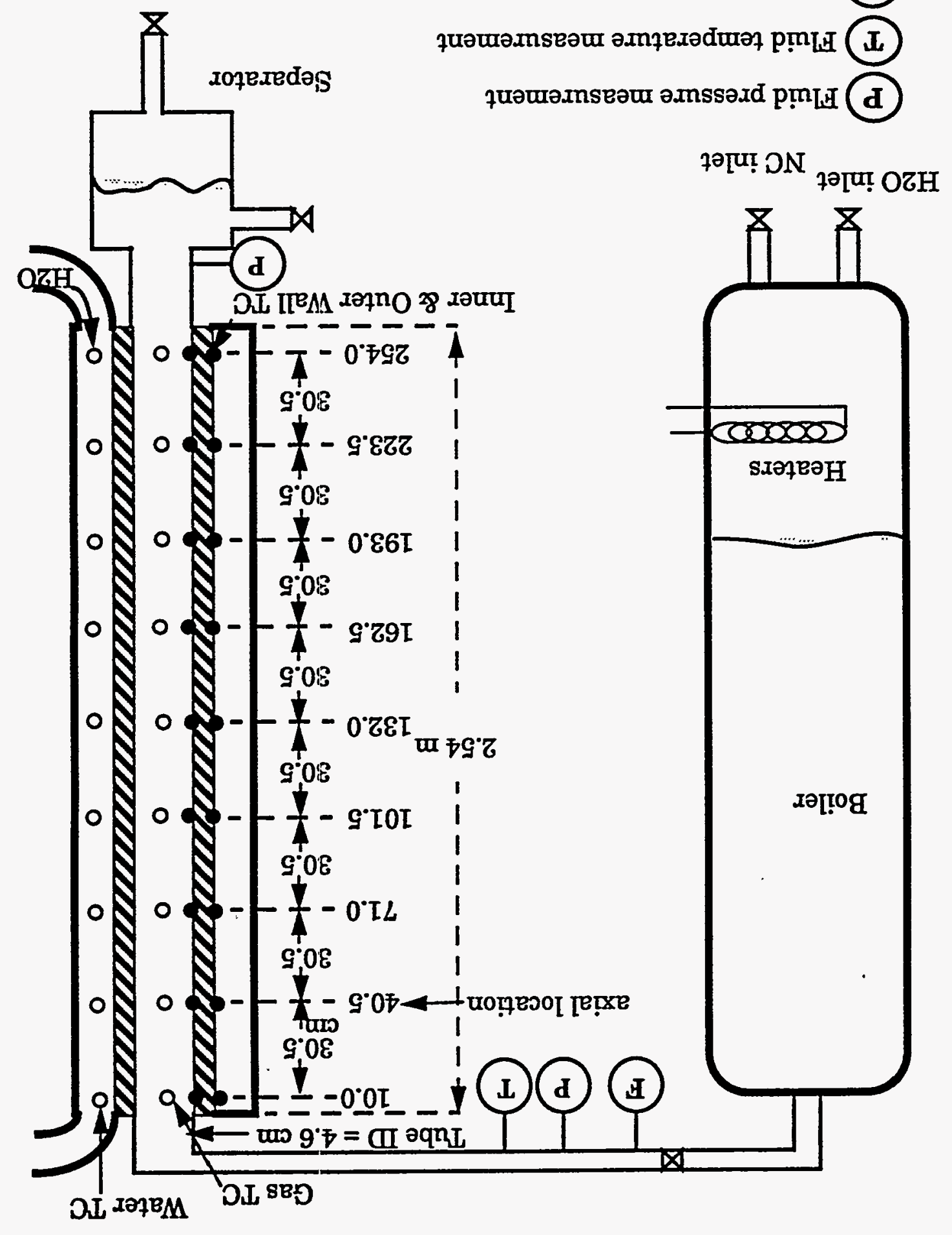


The condenser test section consisted of one vertical stainless steel tube with the down flowing steam/NC injected at the top of the condenser section. This test section had a $50.8 \mathrm{~mm}$ (2.0 inches) outside diameter, $46.0 \mathrm{~mm}$ (1.81 inches) inside diameter, and a length of $2.54 \mathrm{~m}(8.33 \mathrm{ft})$. The condenser region was cooled with a concentric cooling water jacket. The concentric jacket had an outer diameter of $62.7 \mathrm{~mm}$ ( 2.47 inches). Secondary cooling water was pumped into the bottom of the outer annulus of the condenser section and discharged at the top.

\subsection{MIT-Siddique Test Scaling}

The scaling discussion for the UCB-Kuhn experiment (Section 4.2 ) applies to the MIT-Siddique tests. The inside diameter of the MIT experiment test section was slightly smaller than the one used by Kuhn.

\subsection{MIT-Siddique Test Instrumentation}

Thermocouples in the condenser tube region were iron-constantan. These TCs were placed on both the inside and outside of the condenser tube. Thermocouples in the test section were located at nine locations spaced at $30.5 \mathrm{~cm}$ intervals along the condenser region with the first one 10 centimeters from the inlet. The outer thermocouples were attached in a manner similar to the UCB-Kuhn thermocouples. Holes were drilled through the tube wall at an angle to locate the physical junction of the inner tube thermocouples at less than $0.2 \mathrm{~mm}$ from the inner surface. These thermocouples were silver soldered in place.

Gas mixture temperatures were measured along the center line of the condenser region. These thermocouples were fixed at each position since they came through a hole in the test section wall at the elevations shown.

Thermocouples were positioned to measure the secondary bulk coolant temperatures at the inlet and outlet. To get an accurate measure of the bulk secondary water cooling temperature, good mixing was required in the annular region. To obtain mixing without high flow rates and small axial water temperature increases air was injected into the flow stream. Although the amount of injected air was assumed to be small, the amount injected was not quantified. If the water-air mixing was not uniform, there is the possibility of additional experimental uncertainties.

A gas sampling probe could also be inserted at each of the nine measuring stations but condensate in the lines caused this technique to fail. The probe was therefore not used during the reported tests.

Downstream of the boiler the steam/NC mixture flow rate was measured with a flow vortex meter. Gas mixture temperature and pressure were also measured upstream and downstream of the condenser test region.

Immersion heater power levels in the boiler were monitored with a watt meter.

Water flow to the annulus was measured with a rotameter.

The UCB-Kuhn ${ }^{16}$ report compared the MIT and UCB data, and the comparisons look relatively good. But the report also noted that (on page 71): “it 
seems more likely that there was a faulty thermocouple in Siddique's apparatus." The positions of the suspect thermocouples were not stated. The consequence would be incorrect values of reported heat transfer coefficients.

\subsection{MIT-Siddique Data Uncertainty}

Siddique did not report the uncertainty in his reported values of heat flux. He reported the data uncertainties for the experimental heat transfer coefficient, the Tbulk-Twall difference, and the annulus coolant temperature gradient (see Table 3). To obtain the heat flux uncertainty, Siddique's procedures for calculating uncertainty were followed.

Table 5. Uncertainty of MTT Data

\begin{tabular}{|l|l|}
\hline Reduced Quantity & Average Relative Uncertainty \\
\hline \hline Heat Flux & $\pm 15.0 \%$ \\
\hline Experimental Heat Transfer Coefficient & $\pm 17.3 \%$ \\
\hline Tbulk-Twall & $\pm 8.48 \%$ \\
\hline Annulus coolant temperature gradient & $\pm 15.0 \%$ \\
\hline
\end{tabular}

The heat flux is:

$$
\ddot{q}_{w i}^{\prime \prime}(x)=-\frac{W_{c w} C_{p}}{\pi d_{i}} \cdot \frac{d T_{a}(x)}{d x}
$$

where the terms are defined as in Equation 9. The heat flux uncertainty is defined as:

$$
\frac{\sigma_{q^{\prime \prime}}}{q^{\prime \prime}}=\left[\left(\frac{\frac{\partial}{\partial W_{c W}} q^{\prime \prime}}{q^{\prime \prime}}\right)^{2} \sigma_{W}^{2}+\left(\frac{\frac{\partial}{\partial\left(\frac{d T}{d x}\right)^{\prime \prime}}}{q^{\prime \prime}}\right)^{2} \sigma_{\frac{d T}{d x}}^{2}\right]^{\frac{1}{2}}
$$

where

$$
\sigma \quad=\text { uncertainty. }
$$

The partial differential of Equation 11 with respect to $W$ divided by $q^{\text {" is }} 1 /$ $\mathrm{W}_{\mathrm{cW}}$ and the partial differential with respect to the temperature gradient divided by $q^{m}$ is one over the temperature gradient. Therefore Equation 12 becomes: 


$$
\frac{\sigma_{q^{\prime \prime}}}{q^{\prime \prime}}=\left[\frac{\sigma_{W}^{2}}{W_{c w}^{2}}+\frac{\sigma_{d T}^{2}}{\left(\frac{d T}{d x}\right)^{2}}\right]
$$

Most of this uncertainty comes from the uncertainty in the axial gradient of the cooling water temperature. The report gives the following information:

$$
\begin{aligned}
& \sigma_{W}=0.01 W_{c w} \\
& \sigma_{\frac{d T}{d x}}=0.15\left(\frac{d T}{d x}\right)
\end{aligned}
$$

Using Equation 14 and Equation 15 in Equation 13 yields a heat flux uncertainty of about $15 \%$.

The temperature gradients were calculated by taking derivatives from a least squares polynomial fit of the annulus water temperature measurement.

As was the case for the UCB-Kuhn tests, no NC uncertainties are reported.

Siddique used air injection to help get a well mixed average cooling water temperature. This may have caused accuracy problems that were not accounted for. Page 71 of the UCB-Kuhn ${ }^{16}$ report says that: " recent use of Siddique's equipment has shown that the measured bulk temperatures depend on the air flowrate. Further it has not been found possible to reproduce Siddique's data." No reference is given for the 'recent use'. This implies that the above uncertainties may be optimistic.

\subsection{MIT-Siddique Data Repeatabilitey}

Duplicate tests were not performed.

\subsection{MIT-Siddique Data Reduction Method}

Siddique found the axial heat flux values from Equation 9 as was done for the UCB experiment, except that the temperature was the bulk water temperature instead of the annulus wall temperature. No iterative check on the exit annulus water temperature and analytical solution for the radial temperature profile was needed because Siddique's measured annulus temperature was in the bulk stream rather than at the wall. This assumes good mixing was occurring. Siddique's data tables show the integral of the estimated heat flux into the water jacket. On a few of the tests, this integral value was checked against the reported flow rate times the total enthalpy change calculated from the inlet and outlet water temperatures. Differences of less than $1 \%$ were found.

Siddique tried to check the heat flux obtained from the annulus water temperature gradient by using the measured gradient across the condenser tube wall. This method failed because of "a large scatter in the tube outer wall tem- 
perature measurements (possibly due to fluctuations in the cooling water flow field)". The probability of air bubbles causing the fluctuations is unknown.

\subsection{MIT-Siddique Test Deficiencies}

All the deficiencies in the UCB tests were present in the MTT tests. In addition, the MIT tests had no steam-only cases and no repeatability tests were reported. Also air injection in the water jacket to promote mixing may have been a problem. The measured heat flux values, which will be compared to RELAP5 predicted values, have a larger uncertainty band than those for UCB.

\subsection{RELAP5 Wall Condensation Models}

Two wall condensation models will be available in Mod 3.2 because the model selection process is not complete. The base model is Nusselt with UCB multiplier $\mathrm{fl}$, see Equation 6, to account for gas shear on the liquid film and f2, see Equation 8, to account for heat transfer degradation caused by the presence of noncondensable gas. ${ }^{\text {a }}$

The second RELAP5 condensation option is the maximum of the Nusselt and the Shaw ${ }^{20}$ model in place of the Nusselt model the $f 1$ factor and the Colburn-Hougen ${ }^{21}$ diffusion method in place of the $f 2$ factor. The details of the last model can be found in Volume 4 of the 1995 RELAP5 documentation of MOD 3.2. The Colburn-Hougen diffusion calculation involves an iterative process to solve for the steam saturation temperature at the interface between the steam and water film. A third condensation model is being developed which will use the diffusion method for both the wall and steam-water interfacial heat transfer rates. Currently the two wall condensation models are partially uncoupled from the interfacial heat transfer model. The mass transfer rate calculated in either of the two wall condensation heat transfer sections of the code are used in the energy and mass continuity equations. However, the bulk interfacial part of the code does not recognize a unique film condensation mode where, in steady state, heat from the gas must equal heat to the wall.

\subsection{RELAP5 Model of UCB-Kuhn Test Apparatus}

Figure 14 shows the RELAP5 model components. Nine cells were used in the pipe to cover all the locations where heat flux data is reported. The model cell $\mathrm{L} / \mathrm{D}$ was about 4 . RELAP5 models of the SBWR reactor PCCS normally have about eight cells with an I/D of 4.6.

Since the task objective is to assess the ability of the code to predict condi-

a. The RELAP5 correlation is believed to be similar to the one used by TRACG. Vial and Schrock ${ }^{19}$ compared TRACG with MIT and early UCB data but did not report the details of the correlation implementation. 


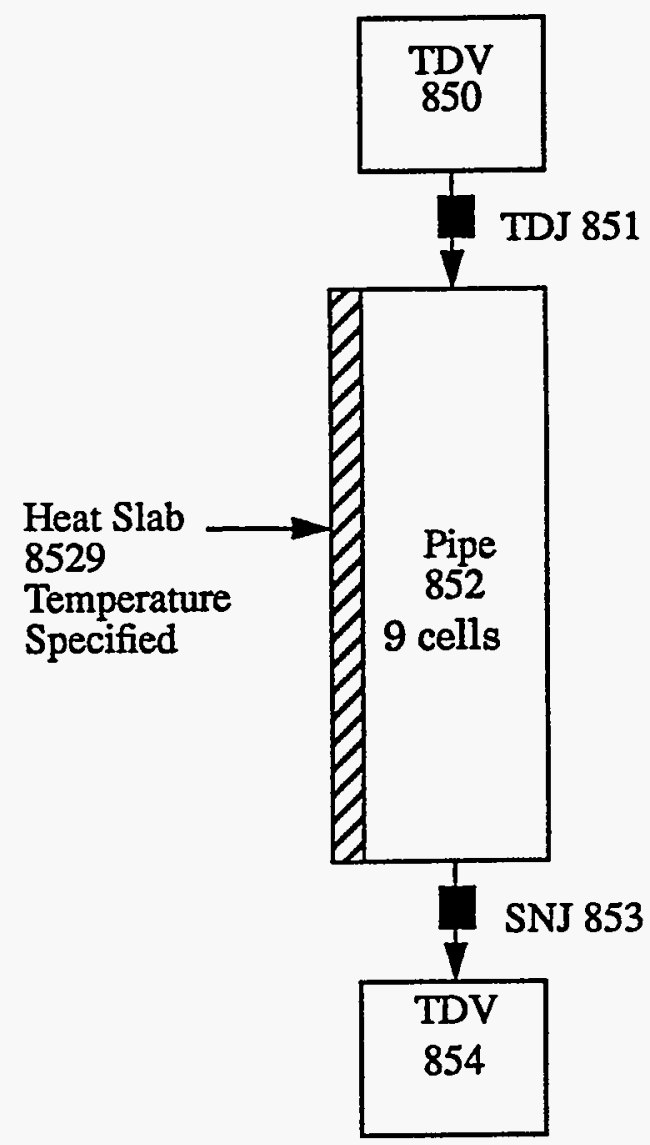

FIGURE 14. RELAP5 Model of UCB and MIT experiment.

tions inside the tube, the coolant channel was not modelled. 'I'he outer boundary condition is the measured inside wall temperature. The wall was modeled as a thin wall with high thermal conductivity so the inner and outer temperature would be nearly the same. RELAP5 was compared with 'measured' heat flux and noncondensable quality values.

\subsection{UCB-Kuhn Tests Chosen for Assessment}

Of the 141 tests performed by Kuhn, 27 were chosen for code assessment (see Table 6). They were chosen to systematically cover the entire test matrix. Nine of the tests are steam-only, fifteen are steam-air and three are steam- 
helium. The inlet gas Reynolds numbers were calculated by RELAP5.

Table 6. UCB-Kuhn Tests Selected for Assessment

\begin{tabular}{|c|c|c|c|c|c|c|}
\hline \# & $\begin{array}{l}\text { Test } \\
\text { Number-Gas }\end{array}$ & $\begin{array}{l}\text { Inlet } \\
\text { Press } \\
\text { ure } \\
(\mathrm{MPa})\end{array}$ & $\begin{array}{l}\text { Inlet NC } \\
\text { Mass } \\
\text { Fraction } \\
(\%)\end{array}$ & $\begin{array}{l}\text { Gas } \\
\text { Mixture } \\
\text { Flow } \\
\text { Rate(kg/ } \\
\text { s)x100 }\end{array}$ & $\begin{array}{l}\text { Inlet Gas } \\
\text { Mass } \\
\text { Flux } \\
\left(\mathrm{kg} / \mathrm{s}-\mathrm{m}^{2}\right)\end{array}$ & $\begin{array}{l}\text { Inlet Gas } \\
\text { Reynolds } \\
\text { Number } \\
\text { (Approx.) }\end{array}$ \\
\hline 1 & 1.1-1-Steam & 0.1 & 0 & 1.67 & 9.44 & 36000 \\
\hline 2 & 1.1-2-Steam & 0.2 & 0 & 1.71 & 9.64 & 35000 \\
\hline 3 & 1.1-3-Steam & 0.3 & 0 & 1.67 & 9.41 & 32000 \\
\hline 4 & 1.1-4-Steam & 0.4 & 0 & 1.67 & 9.44 & 31000 \\
\hline 5 & 1.1-5-Steam & 0.5 & 0 & 1.69 & 9.56 & 30000 \\
\hline 6 & 1.4-1-Steam & 0.1 & 0 & 0.833 & 4.70 & 18000 \\
\hline 7 & 1.4-3-Steam & 0.3 & 0 & 0.786 & 4.43 & 14000 \\
\hline 8 & 1.4-5-Steam & 0.5 & 0 & 0.819 & 4.62 & 14000 \\
\hline 9 & 6.1-5-Steam & 0.5 & 0 & 1.64 & 9.28 & 30000 \\
\hline 10 & 2.1-1-Air & 0.4 & 1 & .41 & 7.93 & 25000 \\
\hline 11 & 2.1-7-Air & 0.4 & 10 & 1.56 & 8.79 & 27000 \\
\hline 12 & 3.1-2-Air & 0.2 & 1 & 1.65 & 9.30 & 32000 \\
\hline 13 & 3.2-2-Air & 0.2 & 5 & 1.66 & 9.39 & 32000 \\
\hline 14 & 3.3-2-Air & 0.2 & 10 & 1.84 & 10.4 & 34000 \\
\hline $15^{\circ}$ & 3.4-2-Air & 0.2 & 20 & 1.66 & 9.39 & 30000 \\
\hline 16 & 3.5-2-Air & 0.2 & 40 & 1.66 & 9.37 & 28000 \\
\hline 17 & 3.1-5-Air & 0.5 & 1 & 1.66 & 9.37 & 29000 \\
\hline 18 & 3.3-5-Air & 0.5 & 10 & 1.84 & 10.4 & 32000 \\
\hline 19 & 3.5-5-Air & 0.5 & 40 & 2.63 & 14.9 & 41000 \\
\hline 20 & 4.1-2-Air & 0.2 & 1 & 0.839 & 4.74 & 16000 \\
\hline 21 & 4.3-2-Air & 0.2 & 10 & 0.965 & 5.45 & 19000 \\
\hline 22 & 4.5-2-Air & 0.2 & 40 & 1.39 & 7.87 & 23000 \\
\hline 23 & 4.3-5-Air & 0.5 & 10 & 1.01 & 5.68 & 17000 \\
\hline 24 & 4.5-5-Air & 0.5 & 40 & 1.39 & 7.84 & 21000 \\
\hline
\end{tabular}


Table 6. UCB-Kuhn Tests Selected for Assessment (Continued)

\begin{tabular}{|l|l|l|l|l|l|l|}
\hline & & $\begin{array}{l}\text { Inlet } \\
\text { Press } \\
\text { ure } \\
\text { (MPa) }\end{array}$ & $\begin{array}{l}\text { Inlet NC } \\
\text { Mass } \\
\text { Fraction } \\
(\%)\end{array}$ & $\begin{array}{l}\text { Gas } \\
\text { Mixture } \\
\text { Flow } \\
\text { Rate(kg/ } \\
\text { s)x100 }\end{array}$ & $\begin{array}{l}\text { Inlet Gas } \\
\text { Mass } \\
\text { Flux } \\
\text { (kg/s-m }\end{array}$ & $\begin{array}{l}\text { Inlet Gas } \\
\text { Reynolds } \\
\text { Number } \\
\text { (Approx.) }\end{array}$ \\
\hline \hline 25 & $5.2-1$-Helium & 0.4 & 0.3 & 1.26 & 7.09 & 23000 \\
\hline 26 & $5.2-3$-Helium & 0.4 & 1 & 1.29 & 7.26 & 23000 \\
\hline 27 & $5.2-6$-Helium & 0.4 & 10 & 1.41 & 7.94 & 23000 \\
\hline
\end{tabular}

\subsection{UCB-Kuhn Heat Flux Comparisons with RELAP5}

Fifty four RELAP5/MOD3 (version 8ci; a developmental version of MOD 3.2) calculations were made to obtain all the comparisons with the UCB-Kuhn data. Appendix A shows the 27 heat flux profiles with data and two RELAP5 calculations on each plot. R5 Default on the plots means RELAP5 was using the Nusselt-UCB model to obtain the results. R5 Diffusion refers to use of the Shaw-Colburn-Hougen model.

All the measured versus predicted data points were processed to obtain the RMS value for the two RELAP5 condensation methods. The RMS value was defined as:

$$
R M S=\sqrt{\left.\frac{\sum_{1}^{N} \mid \frac{q_{\text {predicted }}^{\prime \prime}-q_{\text {measured }}^{\prime \prime}}{q_{\text {measured }}^{\prime \prime}}}{N-1}\right|^{2}}
$$

where

$$
\mathrm{N}=\text { total number of points. }
$$

The values for RMS are given in Table 9. Two-hundred and five data points are in the data set ( 205 is less than 9 cells times 27 tests because some tests only reported data at the first few axial positions). For some tests, only the first three elevations were reported because the tube was full of water below that location. The Diffusion method performs best with data both with and without noncondensables. Reference 16 reports that their Kuhn-SchrockPeterson (K-S-P) prediction method compared to their own data has a standard deviation of 0.129 . The K-S-P correlation is an upgraded version of Equation 5 through Equation 8 and has a different f2 form for air than it 
does for helium.

Table 7. Summary of RMS Values for UCB Data versus RELAP5 Prediction.

\begin{tabular}{|l|l|l|l|l|}
\hline $\begin{array}{l}\text { RELAP5 } \\
\text { Condensation Model }\end{array}$ & $\begin{array}{l}\text { RMS Value } \\
\text { all 205 } \\
\text { points }\end{array}$ & $\begin{array}{l}\text { RMS Value } \\
\text { steam only } \\
\text { 62 points }\end{array}$ & $\begin{array}{l}\text { RMS Value } \\
\text { air only } \\
\text { 119 points }\end{array}$ & $\begin{array}{l}\text { RMS Value } \\
\text { helium only } \\
\text { 24 points }\end{array}$ \\
\hline \hline Default & 0.395 & 0.435 & 0.343 & 0.566 \\
\hline Diffusion & 0.188 & 0.211 & 0.181 & 0.163 \\
\hline
\end{tabular}

To further define where the heat flux uncertainties were the largest, a plot of heat flux error versus pressure for a fixed flow was made using the steam only data (the first five Tests in Table 6). Results are shown in Figure 15 and Figure 16. The Default method agrees best at the highest pressure and the reverse is true of the Diffusion model.

RELAP5 Default Method Errors Kuhn Steam Data vs. Pressure

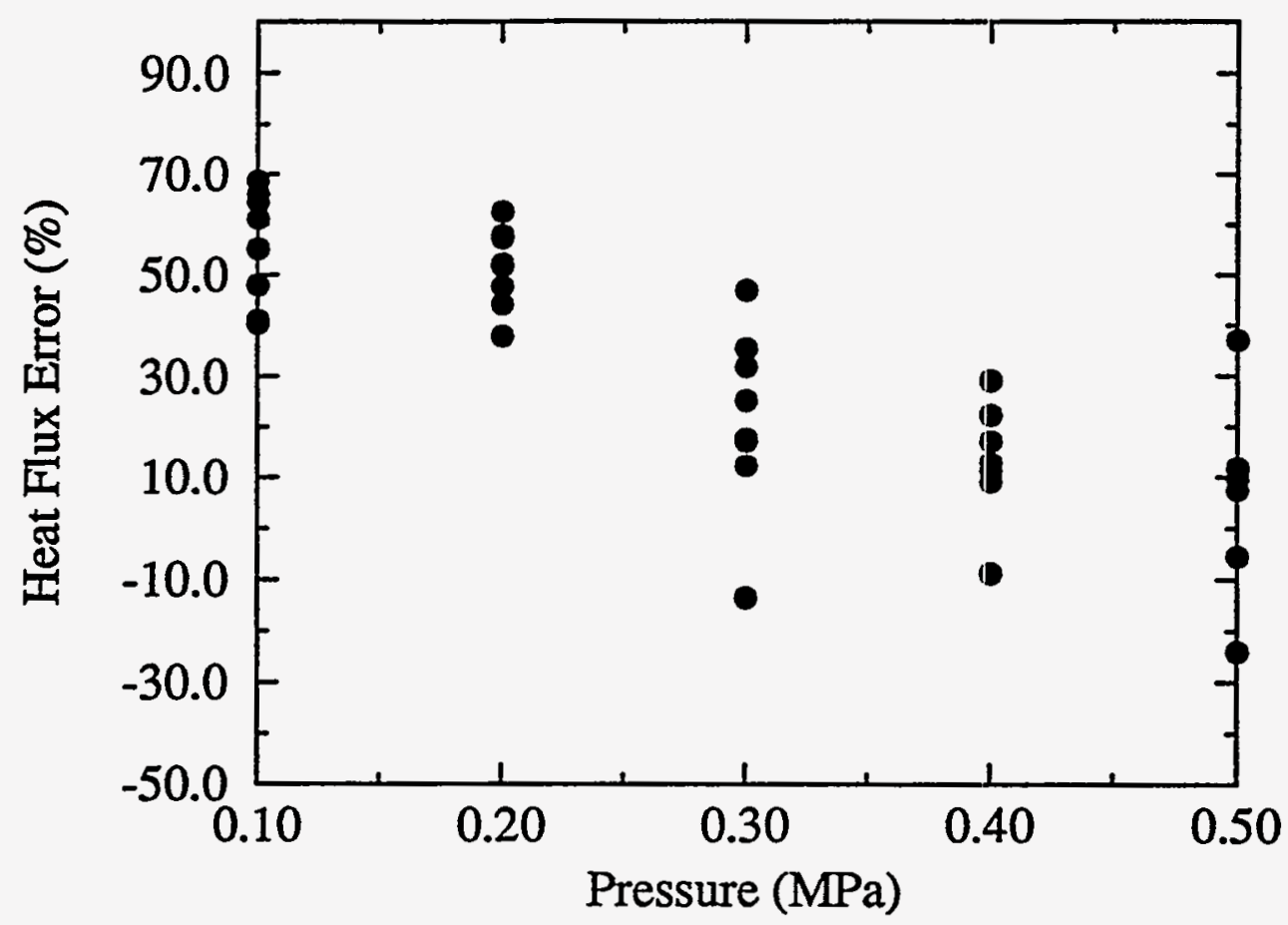

FIGURE 15. RELAP5 Default errors vs. pressure using Kuhn steam data.

Figure 17 shows that the Default method errors are larger at low NC quality values than at high values. The Diffusion method shows the opposite trend (see Figure 18). Tests 3.1-2, 3.2-2, 3.3-2, 3.4-2 and 3.5-2 were used for this later comparison.

Scatter plots of measured heat flux versus predicted heat flux are shown for the two RELAP5 condensation methods in Figure 19 and Figure 20, for all 205 data points. Superior agreement of the Diffusion model with Kuhn data compared to the Default model is evident in these two figures. 


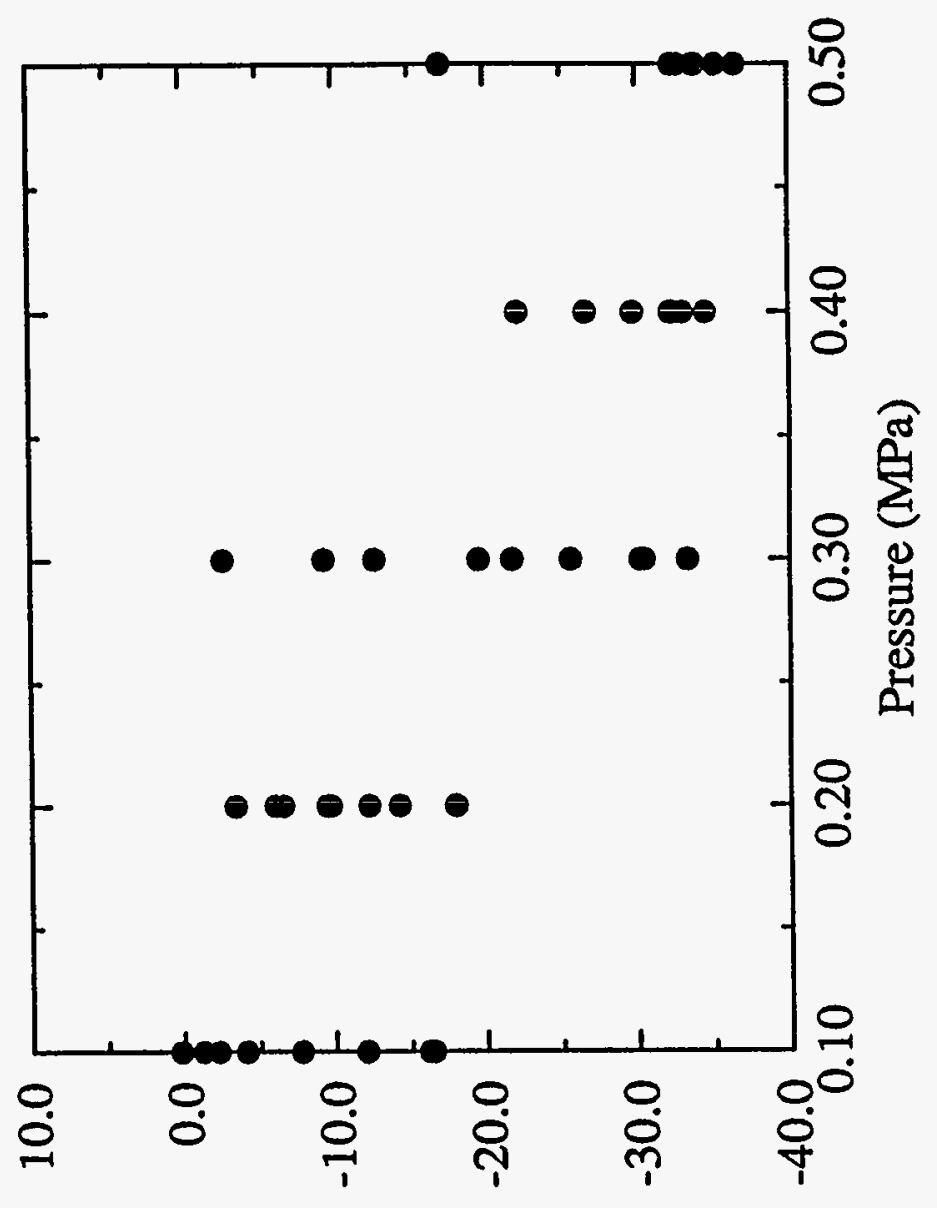

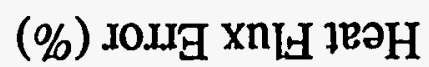

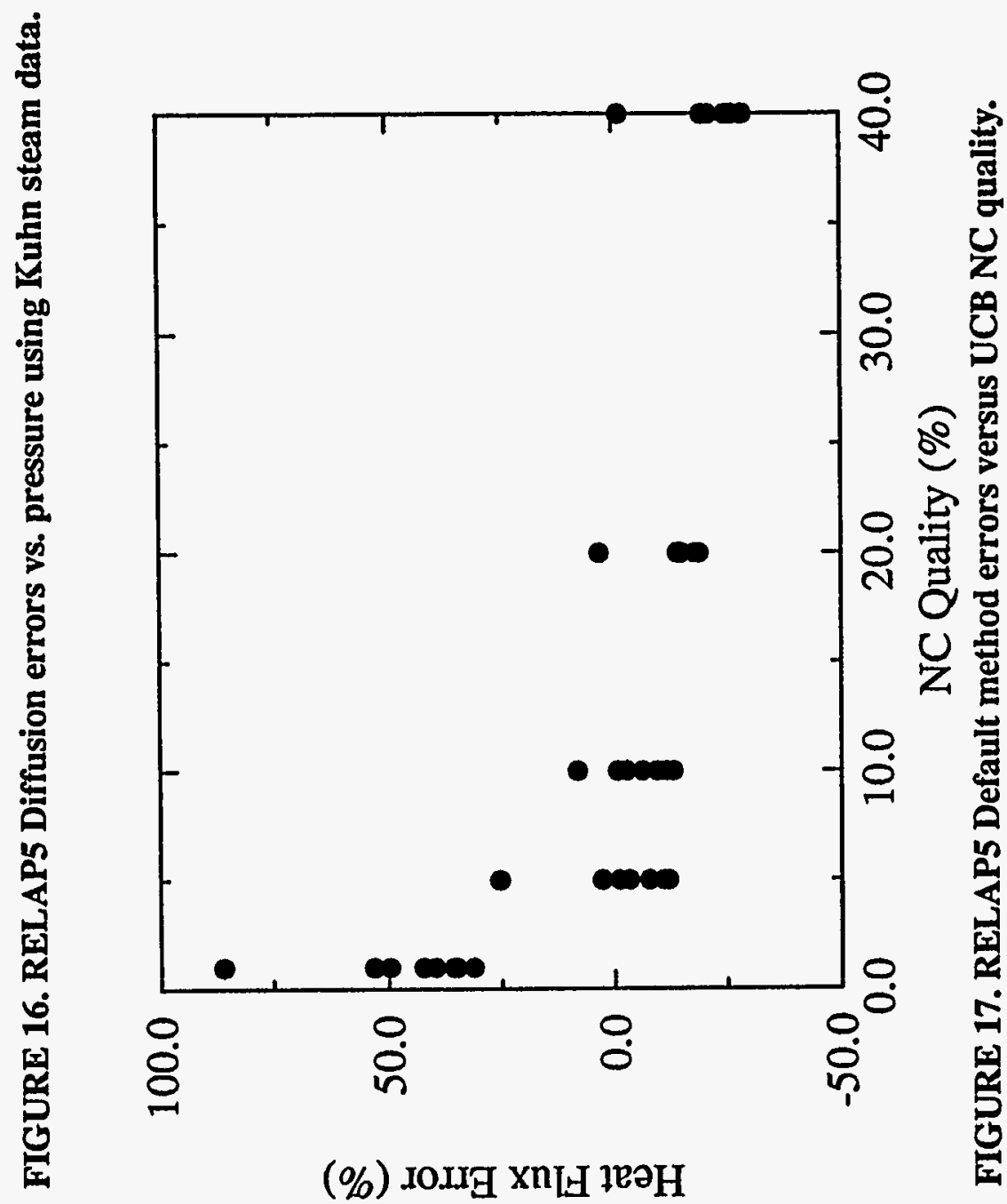




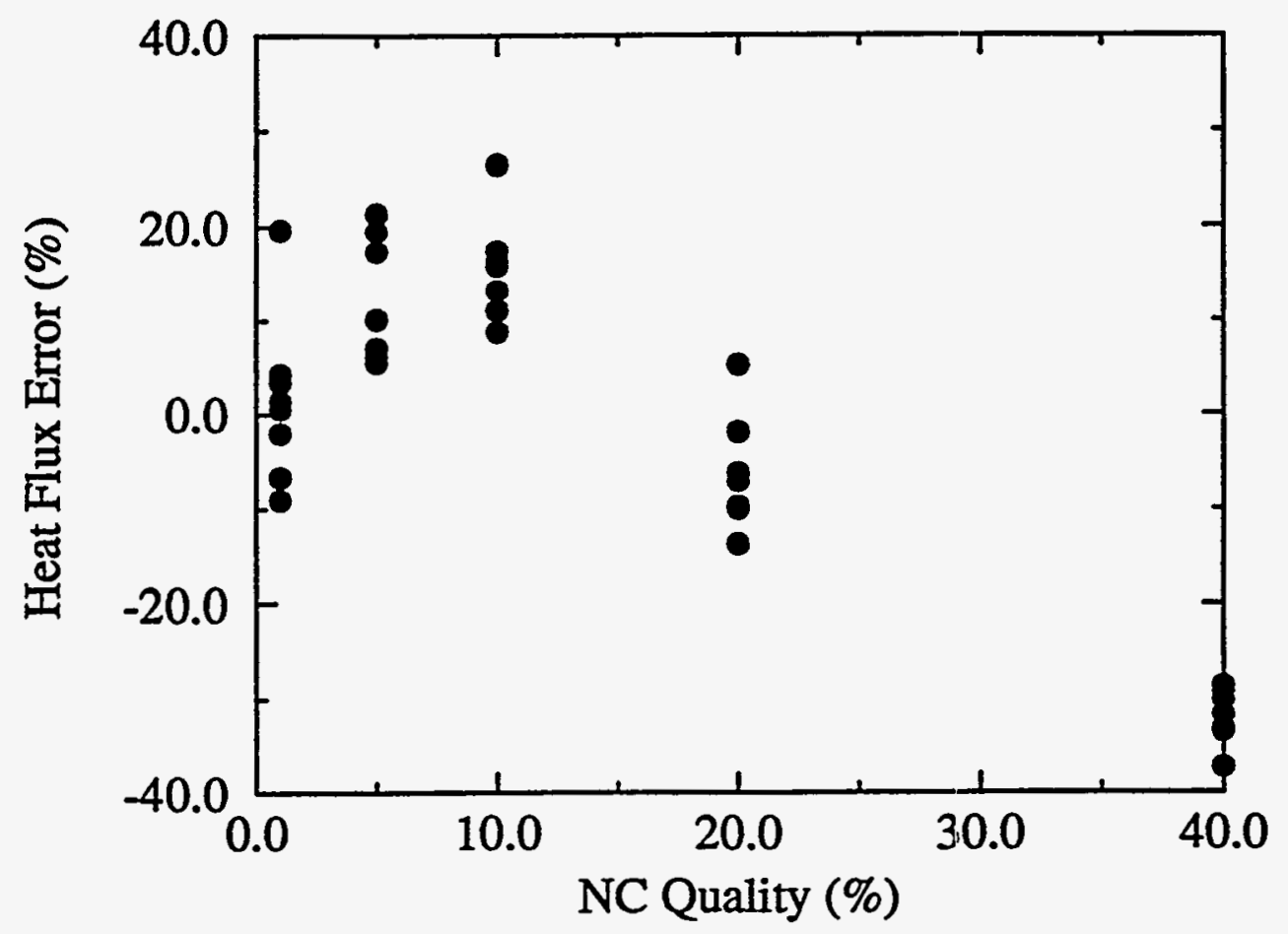

FIGURE 18. RELAP5 Diffusion method errors versus UCB NC quality.

UCB Measured vs R5 Default Heat Flux

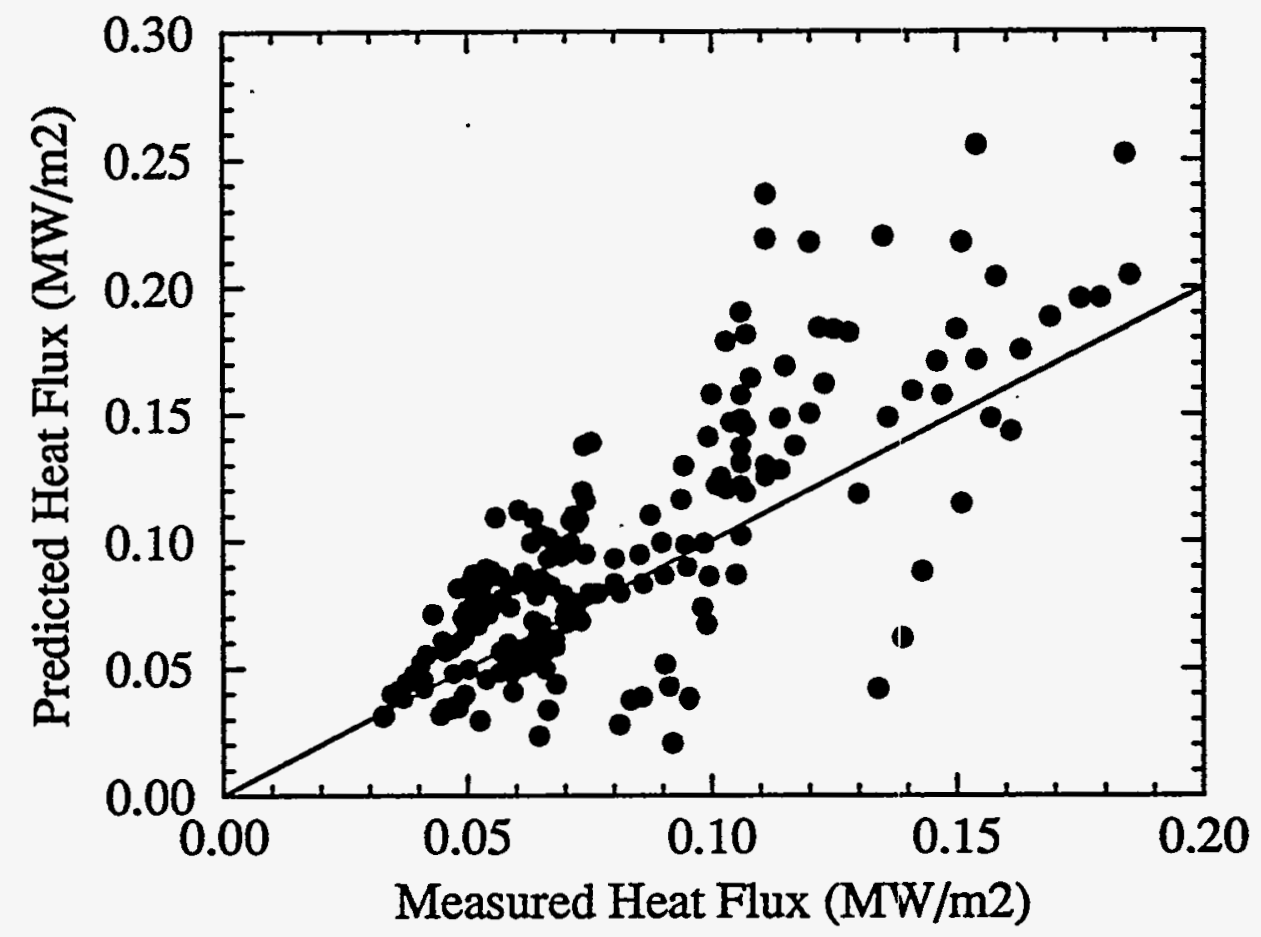

FIGURE 19. UCB measured vs. RELAP5 Default method predicted heat flux. 


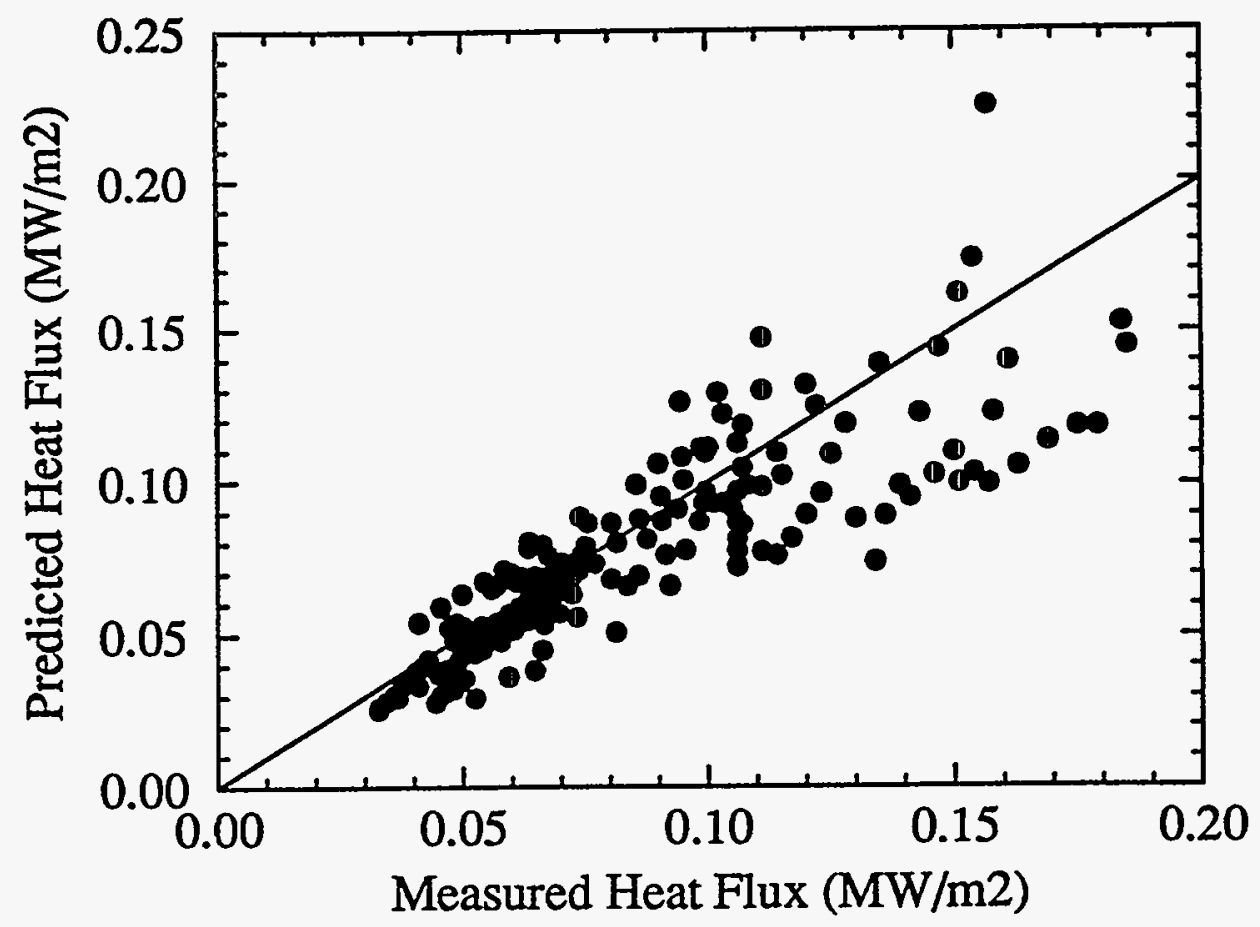

FIGURE 20. UCB measured vs. RELAP5 Diffusion method predicted heat flux.

\subsection{UCB-Kuhn NC Quality Comparisons with RELAP5}

Appendix B shows RELAP5 comparisons with the $18 \mathrm{NC}$ quality profiles. The NC quality is defined as:

$$
X_{N C}=\frac{\operatorname{Mass}(N C)}{\operatorname{Mass}(N C)+\text { Mass }(\text { Steam })}
$$

RELAP5 generally overpredicted the NC quality. The RELAP5 NC quality values are plotted at the RELAP5 cell exit axial position instead of at the cell center position. This was done because the quality reported for a cell is a function of the area integral of the heat flux along the complete length of the cell.

\subsection{RELAP5 Model of MIT-Siddique Test Apparatus}

The MIT test apparatus was similar enough to the Kuhn setup that it was modeled the same way. The main difference was that the lengths of the nine cells were changed to more closely match the MIT instrumentation locations.

\subsection{MIT-Siddique Tests Chosen for Assessment}

Siddique reported results from 52 steam-air tests and 22 steam-helium tests. Eleven air and seven helium tests, shown in Table 8, were chosen for assessment. The tests where chosen to cover the pressure, flow and NC quality ranges available. 
Table 8. MTT-Siddique Test Chosen for Assessment

\begin{tabular}{|c|c|c|c|c|c|c|}
\hline \# & $\begin{array}{l}\text { Test } \\
\text { Number- } \\
\text { Gas }\end{array}$ & \begin{tabular}{|l} 
Inlet \\
Pressure \\
(MPa)
\end{tabular} & $\begin{array}{l}\text { Inlet } \\
\text { NC } \\
\text { Mass } \\
\text { Fraction } \\
(\%)\end{array}$ & $\begin{array}{l}\text { Inlet } \\
\text { Mass } \\
\text { Flux } \\
\text { (kg/m²-s) }\end{array}$ & $\begin{array}{l}\text { Inlet Gas } \\
\text { Reynolds } \\
\text { Number } \\
\text { (Approx.) }\end{array}$ & $\begin{array}{l}\text { Inlet } \\
\text { Mass } \\
\text { Flow } \\
\text { Rate } \\
\text { (kg/s) } \\
\text { x100 }\end{array}$ \\
\hline$\overline{1}$ & 7-Air & 0.209 & $\overline{8.02}$ & 1.71 & 4600 & $\overline{0.284}$ \\
\hline 2 & 8-Air & 0.217 & 13.68 & 1.80 & 4.900 & 0.299 \\
\hline 3 & 19-Air & $\overline{0.114}$ & 16.77 & 3.99 & 14000 & 0.663 \\
\hline 4 & 24-Air & 0.214 & 11.28 & 3.84 & 12000 & 0.639 \\
\hline 5 & 25-Air & 0.221 & 15.46 & 4.12 & 13000 & 0.685 \\
\hline 6 & 26-Air & 0.233 & 22.38 & 4.45 & 13000 & 0.740 \\
\hline 7 & 27-Air & 0.243 & 26.90 & 4.73 & 14000 & 0.786 \\
\hline 8 & 28-Air & 0.252 & 30.60 & 4.90 & 14000 & 0.814 \\
\hline 9 & 29-Air & 0.266 & 35.61 & 5.36 & 15000 & 0.890 \\
\hline 10 & 31-Air & 0.403 & 14.80 & 1.71 & 12000 & 0.644 \\
\hline 11 & 42-Air & 0.221 & 14.85 & 6.08 & 20000 & 1.01 \\
\hline 12 & 6-Helium & 0.244 & 4.792 & 1.53 & 5000 & 0.255 \\
\hline 13 & 14-Helium & 0.144 & 5.317 & 3.28 & 12000 & 0.545 \\
\hline 14 & 16-Helium & 0.214 & 2.133 & 3.16 & 11000 & 0.526 \\
\hline 15 & 17-Helium & 0.252 & 5.363 & 3.30 & 11000 & 0.549 \\
\hline 16 & 18-Helium & 0.271 & 7.306 & 3.33 & 11000 & 0.553 \\
\hline 17 & 19-Helium & 0.293 & 9.322 & 3.33 & 10000 & 0.553 \\
\hline 18 & 22-Helium & 0.465 & 5.426 & 3.59 & 11000 & 0.596 \\
\hline
\end{tabular}

\subsection{MIT-Siddique Heat Flux Comparisons with RELAP5}

Appendix $\mathrm{C}$ shows the RELAP5 calculated versus measured heat flux profiles for the $18 \mathrm{MIT}$ tests for recorded data at $10 \mathrm{~cm}$ downstream of the inlet and below (see Figure 13).

All the measured versus predicted data points were processed to obtain the RMS value for the RELAP5 condensation models. The $10 \mathrm{~cm}$ data were omitted from the RMS study as it was in the UCB study to remove the influence of axial conduction on the RMS errors. This left eight axial data points within the region modeled by RELAP5. Since the RELAP5 cell center positions were not exactly aligned with the measurement positions, interpolation was used to obtain the heat flux at the measurement elevations. The comparison points were also limited to all points with a measured heat flux greater than 0.001 $\mathrm{MW} / \mathrm{m}^{2}$ because the experimental errors became large at low values of heat 
flux. This data limiting procedure was not needed with the UCB-Kuhn data because Kuhn only included the thin film condensation points in the data base. Near the bottom of the MIT test section the heat flux values are small because the steam content is small. Small values of heat flux result in large errors in the derivatives of the axial water temperature profile. The RMS values for the MIT data are given in Table 9. A comparison with points above a heat flux of 0.002 and $0.005 \mathrm{MW} / \mathrm{m}^{2}$ is also given. The RMS values improve as the low heat flux points are removed. On the basis of the comparison to the MIT data, neither of the models appear acceptable.

Table 9. Summary of RMS Values for MIT Data versus RELAP5 Prediction.

\begin{tabular}{|c|c|c|c|c|c|}
\hline $\begin{array}{l}\text { RELAP5 } \\
\text { Condensa } \\
\text { tion Model }\end{array}$ & $\begin{array}{l}\text { RMS Value } \\
\text { with } 136 \\
\text { points } \\
\text { above } \\
\text { q"=1 kW/ } \\
\text { m }^{2}\end{array}$ & $\begin{array}{l}\text { RMS Value } \\
\text { with } 132 \\
\text { points } \\
\text { above } \\
\text { q"=2 kW/ } \\
\text { m }^{2}\end{array}$ & $\begin{array}{l}\text { RMS Value } \\
\text { with } 123 \\
\text { points } \\
\text { above } \\
\text { q"=5 kW/ } \\
\text { m }^{2}\end{array}$ & $\begin{array}{l}\text { RMS Value } \\
\text { with } 61 \text { air } \\
\text { points } \\
\text { above } \\
\text { q"=5 kW/ } \\
\text { m2 }\end{array}$ & $\begin{array}{l}\text { RMS Value } \\
\text { with } 62 \\
\text { helium } \\
\text { points } \\
\text { above } \\
\text { q"'=5 kW/ } \\
\text { m2 }\end{array}$ \\
\hline Default & 1.120 & 0.882 & 0.463 & 0.498 & 0.431 \\
\hline Diffusion & 1.44 & 0.915 & 0.358 & 0.301 & 0.409 \\
\hline
\end{tabular}

Scatter plots are shown for the RELAP5 condensation models in Figure 21 and Figure 22 using the 123 point data set. The percent error near a heat flux of zero is large.

\subsection{MIT-Siddique NC Quality Comparisons with RELAP5}

Appendix D shows the 18 quality profiles. The quality at each location is a function of the inlet quality and the integral of the heat flux and are plotted at the cell exit position. The quality profile comparisons between the data and the predictions appear worse than the heat flux comparisons shown in Appendix $\mathbf{C}$ in many cases. 


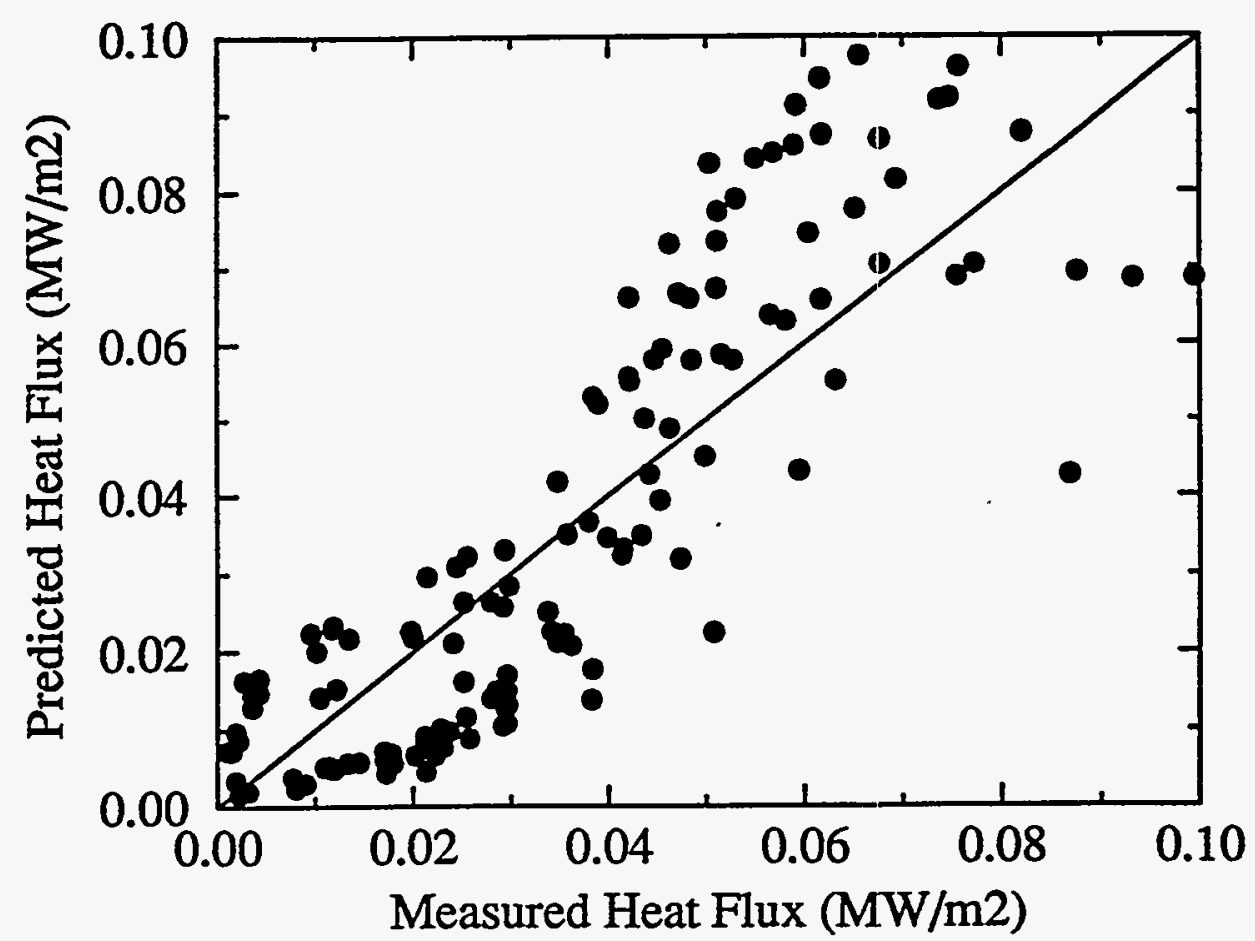

FIGURE 21. MIT measured vs. RELAP5 Default method predicted heat flux.

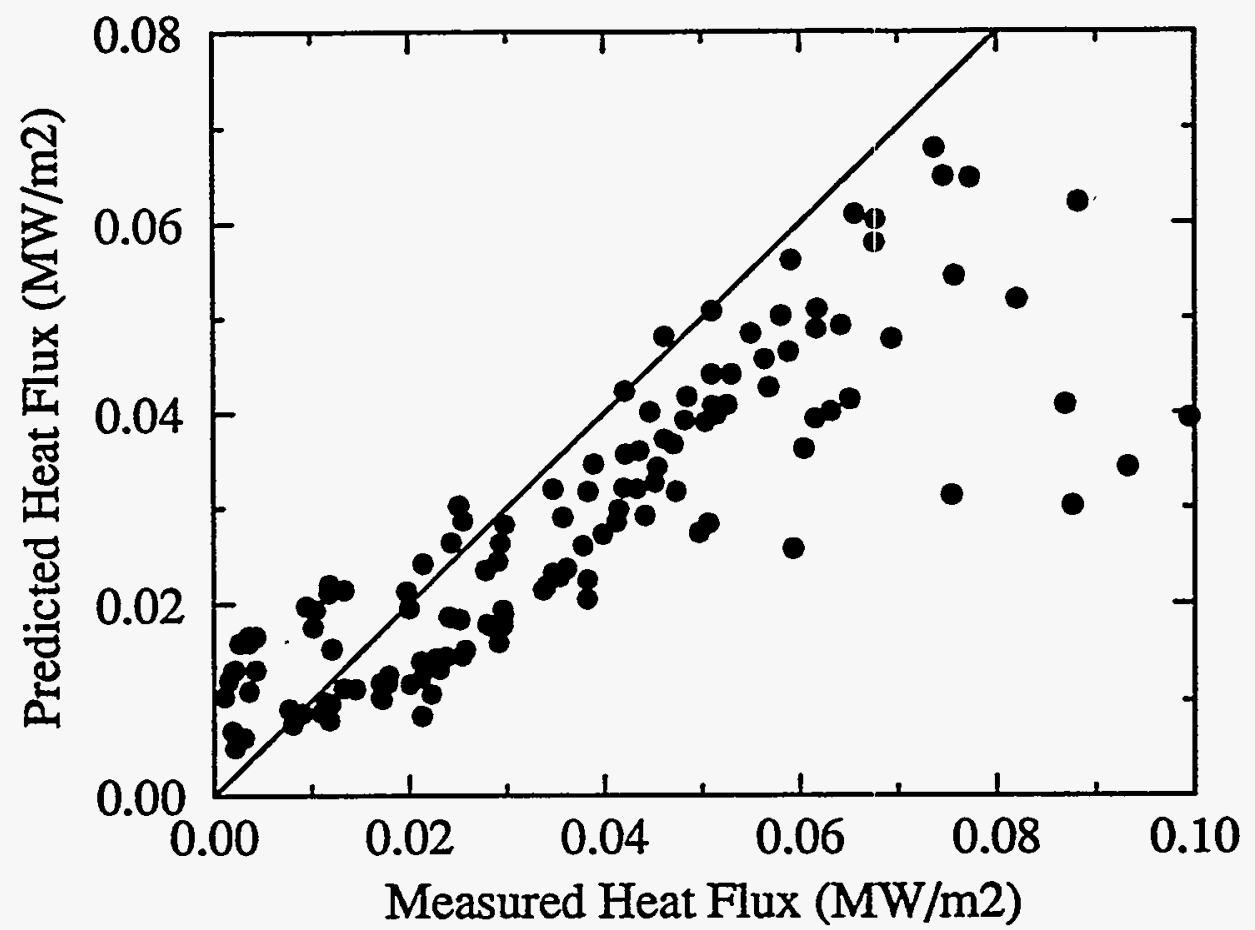

FIGURE 22. MIT measured vs. RELAP5 Diffusion method predicted heat flux. 


\subsection{Summary and Conclusions}

Two assessment efforts are described in the preceding sections: assessment of the tests and assessment of the RELAP5 code.

- Assessment of the UCB and MIT condensation tests yielded the following conclusions:

1. The test scaling and parameter ranges were adequate for characterizing the PCCS but not for the ICS. All of the tests were run at low pressure, whereas the ICS operates at high pressure.

2. A weakness of the early UCB tests and the entire MIT test series was that 'steam-only' data were not taken. Steam-only data offers a base case to quantify the effect of noncondensables on condensation heat transfer.

3. The dominant contributor to the experimental uncertainty in both tests was obtaining the condensation heat flux from the cooling water temperature axial gradient.

4. The uncertainty bands on the UCB-Kuhn heat flux were smaller than those on the MIT-Siddique data. However, the heat flux uncertainty bands appear to be underestimated since some of the UCB test repeatability experiments do not have uncertainty bars which overlap each other when plotted on the same graph.

- Assessment of RELAP5 code using UCB and MIT data resulted in the following conclusions:

1. The RELAP5 Default model prediction accuracy is poor for many of the tests.

2. Neither the Default or the Diffusion model predictions were consistently within the data uncertainty bands.

3. The Diffusion model yielded RMS errors of about $20 \%$ when compared to all the UCB-Kuhn data. Consideration should be given to make the Diffusion model the RELAP5 default model.

4. Both models gave RMS errors on the MIT tests above $35 \%$ even after the low heat flux points were removed from consideration. 


\subsection{References}

1. W. H. McAdams, Heat Transmission, McGraw-Hill Book Company, Inc., New York, New York, 3rd edition, 1954, p. 334.

2. E. F. Carpenter and A. P. Colburn, "The Effect of Vapor Velocity on Condensation Inside Tubes," Proc. of General Discussion on Hleat Transfer, Institute Mechanical Engineering/American Society of Mechanical Engineers, 1951, pp. 20-26.

3. W. H. Rohsenow, J. H. Webber, and A. T. Ling, "Affect of Vapor Velocity on Laminar and Turbulent-Film Condensation," Trans. ASME, Vol 78, 1956.

4. C. M. Kulberg, et al., "Survey of Experimental Data Base for the Simplified Boiling Water Reactor," EGG-NE-10474, May 1993.

5. M. Huggenberger, "PANDA Experimental Facility Conceptual Design," Paul Scherrer Institute, AN-42-91-09, July 18, 1991.

6. M. Huggenberger et al., "PANDA Experimental Facility For Passive Containment Cooling Decay Heat Removal and Fission Product Retention System Test," Paul Scherrer Institute, AN-42-90-11, January 22, 1991.

7. S. Botti et al., "Confirmatory Tests of Full Scale Condensers for the SBWR Isolation Condenser System and the Passive Containment Cooling System," Proc. 2nd ASME-JSME Nuclear Engineering Joint Conf. in San Francisco, CA, 21-24, Vol 1, March 1993, pp. 735-744.

8. V. M. Borishanskiy, "Effect of Uncondensable Gas Content on Heat Transfer in Steam Condensation in a Vertical Tube," Heat Transfer-Soviet Research, Vol. 9, No 2, March-April 1977, pp. 35-42.

9. C. K. Nithianandan, C. D. Morgan, N. H. Shah, F. R. Miller, "RELAP5/ MOD2 Model for Surface Condensation in the Presence of Noncondensibles Gases," Proceedings of 8th International Heat Transfer Conference, San Francisco, Ca., Aug. 17-22, 1986, Vol. 4, pp. 1627-1633.

10. K. M. Vierow, "Behavior of Steam-Air Systems Condensing in Cocurrent Vertical Downflow," MS Thesis, University of California at Berkeley, July 1990, pp 73.

11. K. M. Vierow, V. E. Schrock, "Condensation in a Natural Circulation Loop with Noncondensable Gas Present," Japan-US Seminar on Two-Phase Flow Dynamics, Berkeley, California, July 5-11, 1992.

12. W. Nusselt, "Die Oberflachenkondensation des Wasserdampfes," Z. Ver. Deutsch. Ing., Vol. 60 (1916), pp. 541, 569. 
13. D. Ogg, "Vertical Downflow Condensation Heat Transfer in Gas-Steam Mixtures," M. S. Thesis, UCB, Dec. 1991.

14. E. Vial and V. E. Schrock, "A Correlation Based on the Combined UCB and MIT Data Sets for Condensation Inside Tubes with Noncondensable Gas," UCB-NE-4193, April 1993.

15. T. Kageyama, "Application of Diffusion Layer Theory to Vertical Downflow Condensation Heat Transfer," MS Thesis, UCB, 1992.

16. S. Z. Kuhn, V. E. Schrock, and P. F. Peterson, "Final Report on U. C. Berkeley Single Tube Condensation Studies," UCB-NE-4201, Rev. 2, August 1994.

17. K. Lucas, and B. Moser, "Laminar Film Condensation of Pure Vapours in Tubes," Int J. Heat and Mass Transfer, Vol. 22, pp.431-435, 1979.

18. M. Siddique, "The Effects of Noncondensable Gases on Steam Condensation Under Forced Convection Conditions," Ph.D. Thesis for Department of Nuclear Engineering, MIT, January 1992.

19. E. Vial, and V. E. Schrock, "A Correlation Based on the Combined UCB and MIT Data Sets for Condensation Inside Tubes with Noncondensable Gas," UCB-NE-4193, April, 1993.

20. M. M. Shaw, "A General Correlation for Heat Transfer During Film Condensation Inside Pipes," Int. J. Heat Mass Transfer, Vol. 22, pp. 547-556, 1979.

21. A. P. Colburn and O. A. Hougen, "Design of Cooler Condensers for Mixtures of Vapors with Non-Condensing Gases," Ind. Engng. Chem., Vol. 26, pp. 1178-1182, 1934. 


\section{APPENDIX A}

\section{UCB Wall Condensation Heat Flux Comparisons with RELAP5/MOD3.2}




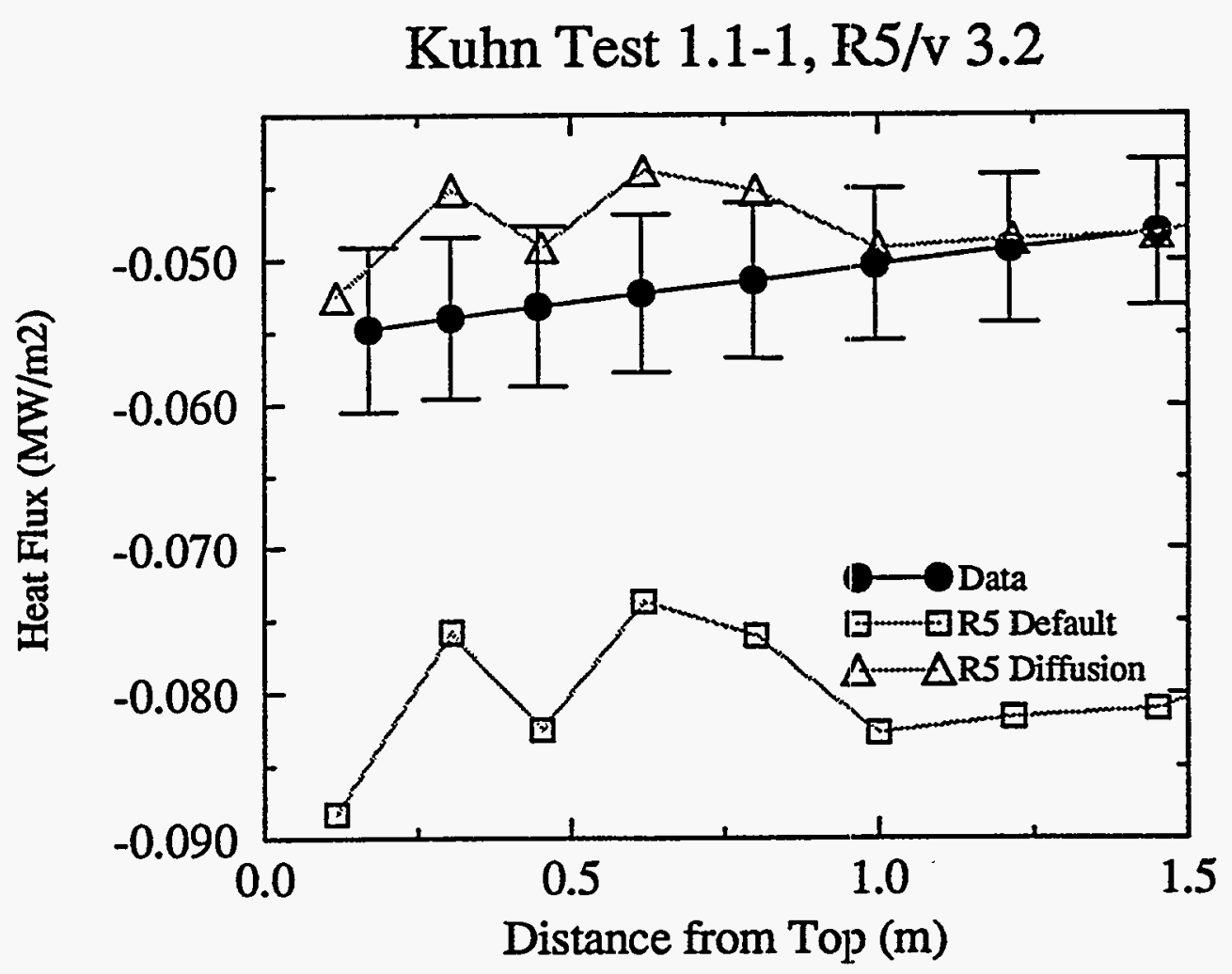

FIGURE A1. RELAP5 heat flux comparison with UCB-Kuhn Test 1.1-1

Kuhn Test 1.1-2, R5/v 3.2

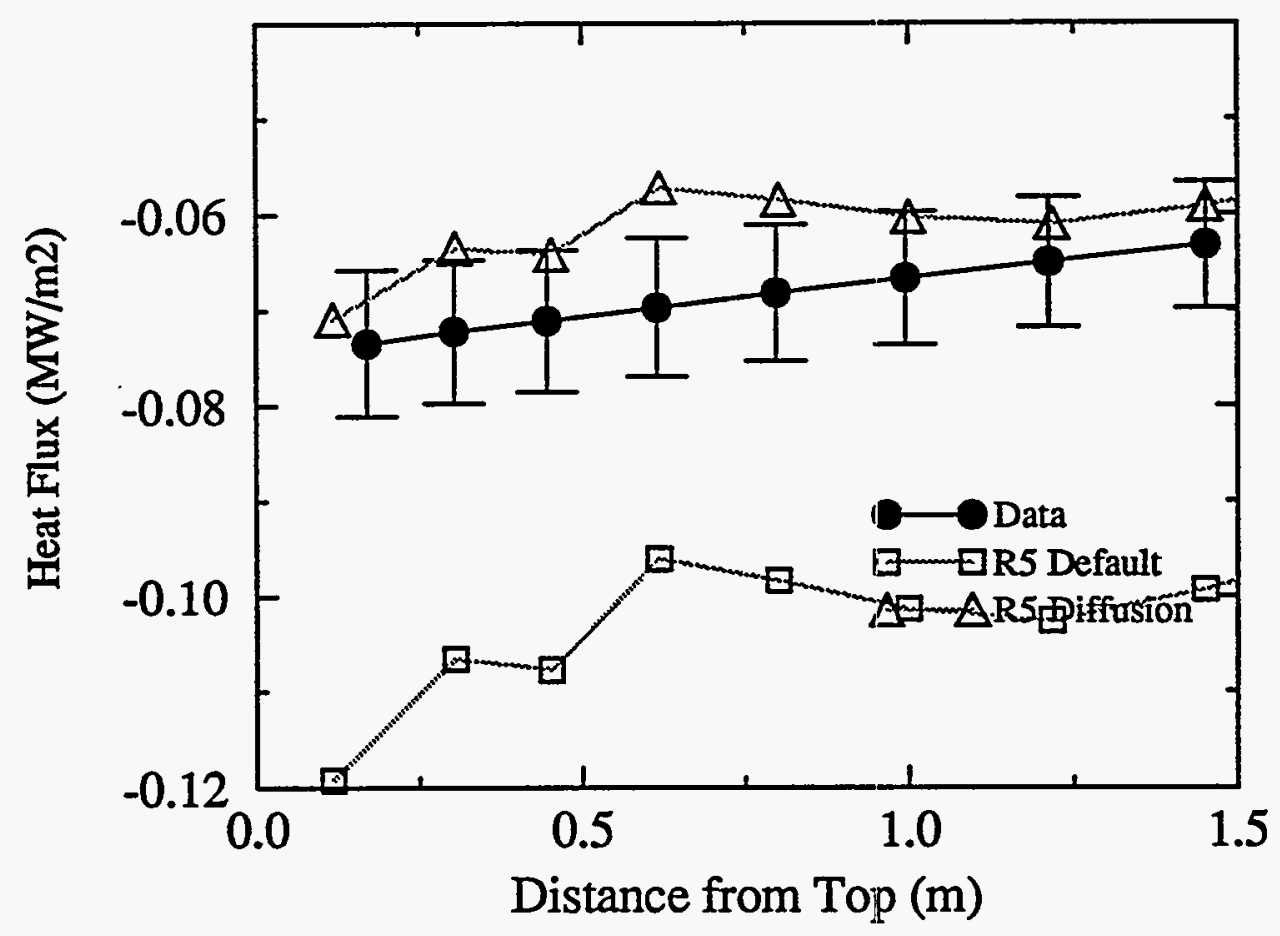

FIGURE A2. RELAP5 heat flux comparison with UCB-Kuhn Test 1.1-2 


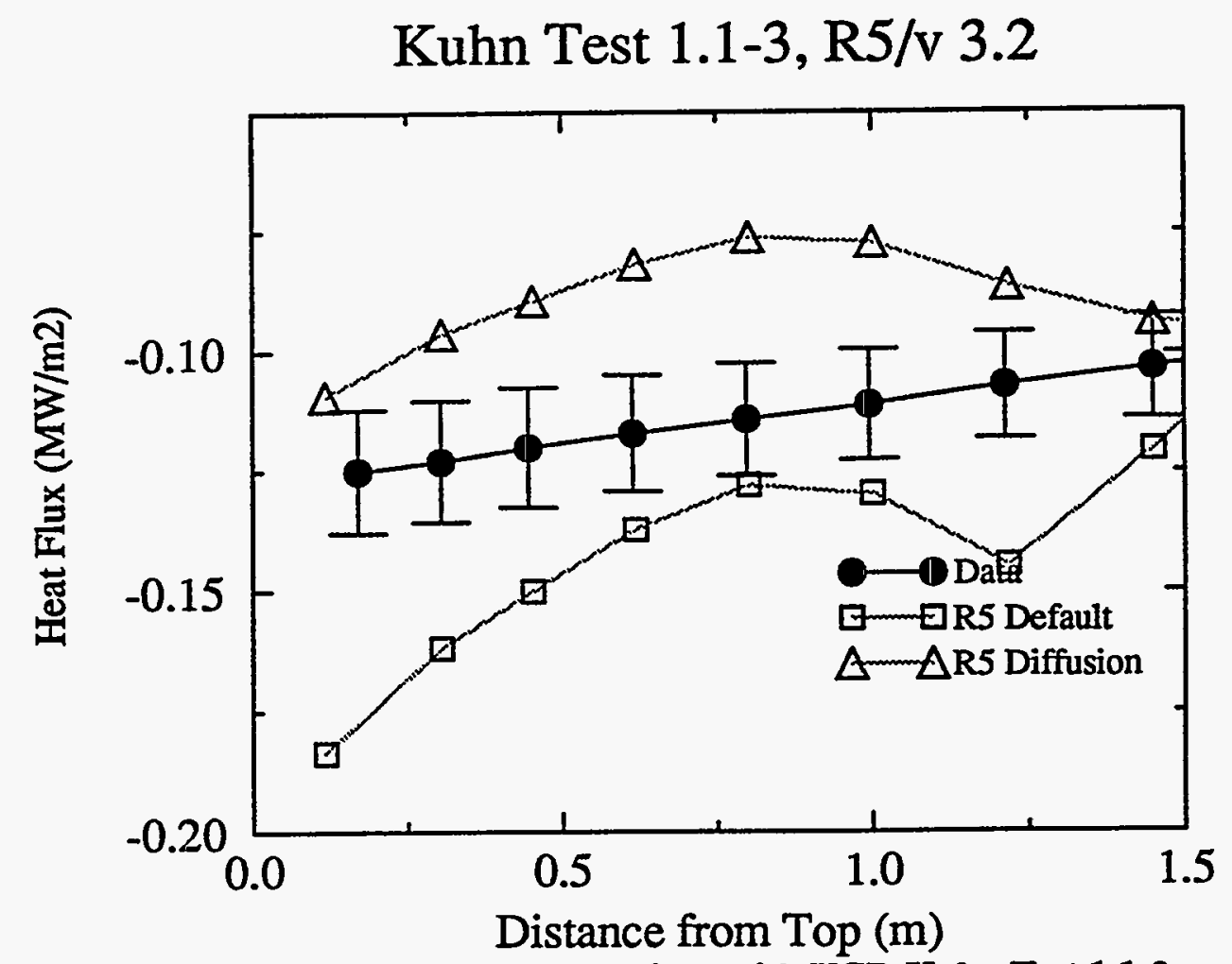

FIGURE A3. RELAP5 heat flux comparison with UCB-Kuhn Test 1.1-3

Kuhn Test 1.1-4, R5/v 3.2

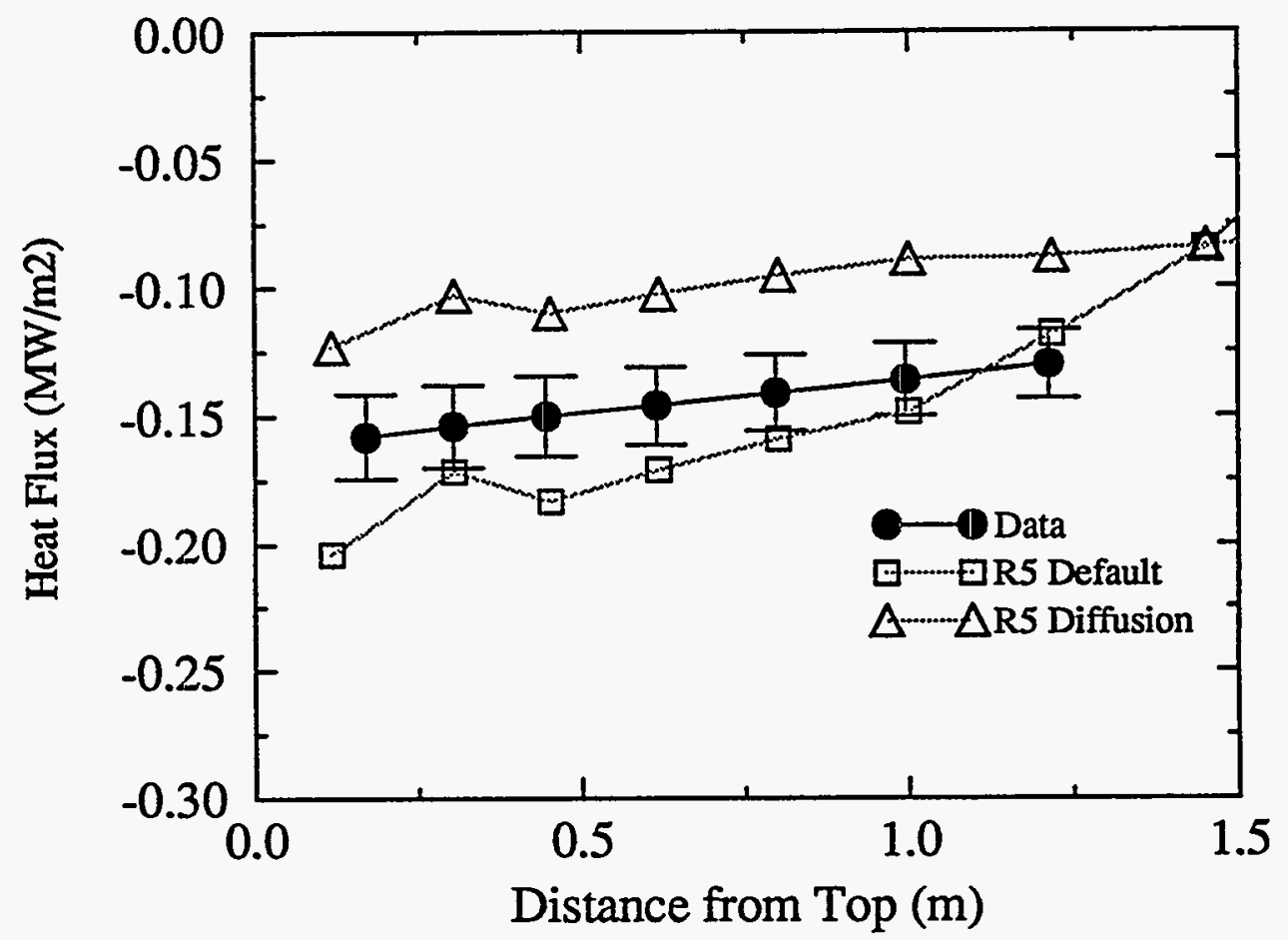

FIGURE A4. RELAP5 heat flux comparison with UCB-Kuhn Test 1.1-4 


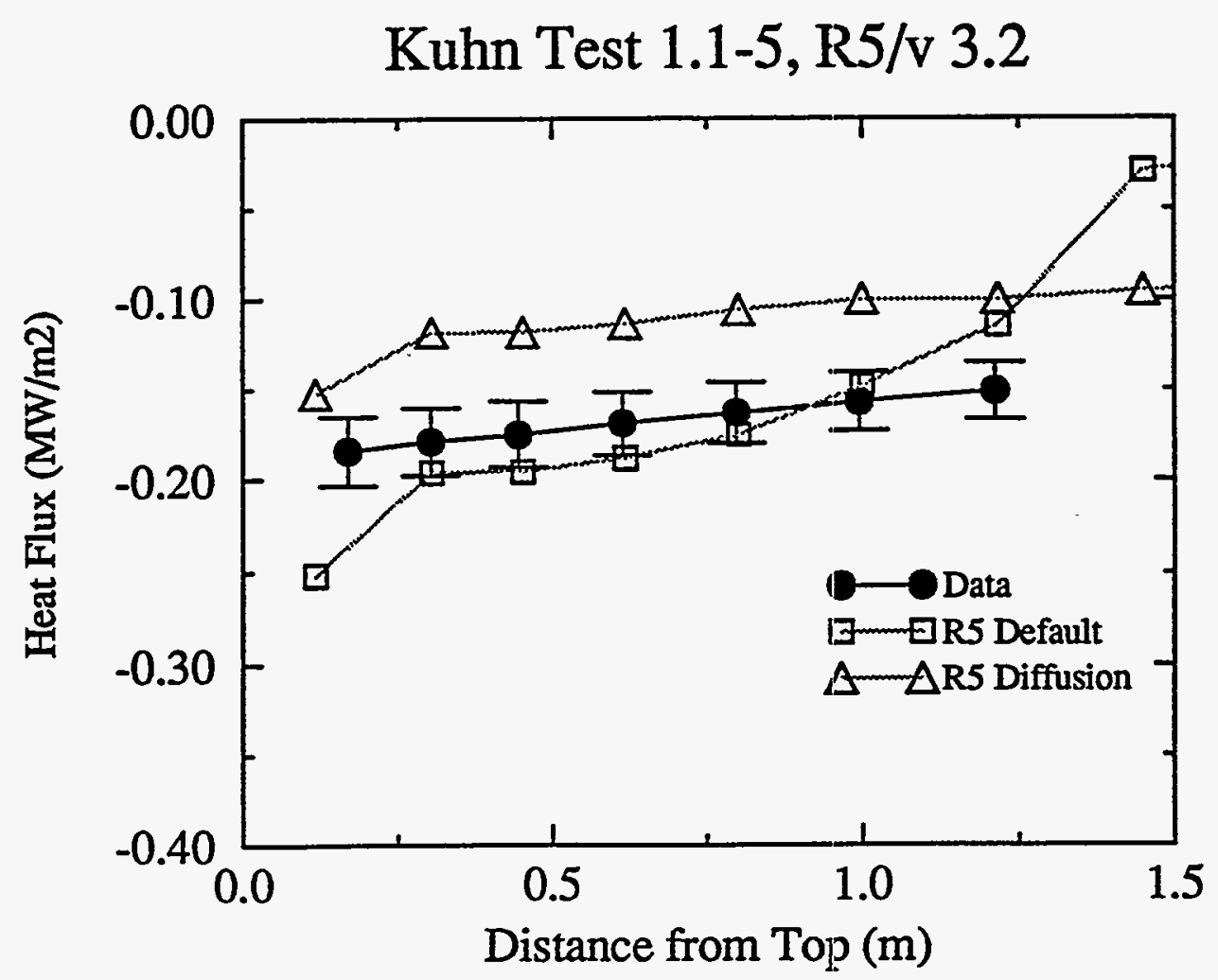

FIGURE A5. RELAP5 heat flux comparison with UCB-Kuhn Test 1.1-5

Kuhn Test $1.4-1, \mathbb{R} 5 / \mathrm{v} 3.2$

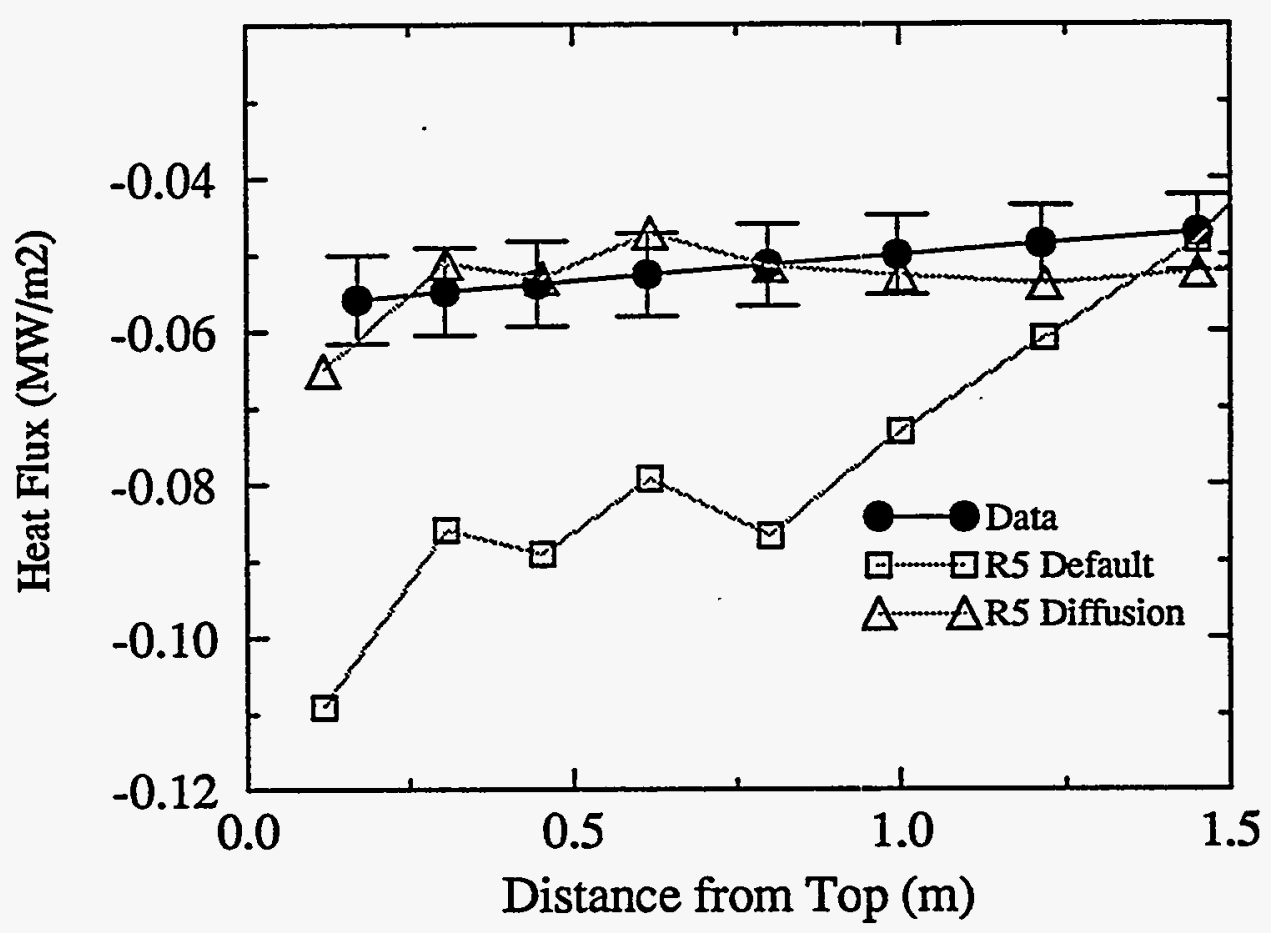

FIGURE A6. RELAP5 heat flux comparison with UCB-Kuhn Test 1.4-1 


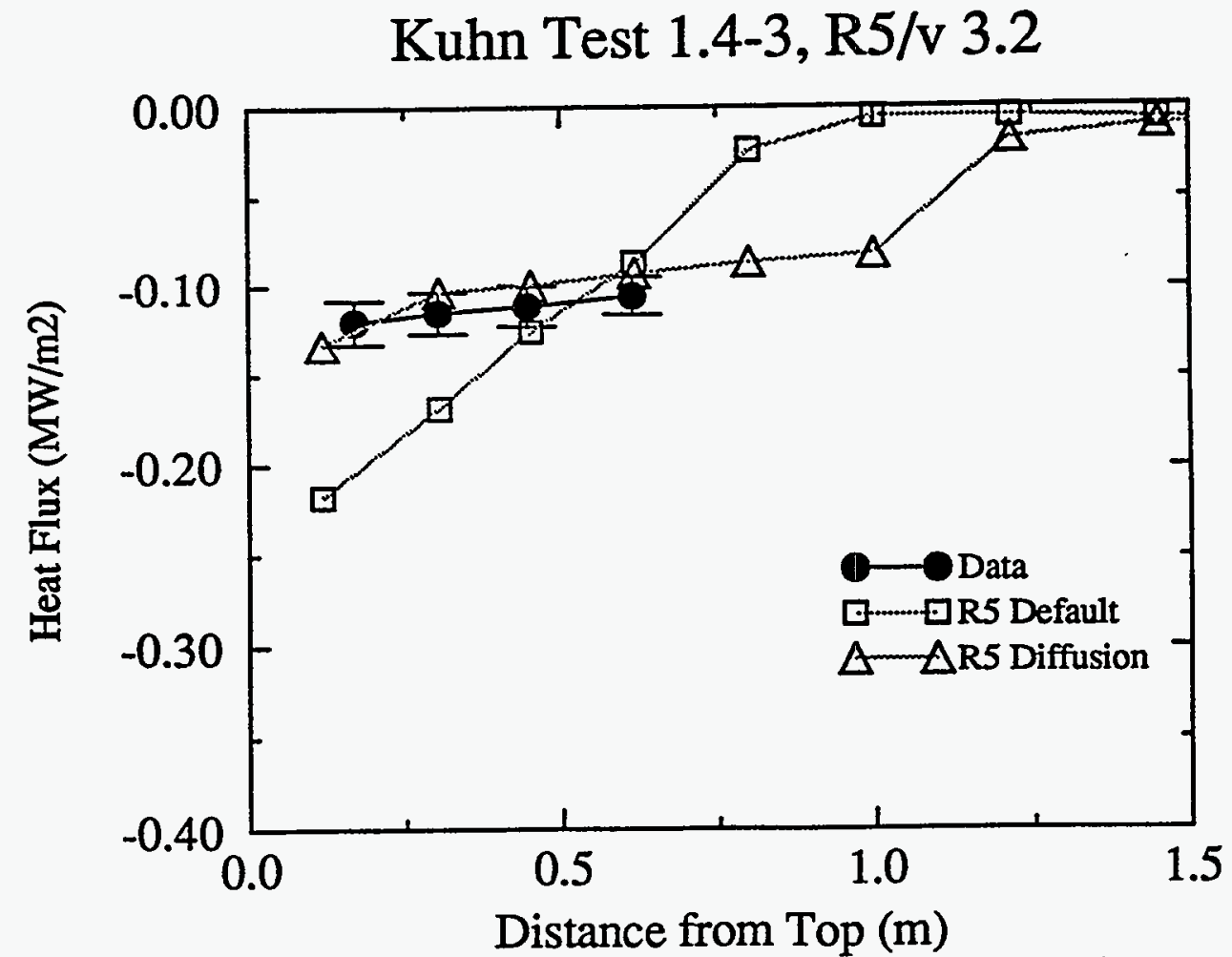

FIGURE A7. RELAP5 heat flux comparison with UCB-Kuhn Test 1.4-3

Kuhn Test 1.4-5, R5/v 3.2

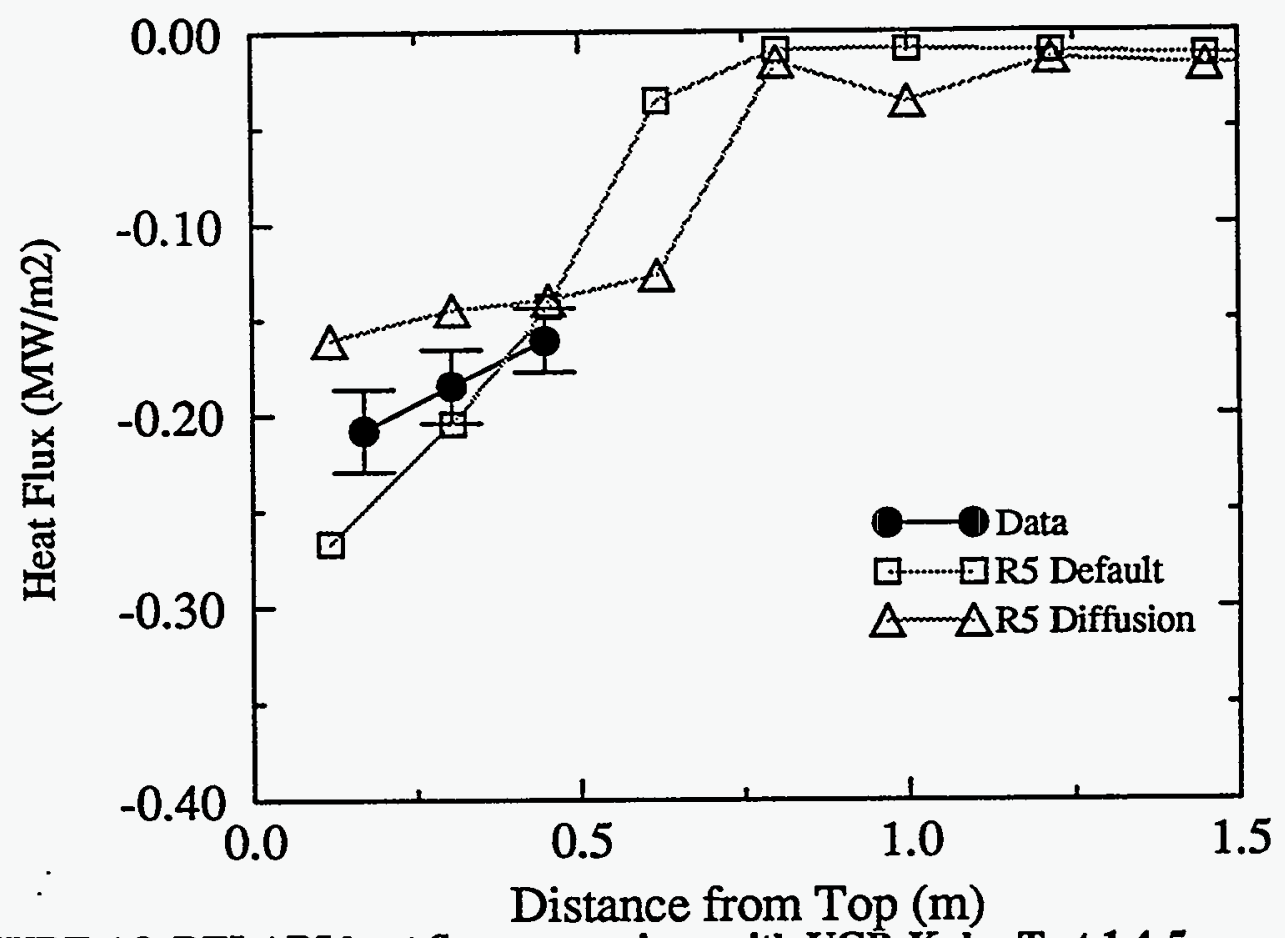

FIGURE A8. RELAP5 heat flux comparison with UCB-Kuhn Test 1.4-5 


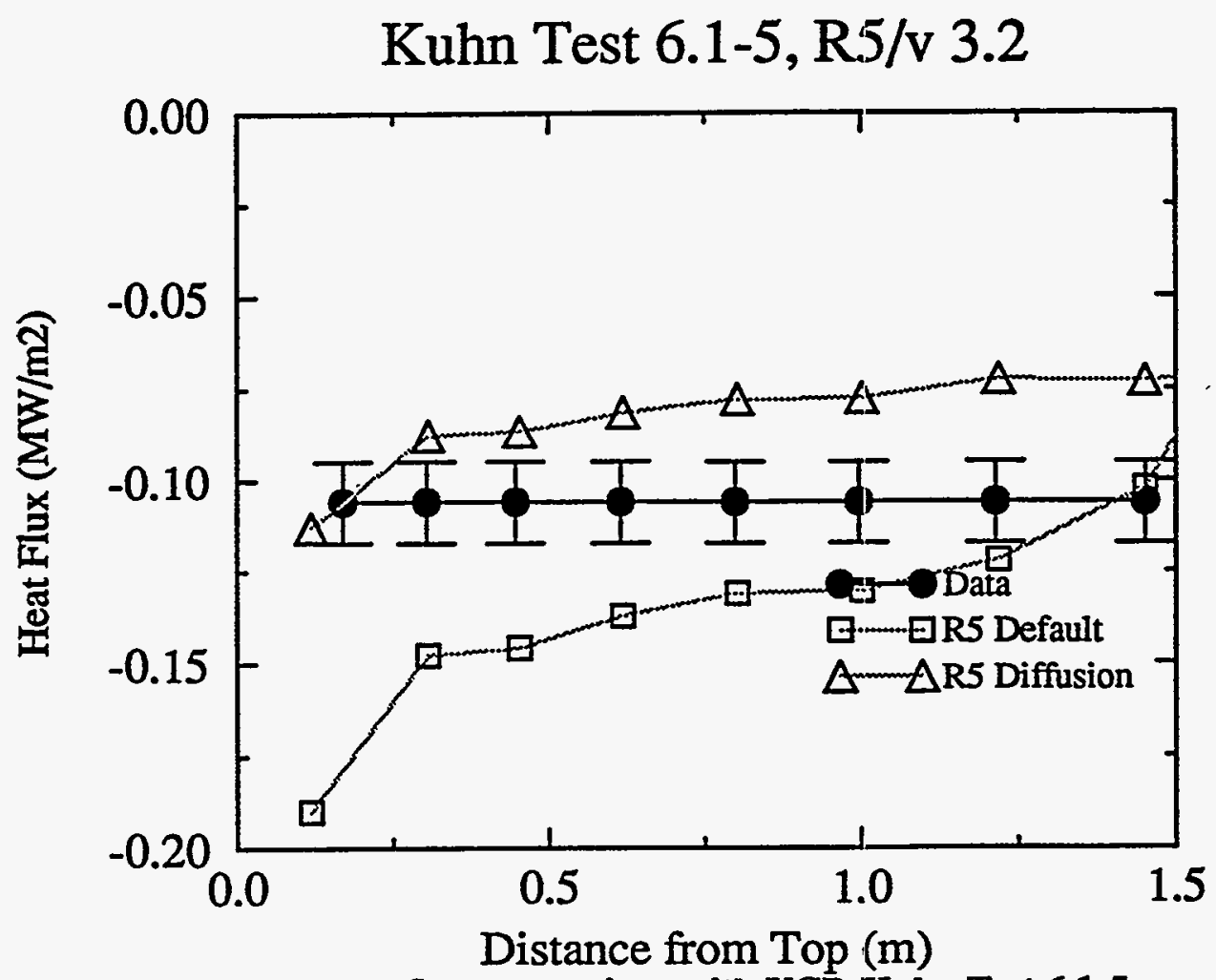

FIGURE A9. RELAP5 heat flux comparison with UCB-Kuhn Test 6.1-5

Kuhn Test 2.1-1, R5/v 3.2

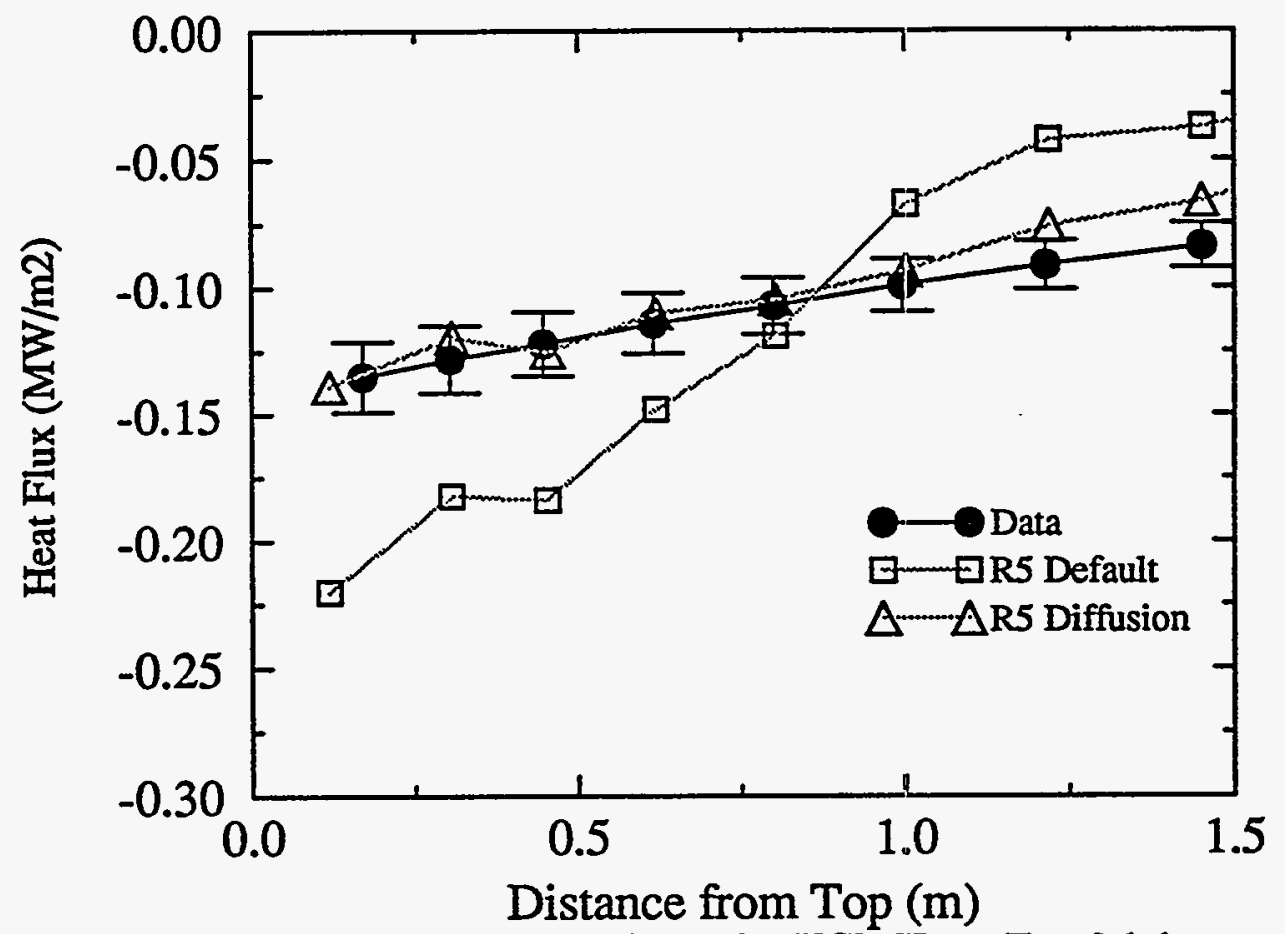

FIGURE A10. RELAP5 heat flux comparison with UCB-IKuhn Test 2.1-1 


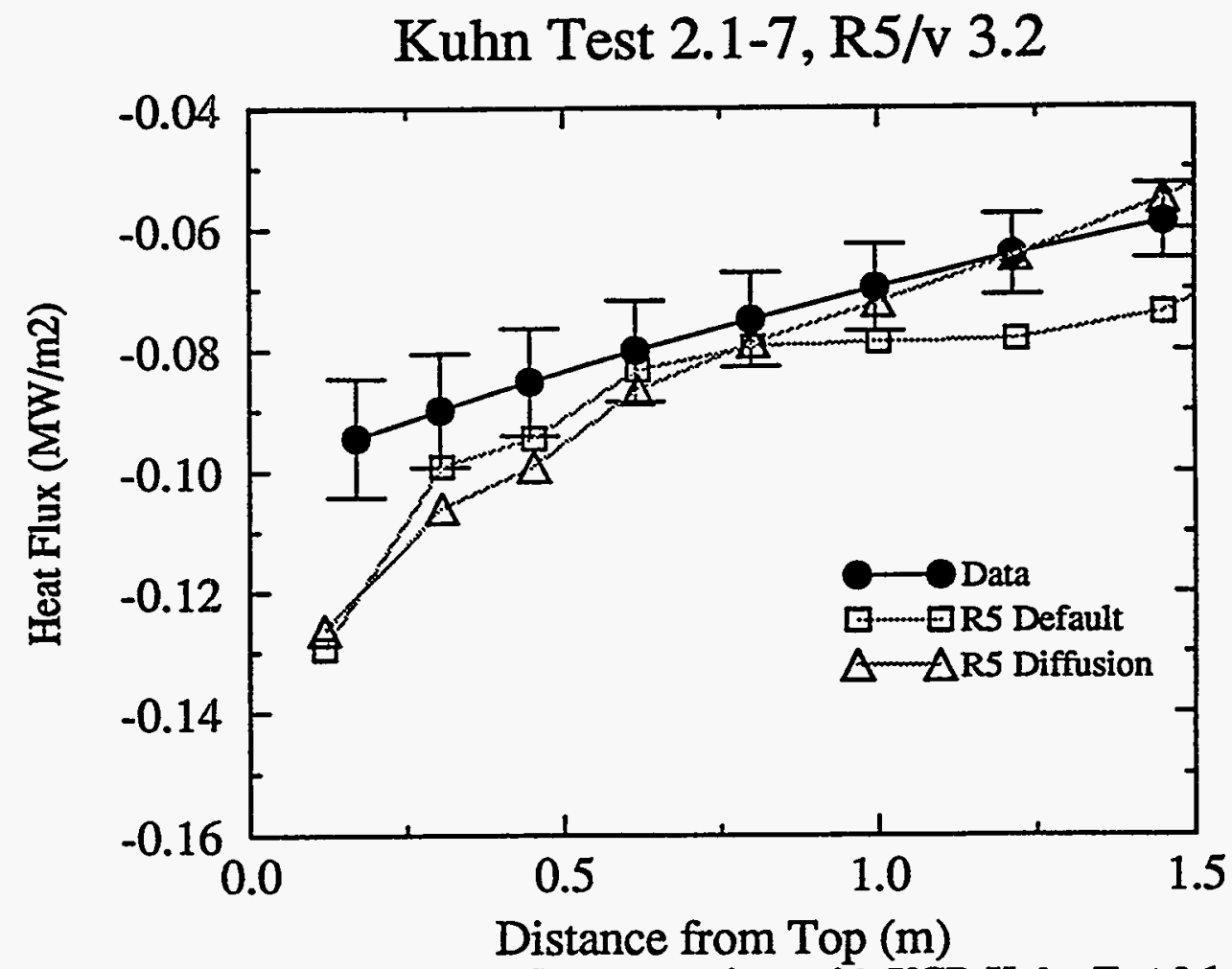

FIGURE A11. RELAP5 heat flux comparison with UCB-Kuhn Test 2.1-7

Kuhn Test 3.1-2, R5/v 3.2

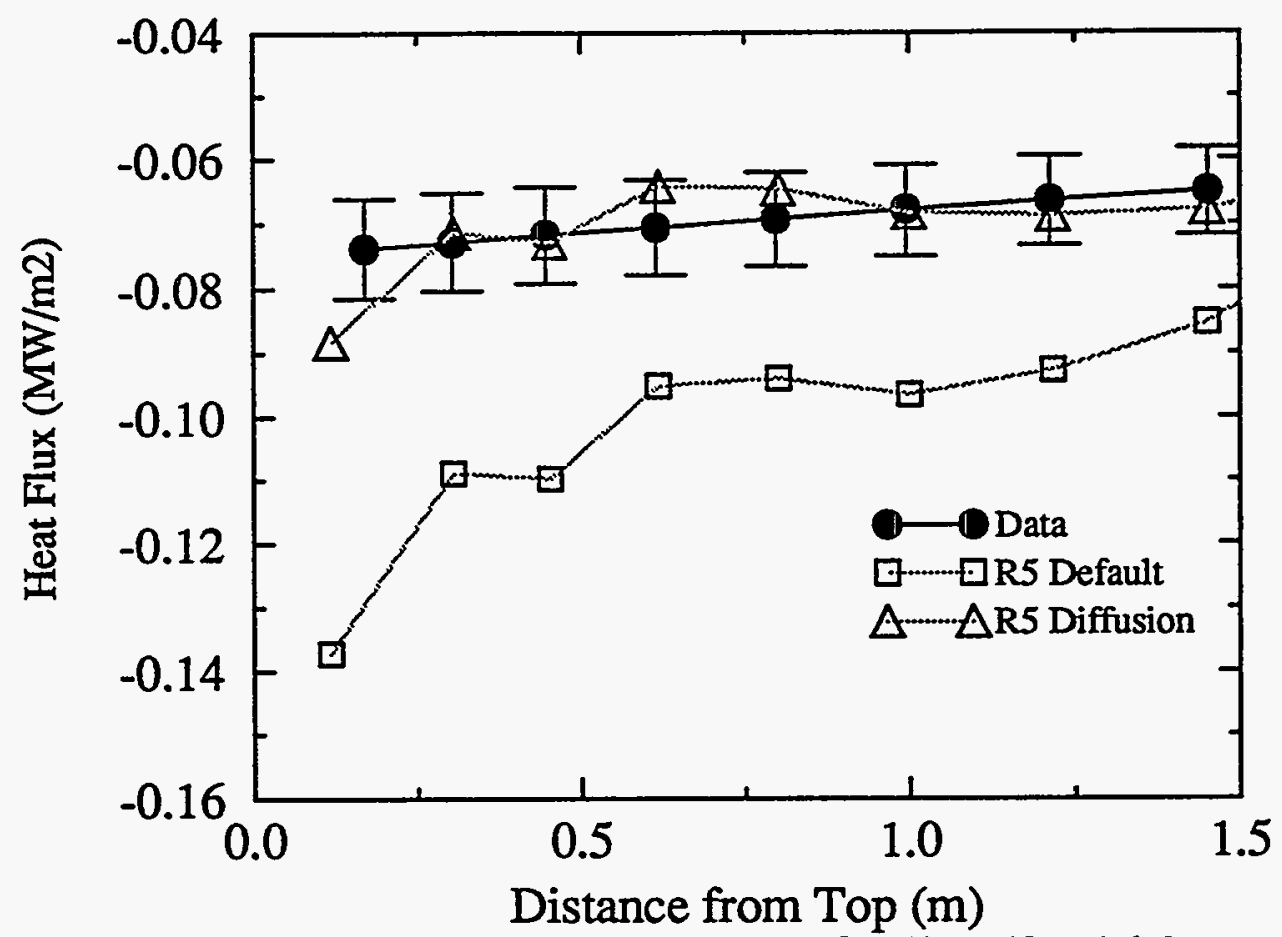

FIGURE A12. RELAP5 heat flux comparison with UCB-Kuhn Test 3.1-2 


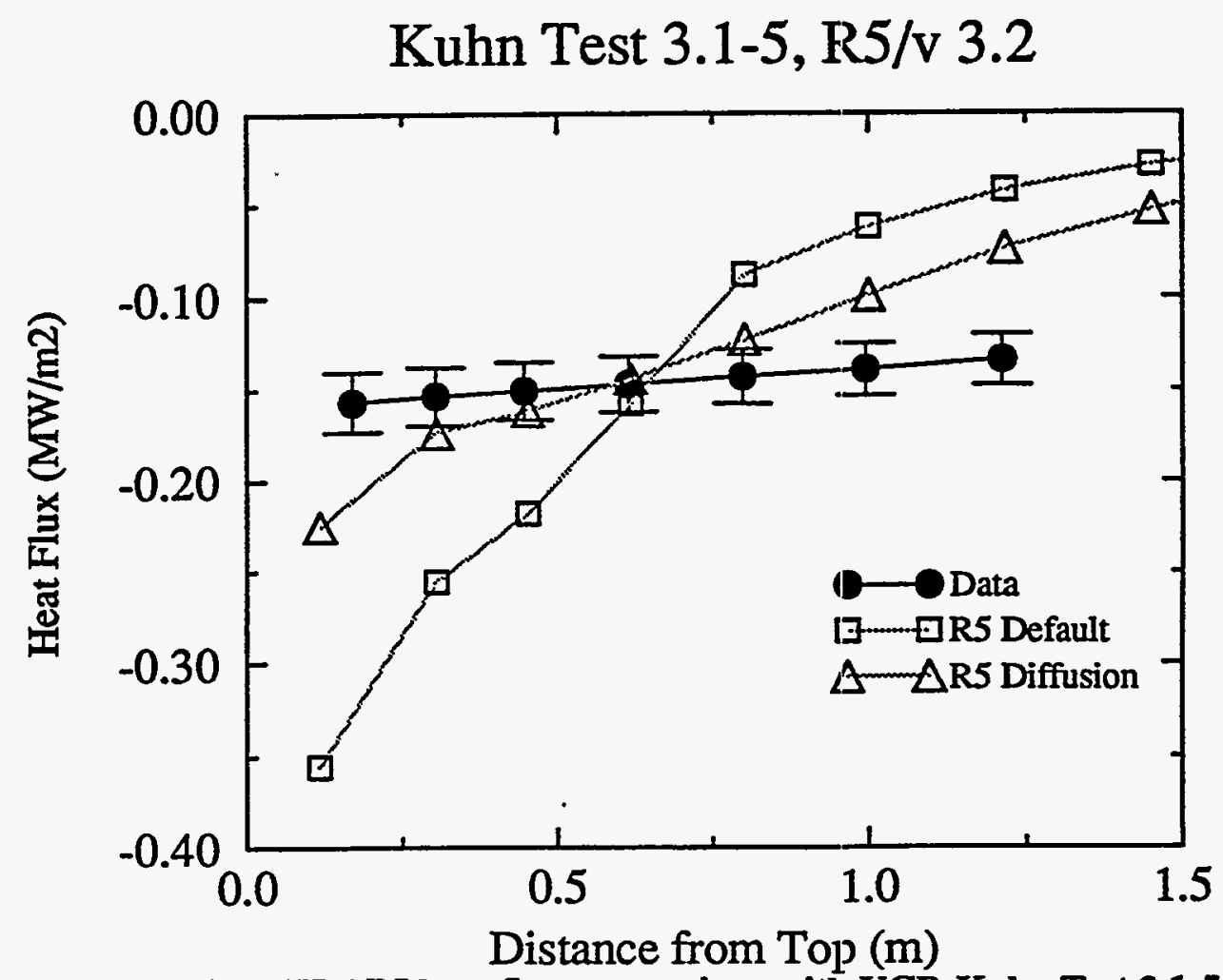

FIGURE A13. RELAP5 heat flux comparison with UCB-Kuhn Test 3.1-5

Kuhn Test 3.2-2, R5/v 3.2

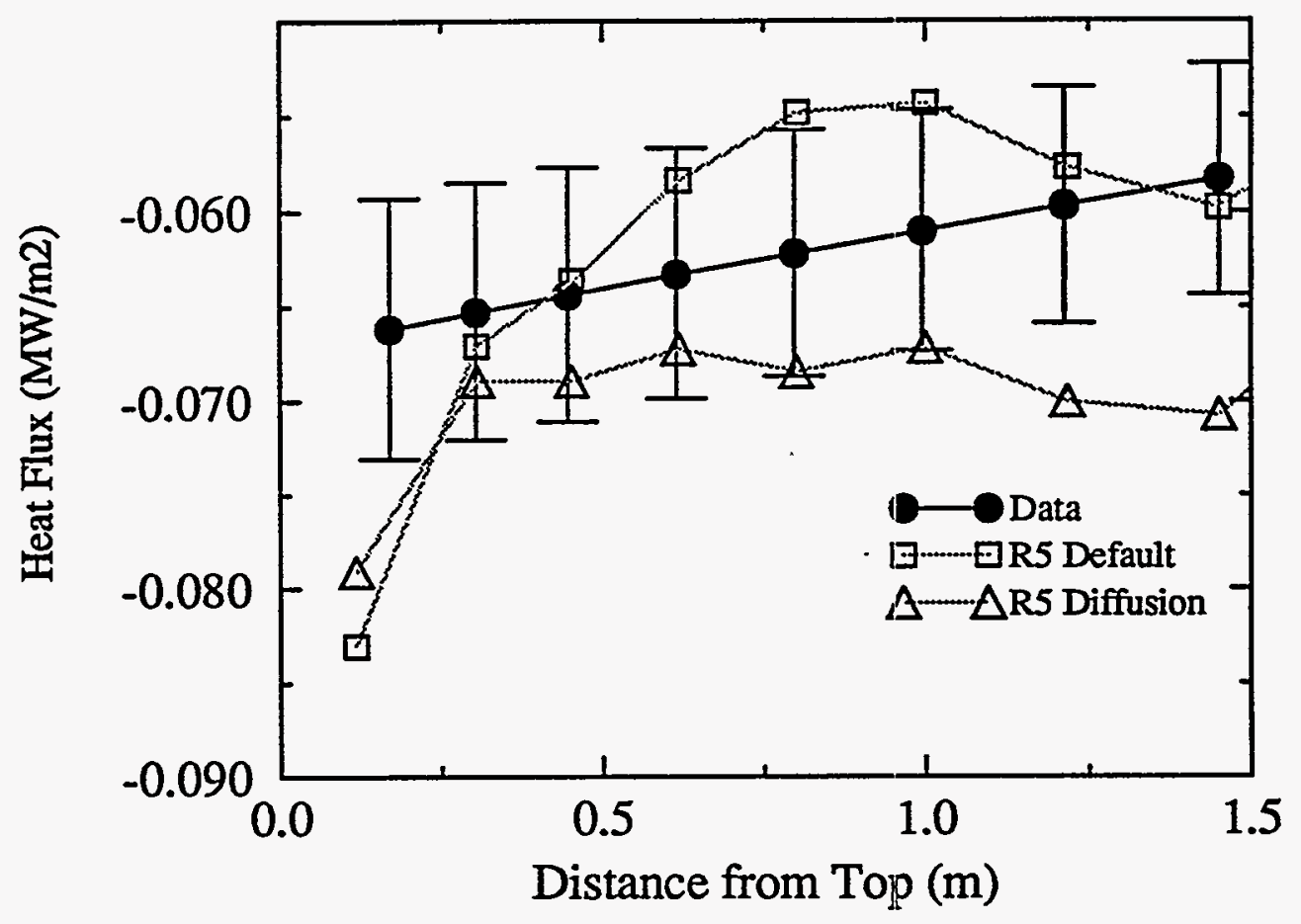

FIGURE A14. RELAP5 heat flux comparison with UCB-Kuhn Test 3.2-2 


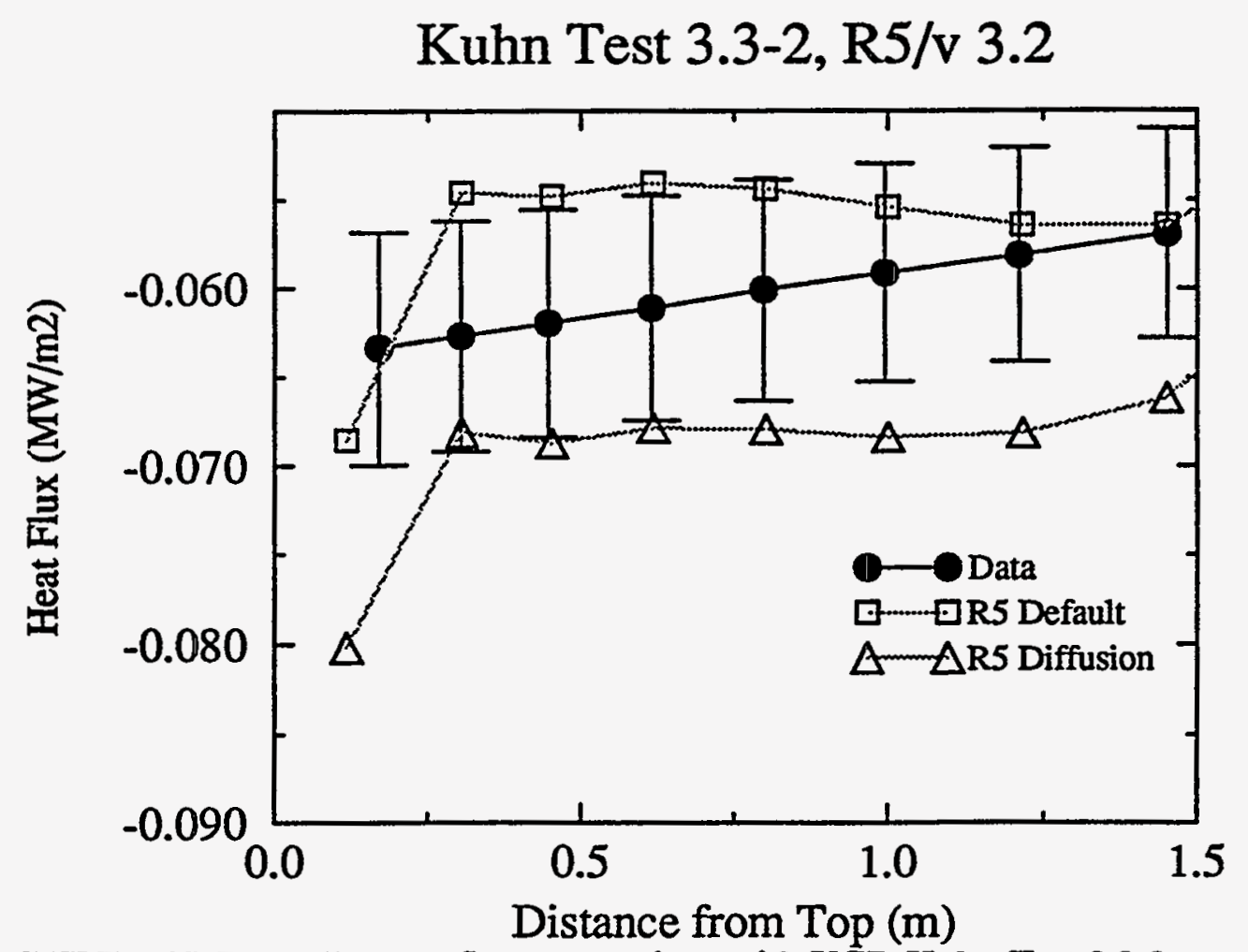

FIGURE A15. RELAP5 heat flux comparison with UCB-Kuhn Test 3.3-2

Kuhn Test 3.3-5, R5/v 3.2

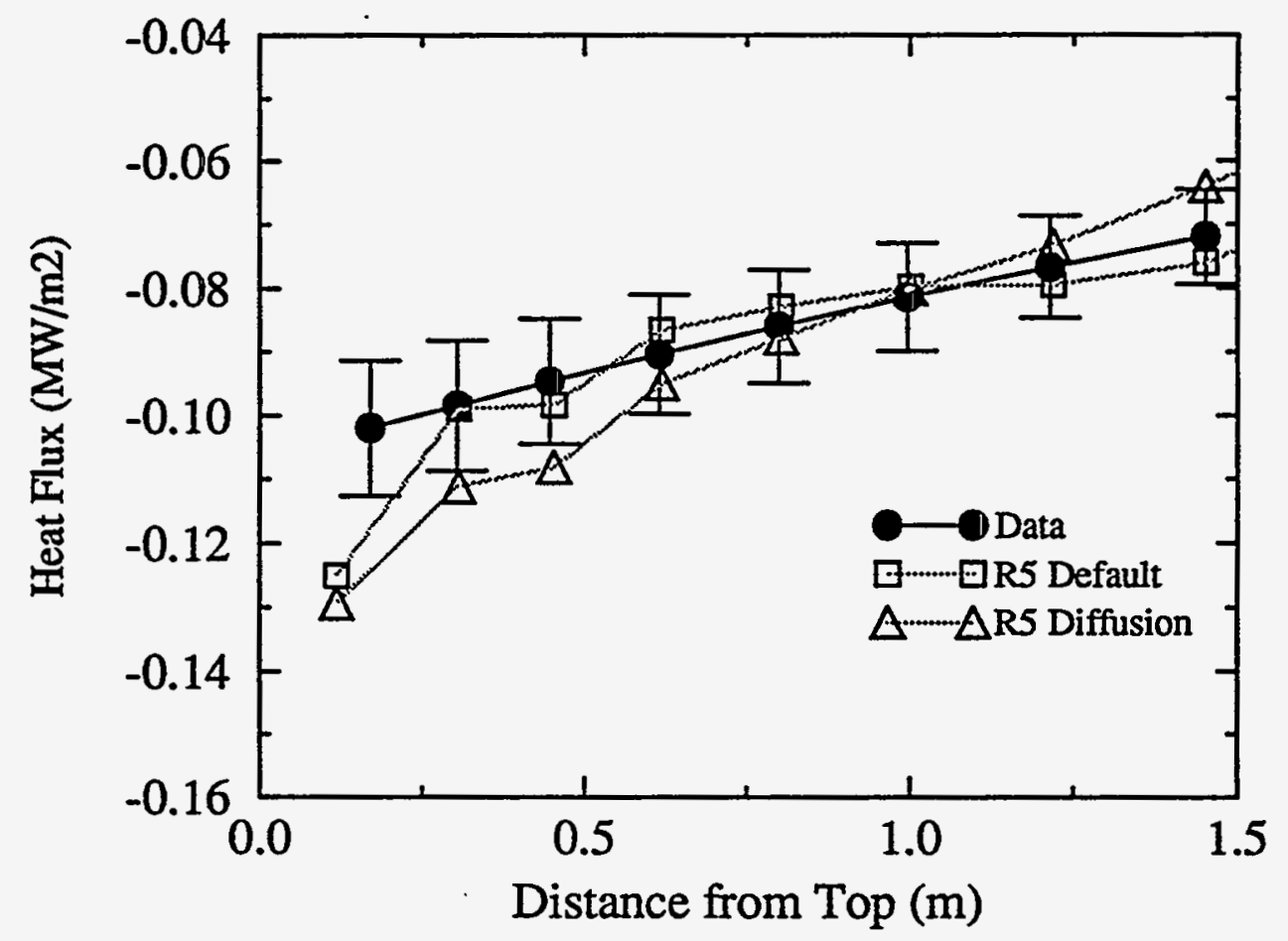

FIGURE A16. RELAP5 heat flux comparison with UCB-Kuhn Test 3.3-5 


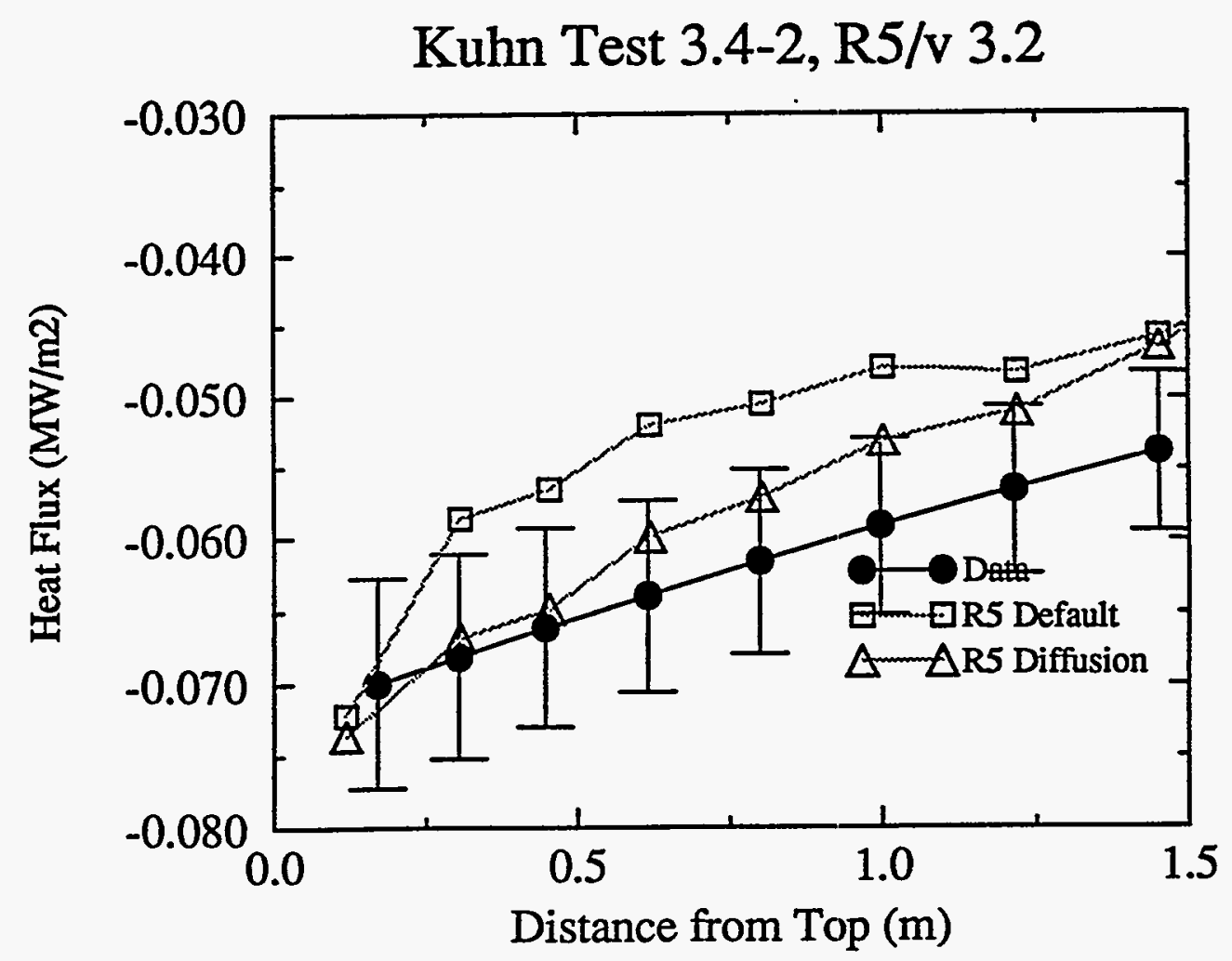

FIGURE A17. RELAP5 heat flux comparison with UCB-Kuhn Test 3.4-2

Kuhn Test 3.5-2, R5/v 3.2

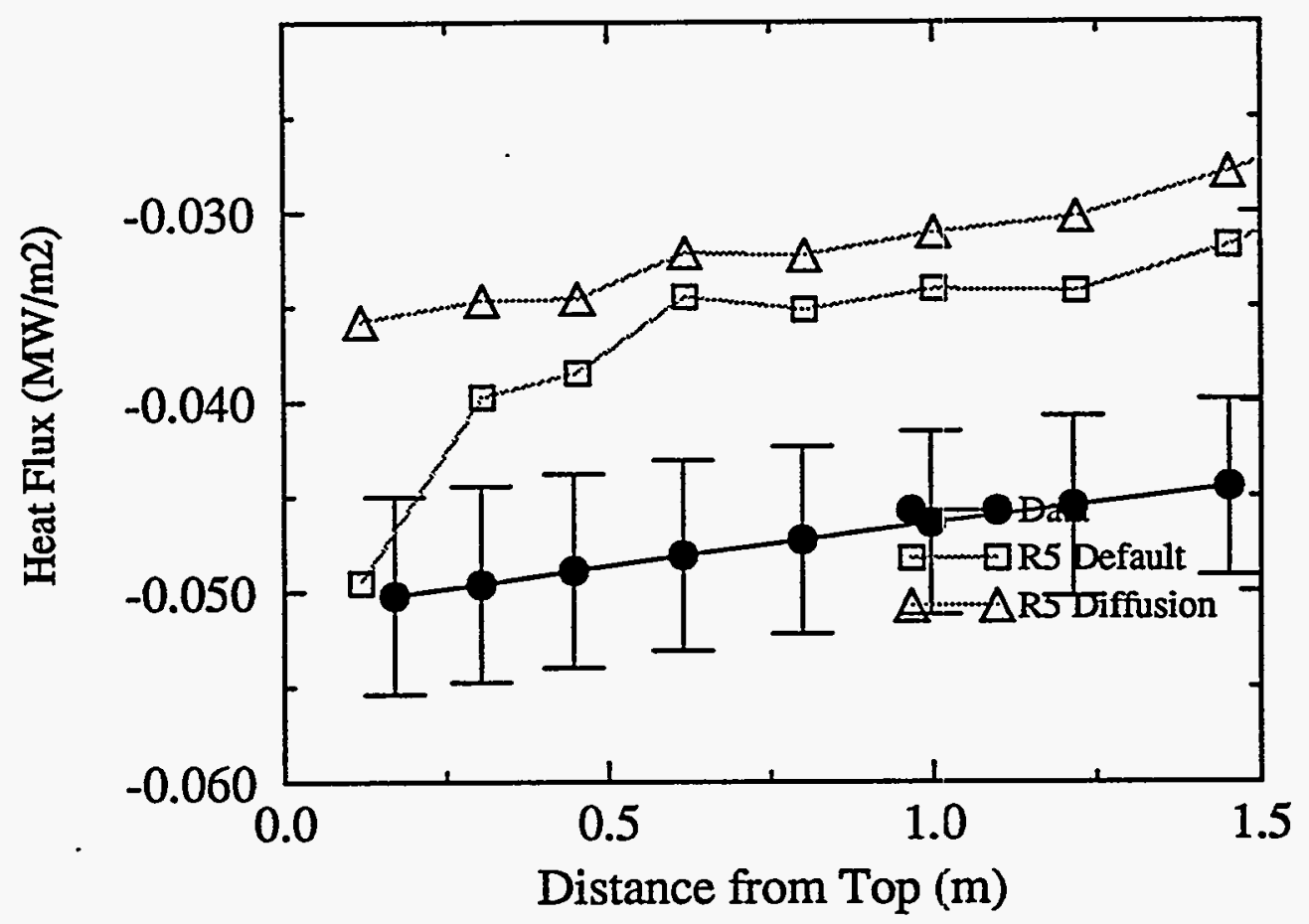

FIGURE A18. RELAP5 heat flux comparison with UCB-Kuhn Test 3.5-2 


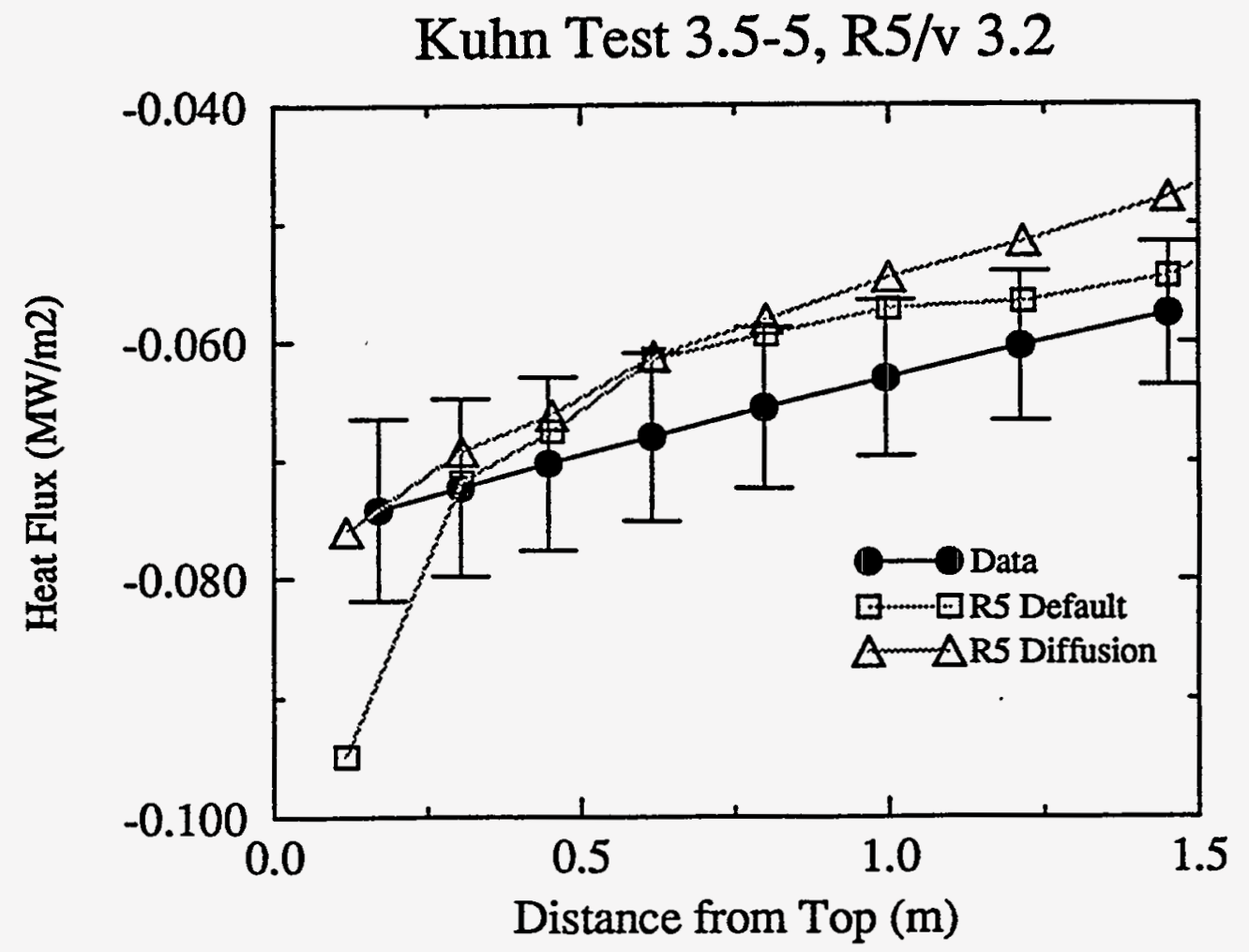

FIGURE A19. RELAP5 heat flux comparison with UCB-Kuhn Test 3.5-5

Kuhn Test 4.1-2, R5/v 3.2

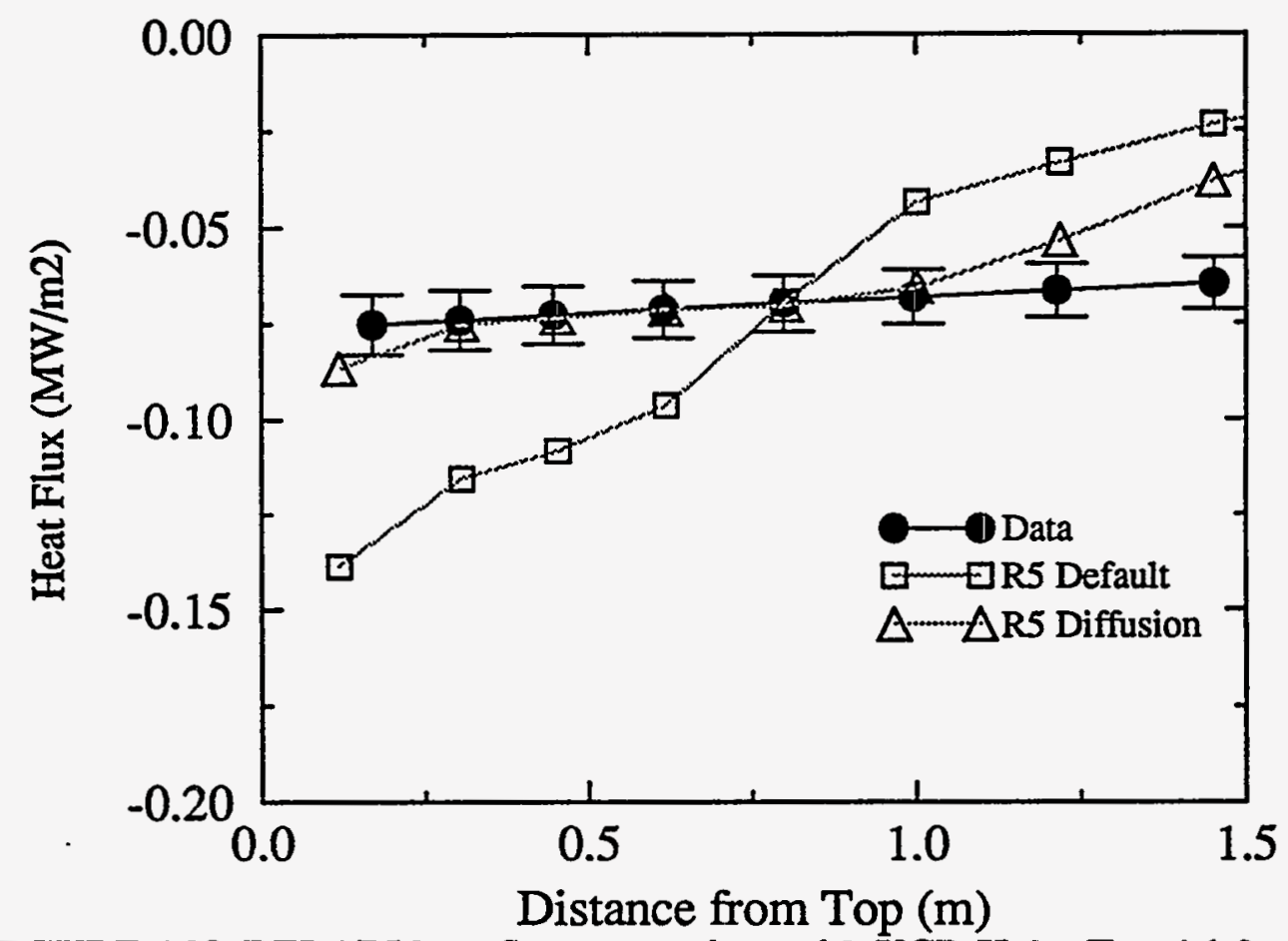

FIGURE A20. RELAP5 heat flux comparison with UCB-Kuhn Test 4.1-2 


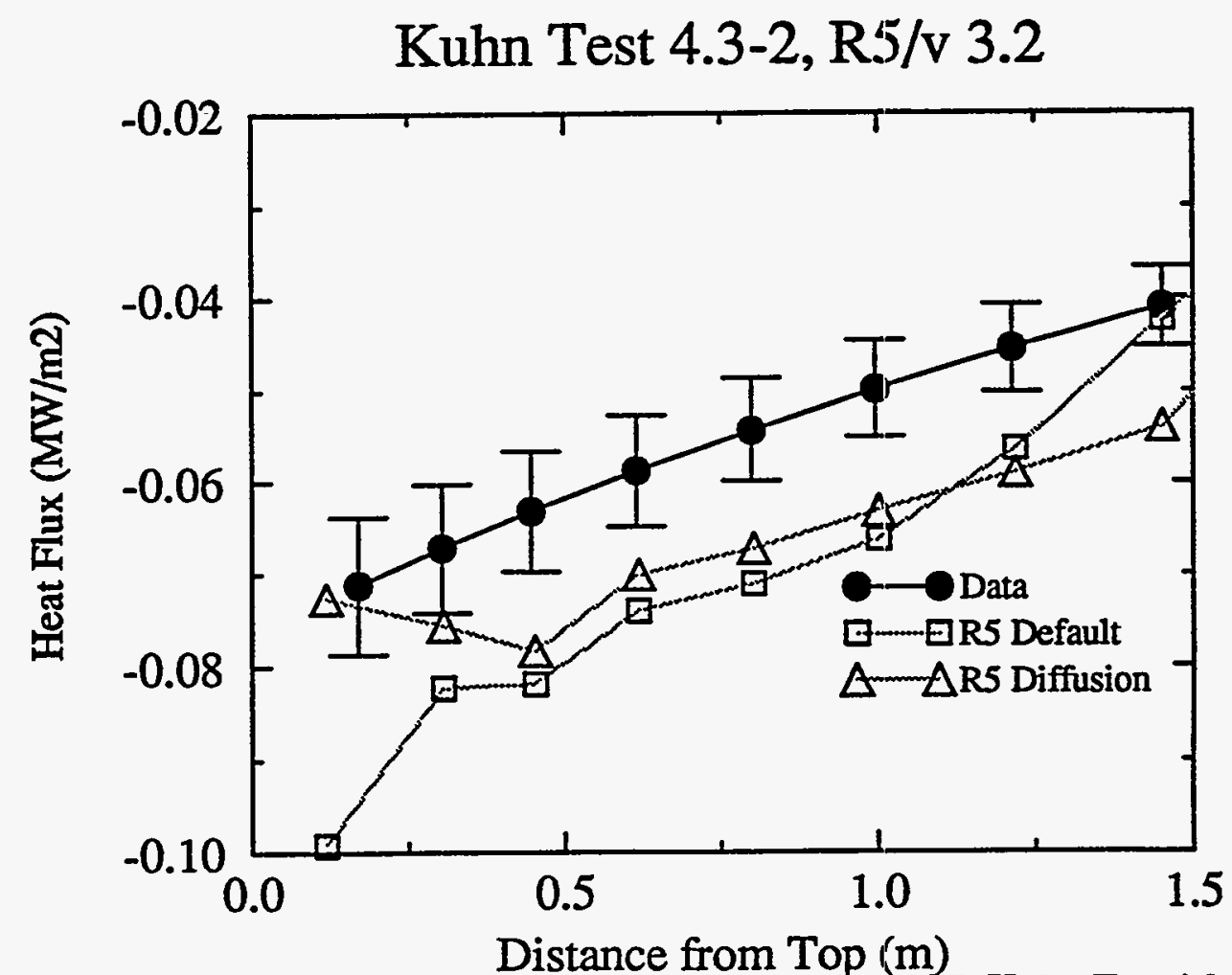

FIGURE A21. RELAP5 heat flux comparison with UCB-Kuhn Test 4.3-2 Kuhn Test 4.3-5, R5/v 3.2 .

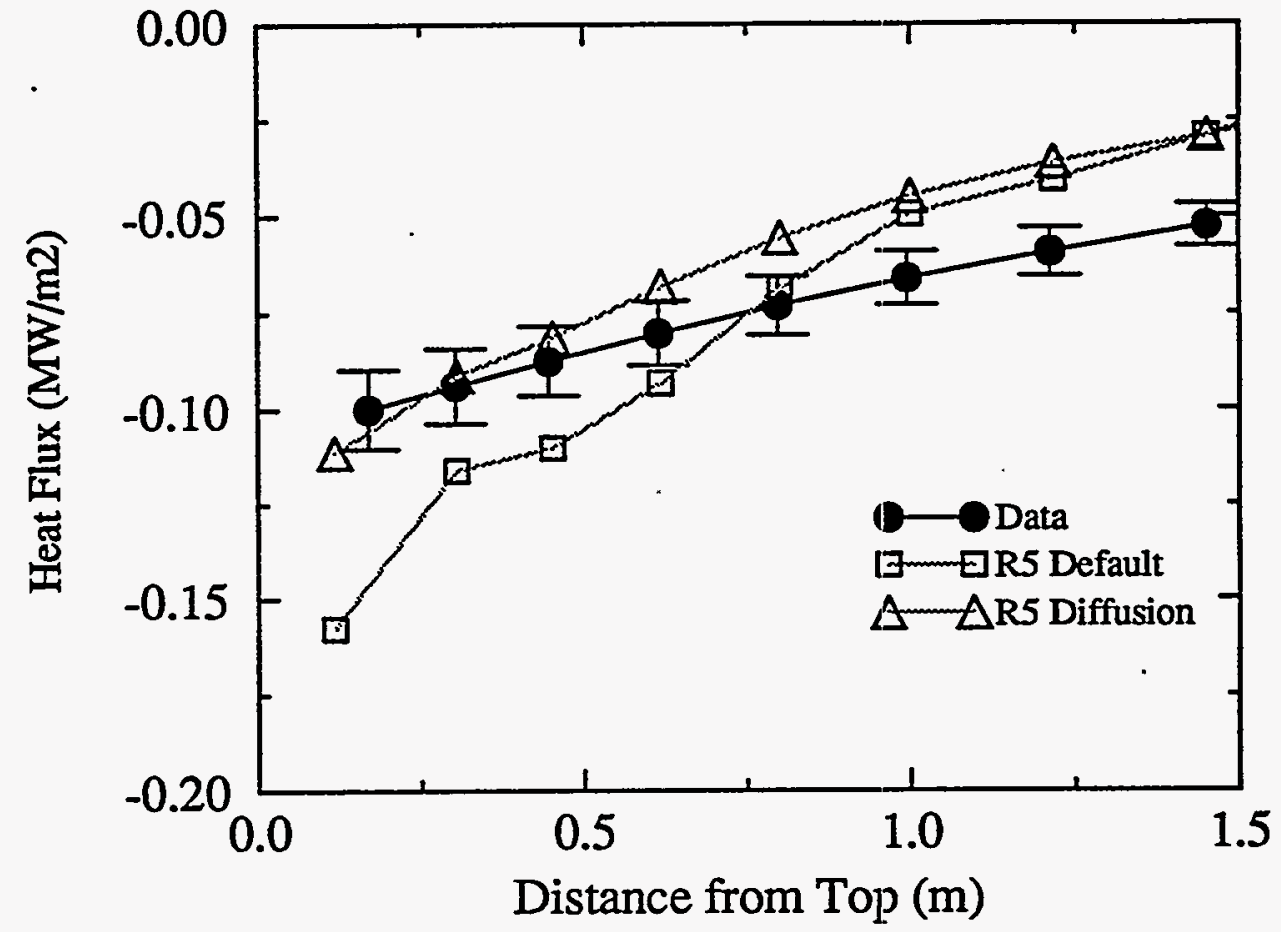

FIGURE A22. RELAP5 heat flux comparison with UCB-Kuhn Test 4.3-5 


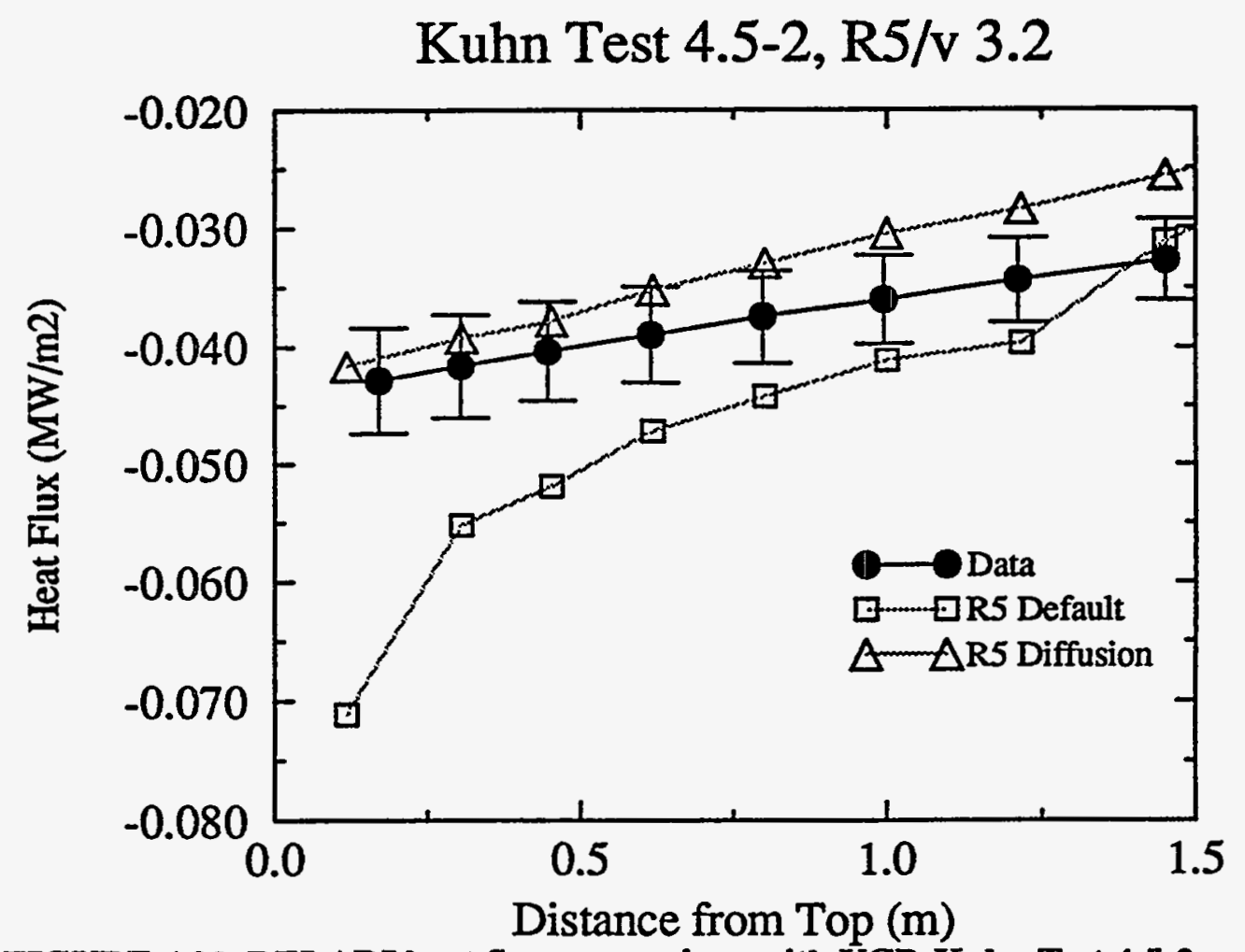

FIGURE A23. RELAP5 heat flux comparison with UCB-Kuhn Test 4.5-2

Kuhn Test 4.5-5, R5/v 3.2

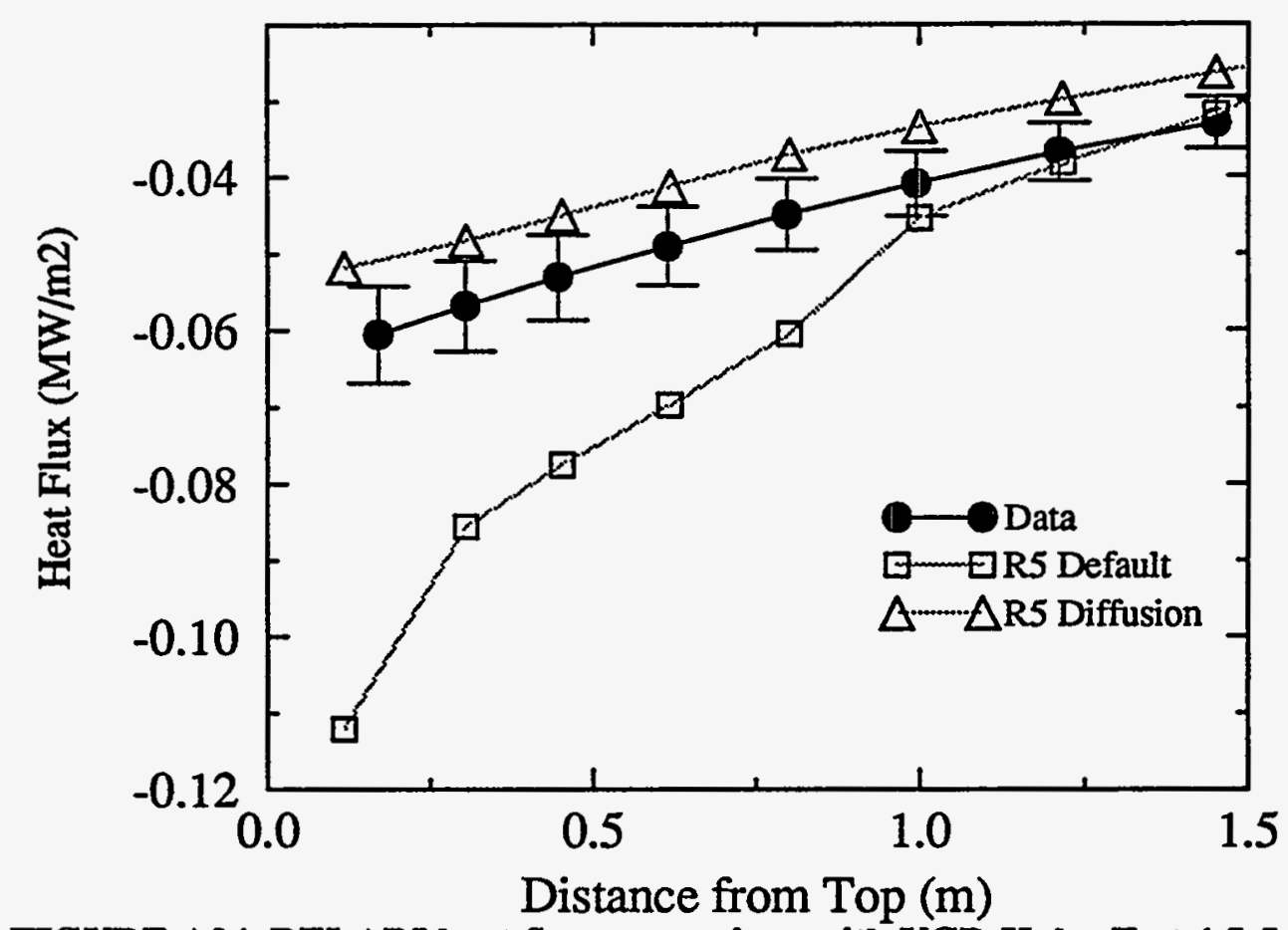

FIGURE A24. RELAP5 heat flux comparison with UCB-Kuhn Test 4.5-5 


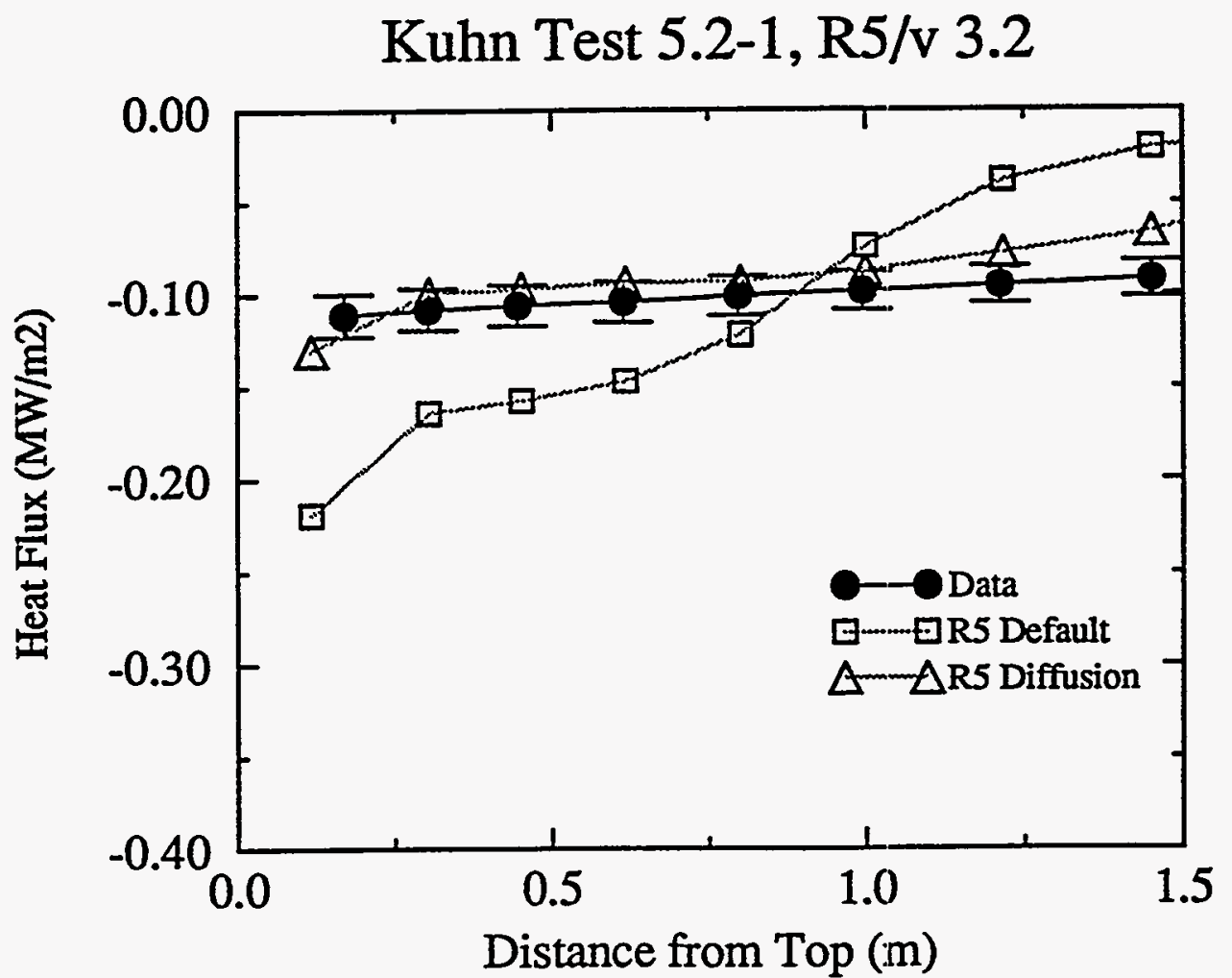

FIGURE A25. RELAP5 heat flux comparison with IJCB-Kuhn Test 5.2-1

Kuhn Test 5.2-3, R.5/v 3.2

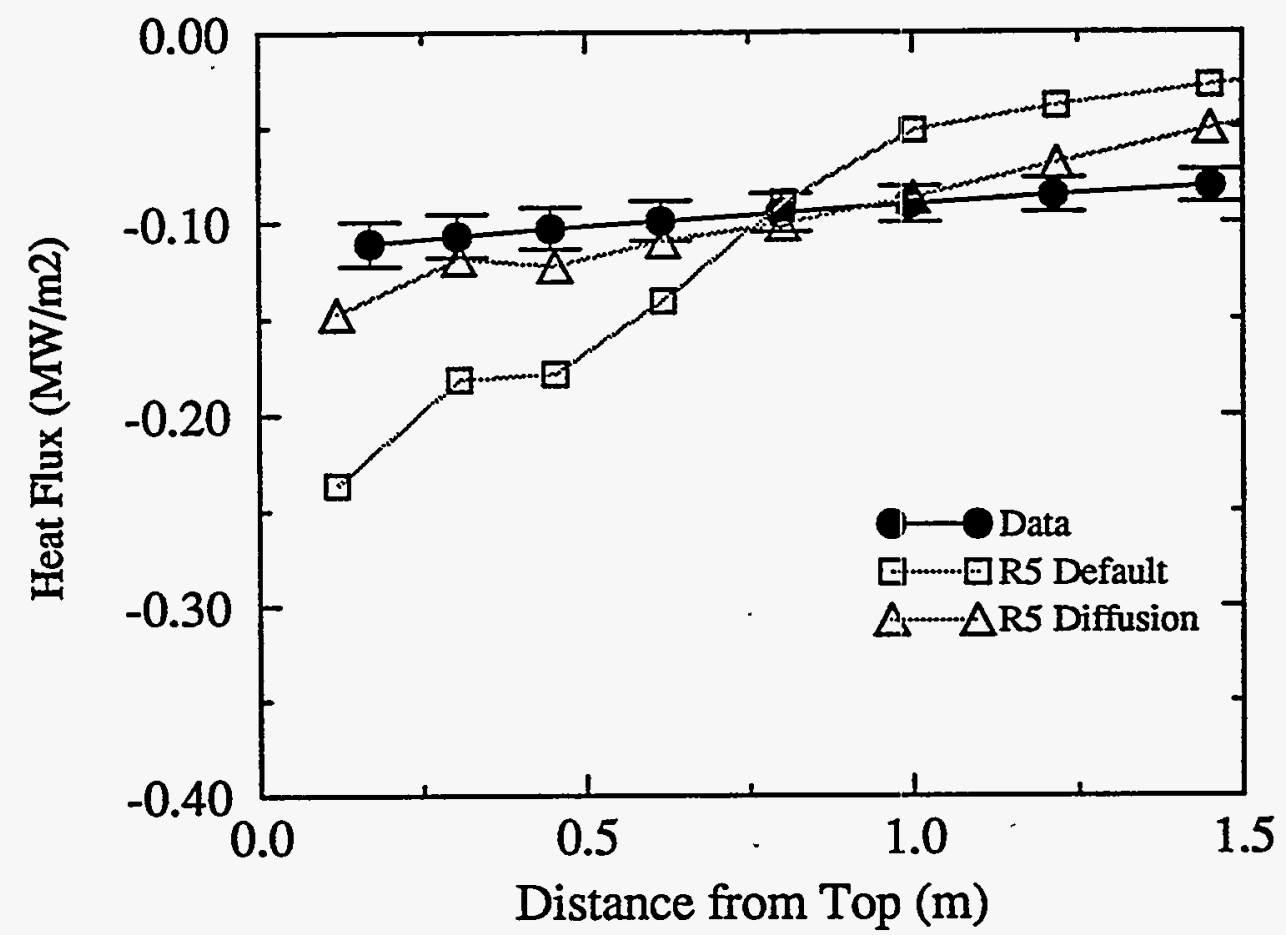

FIGURE A26. RELAP5 heat flux comparison with UCB-Kuhn Test 5.2-3 


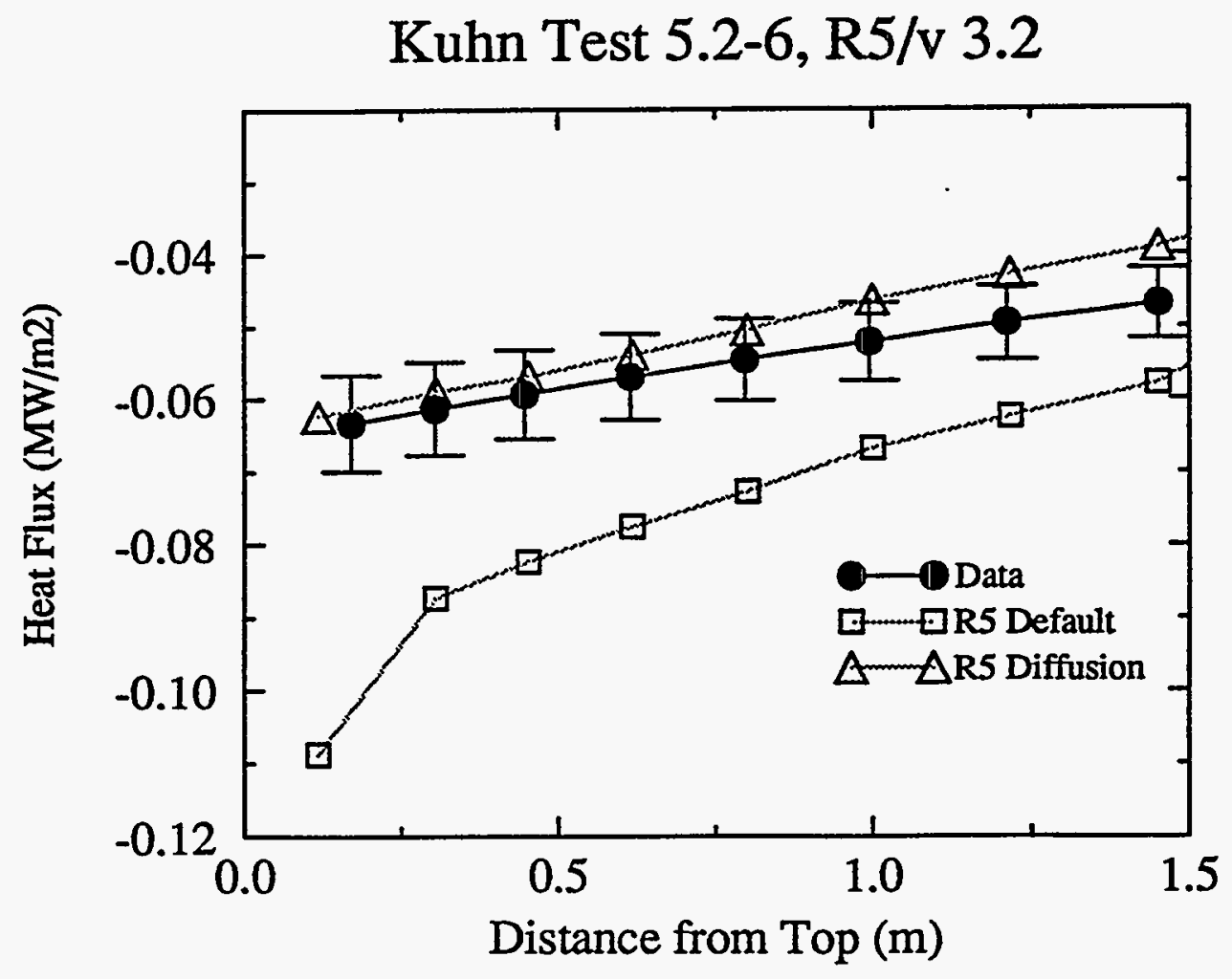

FIGURE A27. RELAP5 heat flux comparison with UCB-Kuhn Test 5.2-6 


\section{APPENDIX B}

\section{UCB Wall Condensation NC Quality Comparisons with RELAP5/MOD3.2}




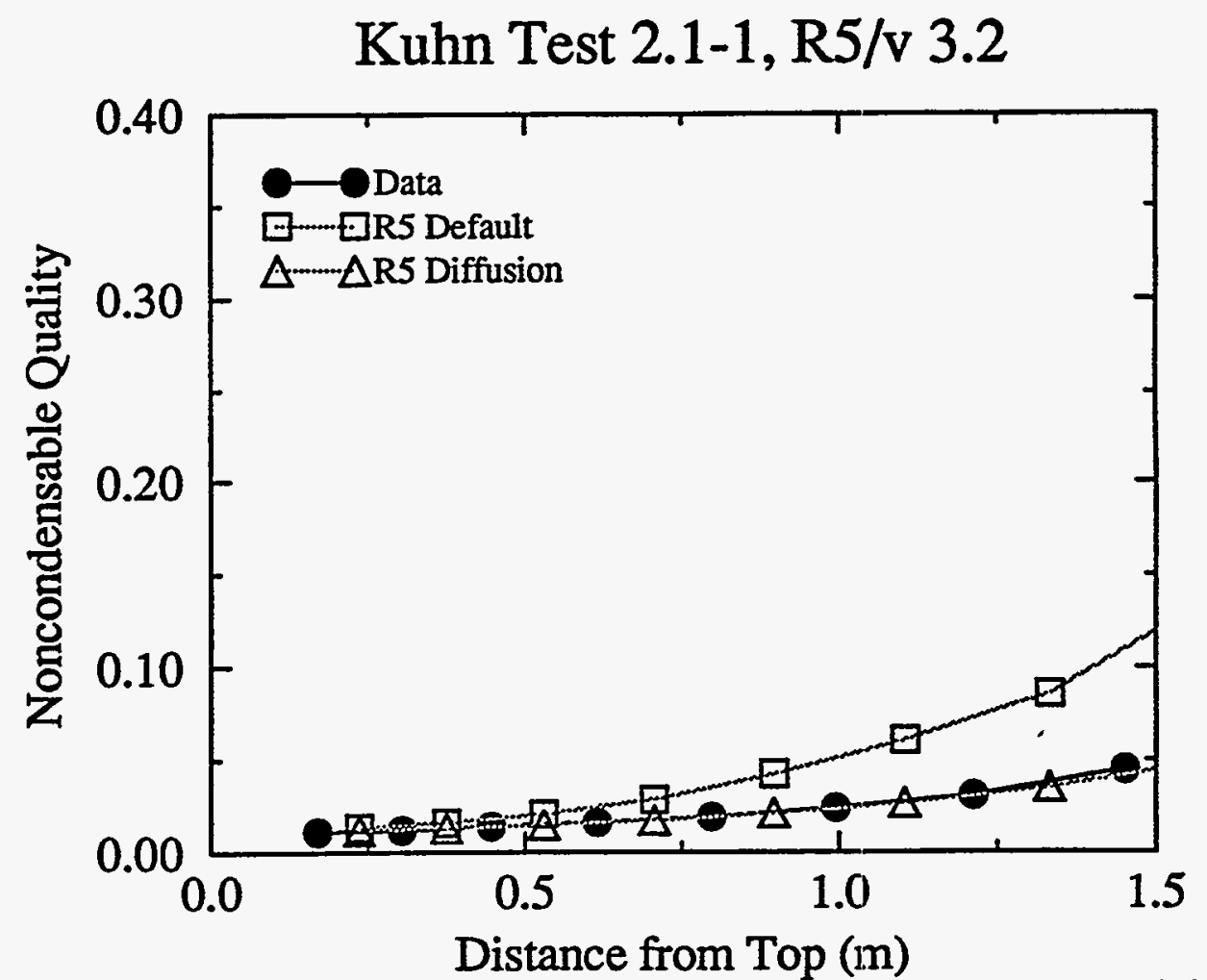

FIGURE B1. RELAP5 NC quality comparison with UCB-Kuhn Test 2.1-1

Kuhn Test 2.1-7, R5/v 3.2

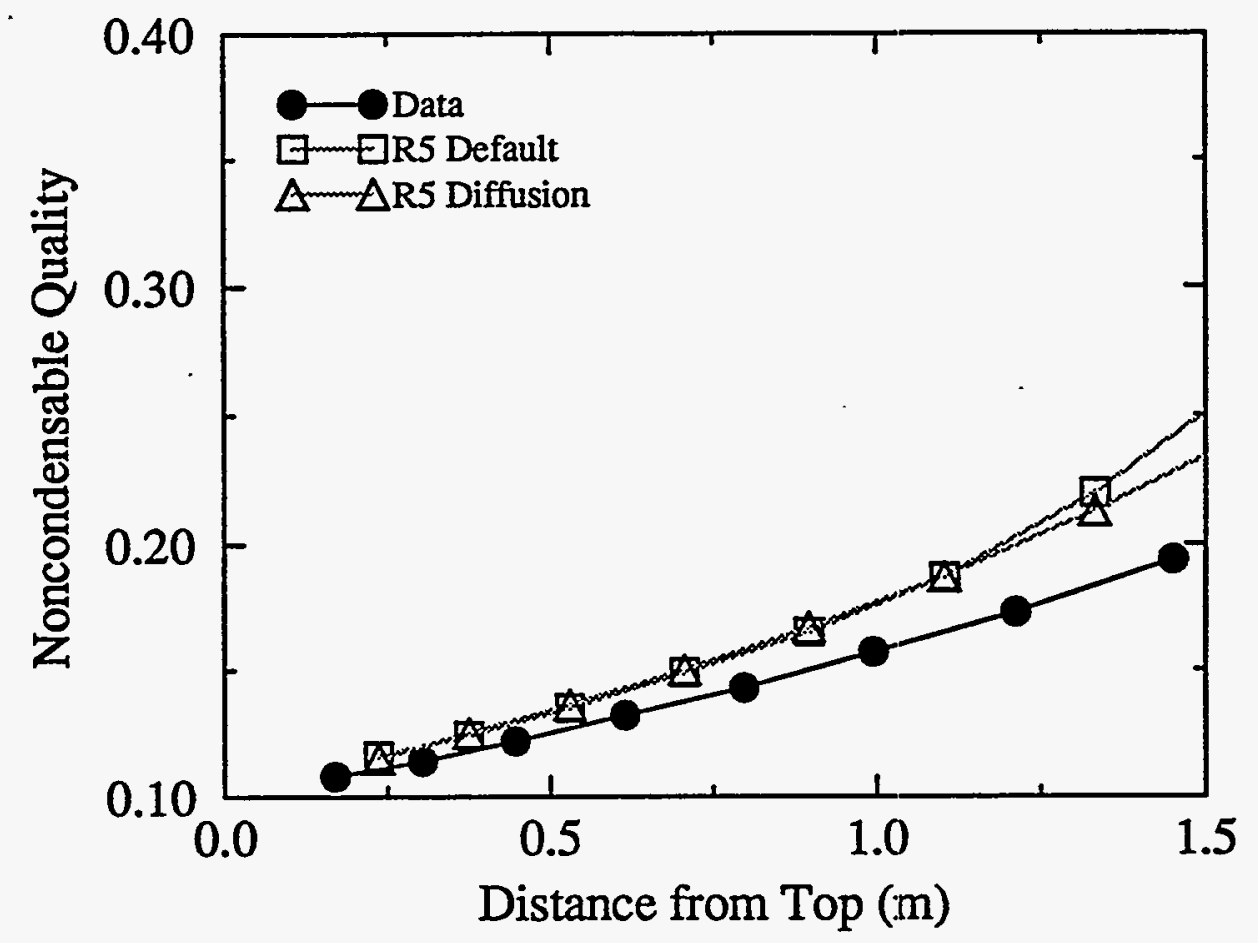

FIGURE B2. RELAP5 NC quality comparison with UCB-Kuhn Test 2.1-7 


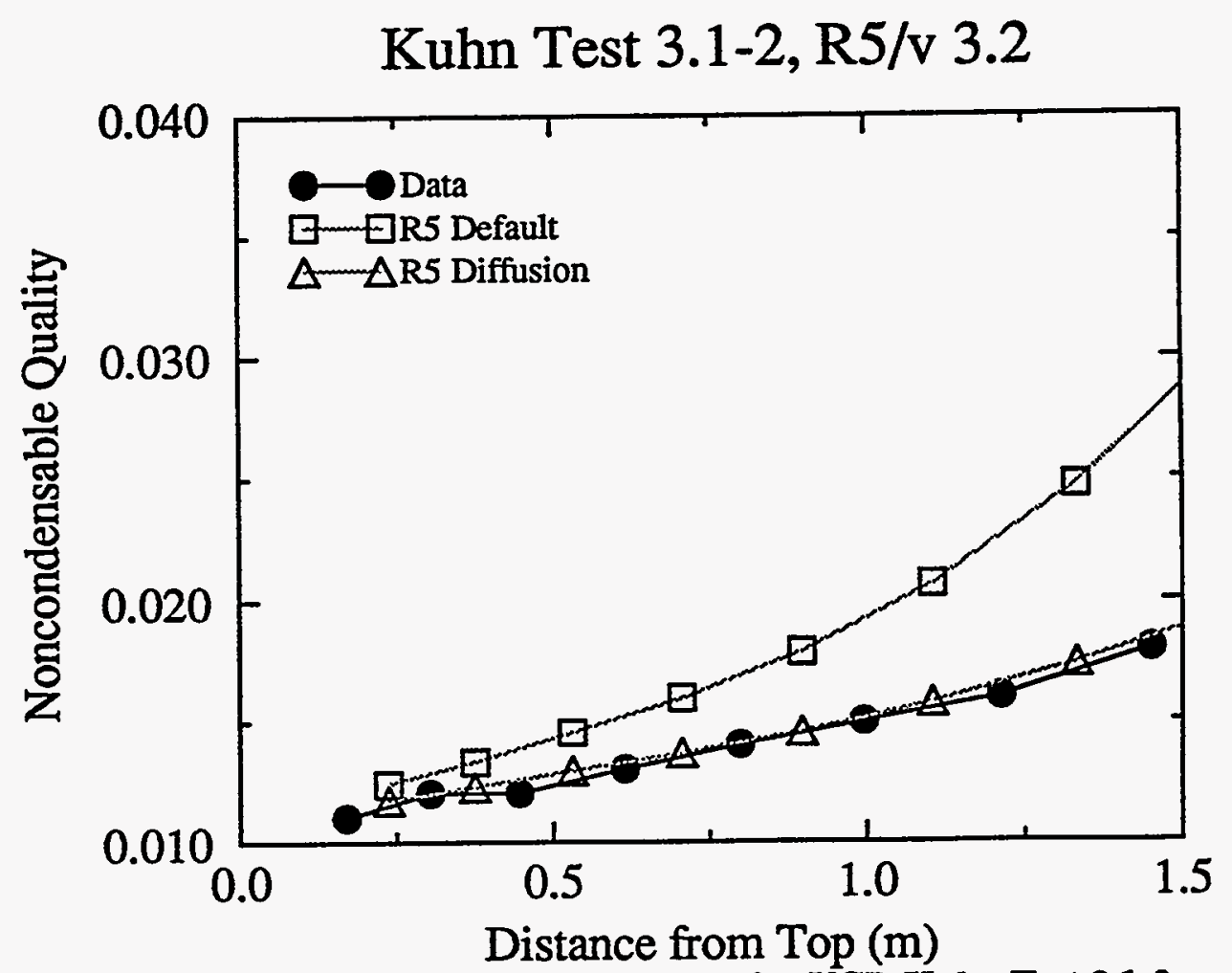

FIGURE B3. RELAP5 NC quality comparison with UCB-Kuhn Test 3.1-2

Kuhn Test 3.1-5, R5/v 3.2

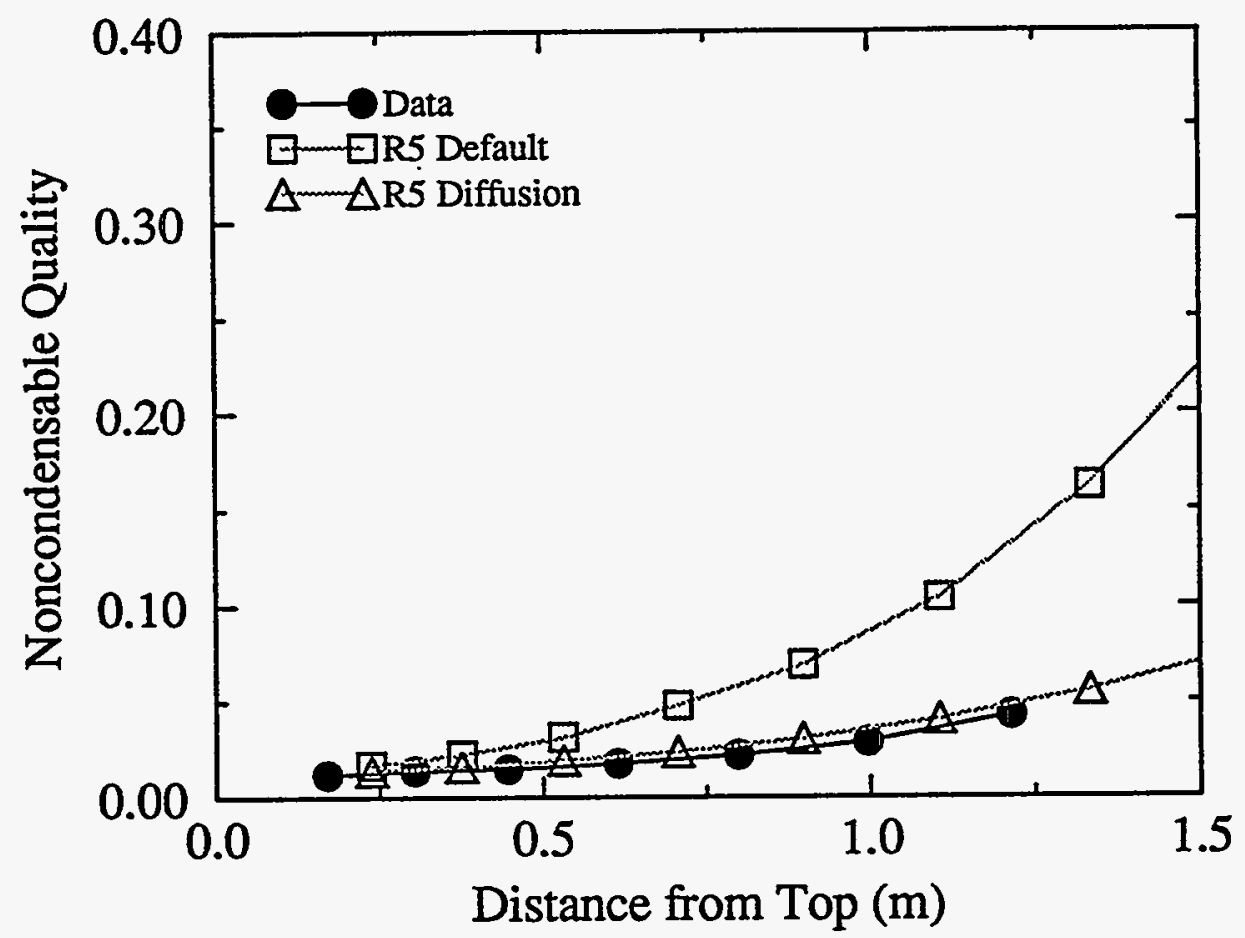

FIGURE B4. RELAP5 NC quality comparison with UCB-Kuhn Test 3.1-5 


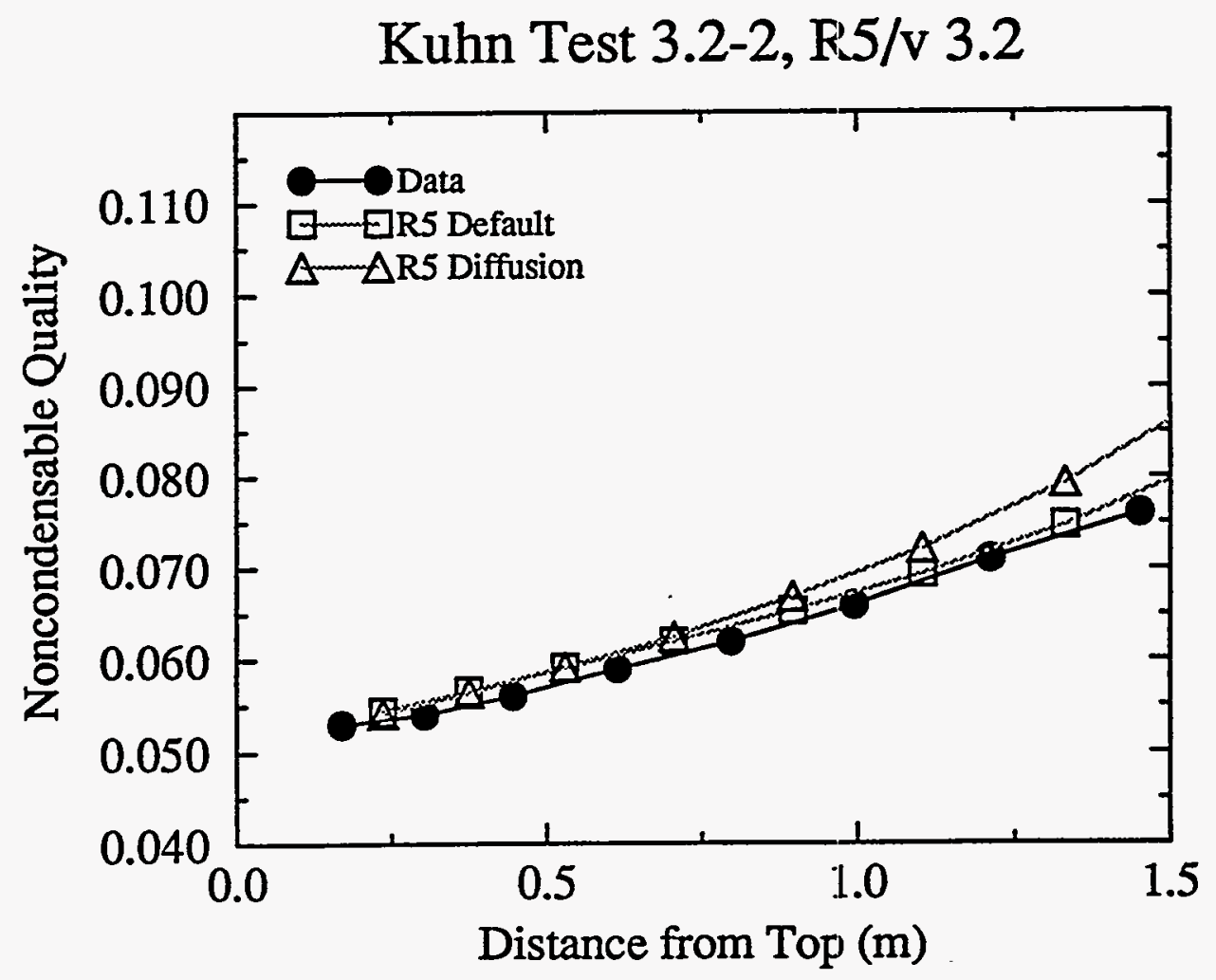

FIGURE B5. RELAP5 NC quality comparison with UCB-Kuhn Test 3.2-2

Kuhn Test 3.3-2, R5/v 3.2

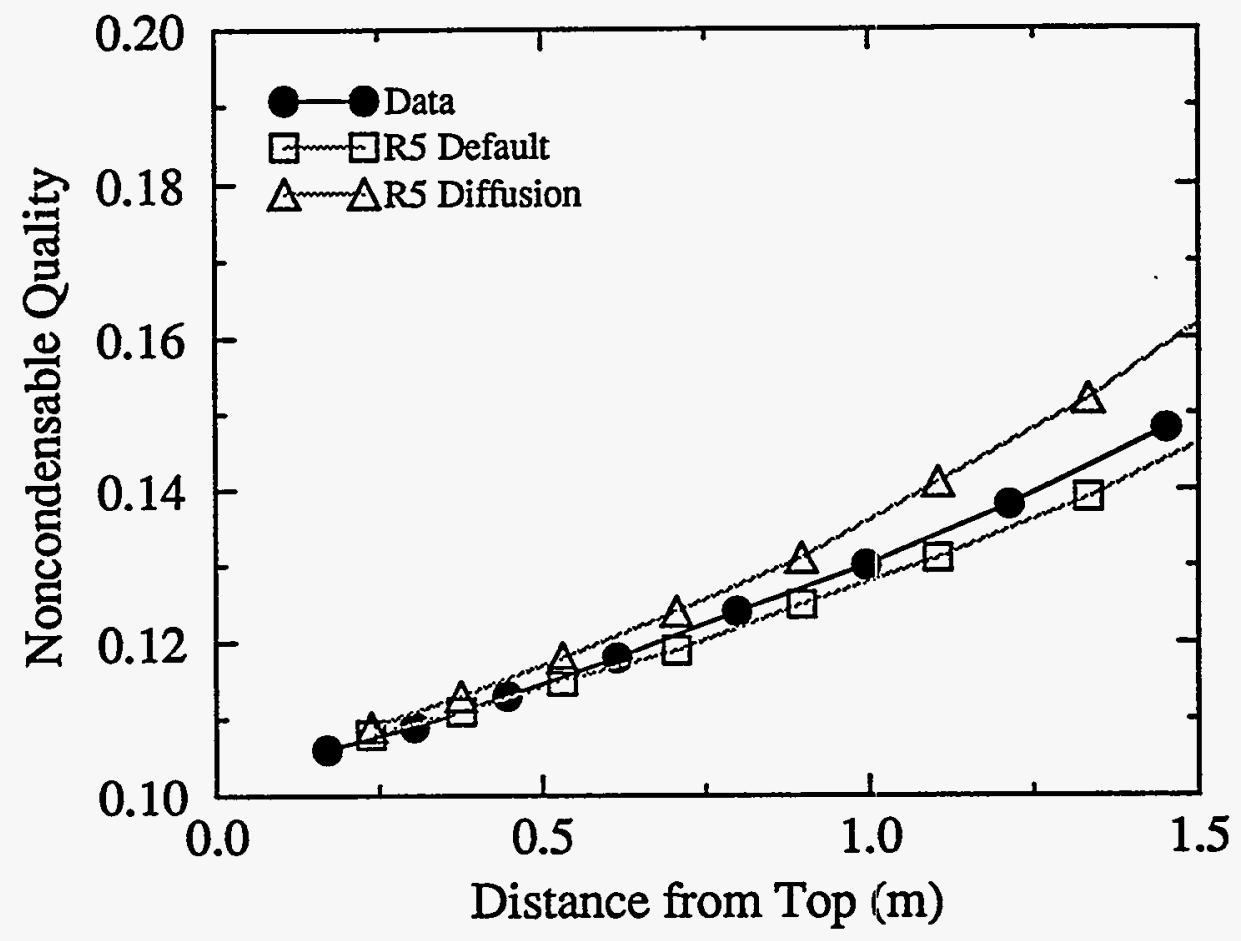

FIGURE B6. RELAP5 NC quality comparison with UCB-Kuhn Test 3.3-2 


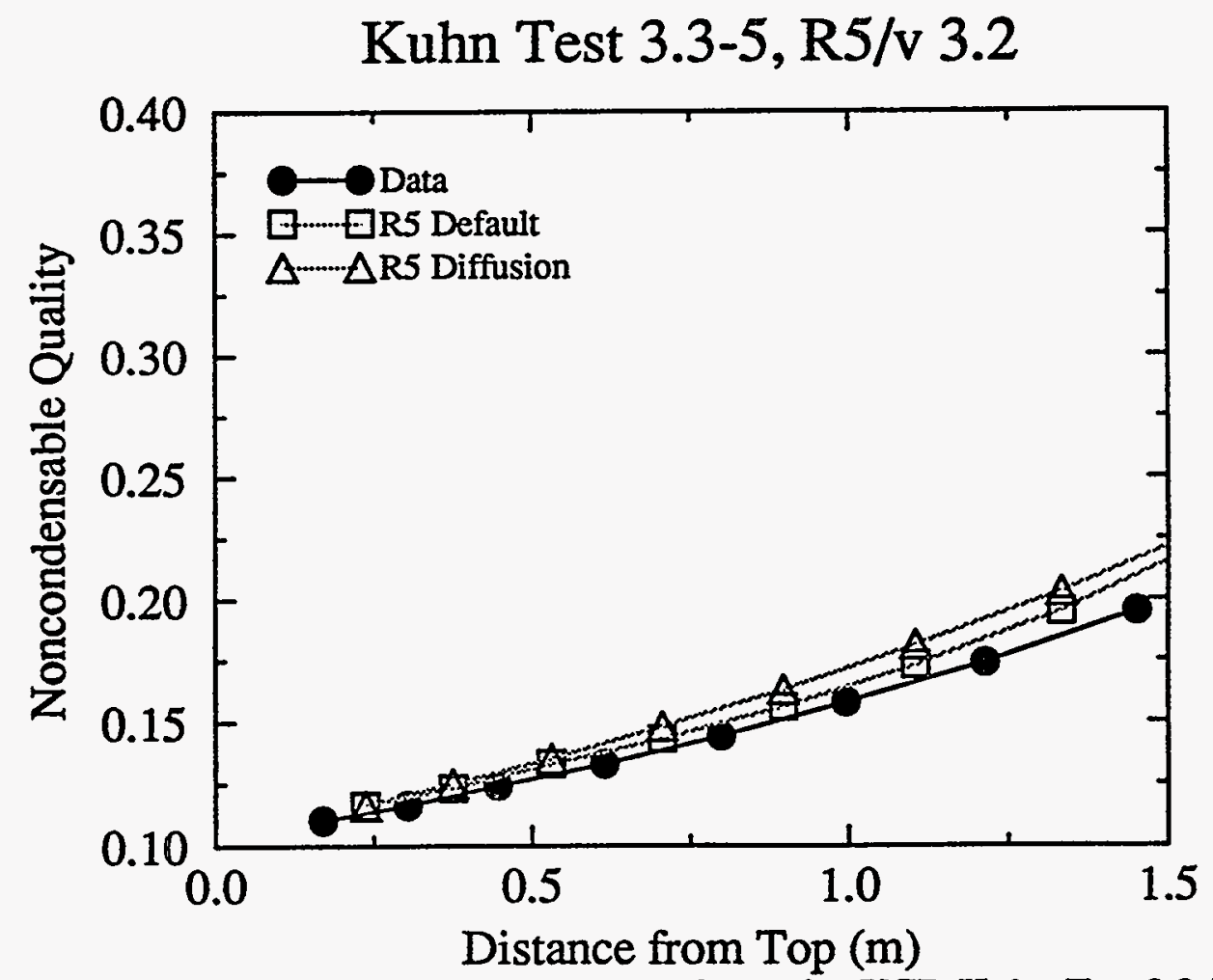

FIGURE B7. RELAP5 NC quality comparison with UCB-Kuhn Test 3.3-5

Kuhn Test 3.4-2, R5/v 3.2

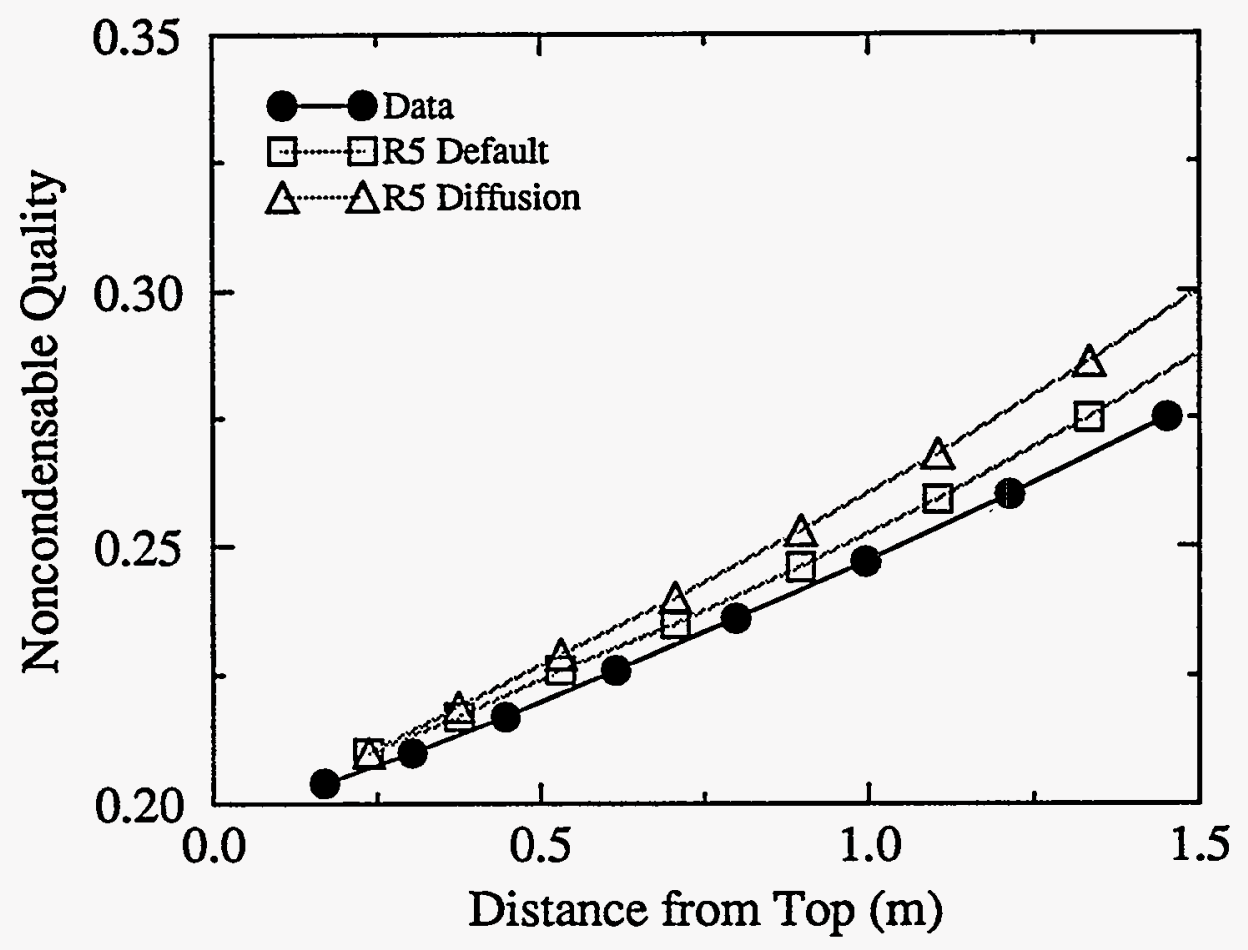

FIGURE B8. RELAP5 NC quality comparison with UCB-Kuhn Test 3.4-2 
Kuhn Test 3.5-2, R5/v 3.2

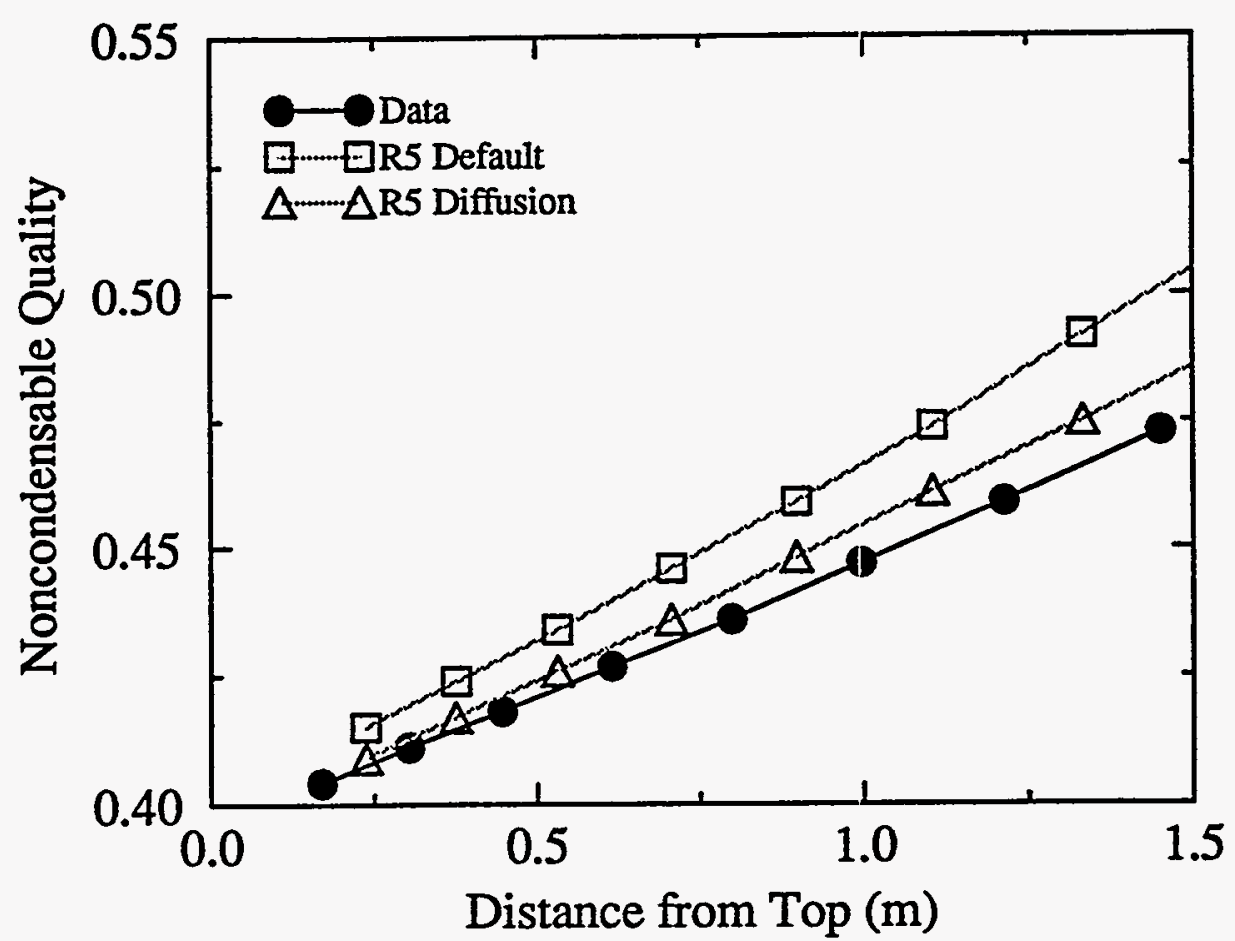

FIGURE B9. RELAP5 NC quality comparison with UCB-Kuhn Test 3.5-2 Kuhn Test 3.5-5, R5/v 3.2

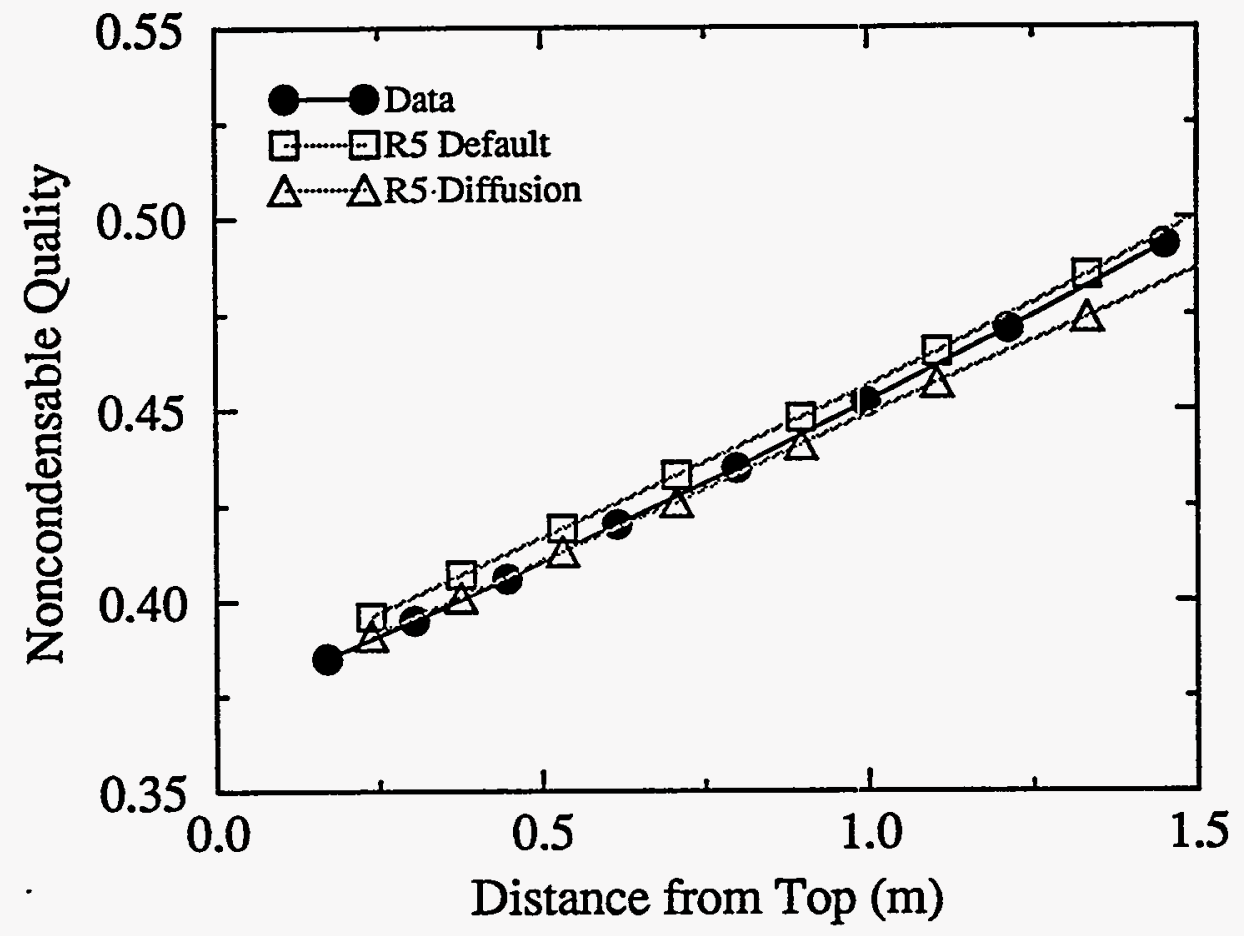

FIGURE B10. RELAP5 NC quality comparison with UCB-Kuhn Test 3.5-5 


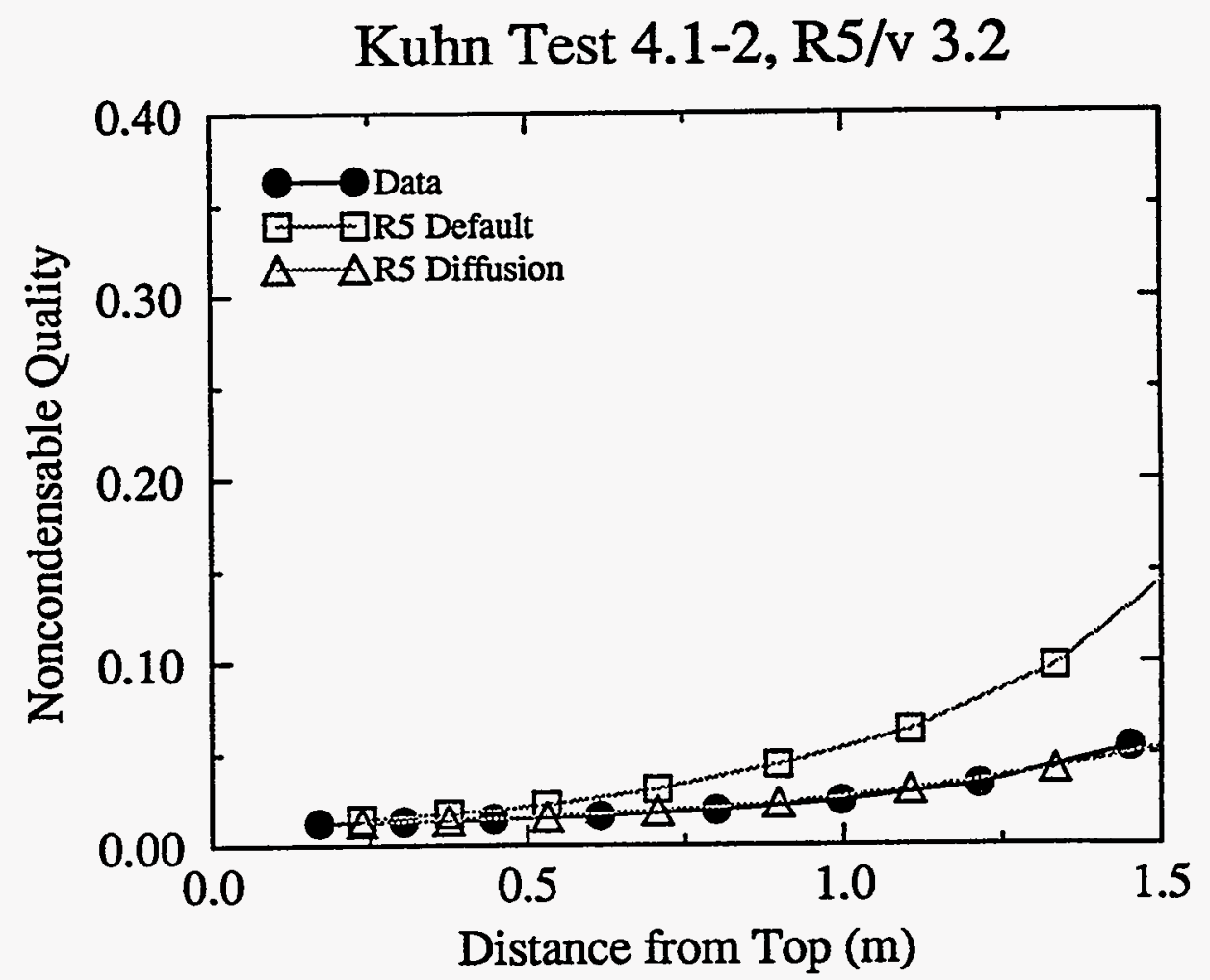

FIGURE B11. RELAP5 NC quality comparison with UCB-Kuhn Test 4.1-2 Kuhn Test 4.3-2, R5/v 3.2

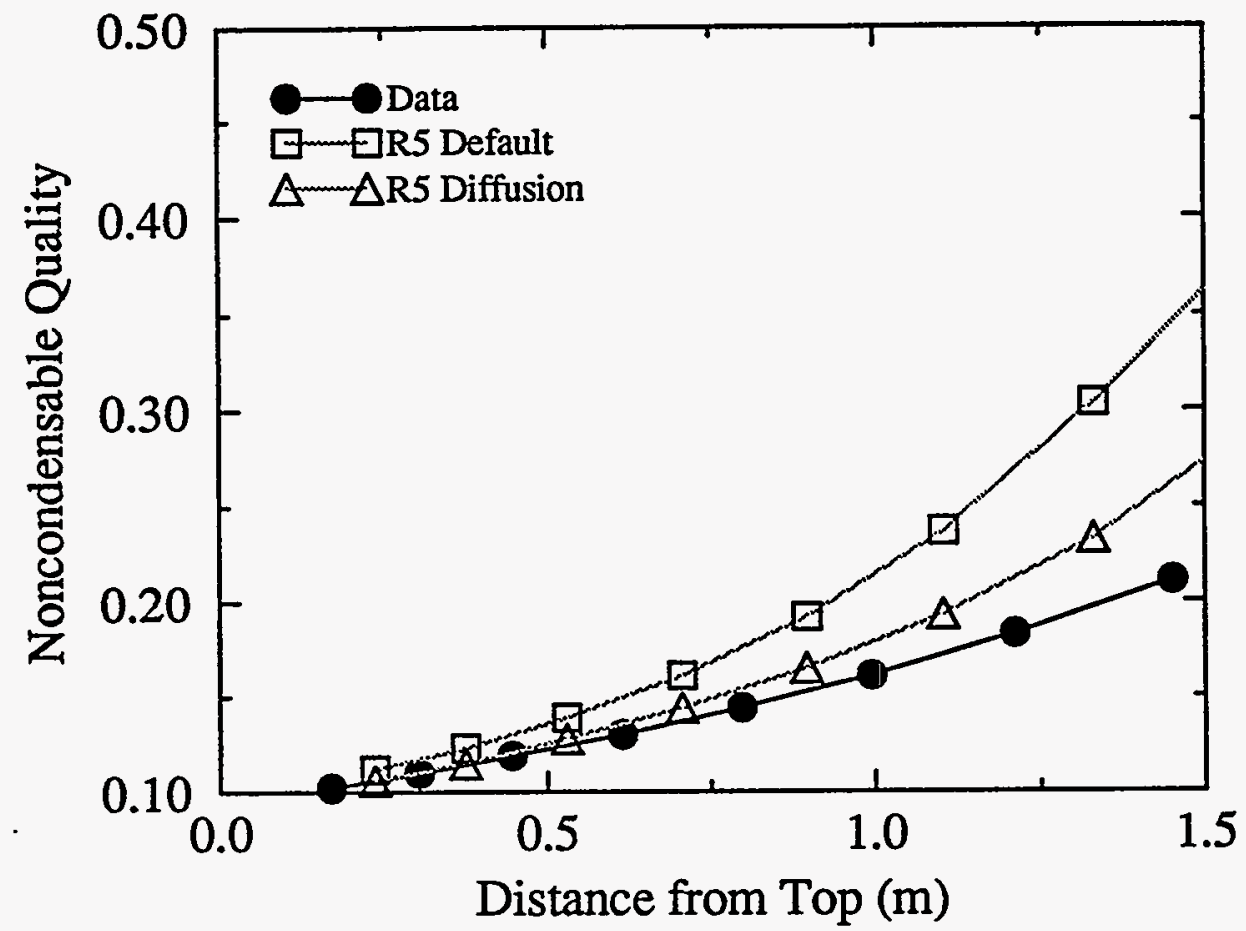

FIGURE B12. RELAP5 NC quality comparison with UCB-Kuhn Test 4.3-2 


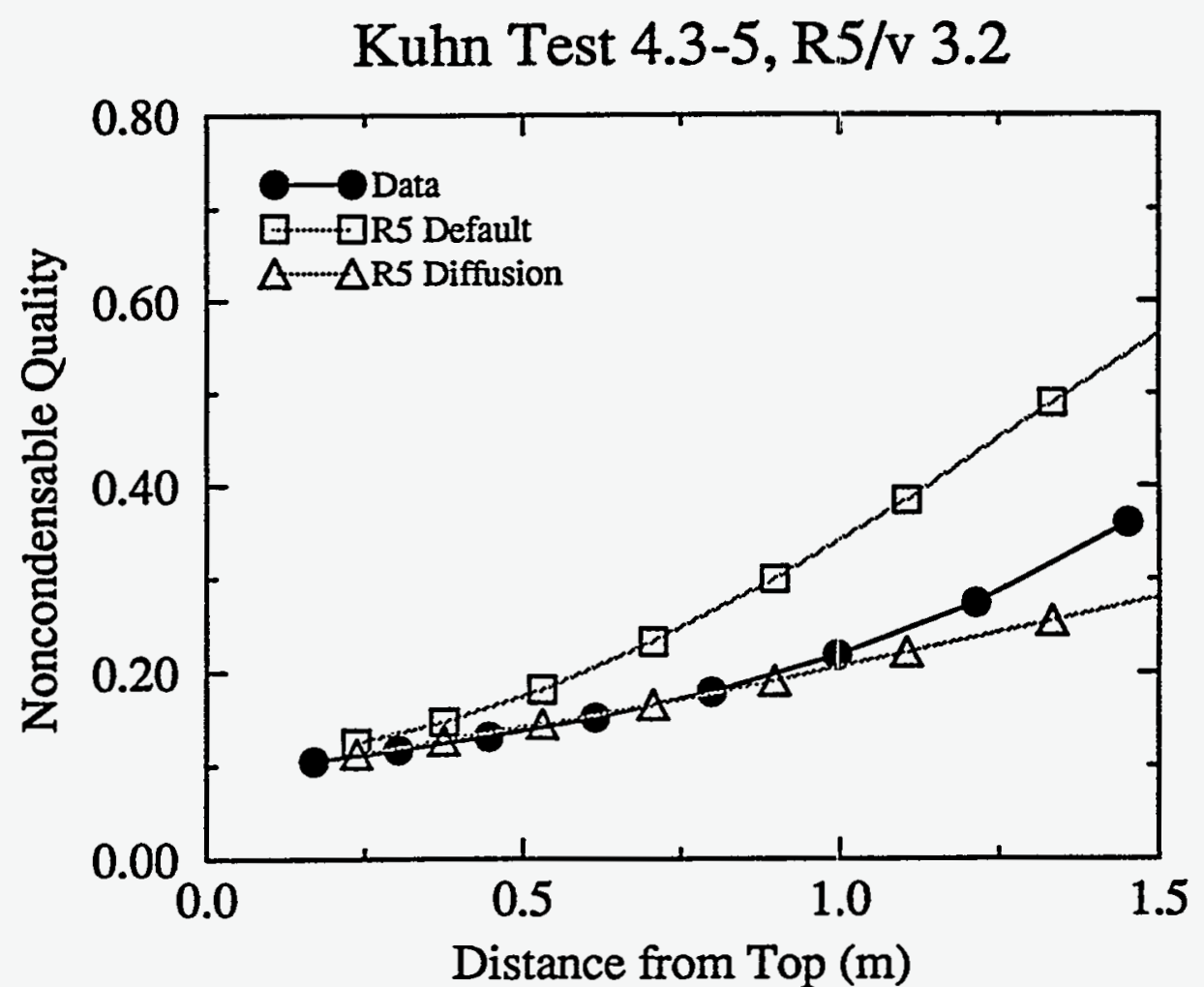

FIGURE B13. RELAP5 NC quality comparison with UCB-Kuhn Test 4.3-5

Kuhn Test 4.5-2, R5/v 3.2

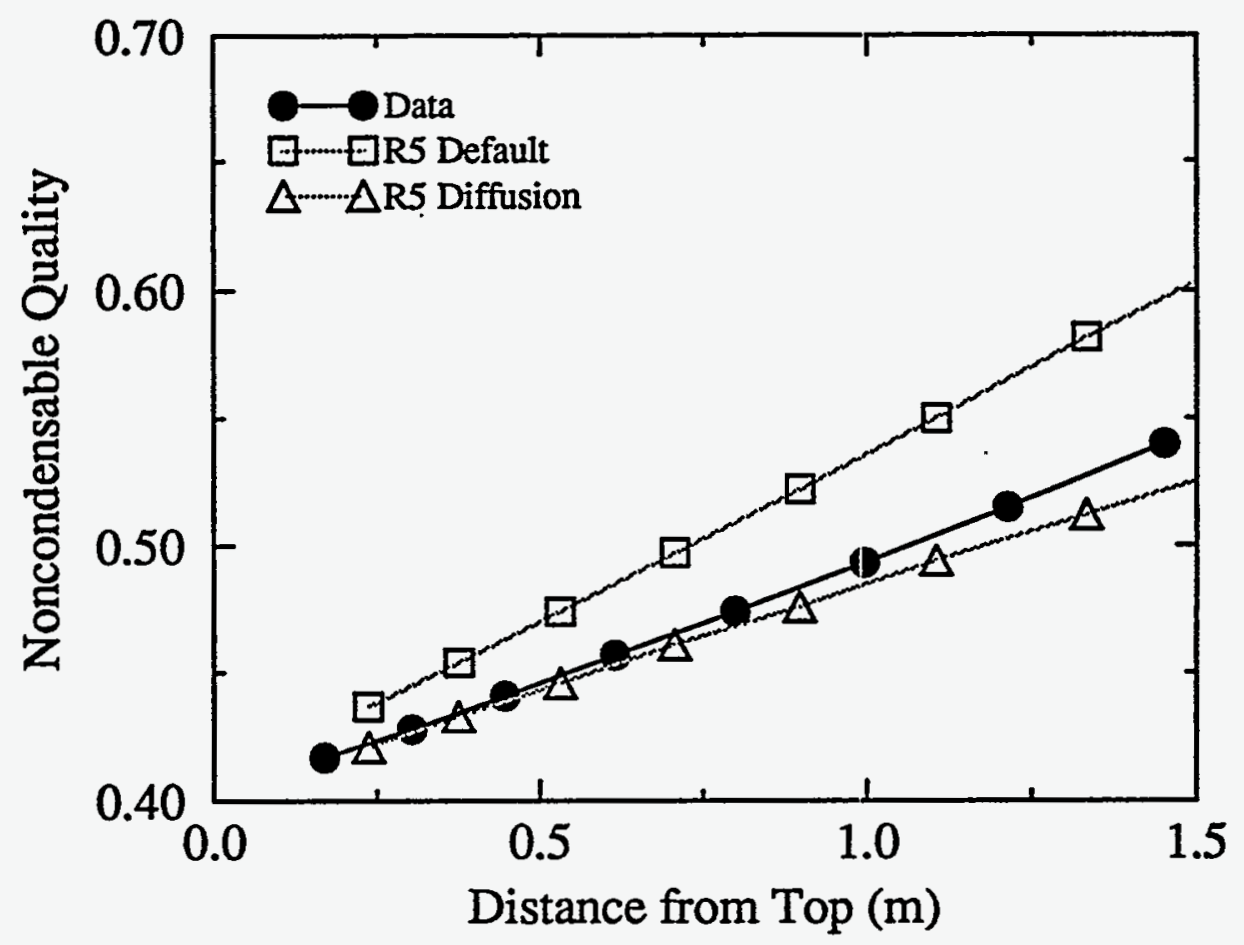

FIGURE B14. RELAP5 NC quality comparison with UCB-Kuhn Test 4.5-2 


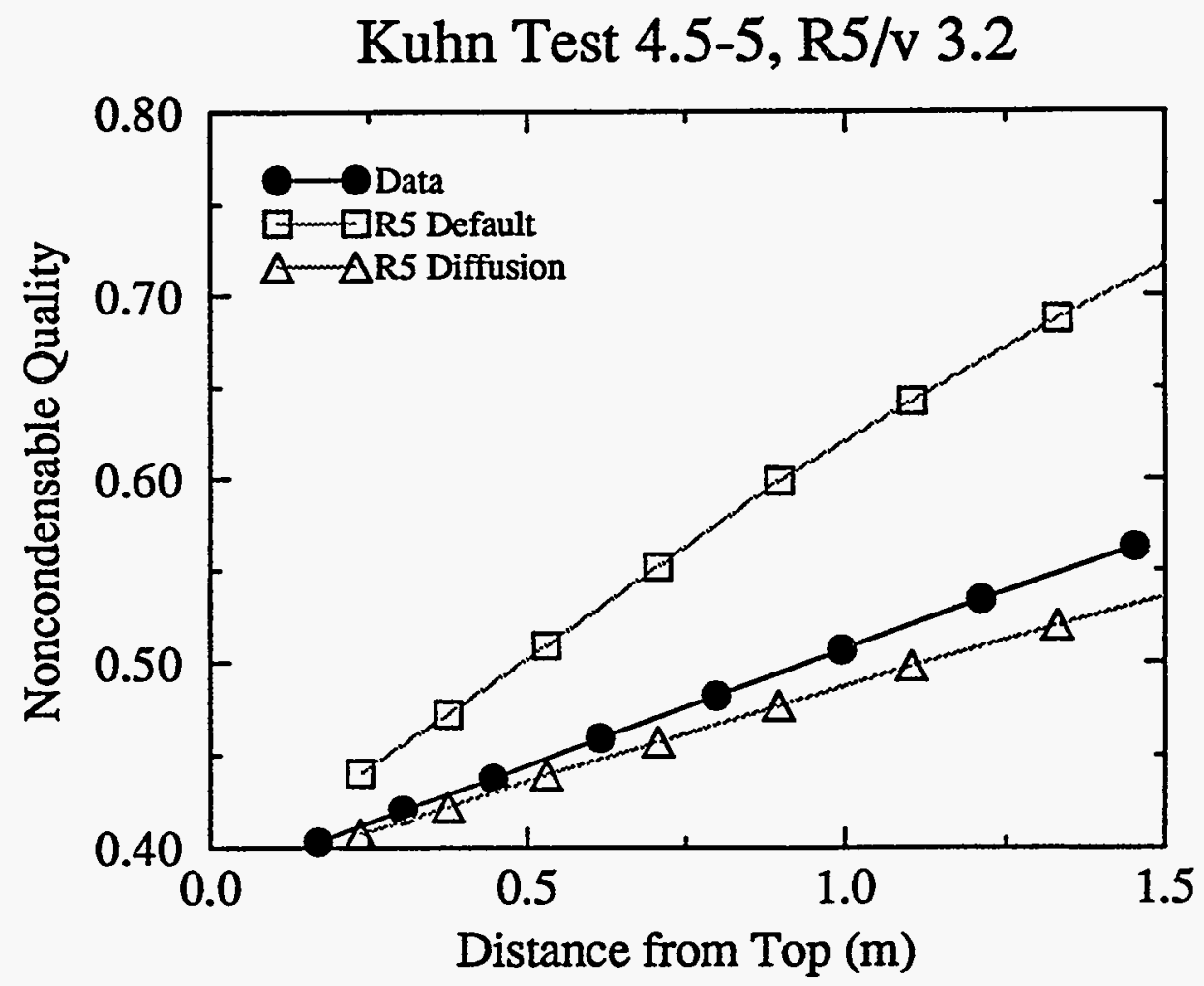

FIGURE B15. RELAP5 NC quality comparison with UCB-Kuhn Test 4.5-5 Kuhn Test 5.2-1, R5/v 3.2

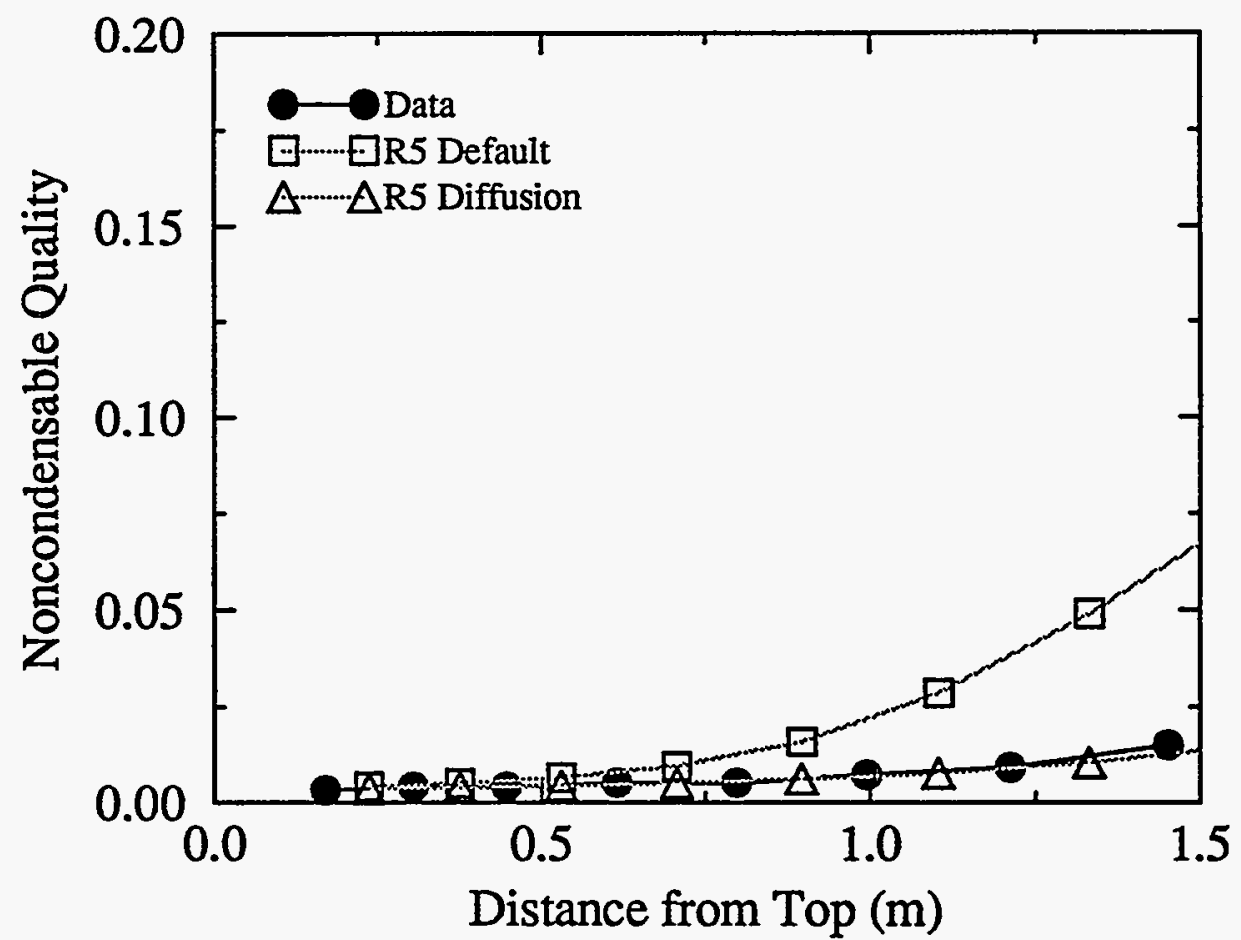

FIGURE B16. RELAP5 NC quality comparison with UCB-Kuhn Test 5.2-1 


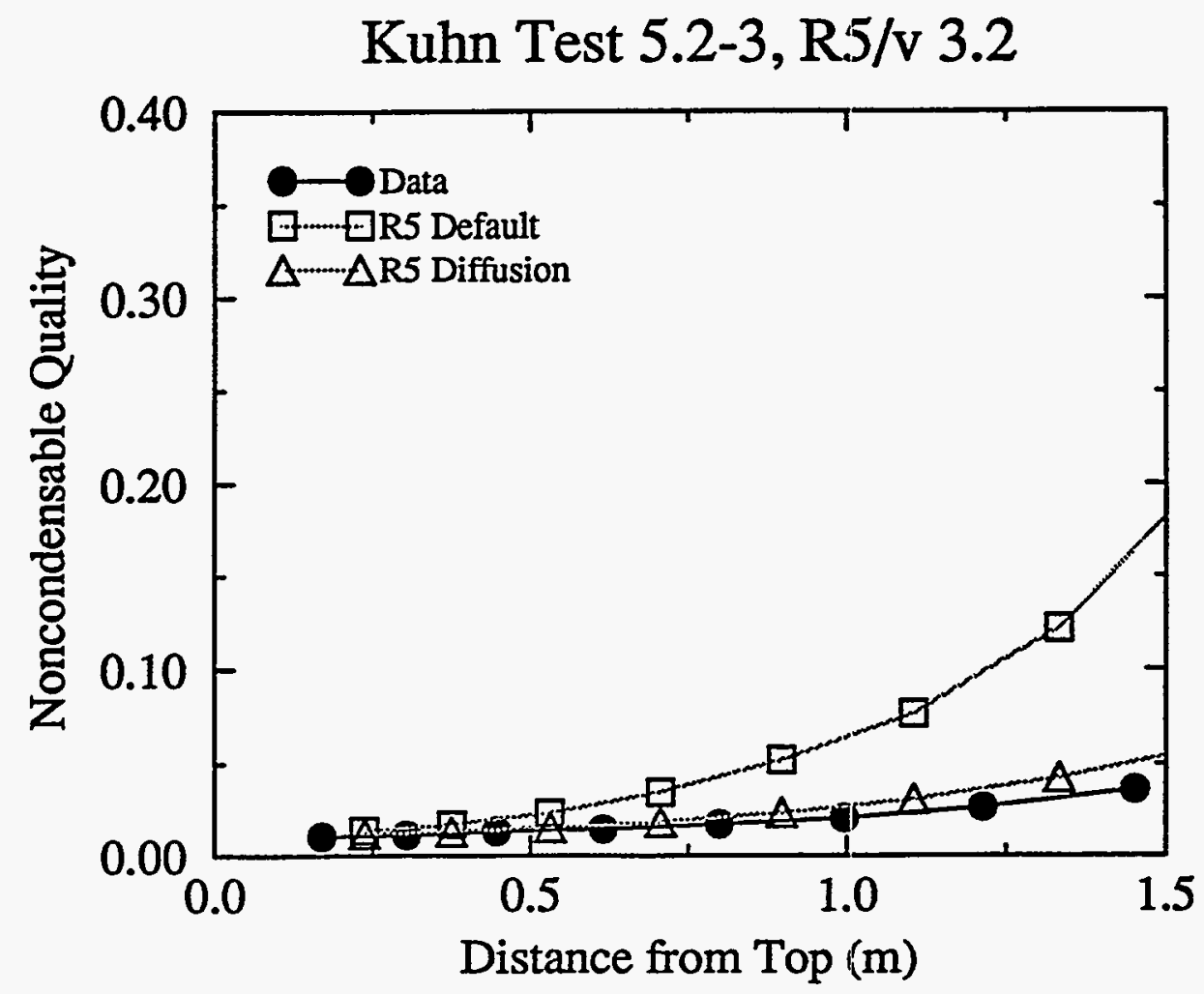

FIGURE B17. RELAP5 NC quality comparison with UCB-Kuhn Test 5.2-3

Kuhn Test 5.2-6, R.5/v 3.2

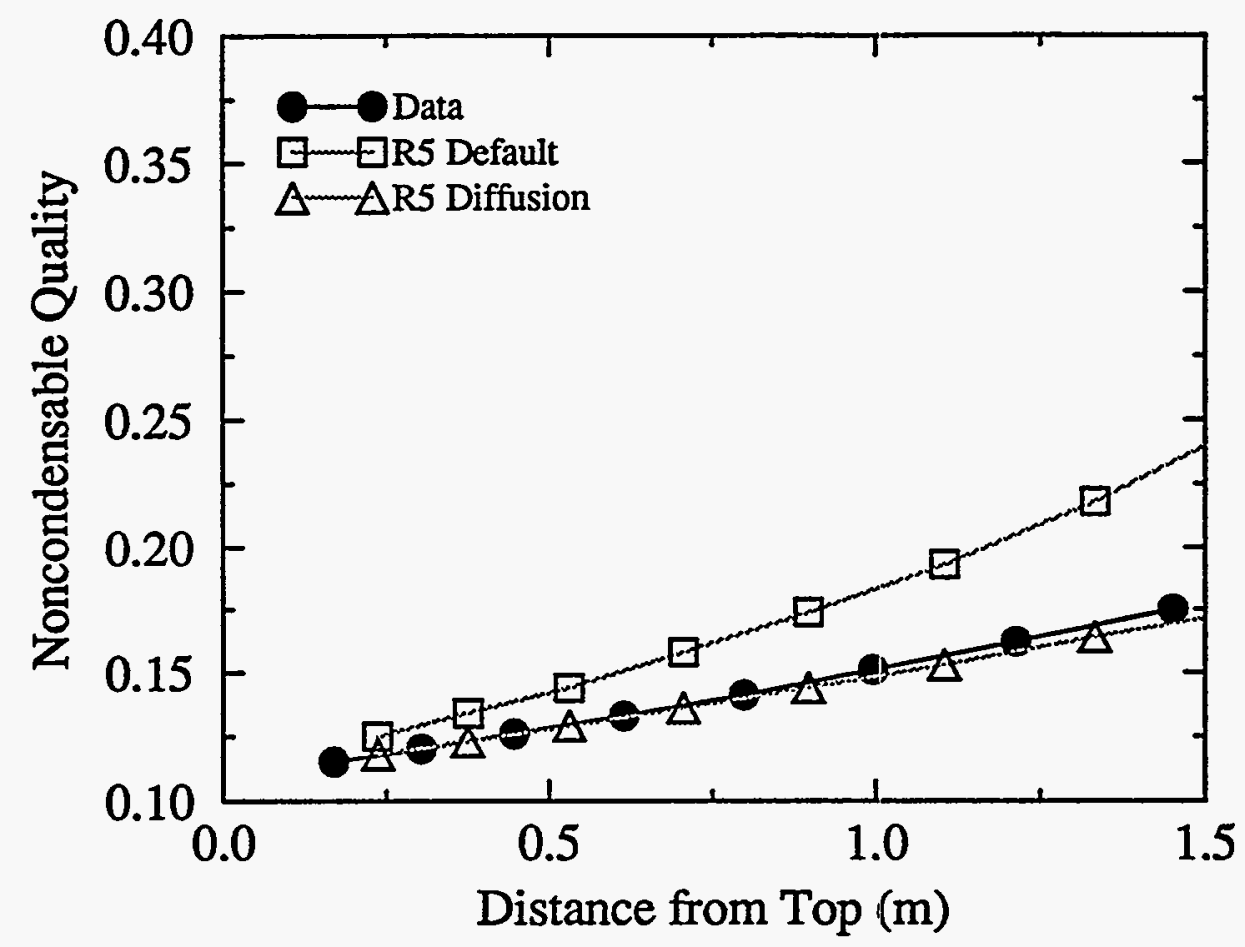

FIGURE B18. RELAP5 NC quality comparison with UCB-Kuhn Test 5.2-6 


\section{APPENDIX C}

\section{MIT Wall Condensation Heat Flux Comparisons with RELAP5/MOD3.2}




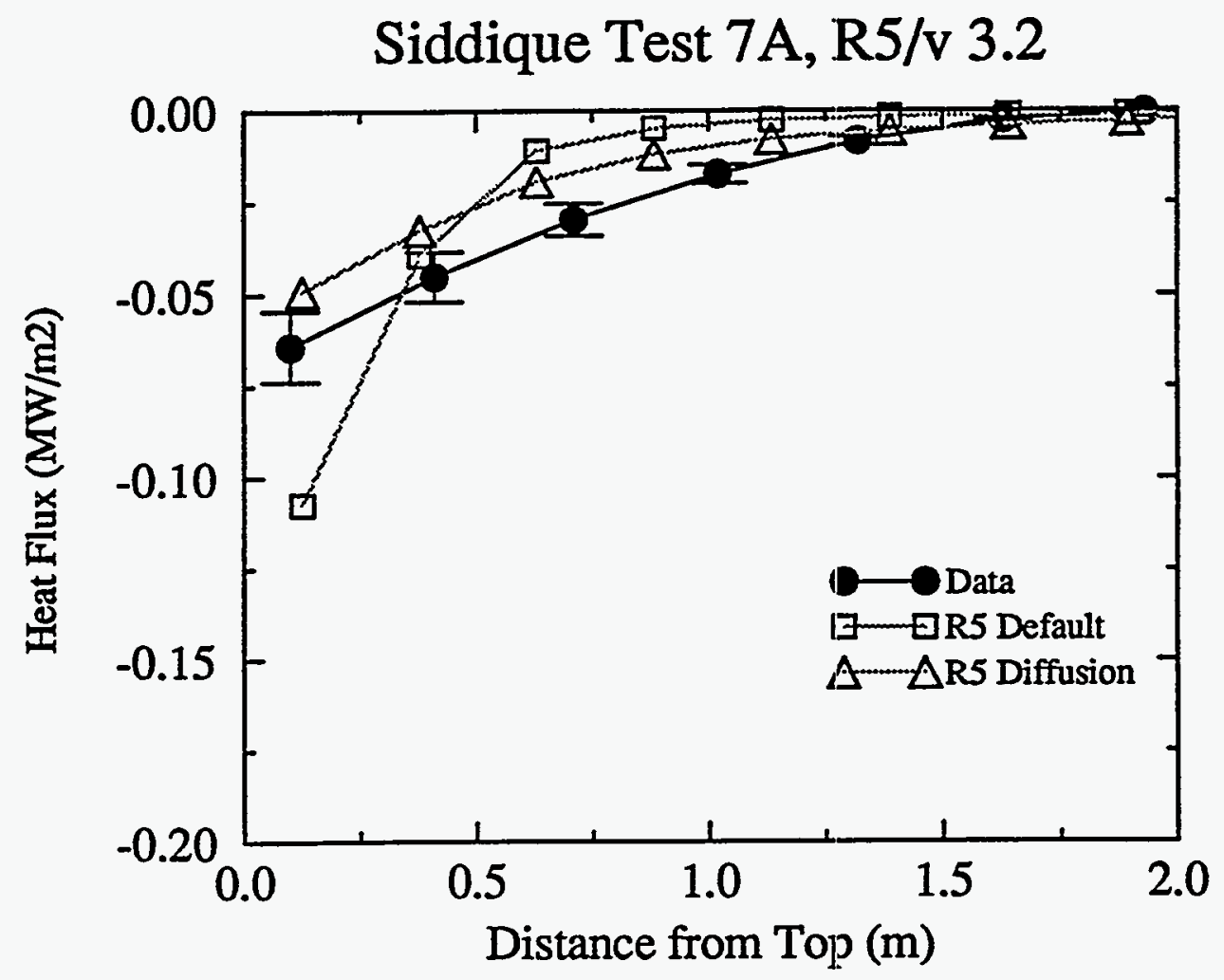

FIGURE C1. RELAP5 heat flux comparison with MIT-Siddique Test 7A Siddique Test 8A, R5/v 3.2

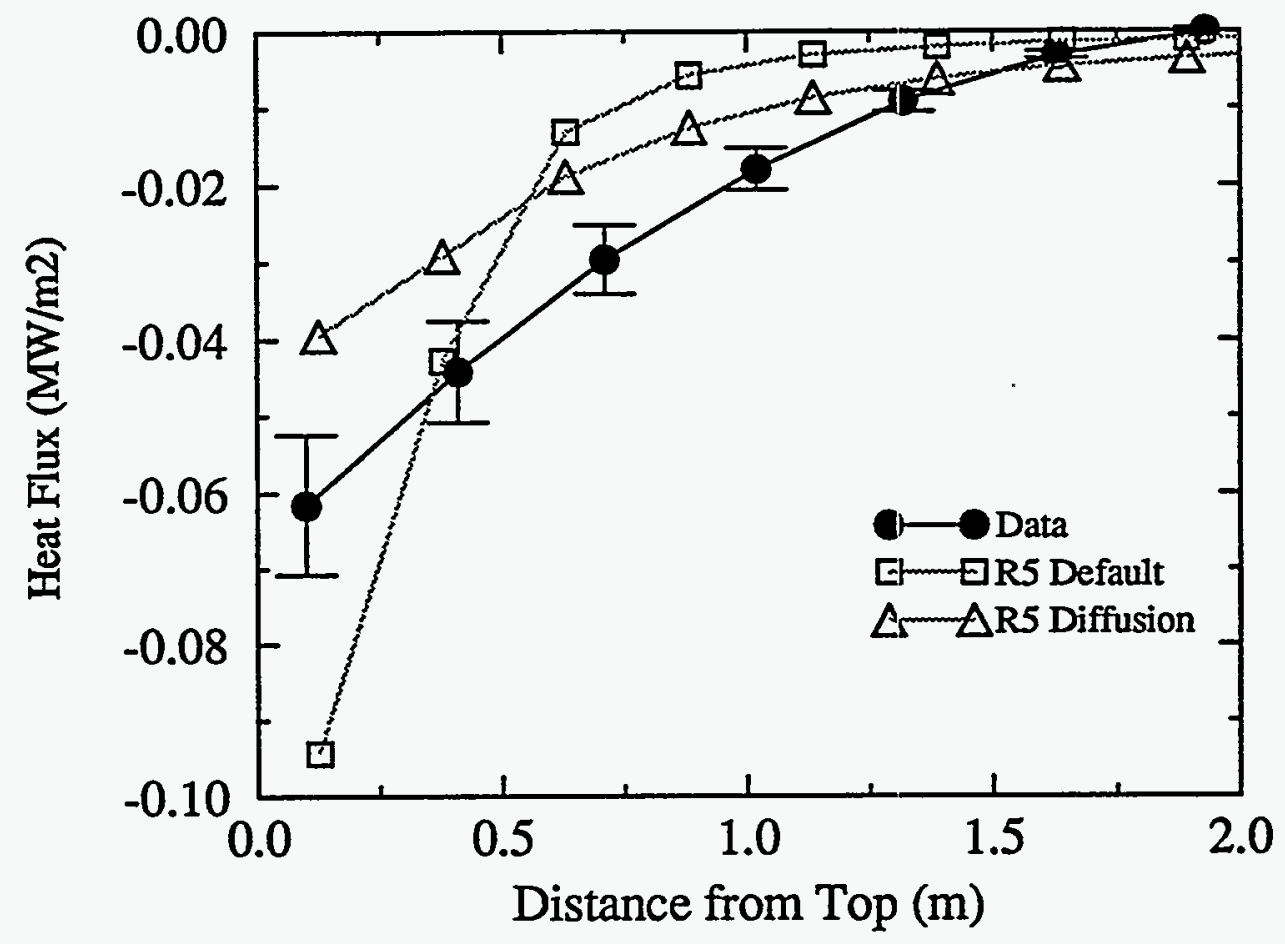

FIGURE C2. RELAP5 heat flux comparison with MIT-Siddique Test 8A 


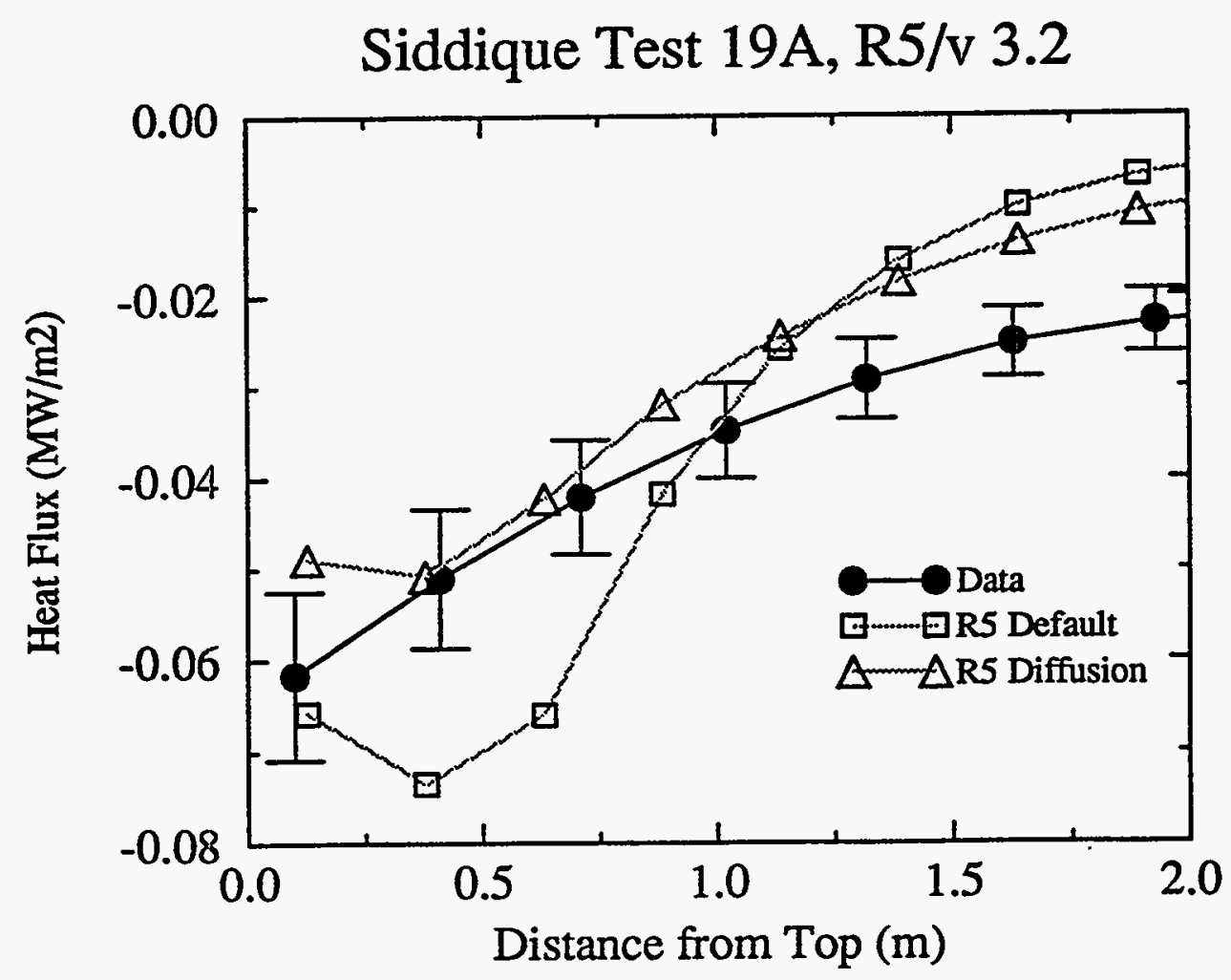

FIGURE C3. RELAP5 heat flux comparison with MIT-Siddique Test 19A

Siddique Test 24A, R5/v 3.2

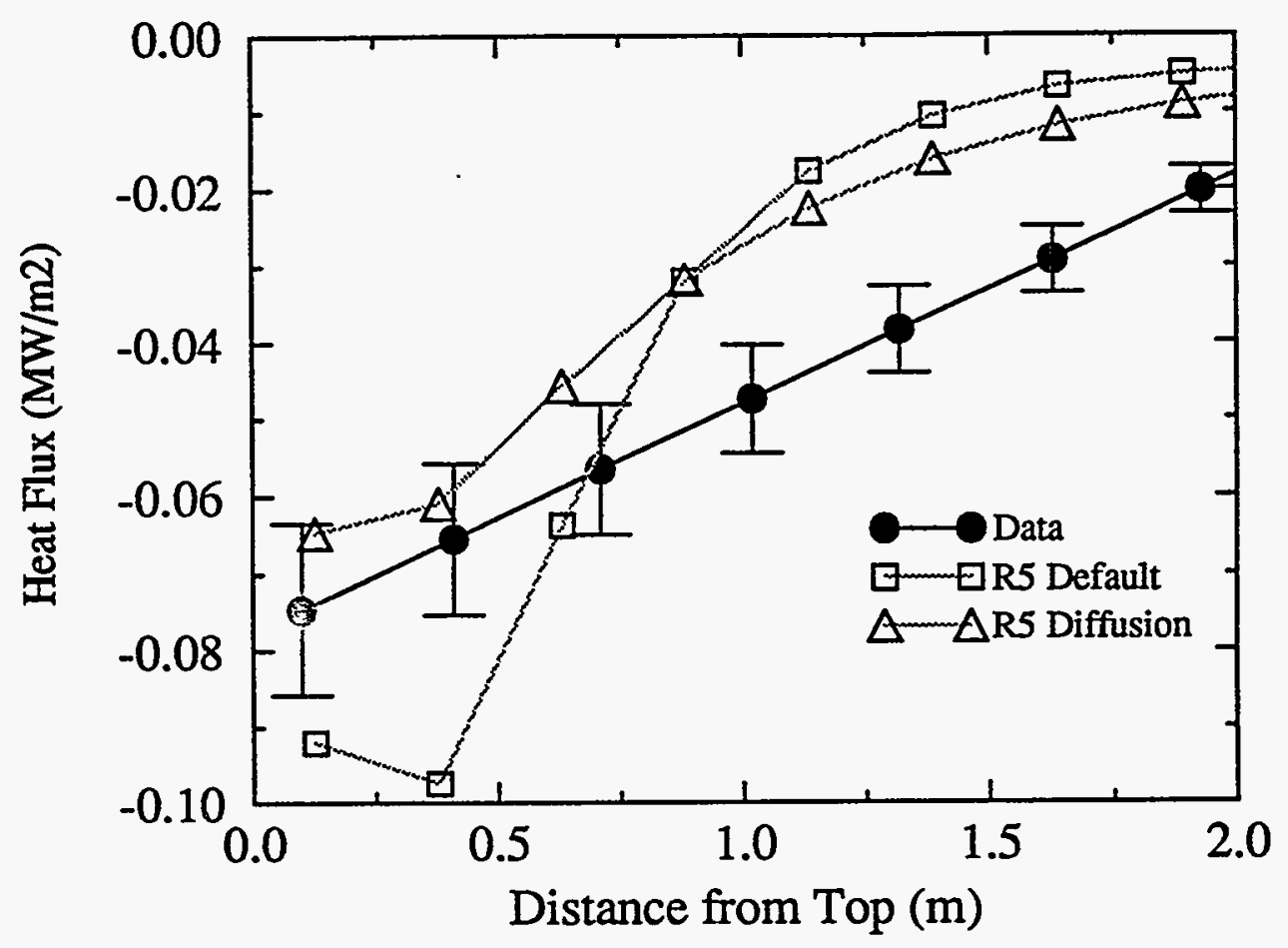

FIGURE C4. RELAP5 heat flux comparison with MIT-Siddique Test 24A 


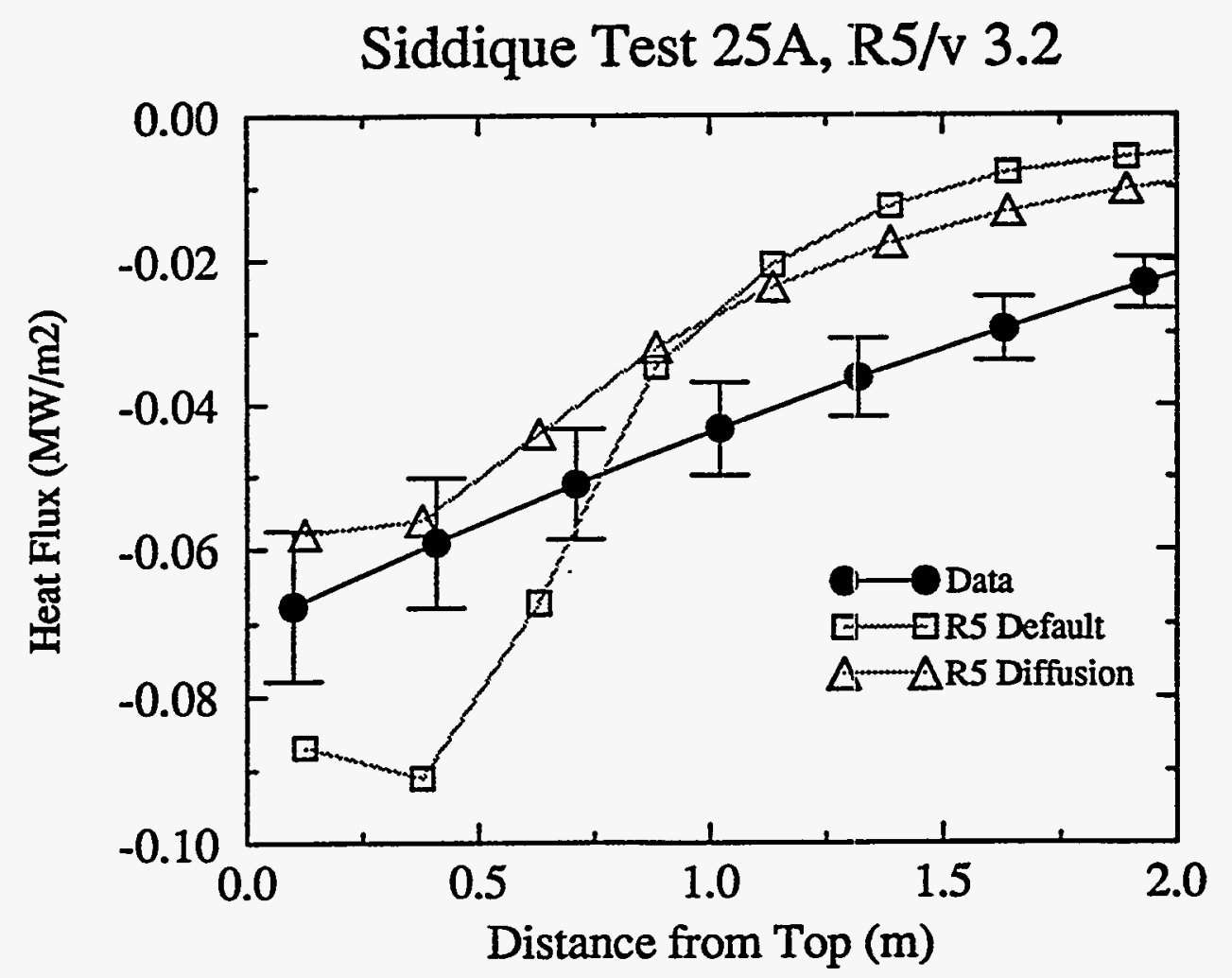

FIGURE C5. RELAP5 heat flux comparison with MIT-Siddique Test 25A Siddique Test 26A, R5/v 3.2

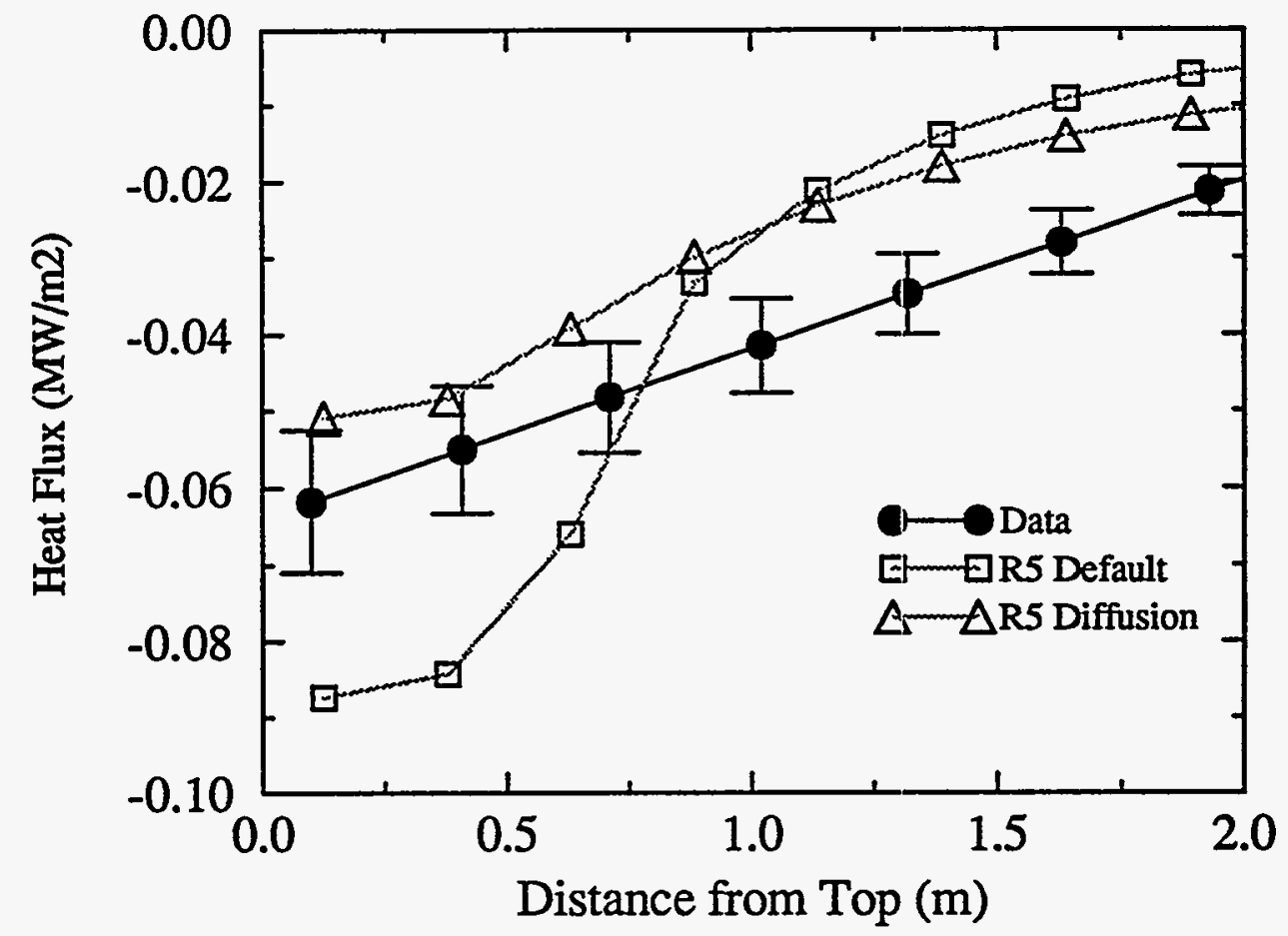

FIGURE C6. RELAP5 heat flux comparison with MIT-Siddique Test 26A 


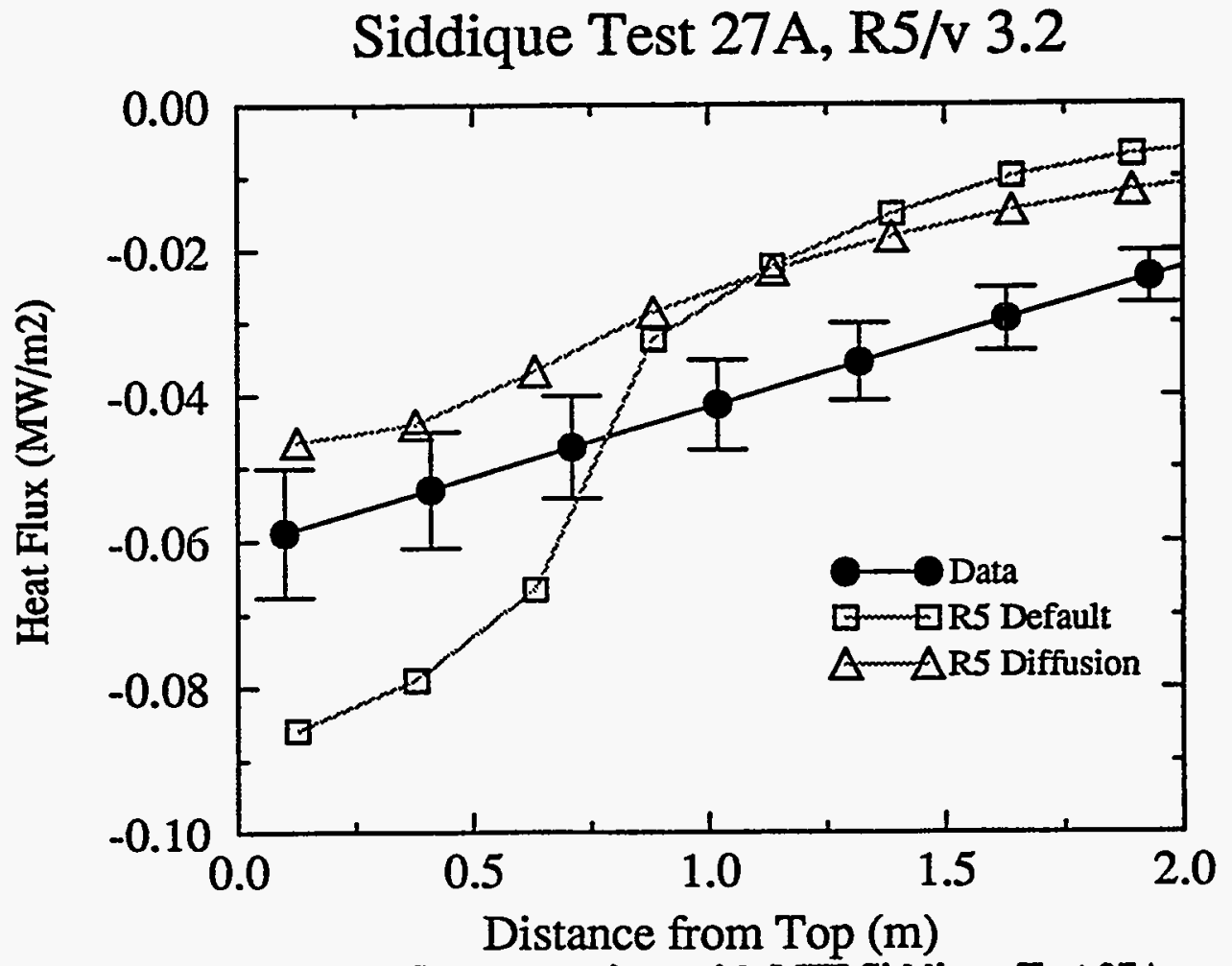

FIGURE C7. RELAP5 heat flux comparison with MTT-Siddique Test 27A

Siddique Test 28A, R5/v 3.2

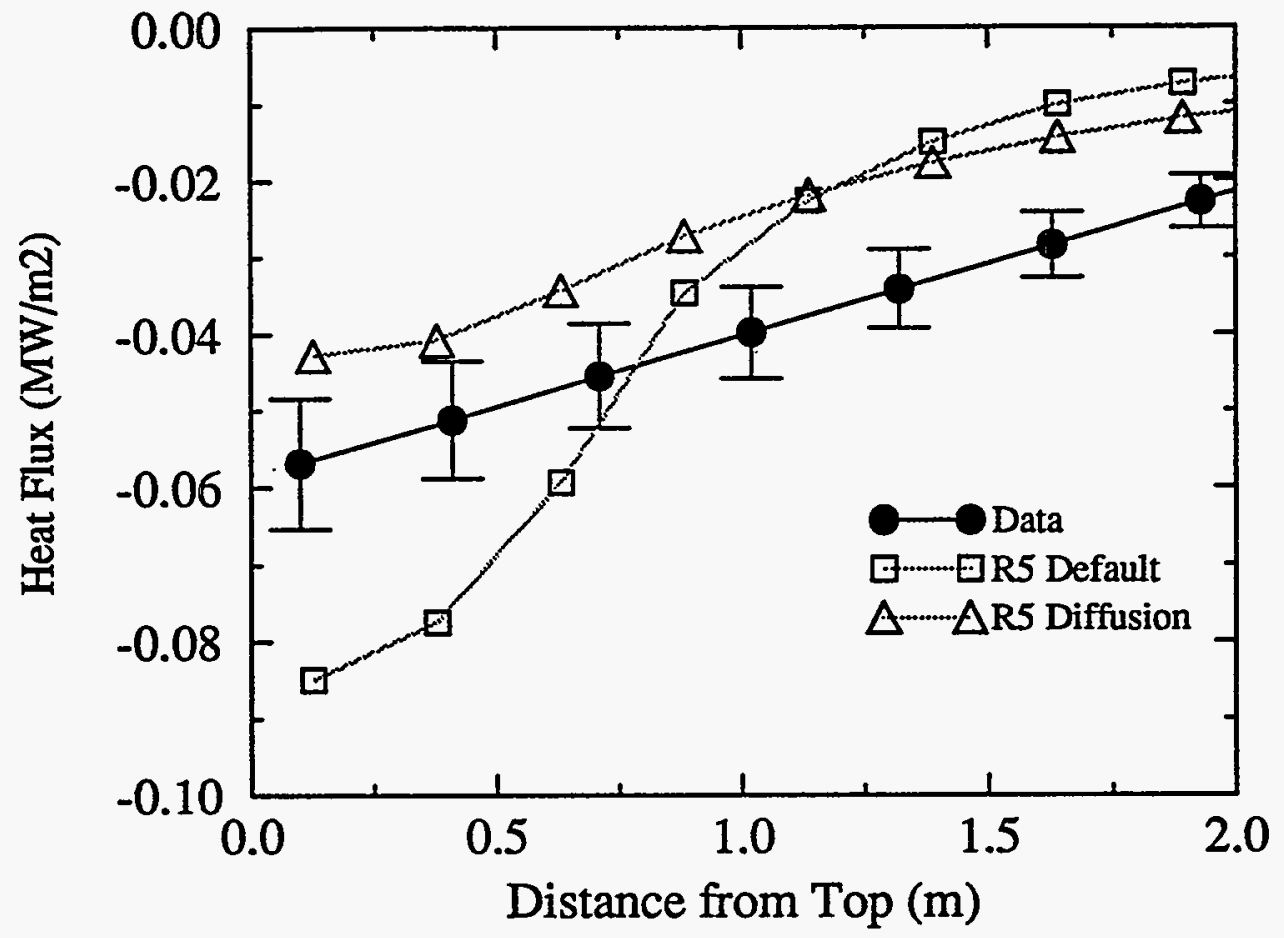

FIGURE C8. RELAP5 heat flux comparison with MIT-Siddique Test 28A 


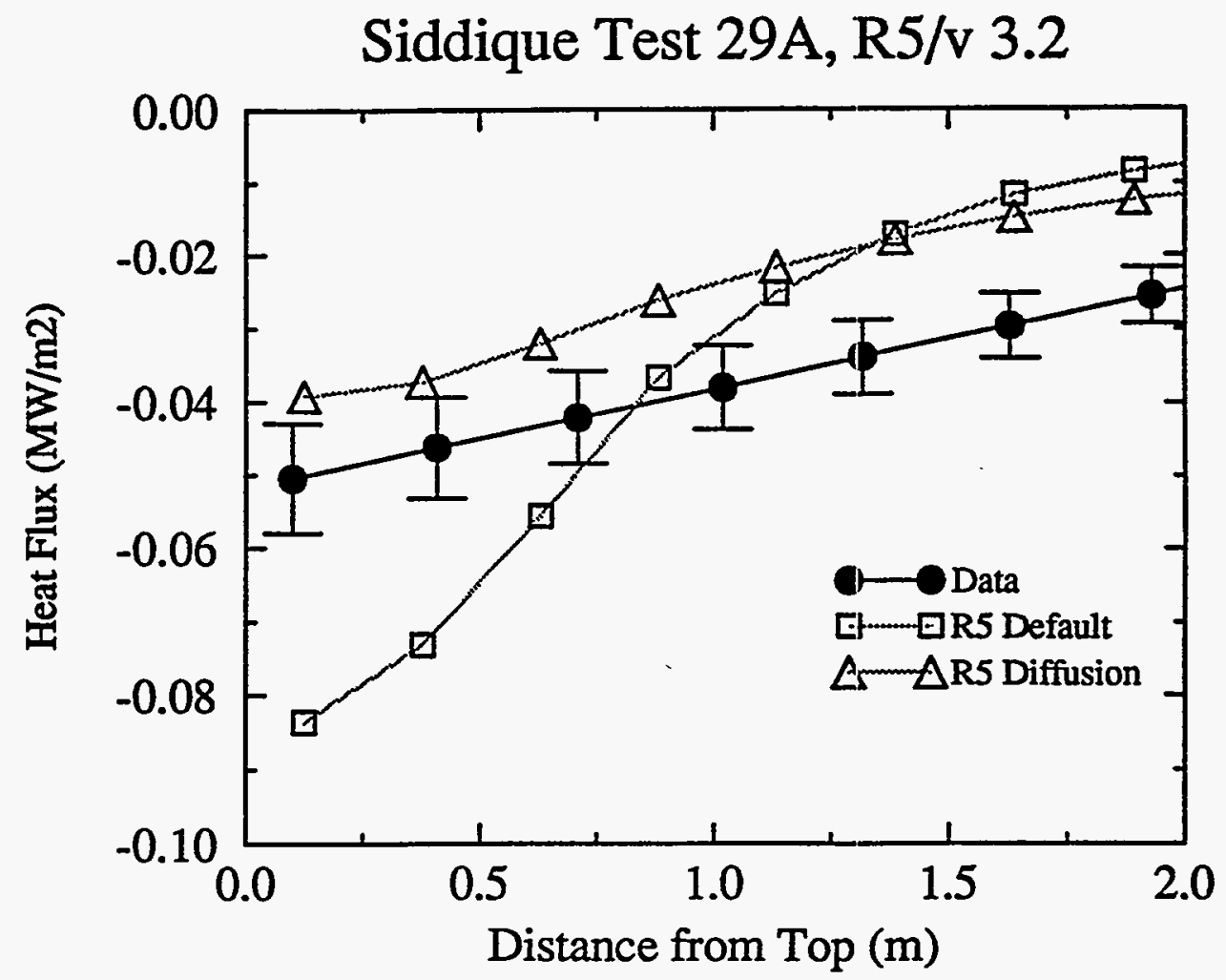

FIGURE C9. RELAP5 heat flux comparison with MIT-Siddique Test 29A

Siddique Test 31A, R5/v 3.2

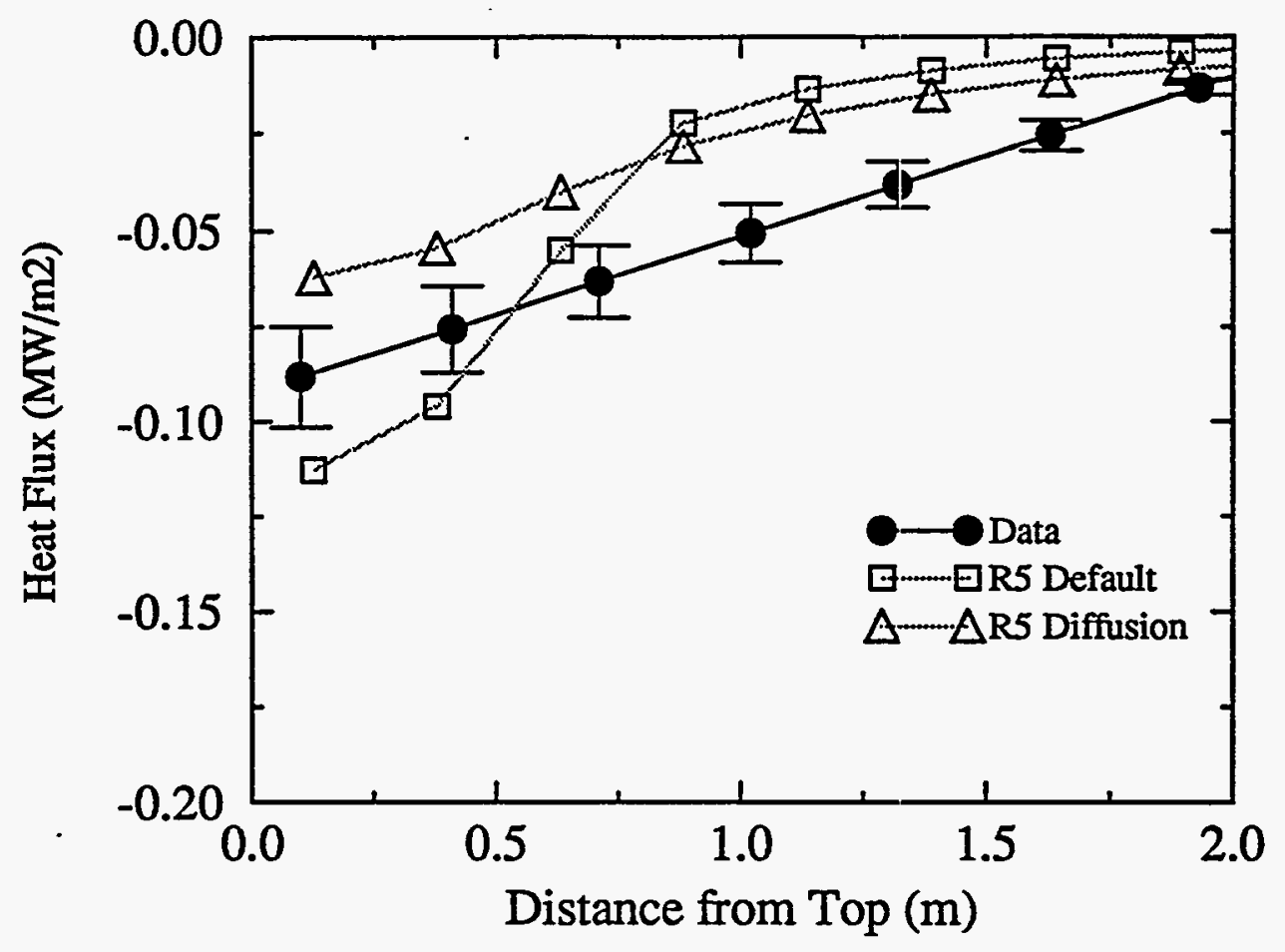

FIGURE C10. RELAP5 heat flux comparison with MIT-Siddique Test 31A 


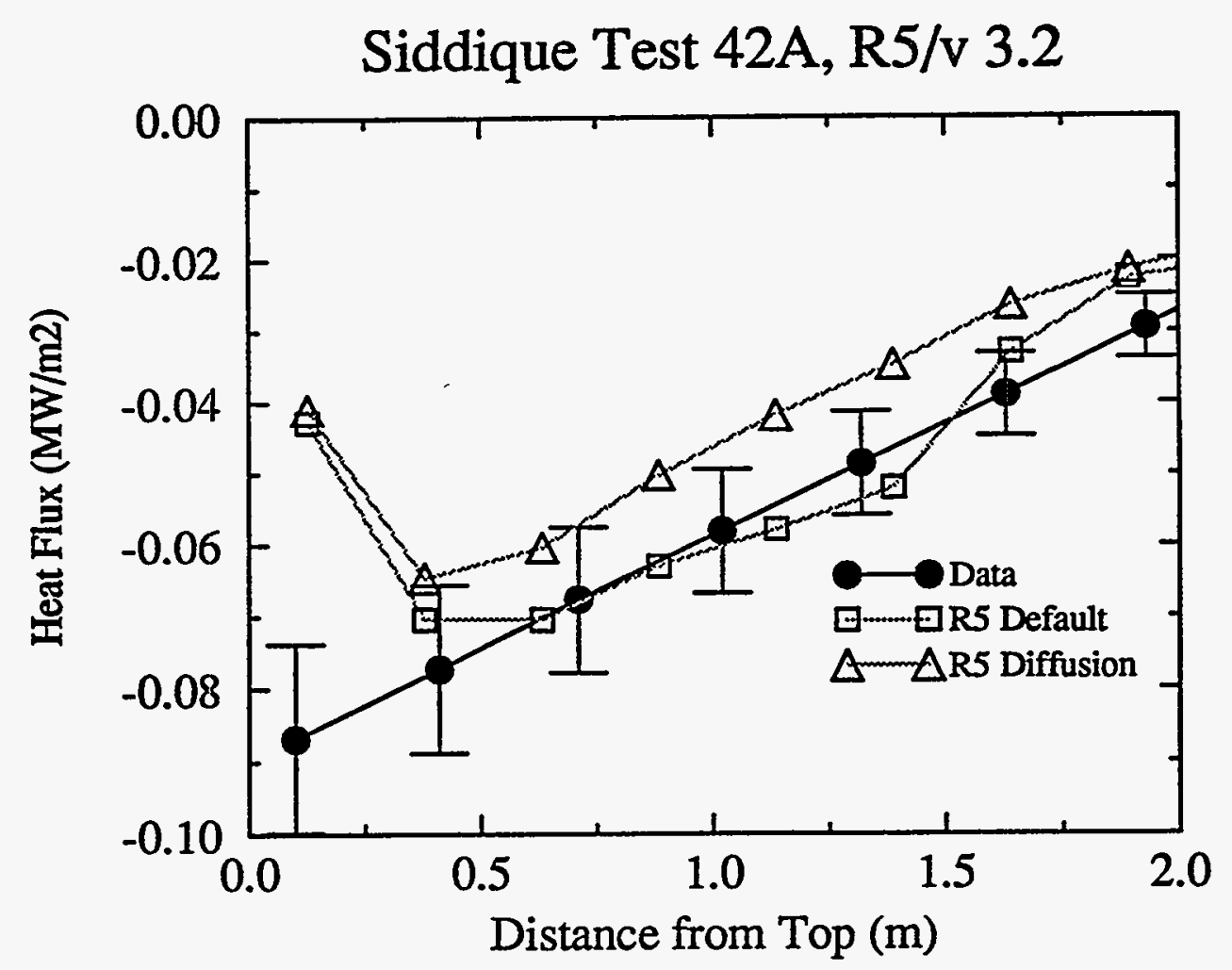

FIGURE C11. RELAP5 heat flux comparison with MIT-Siddique Test 42A

Siddique Test $6 \mathrm{H}, \mathrm{R} 5 / \mathrm{v} 3.2$

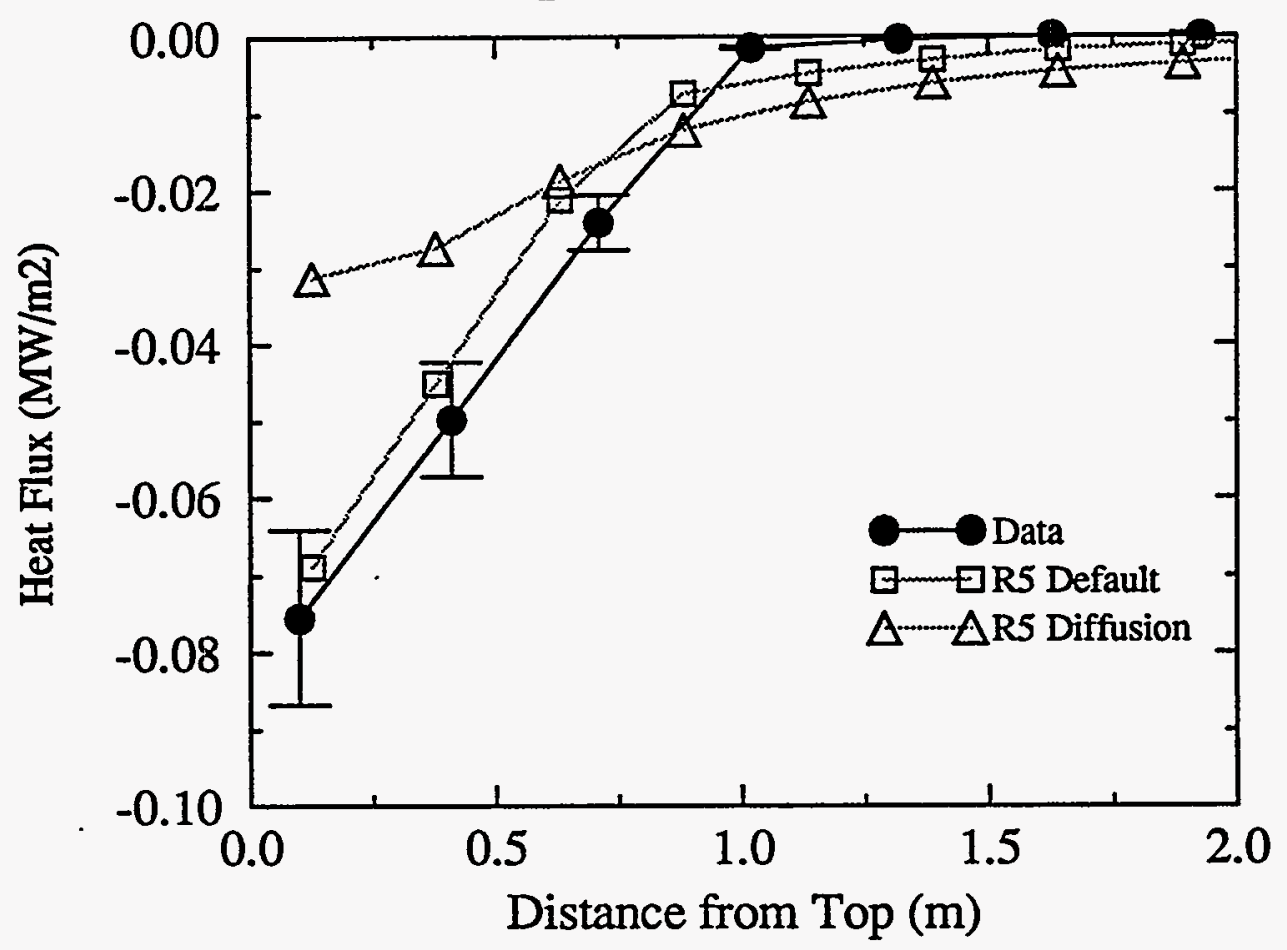

FIGURE C12. RELAP5 heat flux comparison with MIT-Siddique Test $6 \mathrm{H}$ 


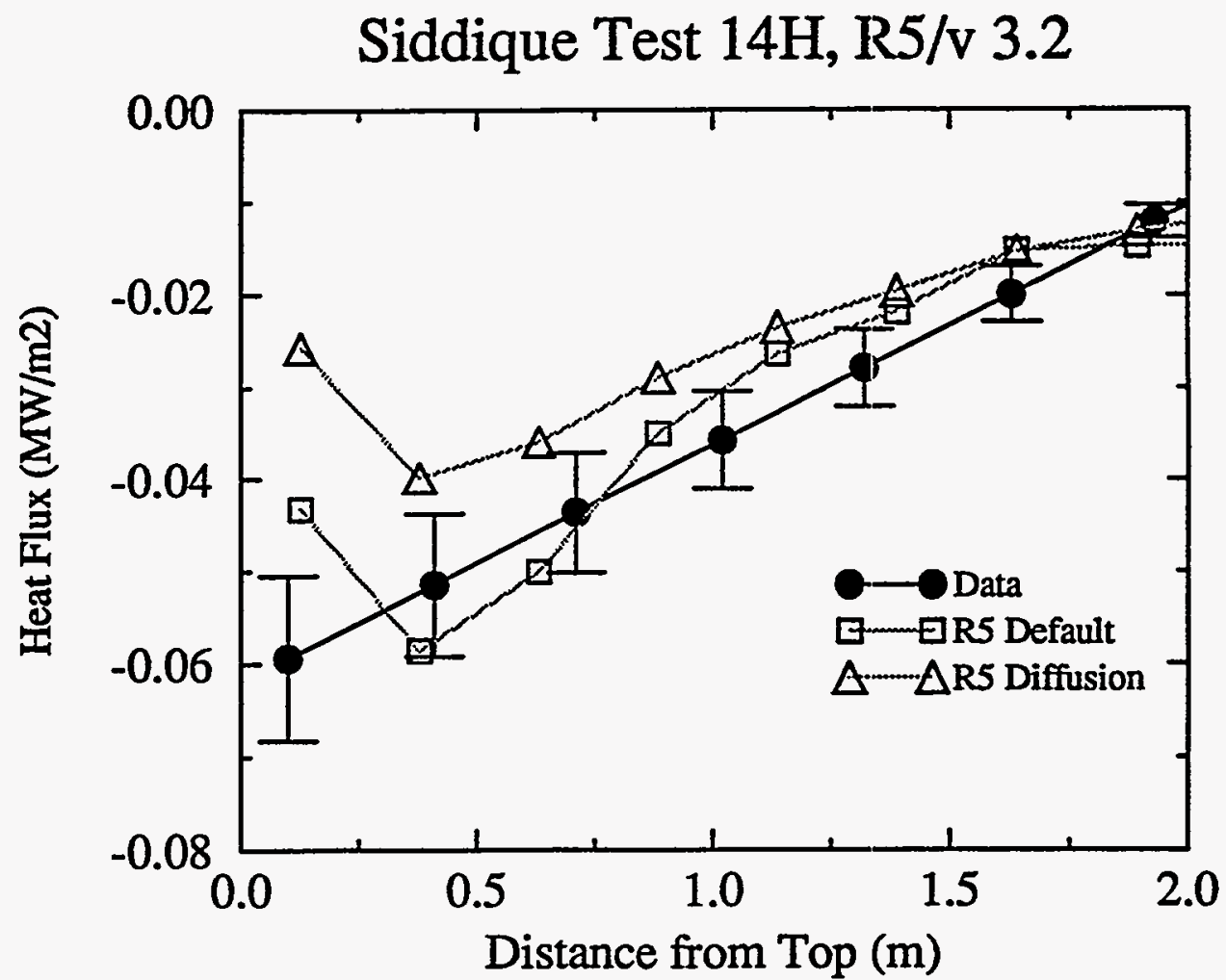

FIGURE C13. RELAP5 heat flux comparison with MT-Siddique Test 14H Siddique Test $16 \mathrm{H}, \mathrm{R} 5 / \mathrm{v} 3.2$

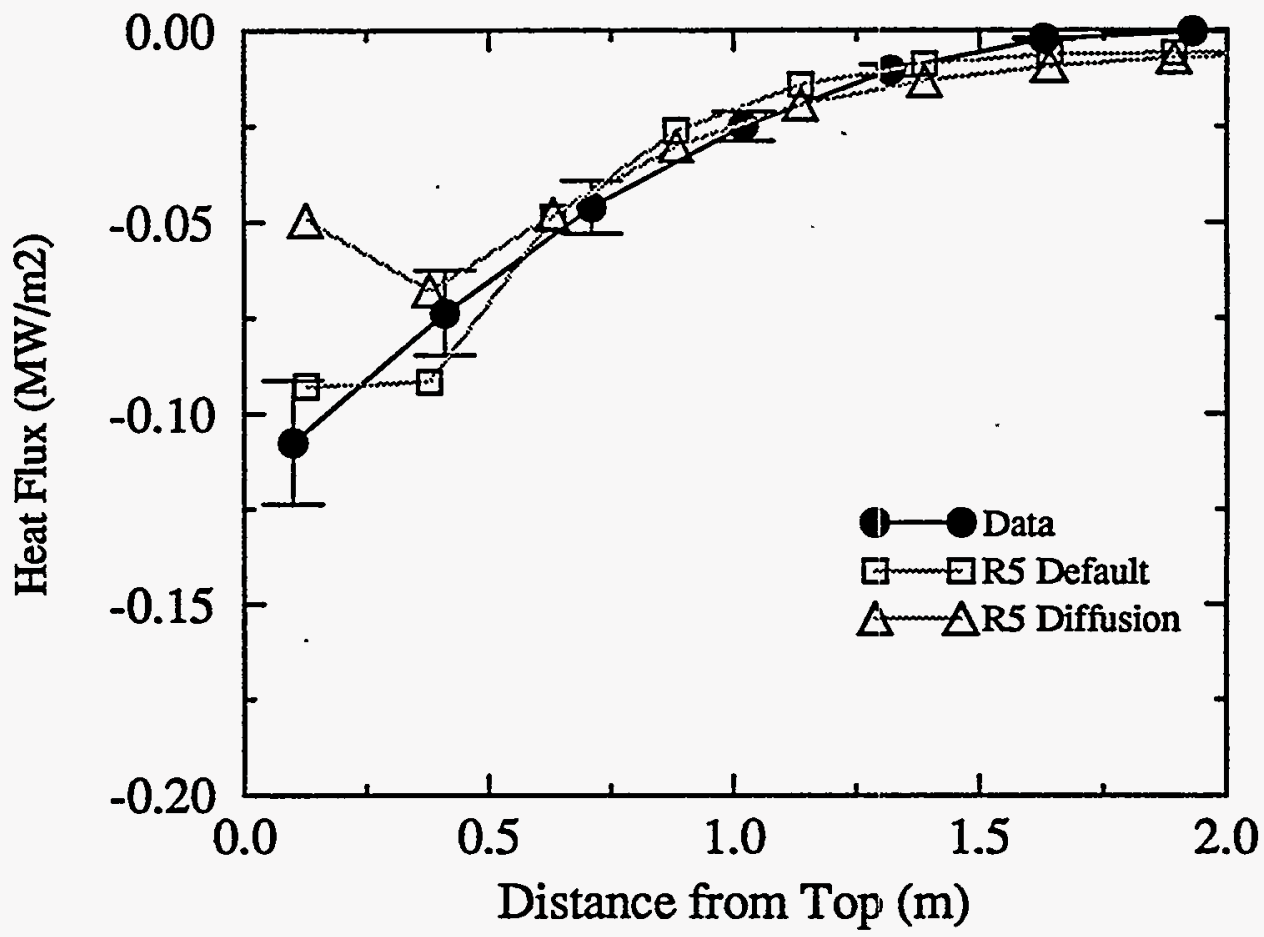

FIGURE C14. RELAP5 heat flux comparison with MITT-Siddique Test $16 \mathrm{H}$ 


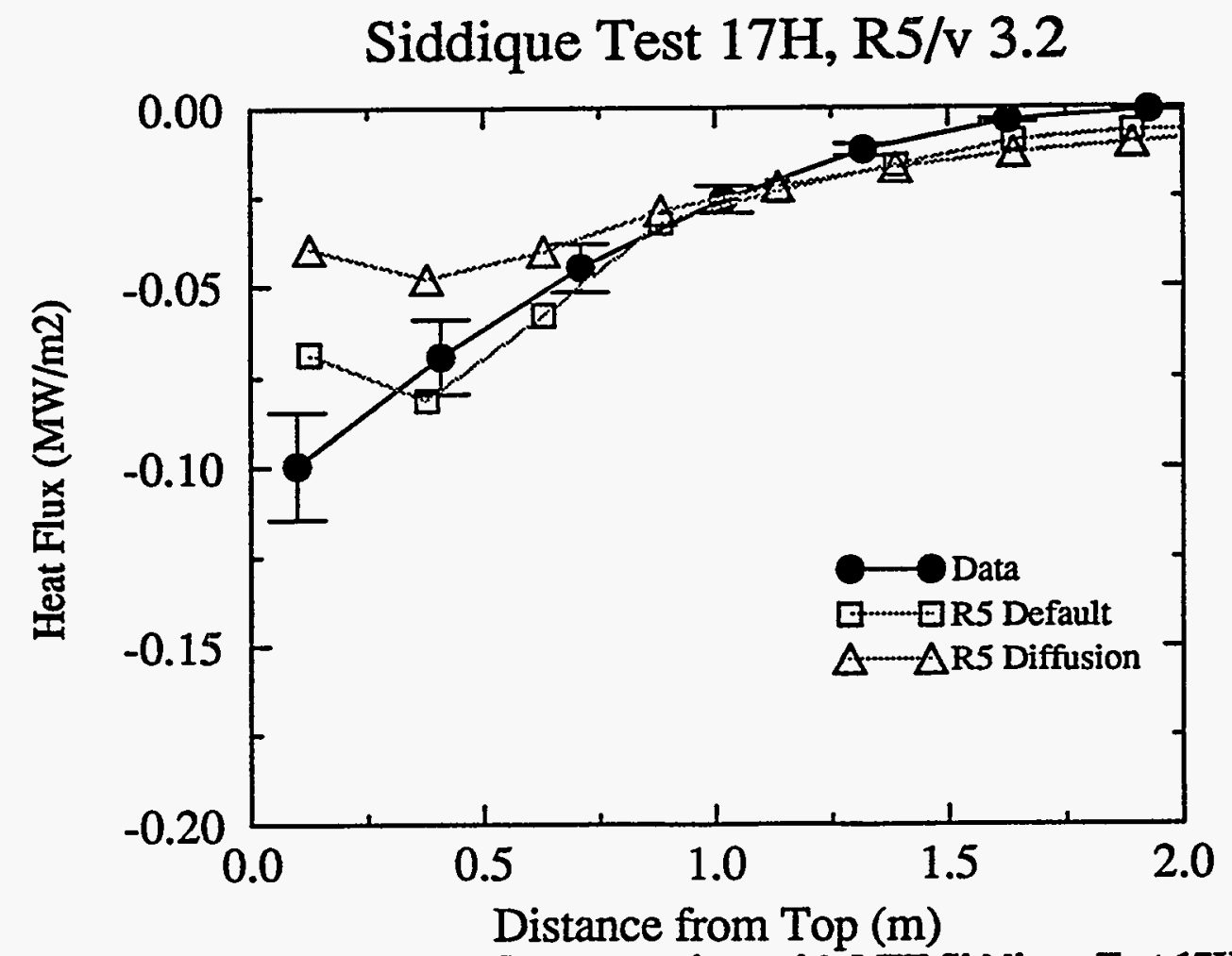

FIGURE C15. RELAP5 heat flux comparison with MIT-Siddique Test 17H

Siddique Test 18H, R5/v 3.2

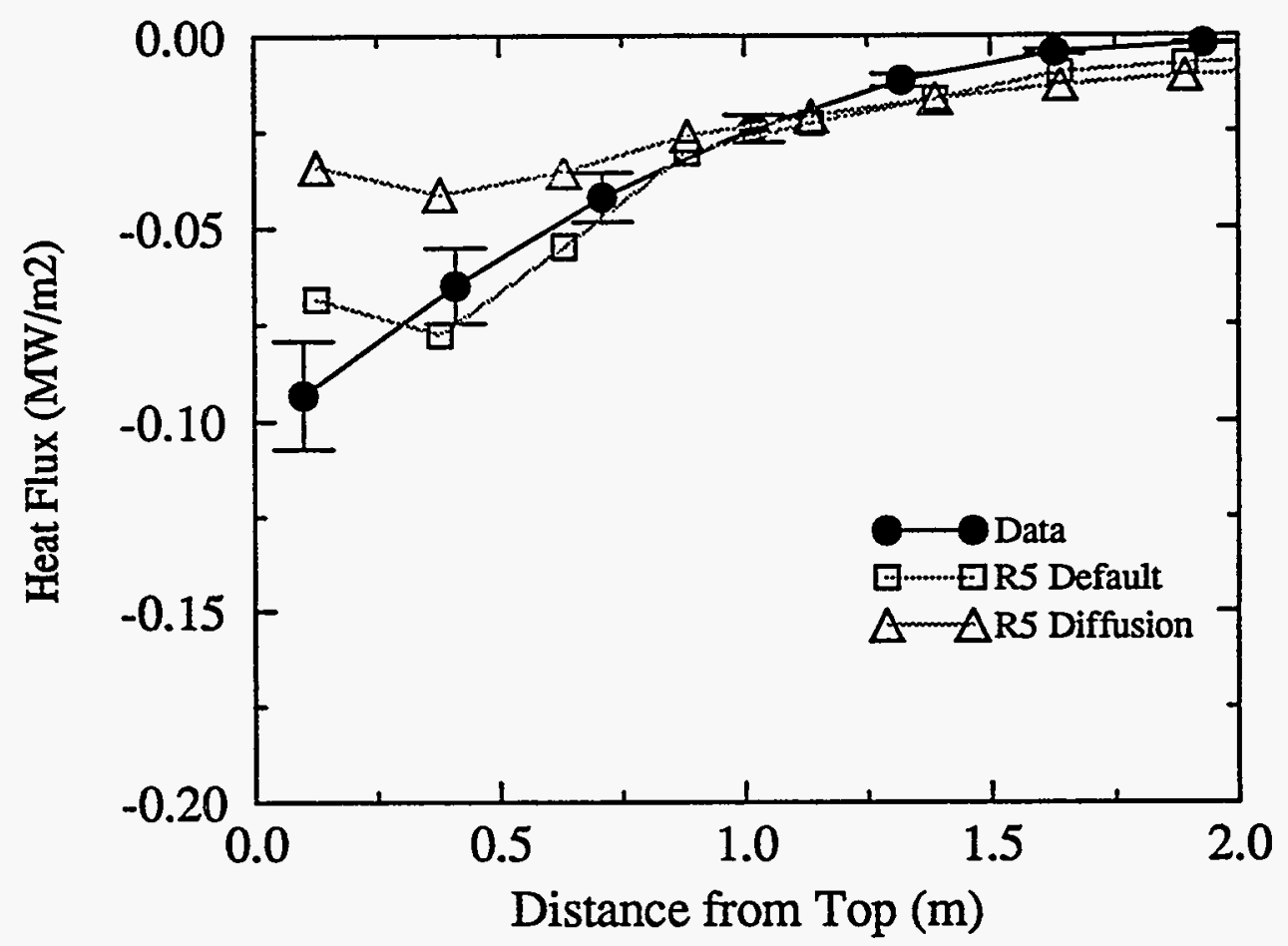

FIGURE C16. RELAP5 heat flux comparison with MIT-Siddique Test 18H 
Siddique Test 19H, R5/v 3.2

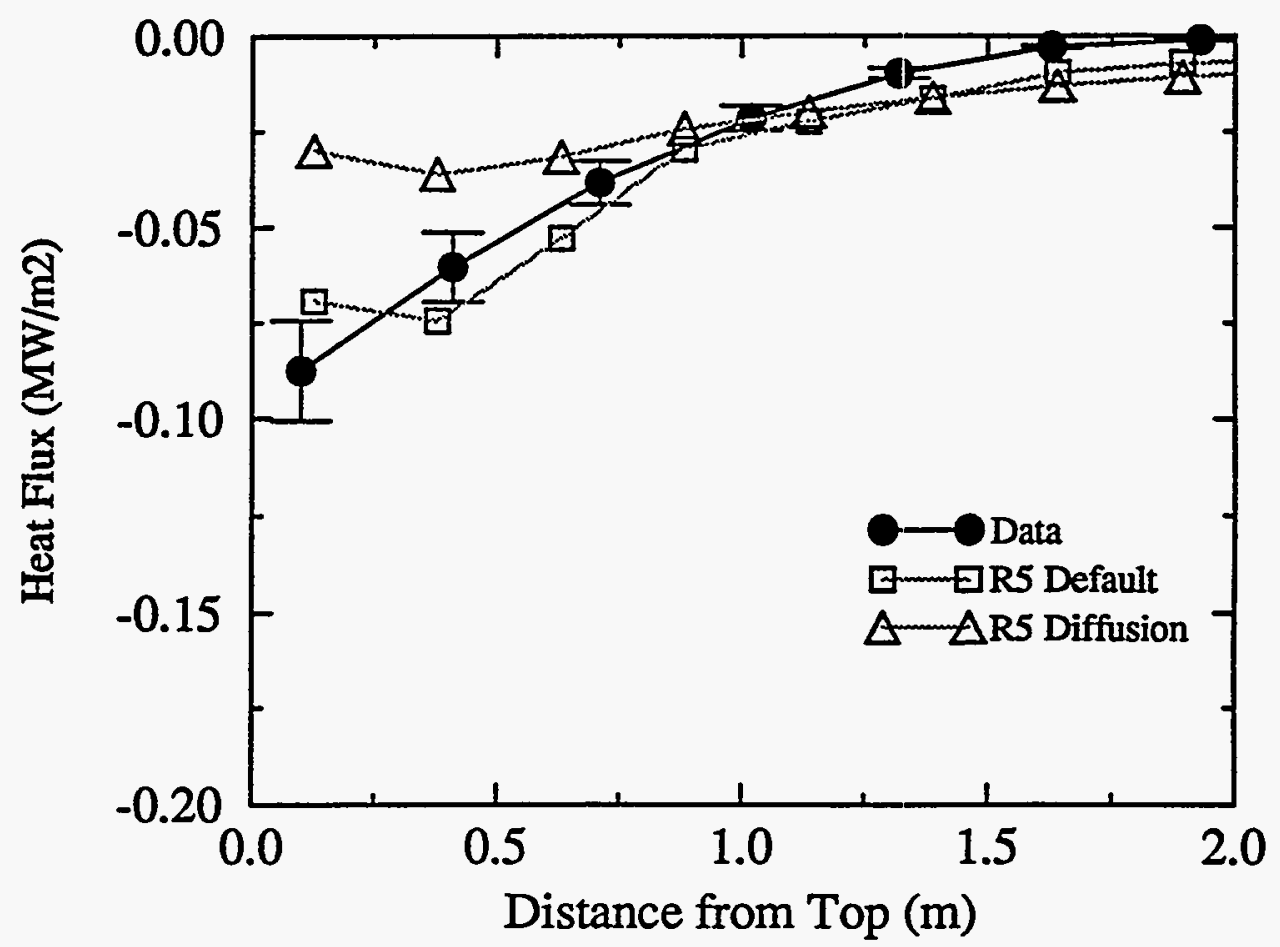

FIGURE C17. RELAP5 heat flux comparison with MTT-Siddique Test 19H

Siddique Test 22H, R5/v 3.2

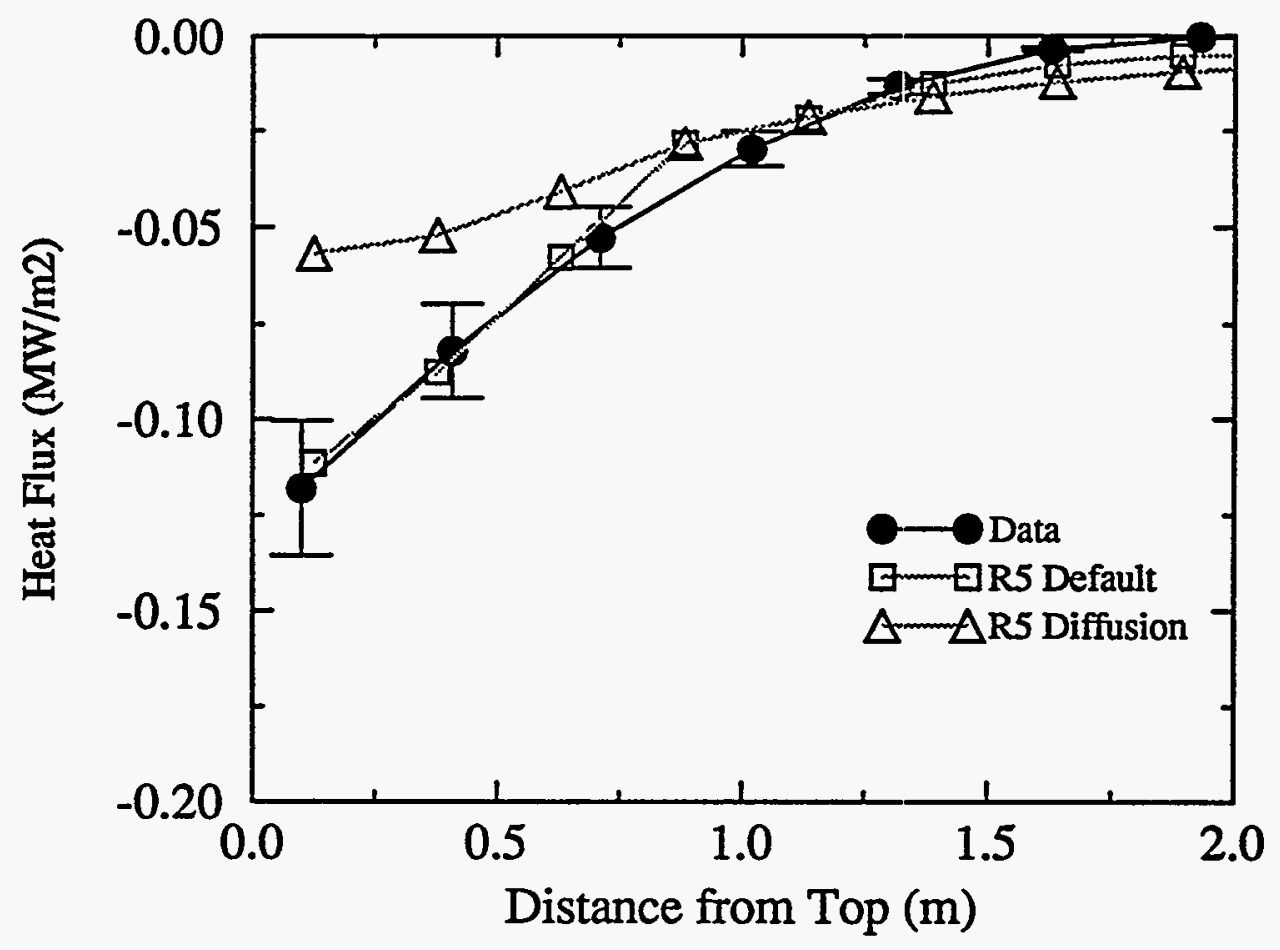

FIGURE C18. RELAP5 heat flux comparison with MIT-Siddique Test 22H 


\section{APPENDIX D}

\section{MIT Wall Condensation NC Quality Comparisons with RELAP5/MOD3.2}


Siddique Test $7 A, \mathrm{R} .5 / \mathrm{v} 3.2$

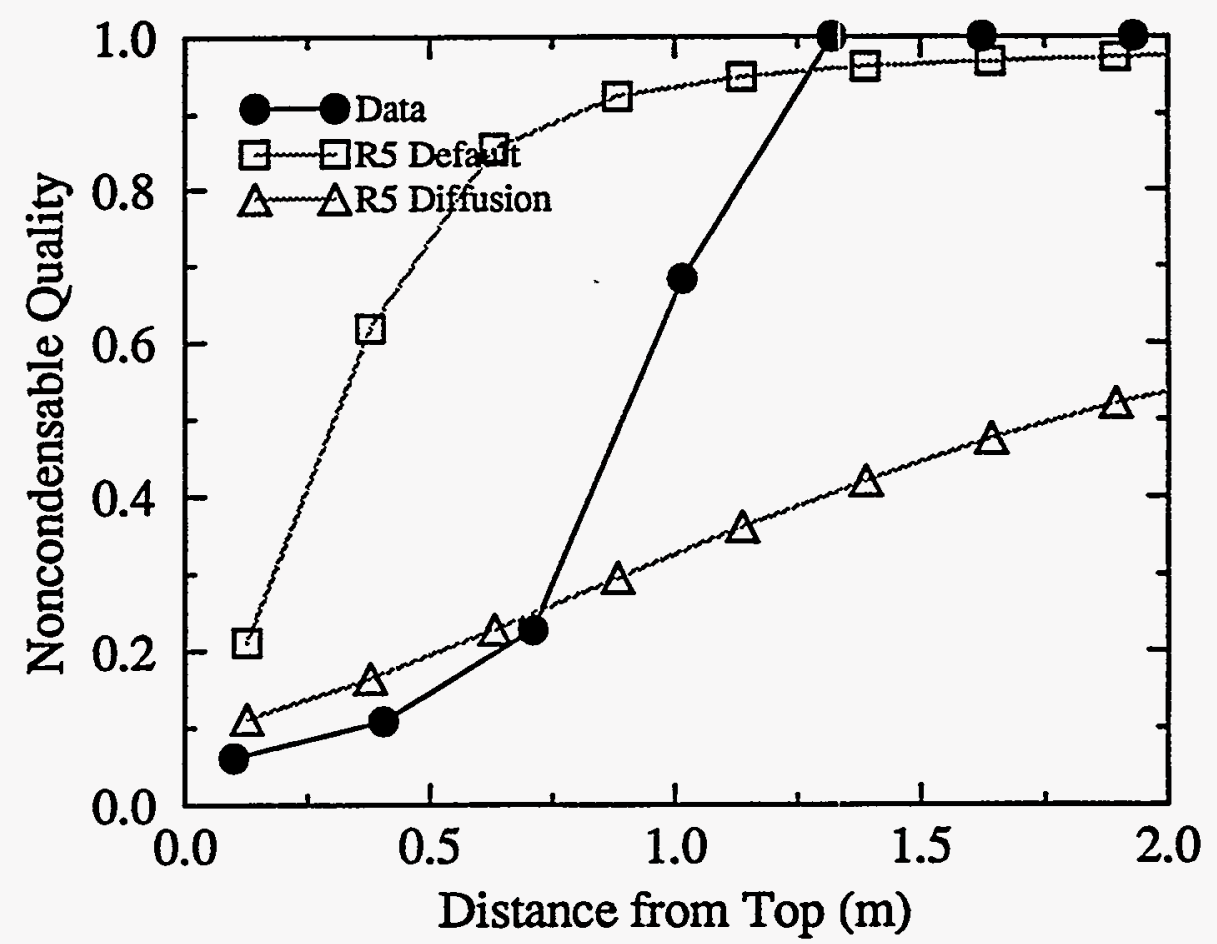

FIGURE D1. RELAP5 NC quality comparison with MIT-Siddique Test 7A. Siddique Test 8A, R5/v 3.2

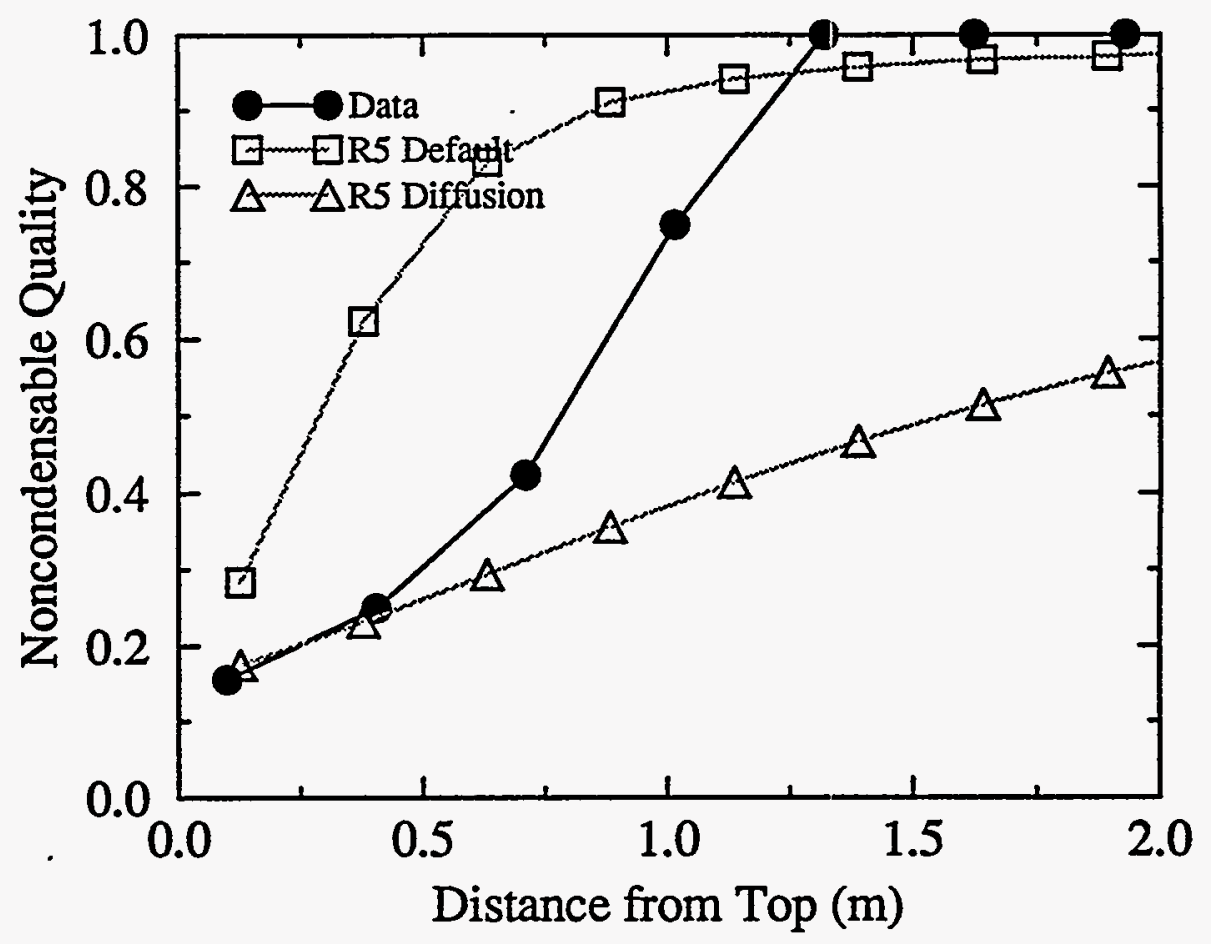

FIGURE D2. RELAP5 NC quality comparison with MIT-Siddique Test 8A. 
Siddique Test 19A, R5/v 3.2

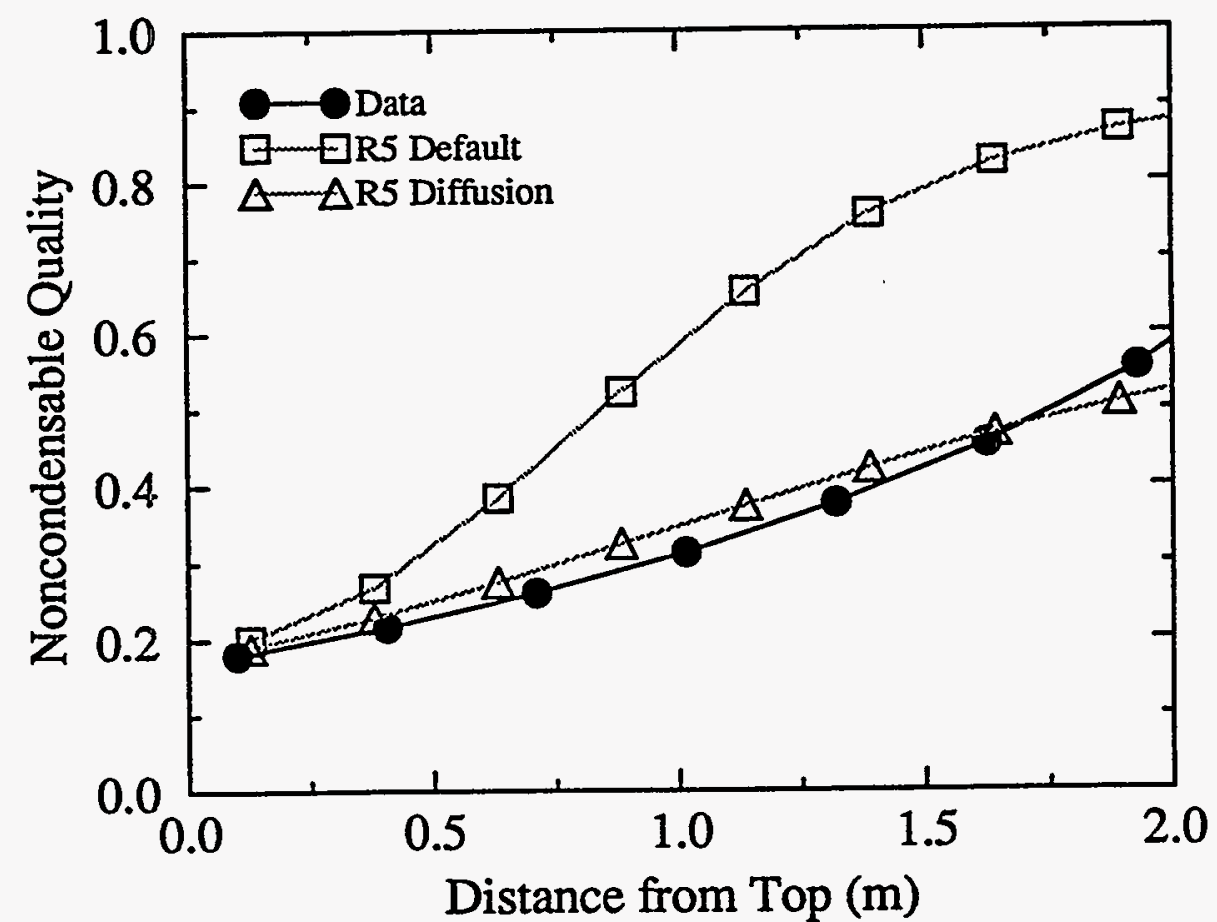

FIGURE D3. RELAP5 NC quality comparison with MIT-Siddique Test 19A.

Siddique Test 24A, R5/v 3.2

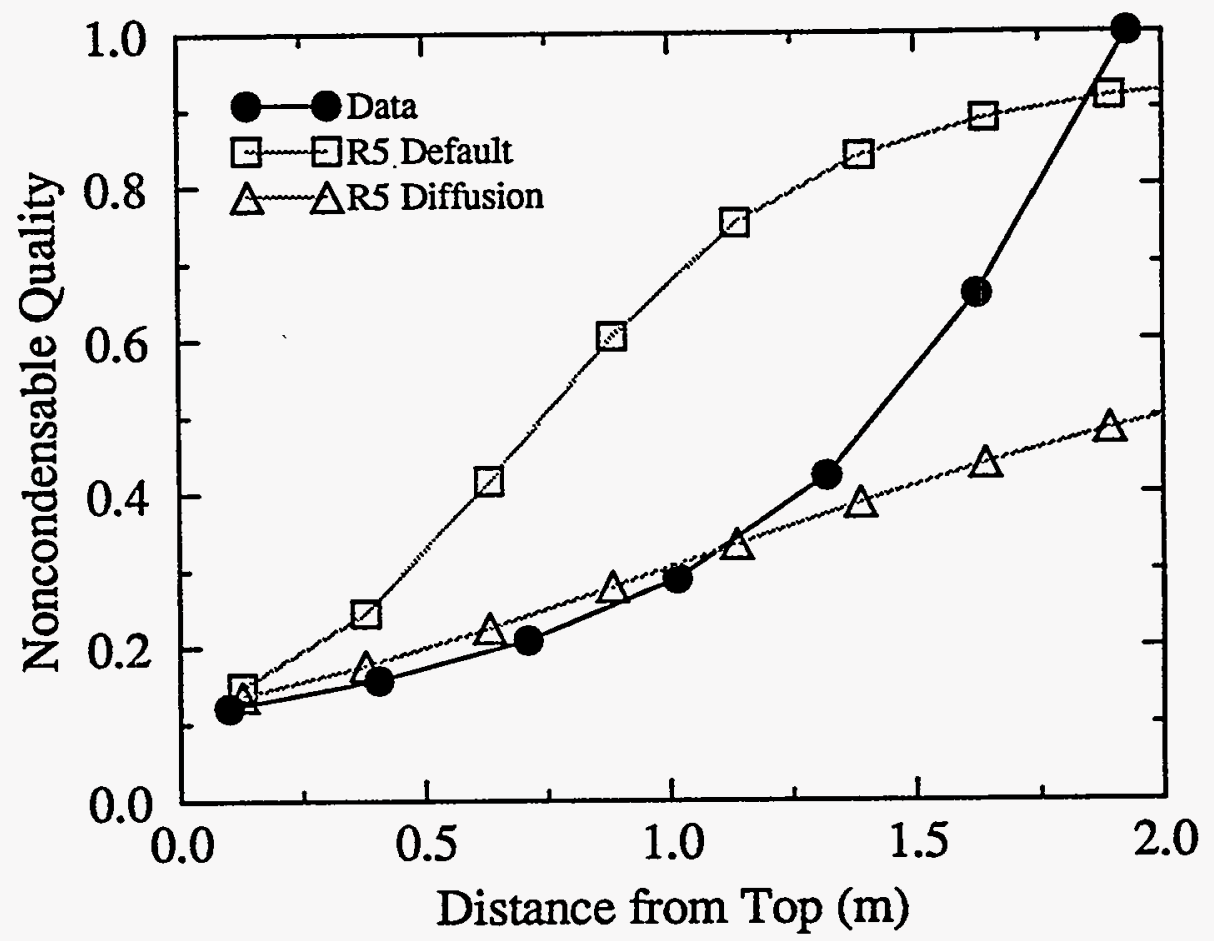

FIGURE D4. RELAP5 NC quality comparison with MTT-Siddique Test 24A. 


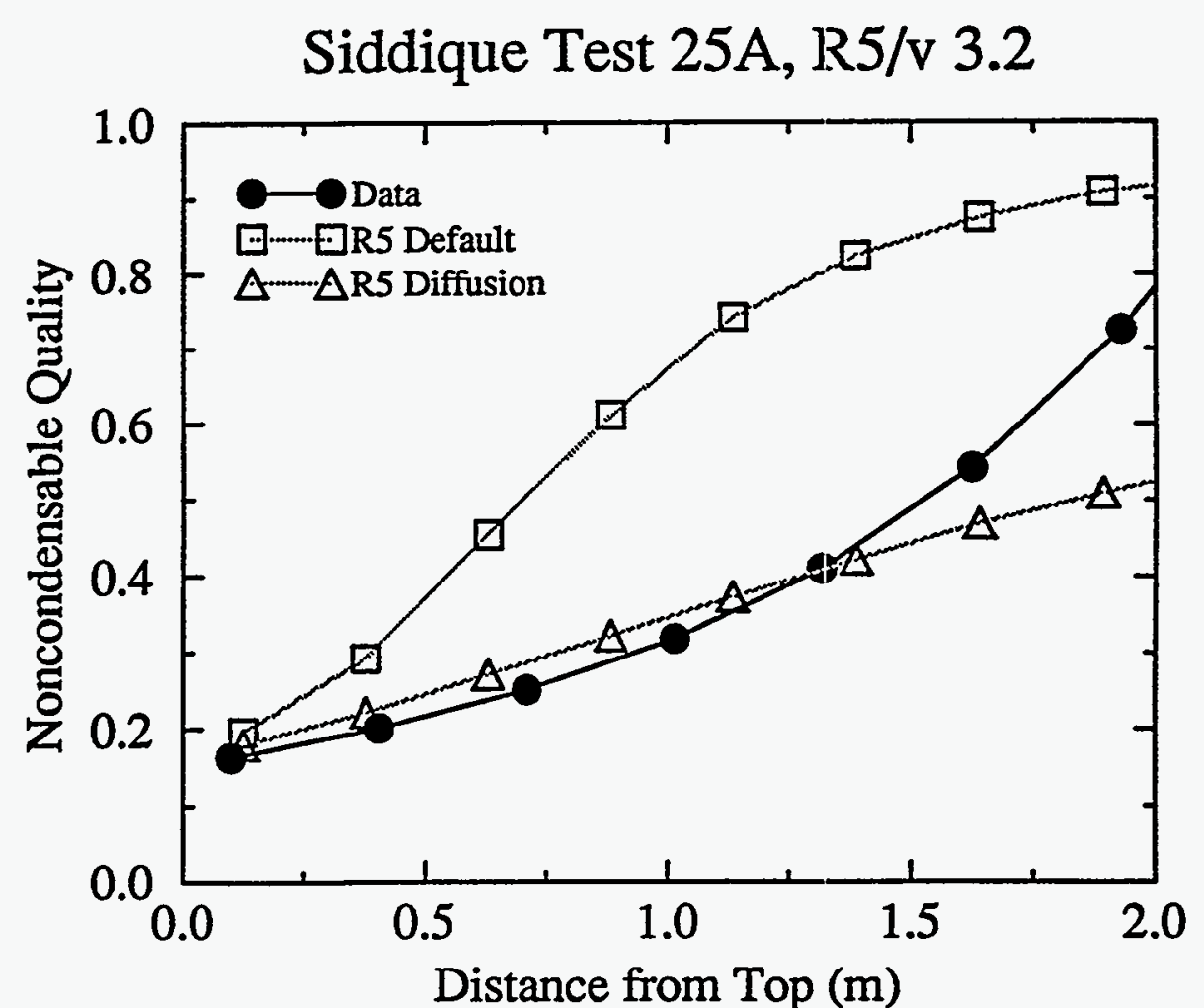

FIGURE D5. RELAP5 NC quality comparison with MIT-Siddique Test 25A.

Siddique Test 26A, R5/v 3.2

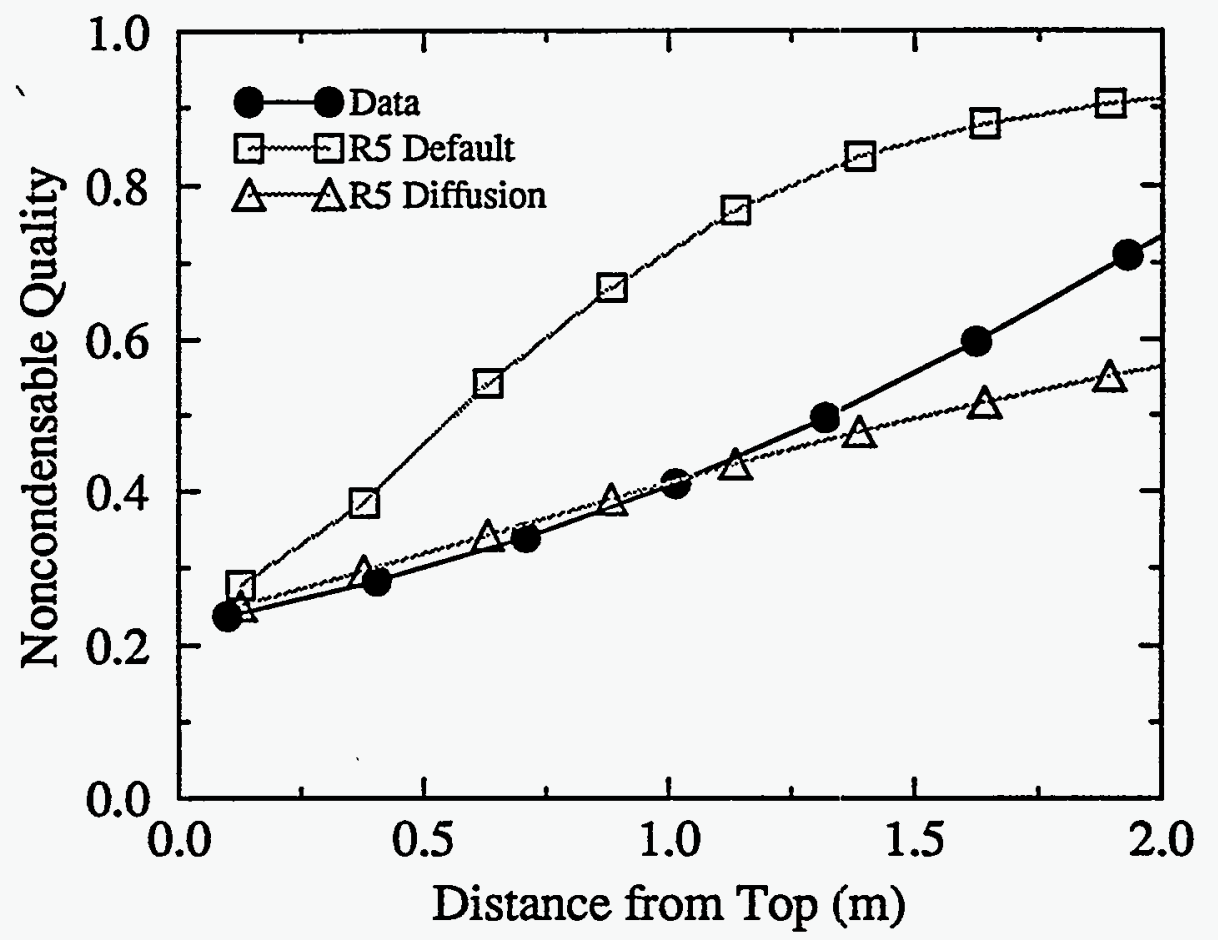

FIGURE D6. RELAP5 NC quality comparison with MIT-Siddique Test 26A. 


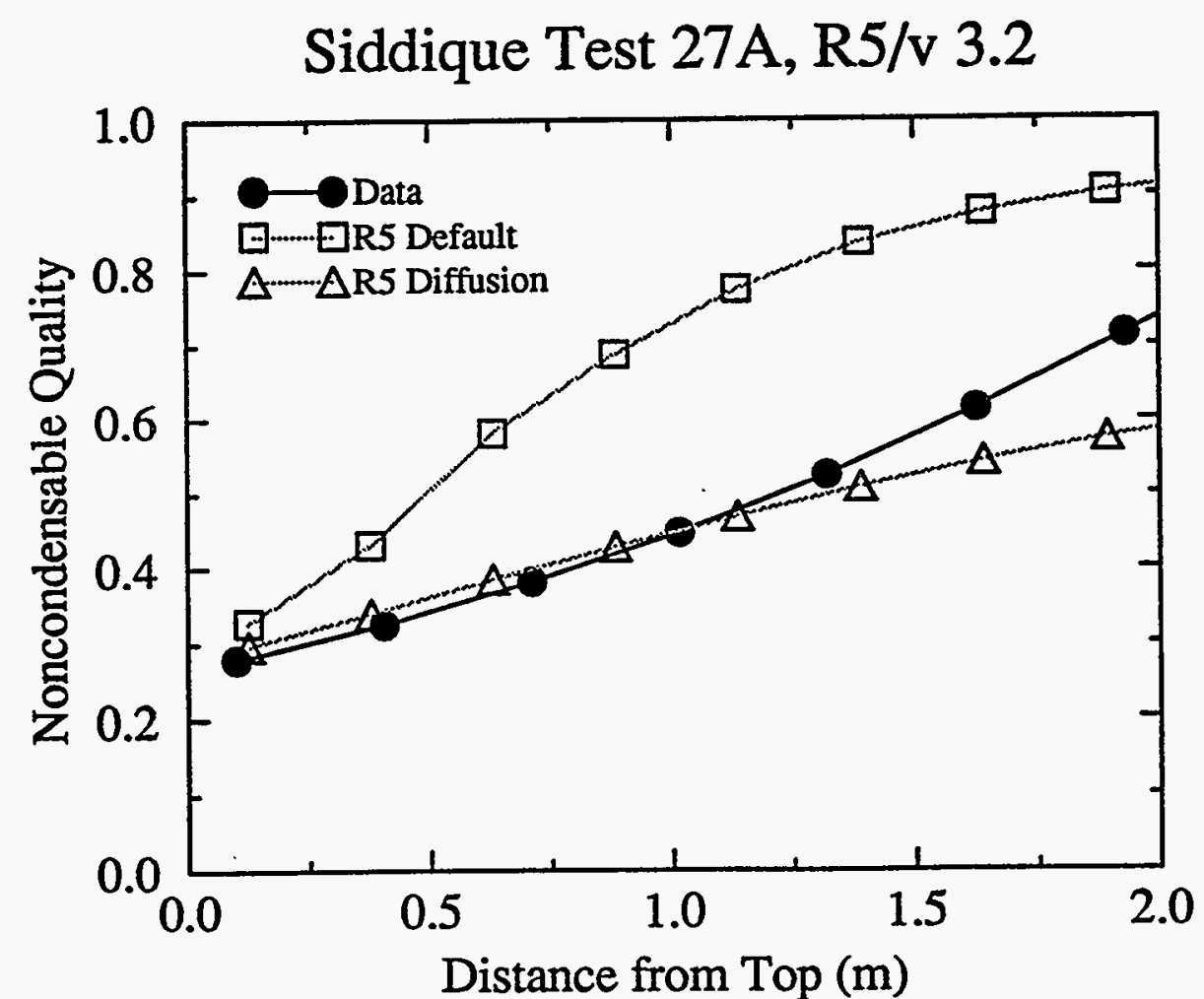

FIGURE D7. RELAP5 NC quality comparison with MIT-Siddique Test 27A. Siddique Test 28A, R5/v 3.2

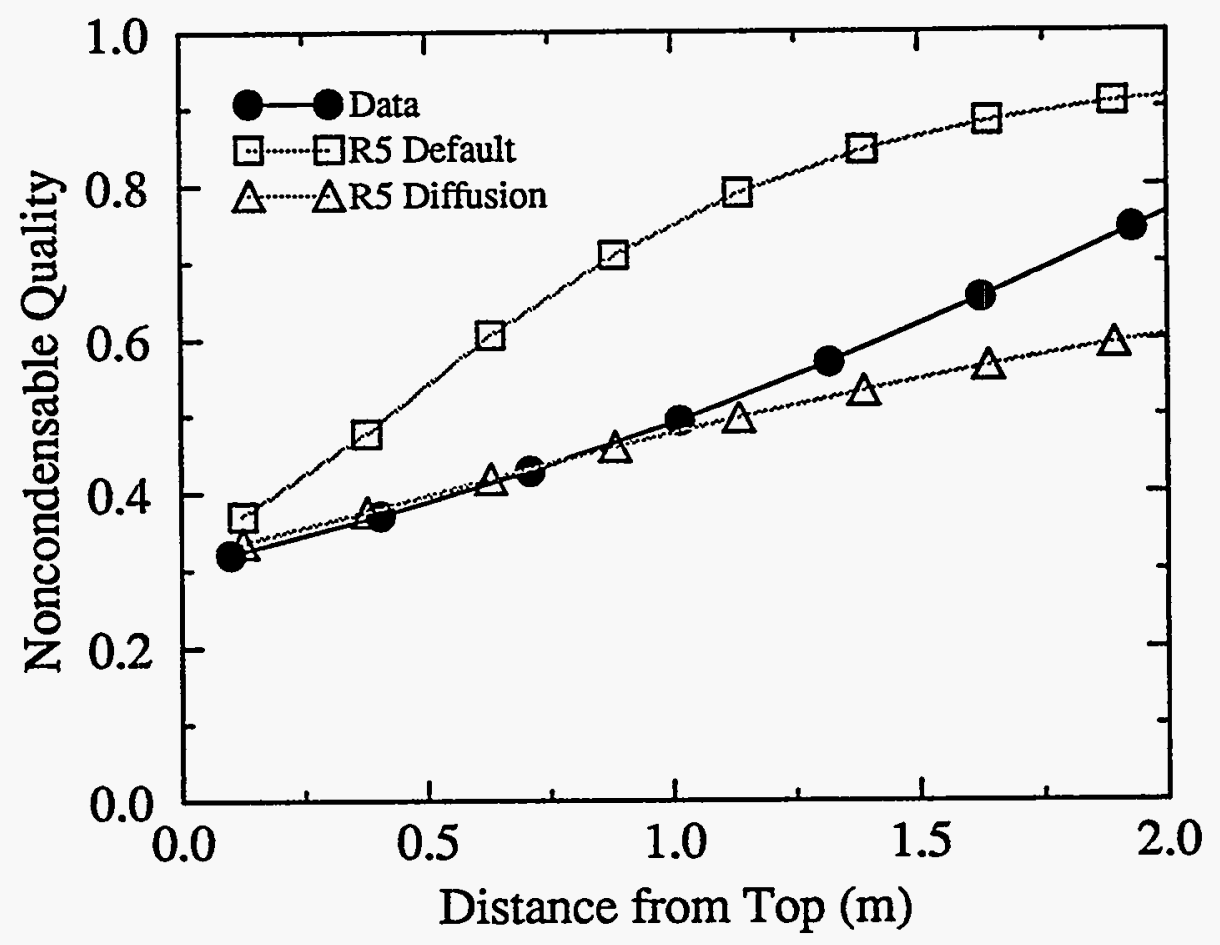

FIGURE D8. RELAP5 NC quality comparison with MIT-Siddique Test 28A. 
Siddique Test 29A, R5/v 3.2

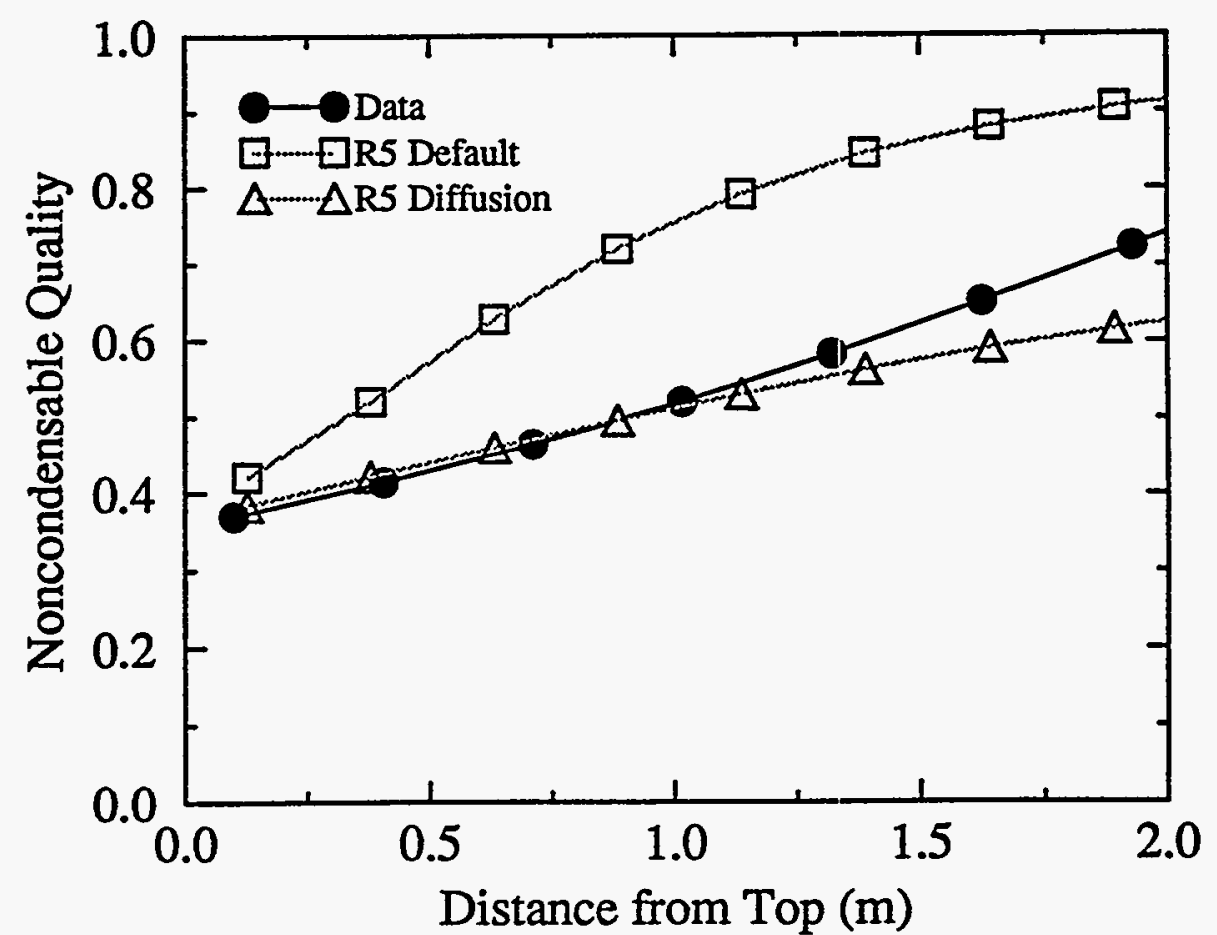

FIGURE D9. RELAP5 NC quality comparison withMIT-Siddique Test 29A.

Siddique Test 31A, R5/v 3.2

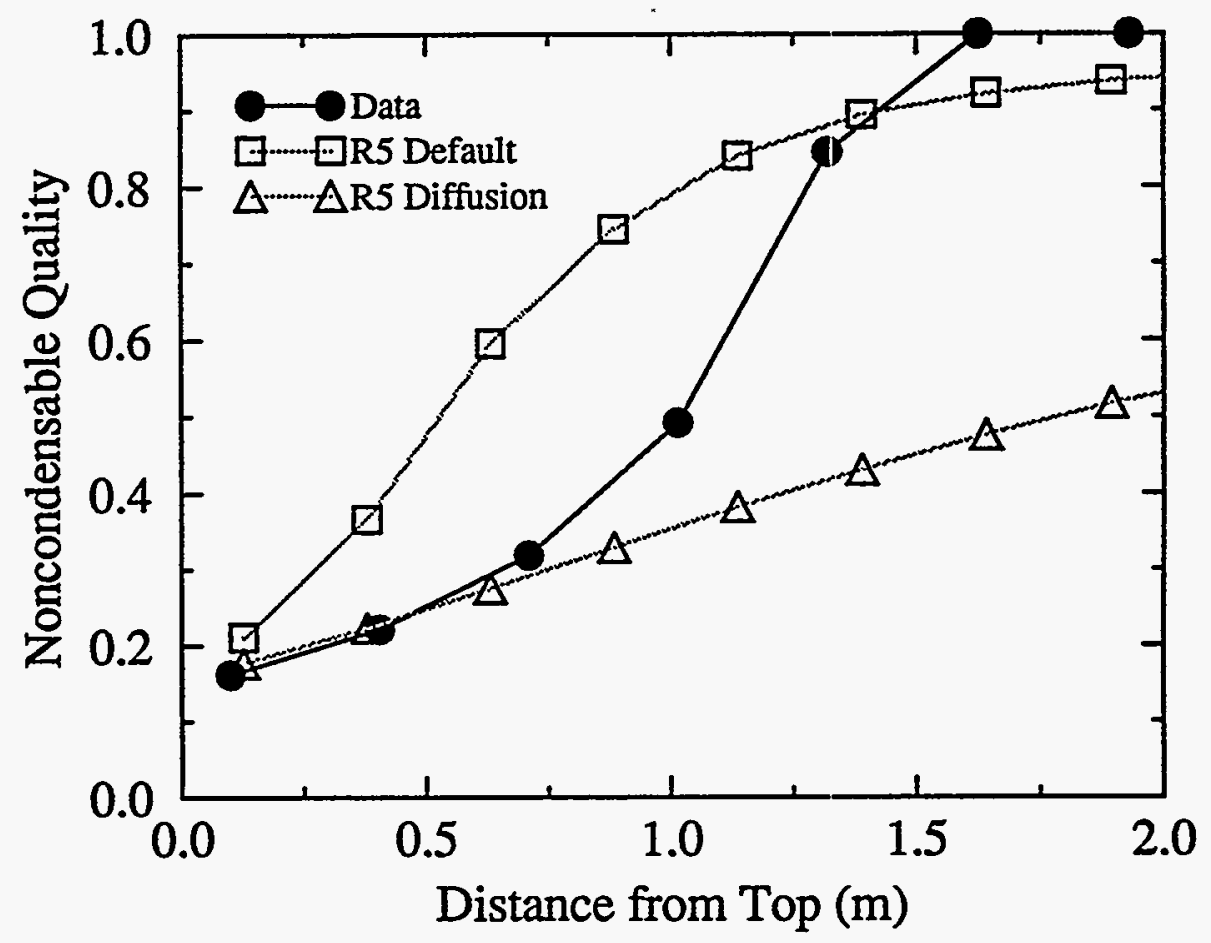

FIGURE D10. RELAP5 NC quality comparison with MIT-Siddique Test 31A. 


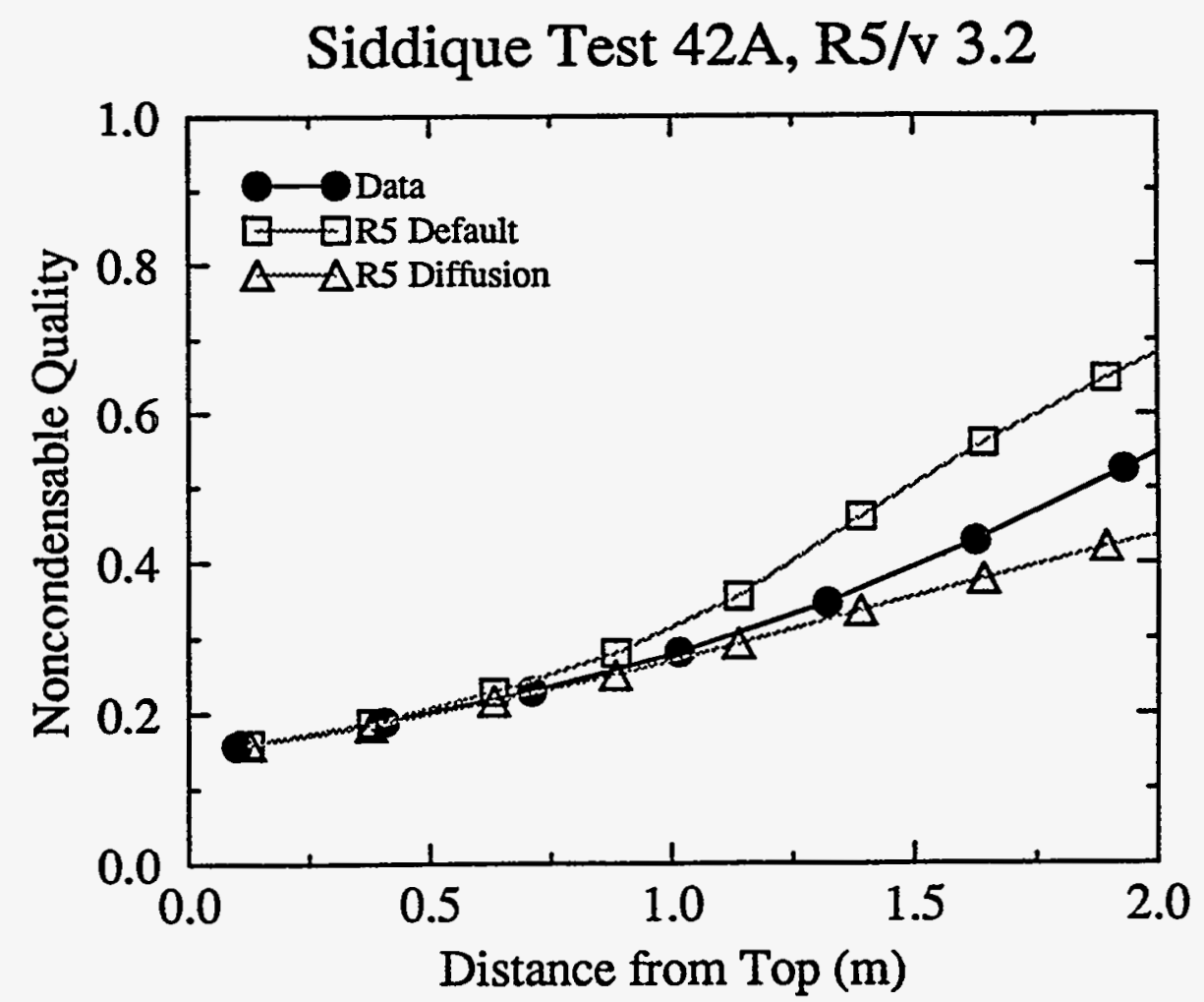

FIGURE D11. RELAP5 NC quality comparison with MIT-Siddique Test 42A.

Siddique Test $6 \mathrm{H}, \mathrm{R} 5 / \mathrm{v} 3.2$

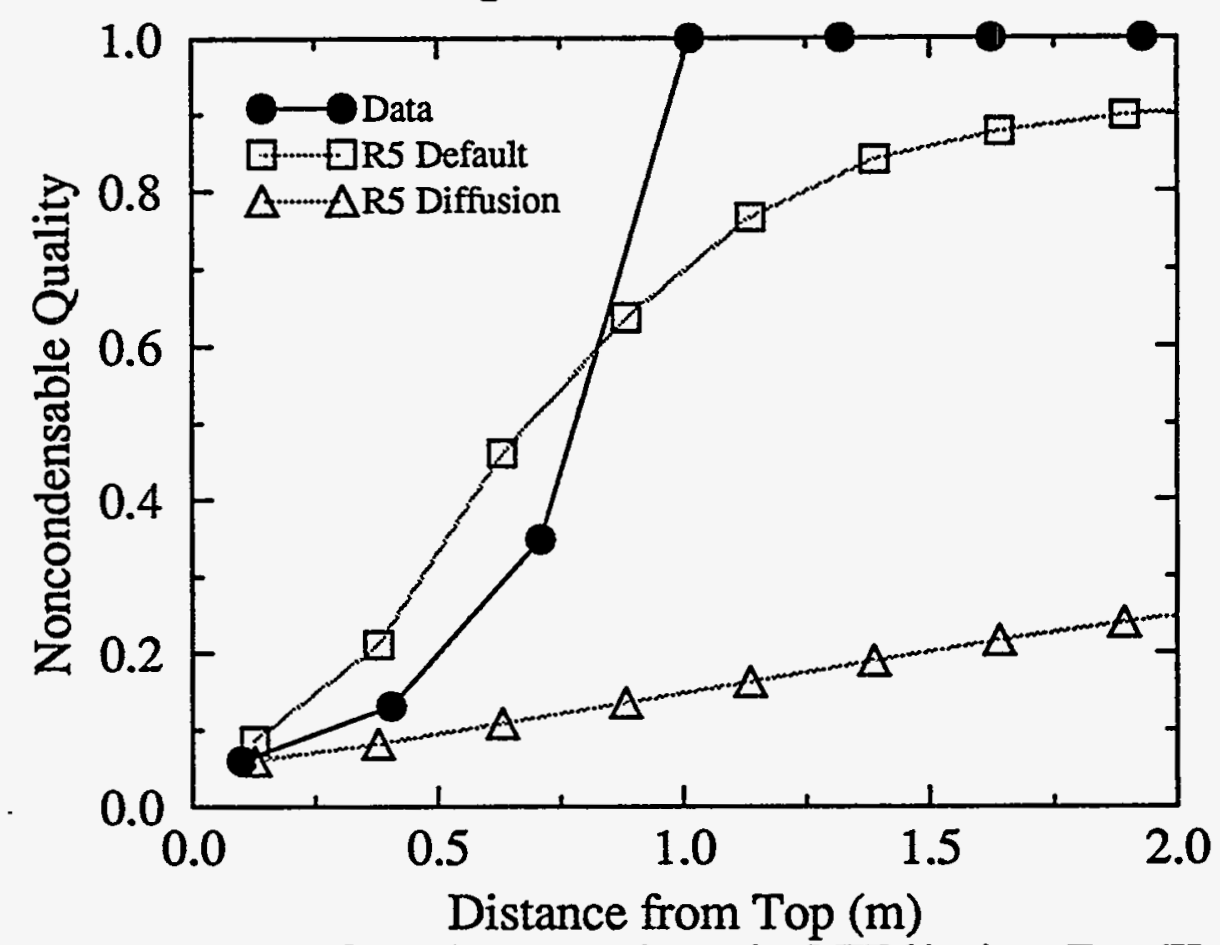

FIGURE D12. RELAP5 NC quality comparison with MIT-Siddique Test $6 \mathrm{H}$. 
Siddique Test $14 \mathrm{H}, \mathrm{R} 5 / \mathrm{v} 3.2$

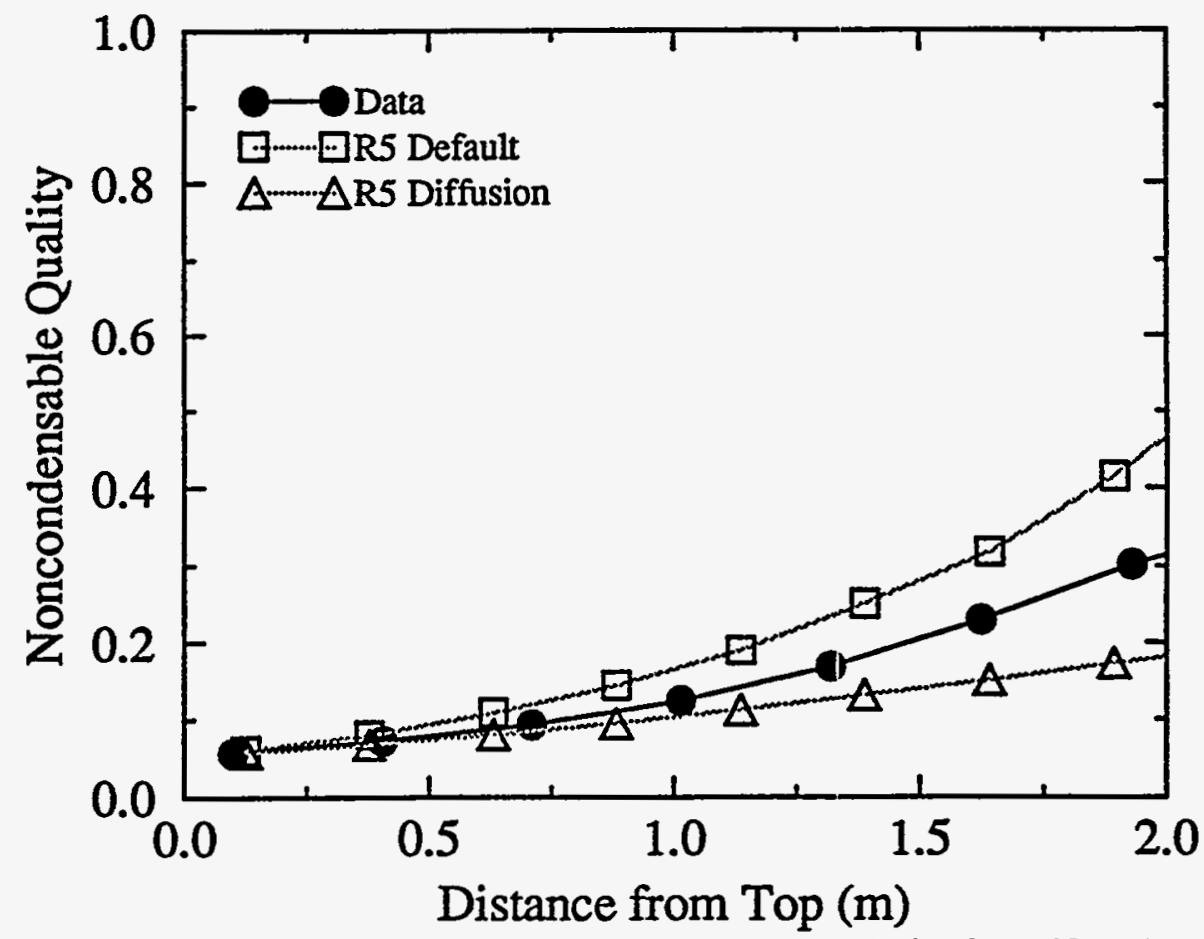

FIGURE D13. RELAP5 NC quality comparison with MIT-Siddique Test $14 H$.

Siddique Test $16 \mathrm{H}, \mathrm{R} 5 / \mathrm{v} 3.2$

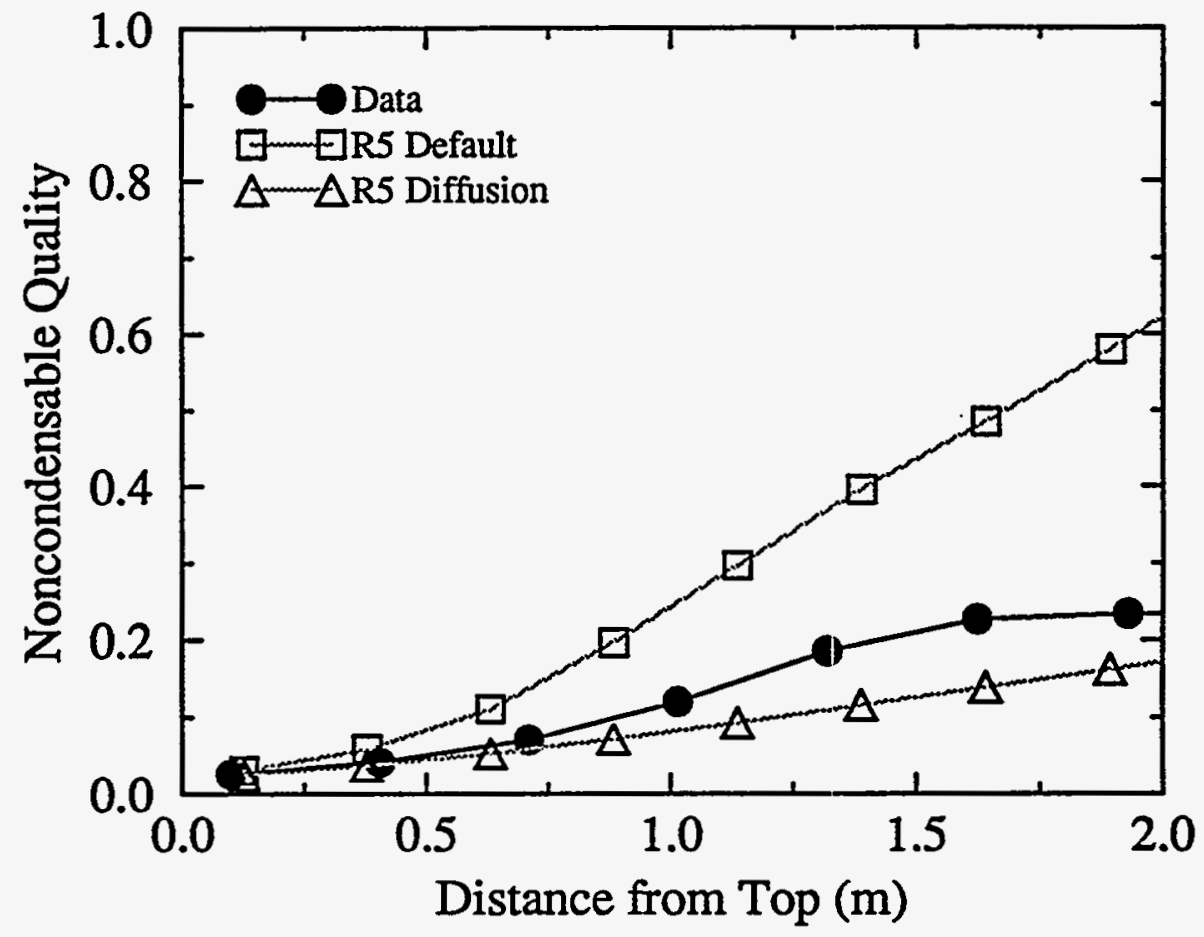

FIGURE D14. RELAP5 NC quality comparison with MIT-Siddique Test $16 \mathrm{H}$. 


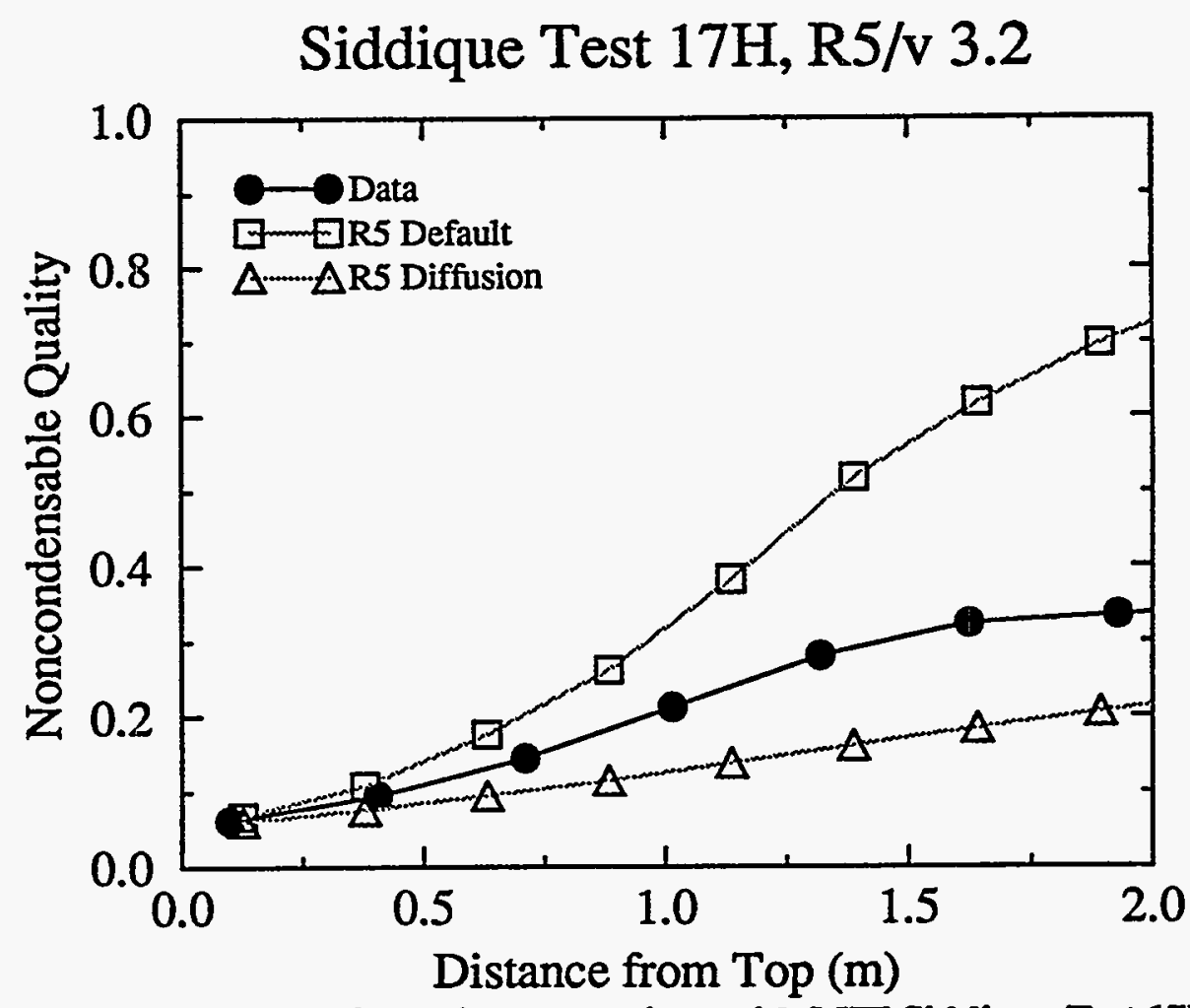

FIGURE D15. RELAP5 NC quality comparison with MIT-Siddique Test 17H.

Siddique Test $18 \mathrm{H}, \mathrm{R} 5 / \mathrm{v} 3.2$

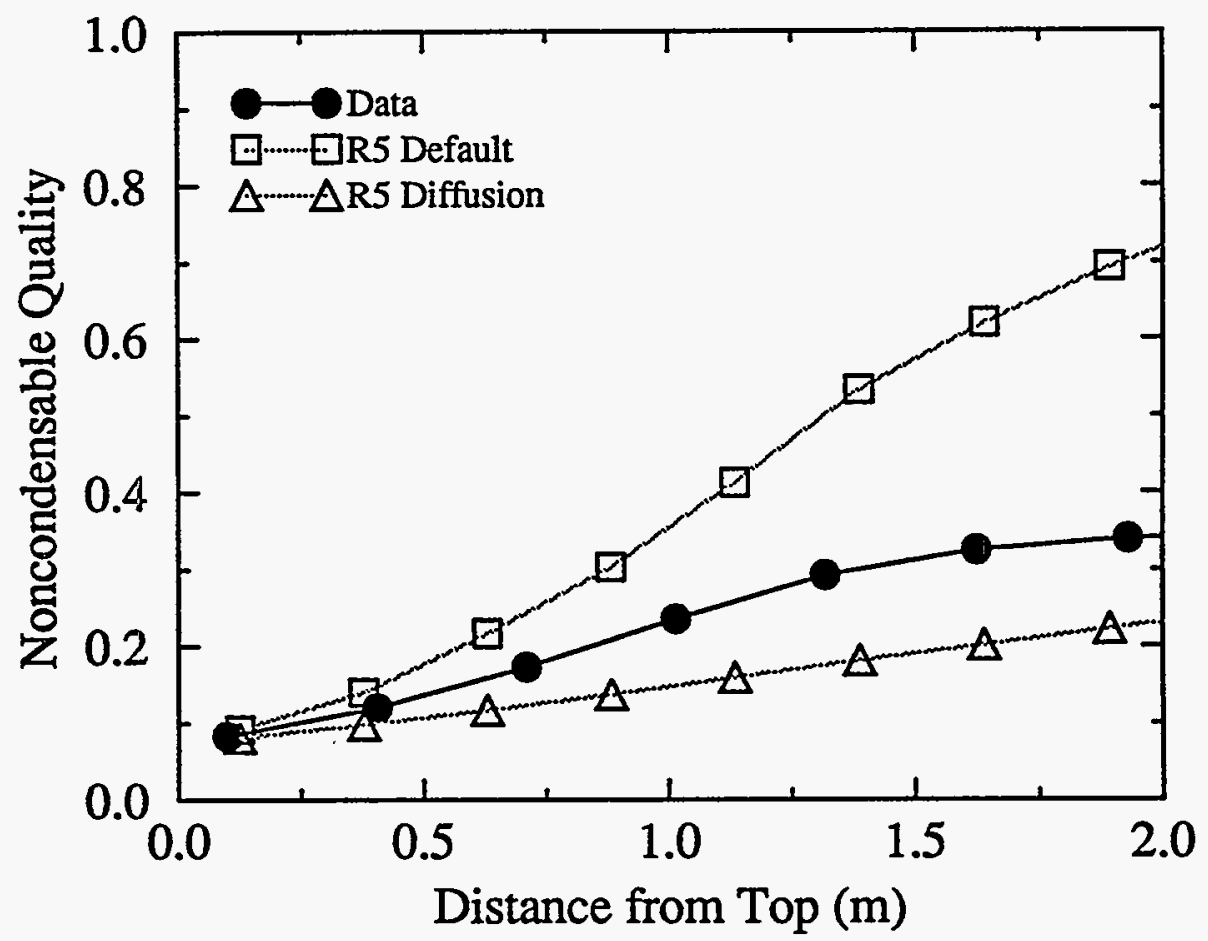

FIGURE D16. RELAP5 NC quality comparison with MTT-Siddique Test $18 \mathrm{H}$. 


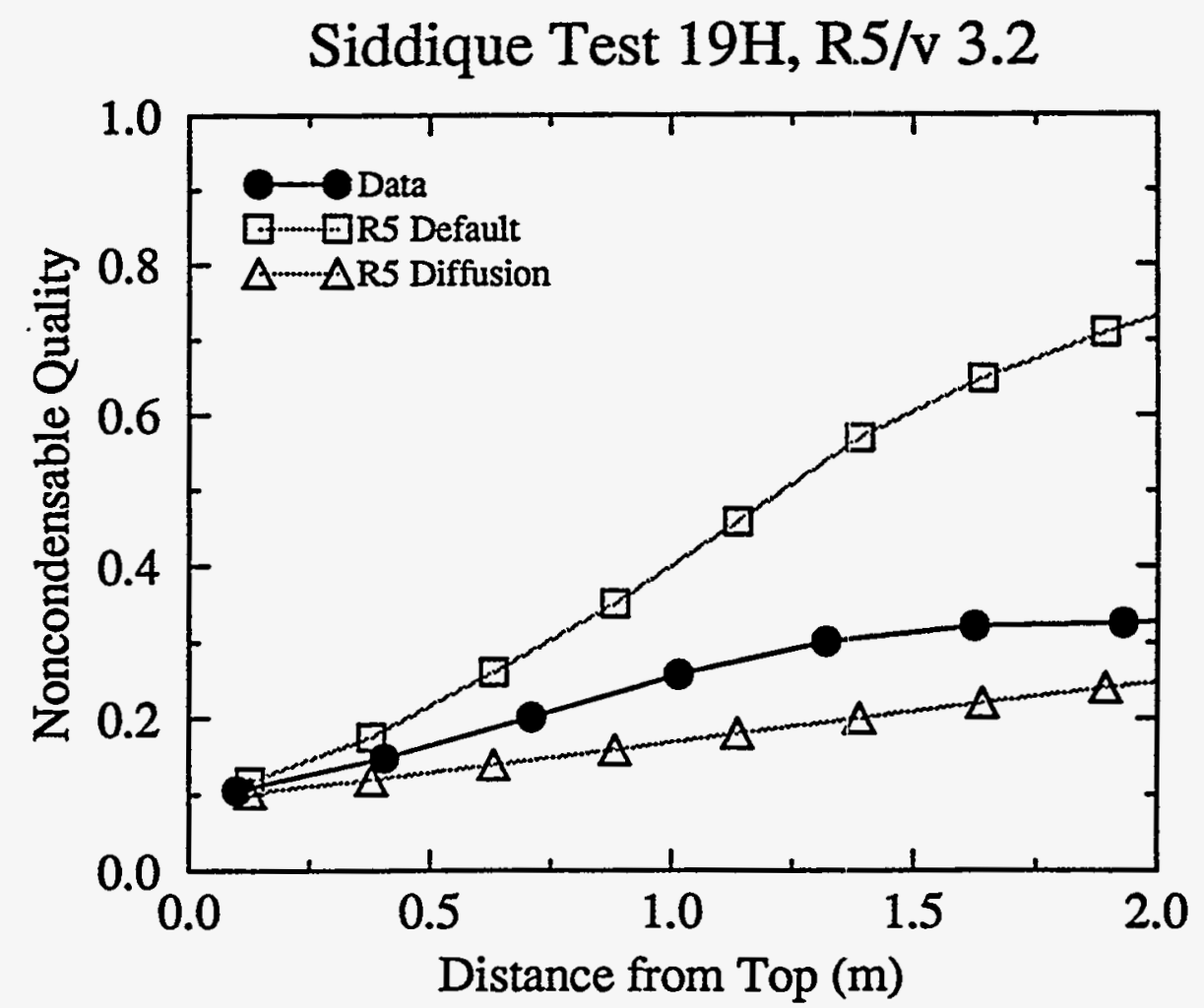

FIGURE D17. RELAP5 NC quality comparison with MIT-Siddique Test 19H. Siddique Test $22 \mathrm{H}, \mathrm{R} 5 / \mathrm{v} 3.2$

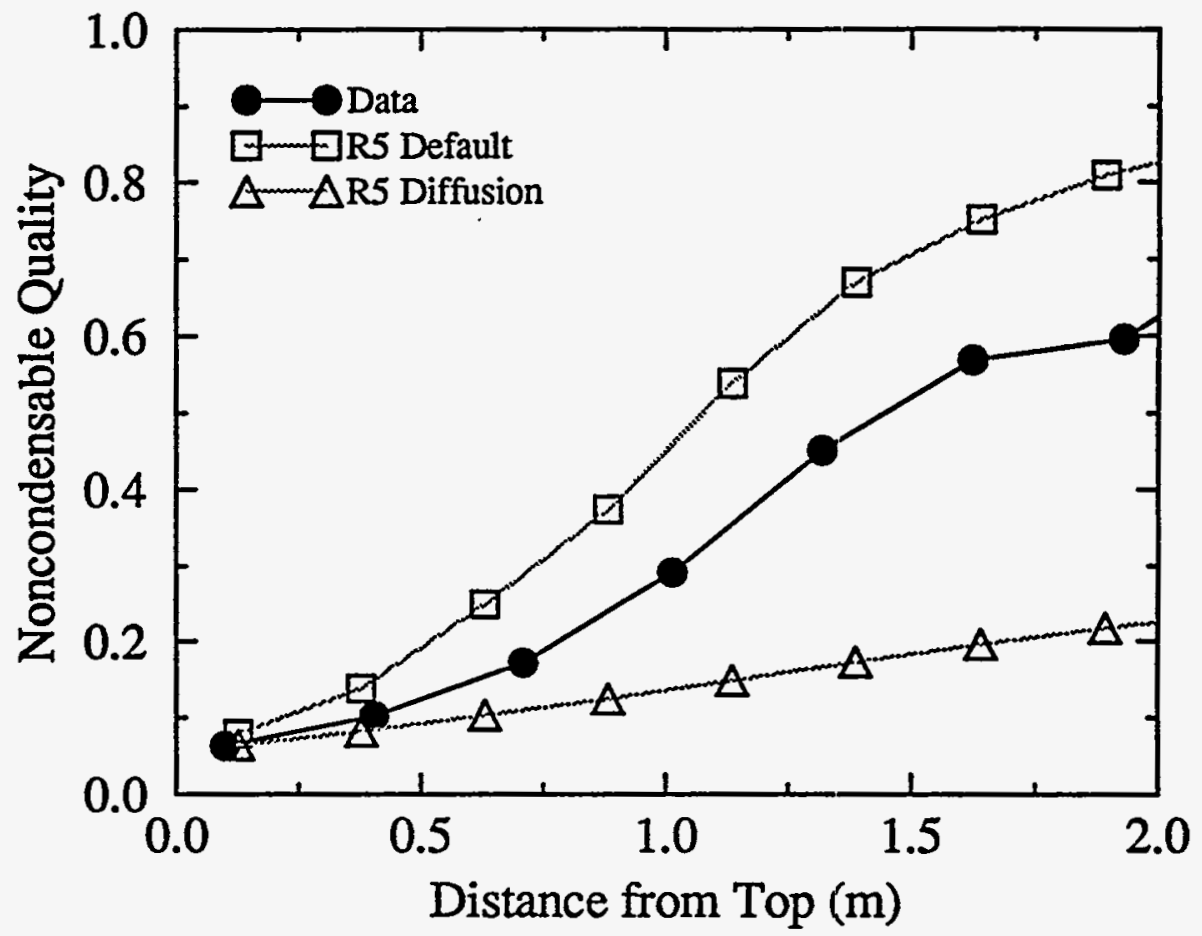

FIGURE D18. RELAP5 NC quality comparison with MIT-Siddique Test $22 \mathrm{H}$. 